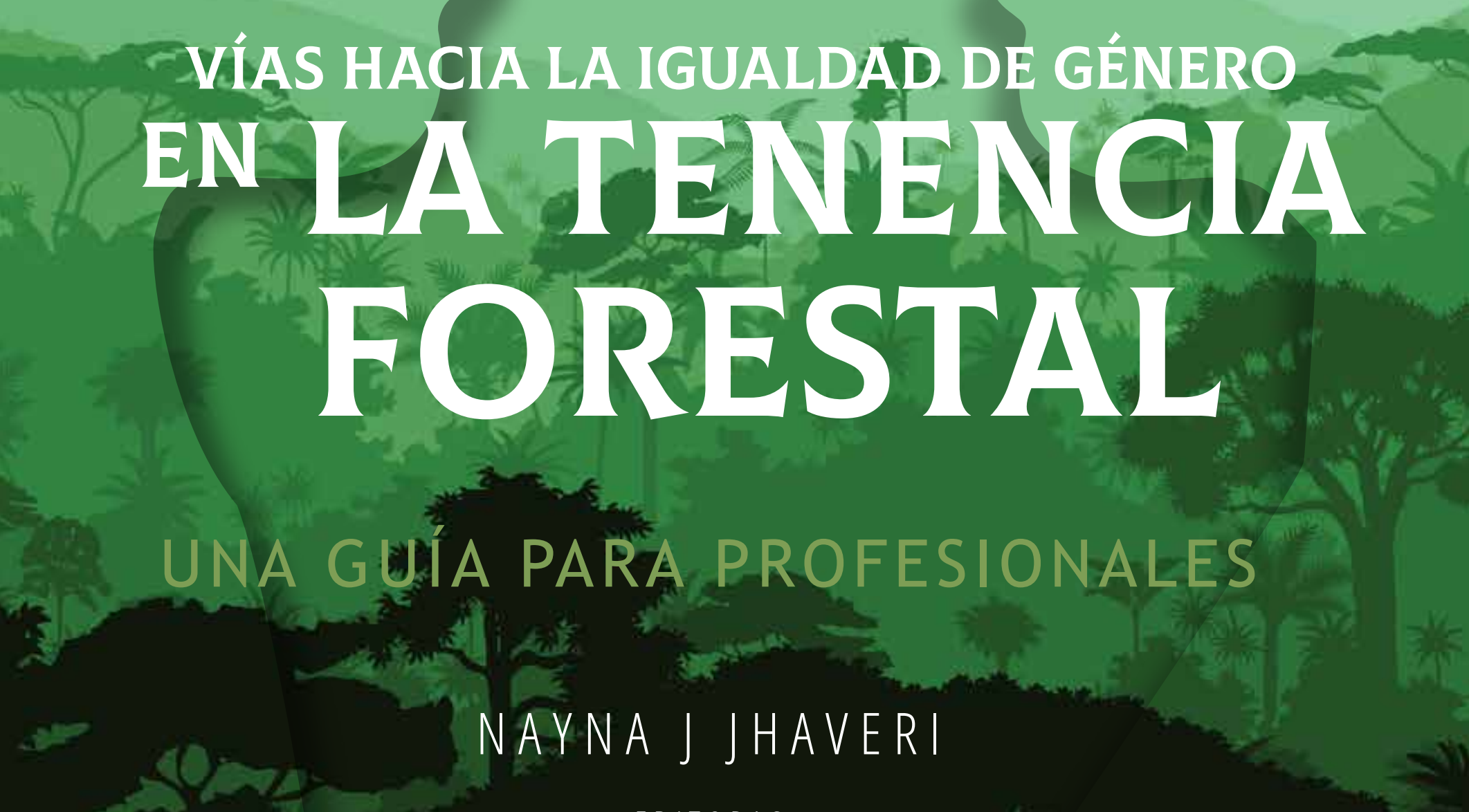

Tit EDITORAS

ILIANA MONTERROSOY ANNE M LARSON
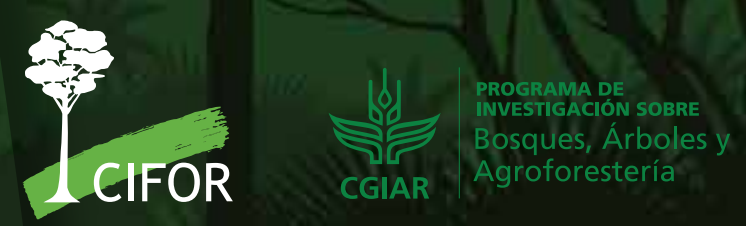

\begin{tabular}{l|l} 
CGIAR & $\begin{array}{l}\text { RESEARCH } \\
\text { PROGRAM on } \\
\text { Policies, } \\
\text { Institutions, } \\
\text { and Markets }\end{array}$ \\
and Mark
\end{tabular} 



\section{VÍAS HACIA LA IGUALDAD DE GÉNERO EN LA TENENCIA FORESTAL UNA GUÍA PARA PROFESIONALES}

NAYNA J JHAVERI
EDITORAS
ILIANA MONTERROSO YANNE M LARSON 
(C) 2021 por el Centro de Investigación Forestal Internacional.

Todos los derechos reservados.

(c) (i) Los contenidos de esta publicación están bajo licencia Creative Commons

Attribution 4.0 International (CC BY 4.0), http://creativecommons.org/licenses/by/4.0/

DOI: $10.17528 /$ cifor/008379

Jhaveri NJ. 2021. Vías hacia la igualdad de género en la tenencia forestal: Una guía para profesionales. Editoras: Iliana Monterroso y Anne M Larson. Bogor, Indonesia: CIFOR.

Traducción de: Jhaveri NJ. 2020. Forest tenure pathways to gender equality: A practitioner's guide. Editors: I Monterroso and AM Larson. Bogor, Indonesia: CIFOR.

Diseñado por: The Other Design Studio

www.theotherdesignstudio.com

CIFOR

Jl. CIFOR, Situ Gede

Bogor Barat 16115

Indonesia

$\mathrm{T}+62(251) 8622-622$

$\mathrm{F}+62(251) 8622-100$

E cifor@cgiar.org

cifor.org

Cualquier opinión vertida en este documento es de los autores. No refleja necesariamente las opiniones de CIFOR, de las instituciones para las que los autores trabajan o de los financiadores.

\section{Programa de Investigación del CGIAR sobre Bosques, Árboles y Agroforestería (FTA)}

Esta investigación fue realizada por CIFOR como parte del Programa de Investigación del CGIAR sobre Bosques, Árboles y Agroforestería (FTA). El FTA es el programa de investigación para el desarrollo más grande del mundo, dedicado a mejorar el papel de los bosques, los árboles y la agroforestería para el desarrollo sostenible, la seguridad alimentaria, y frente al cambio climático. CIFOR dirige el programa FTA en asociación con Bioversity International, CATIE, CIRAD, ICRAF, INBAR y TBI.

La investigación del Programa FTA cuenta con el apoyo del Fondo Fiduciario del CGIAR: cgiar.org/funders/

\section{Programa de Investigación del CGIAR sobre Políticas, Instituciones y Mercados (PIM)}

EI Programa de Investigación del CGIAR sobre Políticas, Instituciones y Mercados (PIM) lidera la investigación orientada a la acción para dotar a los tomadores de decisiones con la evidencia requerida para desarrollar políticas alimentarias y agrícolas que sirvan mejor a los intereses de los productores y consumidores pobres, tanto hombres como mujeres. EI PIM combina los recursos de los centros del CGIAR y numerosos socios internacionales, regionales y nacionales. El programa es liderado por el Instituto Internacional de Investigación sobre Políticas Alimentarias (IFPRI). www.pim.cgiar.org 


\section{CONTENIDO}

$\checkmark \quad$ Agradecimientos

vi Siglas y acrónimos

viii La guía para profesionales, en resumen

1 Aceleradores con perspectiva de género para la reforma de la tenencia forestal

$2 \quad 1.1$ El género y el escenario mundial de la tenencia forestal

13

1.2 Creación de aceleradores con perspectiva de género para un cambio eficaz en la tenencia

1.3 Crear cambio paso 1: Analizar

$31 \quad$ 1.4 Crear cambio paso 2: Definir estrategias

1.5 Crear cambio paso 3: Implementar estrategias

Pensar desde una perspectiva de género: políticas de tenencia

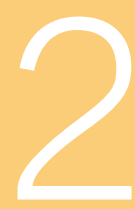
forestal, reforma jurídica y administración gubernamental

2.1 Generar impulso para el cambio: Leyes y políticas de tenencia forestal

2.2 Construir hacia adelante: La perspectiva de género en los organismos gubernamentales

Cuestiones de género en la tenencia forestal colectiva

3.1 Estado de la igualdad de género en la tenencia forestal colectiva

3.2 Creación de una gobernanza de la tenencia con perspectiva de género para la forestería comunitaria

3.3 Género, mapeo participativo y tenencia forestal comunitaria

3.4 Las mujeres emprendedoras aprovechan los derechos de tenencia forestal colectiva

3.5 Género, tenencia forestal y restauración de paisajes forestales multifuncionales

\section{Referencias}




\section{LISTA DE FIGURAS}

1. Acelerar la reforma de la tenencia forestal con perspectiva de género implica tres pasos clave.

2. El conjunto de derechos y responsabilidades de la tenencia.

3. Carácter interseccional de los patrones de discriminación estructural por cuestiones de género.

4. Metas del ODS 5 sobre igualdad de género.

5. Brechas de género en las instituciones de tenencia forestal.

6. Tres pasos para la creación de aceleradores con perspectiva de género para la reforma de la tenencia forestal.

7. Marco para el análisis situacional de género de la tenencia forestal colectiva.

8. Principios rectores para la investigación orientada a la acción sobre género y tenencia forestal.

9. Lecciones para un enfoque estratégico eficaz para la reforma de la tenencia forestal con perspectiva de género.

10. Ámbitos de acción clave para asegurar la reforma de la tenencia forestal con perspectiva de género.

11. Cuatro ámbitos de acción para la reforma de la tenencia forestal con perspectiva de género

12. Ejemplos de intervenciones para abordar las brechas de género en ámbitos de acción específicos.

13. Componentes clave del marco regulatorio de tenencia forestal con perspectiva de género.

14. Las tres etapas de las políticas, la legislación y la administración de la tenencia forestal con perspectiva de género

15. Intervenciones para apoyar la revisión con perspectiva de género de las leyes relacionadas con la tenencia forestal a nivel de gobierno nacional o subnacional.

16. Buenas prácticas legislativas para garantizar los derechos de tenencia forestal de las mujeres indígenas y rurales.

17. Recomendaciones para cambiar la cultura administrativa del gobierno sobre tenencia forestal hacia una cultura con perspectiva de género

18. Proporción de estudiantes de forestería graduados, mujeres y hombres, por nivel de educación, 2000-2015

19. Intervenciones para orientar el proceso de trabajo y el desarrollo de capacidades del personal.

20. Ejemplos de indicadores de monitoreo y evaluación de género y tenencia forestal.

21. Espectro del nivel de devolución en el régimen forestal bajo tenencia colectiva.

22. Etapas en el nivel de gobernanza con perspectiva de género de los bosques de uso común.

23. Factores que afectan la percepción de una tenencia forestal "suficientemente segura" para la igualdad de género.

24. Cómo apoyar los derechos de las mujeres indígenas y rurales a la gobernanza de la tenencia de tierras forestales.

25. Vías con perspectiva de género para obtener resultados.

26. Ocho ámbitos clave para el empoderamiento de las mujeres en la forestería comunitaria.

27. Diseño de intervenciones para un cambio sensible al género en la gobernanza local responsable de la tenencia forestal.

28. Tipología de la participación de la mujer en instituciones forestales de la comunidad. 


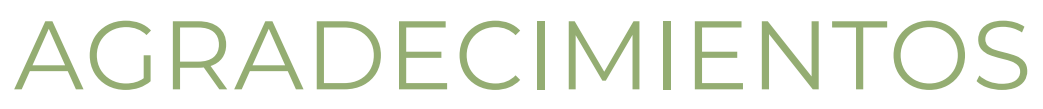

Esta guía es el resultado de varios años de investigación y trabajo en diversos países en el marco del Estudio Comparativo Global sobre Reformas de Tenencia en Tierras Forestales (GCS-Tenure) de CIFOR, dirigido por Anne Larson y quien en vida fuera Esther Mwangi. El análisis de género del proyecto fue coordinado por Iliana Monterroso.

El equipo integrado por la autora y las editoras desea agradecer a los revisores que prestaron su atención cuidadosa a toda la publicación y contribuyeron a dar forma a su contenido. Ellos son Margareta Nillson, Ylwa Renström Svensson, Samuel Munck y Raymond Achu Samdong de The Tenure Facility; Ruth Meinzen-Dick del Instituto Internacional de Investigación sobre Políticas Alimentarias (IFPRI) y Lasse Krantz de la Universidad de Gotemburgo. Esther Obaikol redactó la versión preliminar de esta guía.

Agradecemos profundamente a Gideon Suharyanto de CIFOR, quien supervisó el proceso de edición y publicación, y al equipo creativo de Angeline Pradhan y Upesh Pradhan de The Other Design Studio por el diseño de la publicación.

El GCS-Tenure ha recibido financiamiento de la Comisión Europea y el Fondo para el Medio Ambiente Mundial (FMAM) con el apoyo técnico del Fondo Internacional de Desarrollo Agrícola (FIDA) y la Organización de las Naciones Unidas para la Alimentación y la Agricultura (FAO). El estudio forma parte tanto del Programa sobre Políticas, Instituciones y Mercados (PIM), liderado por el IFPRI, como del Programa de Investigación del CGIAR sobre Bosques, Árboles y Agroforestería (FTA), liderado por CIFOR.

Todas las opiniones expresadas en este documento representan el análisis de la autora y no necesariamente reflejan los puntos de vista de CIFOR, IFPRI, CGIAR o los patrocinadores financieros. 


\section{SIGLAS Y ACRÓNIMOS}

\begin{tabular}{|c|c|c|c|}
\hline AAL & $\begin{array}{l}\text { Adequate asset livelihoods - activos de } \\
\text { medios de subsistencia adecuados }\end{array}$ & GESI & $\begin{array}{l}\text { Gender and social inclusion - igualdad de } \\
\text { género e inclusión social }\end{array}$ \\
\hline ACM & $\begin{array}{l}\text { Adaptive collaborative management - } \\
\text { manejo adaptativo y colaborativo }\end{array}$ & GPA & $\begin{array}{l}\text { Gender plan of action - plan de acción } \\
\text { sobre género }\end{array}$ \\
\hline AMAN & $\begin{array}{l}\text { Aliansi Masyarakat Adat Nusantara - } \\
\text { Alianza de Pueblos Indígenas del } \\
\text { Archipiélago }\end{array}$ & INDC & $\begin{array}{l}\text { Intended Nationally Determined } \\
\text { Contributions- Contribuciones } \\
\text { Nacionalmente Previstas y Determinadas }\end{array}$ \\
\hline BRWA & $\begin{array}{l}\text { Badan Registrasi Wilayah Adat - Agencia de } \\
\text { Registro de Dominios Ancestrales }\end{array}$ & IPCC & $\begin{array}{l}\text { Intergovernmental Panel on Climate } \\
\text { Change - Grupo Intergubernamental de }\end{array}$ \\
\hline \multirow[t]{3}{*}{ CEDAW } & \multirow{3}{*}{$\begin{array}{l}\text { Convention on the Elimination of All } \\
\text { Forms of Discrimination Against Women } \\
\text { - Convención sobre la Eliminación de } \\
\text { Todas las Formas de Discriminación contra } \\
\text { la Mujer }\end{array}$} & & Expertos sobre el Cambio Climático \\
\hline & & JFM & $\begin{array}{l}\text { Joint forest management - manejo forestal } \\
\text { conjunto }\end{array}$ \\
\hline & & JKPP & $\begin{array}{l}\text { Jaringan Kerja Pemetaan Partisipatif - Red } \\
\text { Indonesia de Cartografía Comunitaria }\end{array}$ \\
\hline CFUG & $\begin{array}{l}\text { Community forestry user group -grupo de } \\
\text { usuarios forestales comunitarios }\end{array}$ & KPA & $\begin{array}{l}\text { Konsorium Pembaruan Agraria - Consorcio } \\
\text { para la Reforma Agraria }\end{array}$ \\
\hline CIFOR & $\begin{array}{l}\text { Centro para la Investigación Forestal } \\
\text { Internacional }\end{array}$ & LAL & $\begin{array}{l}\text { Low asset livelihoods - activos de medios } \\
\text { de subsistencia bajos }\end{array}$ \\
\hline CIMT & $\begin{array}{l}\text { Consejo Internacional de las Maderas } \\
\text { Tropicales }\end{array}$ & MED & Mujeres en el Desarrollo \\
\hline CLPI & Consentimiento libre, previo e informado & \multirow[t]{2}{*}{ MRVS } & \multirow{2}{*}{$\begin{array}{l}\text { Monitoring, reporting and verification } \\
\text { system - sistema de monitoreo, reporte y } \\
\text { verificación }\end{array}$} \\
\hline CONAFOR & Comisión Nacional Forestal (México) & & \\
\hline COP & Conferencia de las Partes & \multirow[t]{2}{*}{ NFLRA } & \multirow{2}{*}{$\begin{array}{l}\text { National Forest Landscape Restoration } \\
\text { Assessment - Evaluación Nacional para la } \\
\text { Restauración de Paisajes Forestales }\end{array}$} \\
\hline CRL & $\begin{array}{l}\text { Community Rights Law - Ley de Derechos } \\
\text { Comunitarios }\end{array}$ & & \\
\hline DNUDPI & $\begin{array}{l}\text { Declaración de las Naciones Unidas sobre } \\
\text { los Derechos de los Pueblos Indígenas }\end{array}$ & NMWA & $\begin{array}{l}\text { National Mechanism for Women's Affairs - } \\
\text { Mecanismo Nacional para Asuntos de } \\
\text { la Mujer }\end{array}$ \\
\hline \multirow[t]{2}{*}{ FAO } & \multirow{2}{*}{$\begin{array}{l}\text { Food and Agriculture Organization - } \\
\text { Organización de las Naciones Unidas para } \\
\text { la Alimentación y la Agricultura }\end{array}$} & ODS & Objetivo de Desarrollo Sostenible \\
\hline & & OIMT & Organización Internacional de las Maderas \\
\hline \multirow[t]{2}{*}{ FDST } & \multirow{2}{*}{$\begin{array}{l}\text { Forest Dwelling Scheduled Tribes -Tribus } \\
\text { Registradas que Habitan en los Bosques }\end{array}$} & & \\
\hline & & ONAMIAP & Organización Nacional de Mujeres \\
\hline \multirow[t]{2}{*}{ FECOFUN } & \multirow{2}{*}{$\begin{array}{l}\text { Federación de Grupos de Usuarios } \\
\text { Forestales Comunitarios (Nepal) }\end{array}$} & & 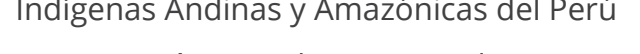 \\
\hline & & ONG & Organización no gubernamental \\
\hline \multirow[t]{2}{*}{ FRA } & \multirow{2}{*}{$\begin{array}{l}\text { Forest Rights Act - Ley de Derechos sobre } \\
\text { los Bosques }\end{array}$} & OSC & Organización de la sociedad civil \\
\hline & & OTFD & Other Traditional Forest Dwellers - Otros \\
\hline \multirow[t]{2}{*}{ FRC } & \multirow{2}{*}{$\begin{array}{l}\text { Forest Rights Committee - Comité de } \\
\text { Derechos Forestales }\end{array}$} & & Habitantes Tradicionales de los Bosques \\
\hline & & PFNM & Producto forestal no maderable \\
\hline GED & Género en el Desarrollo & PICL & Pueblos indígenas y comunidades locales \\
\hline
\end{tabular}


PPA Participatory prospective analysis - análisis de prospectiva participativa

PSA Pago por servicios ambientales

RDC República Democrática del Congo

REDD+ Reducción de las emisiones derivadas de la deforestación y la degradación forestal

ROAM Restoration Opportunities Assessment Methodology - Metodología de evaluación de oportunidades de restauración

RPF Restauración del paisaje forestal

RRI Rights and Resources Initiative - Iniciativa para los Derechos y Recursos

SLAL Severely limited asset livelihoods - activos de medios de subsistencia muy limitados
SSFE Small-scale forest enterprise - pequeña empresa forestal

UICN Unión Internacional para la Conservación de la Naturaleza

VGGT FAO Voluntary Guidelines on the responsible governance of tenure of land, fisheries and forests in the context of national food security - Directrices voluntarias sobre la gobernanza responsable de la tenencia de la tierra, la pesca y los bosques en el contexto de la seguridad alimentaria nacional - FAO

VSG

Violencia sexual y de género 


\section{LA GUÍA PARA PROFESIONALES, EN RESUMEN}

Esta guía para profesionales explica cómo promover una reforma de la tenencia forestal con perspectiva de género en regímenes forestales bajo tenencia colectiva y está dirigida a quienes han asumido este reto en países en desarrollo. No existe un enfoque único para reformar las prácticas de tenencia forestal y lograr la igualdad de género y el empoderamiento de las mujeres. Se trata más bien de aprovechar las oportunidades que surgen en diversos ámbitos institucionales, como el de la formulación e implementación de políticas y leyes, la administración gubernamental, la gobernanza de la tenencia consuetudinaria o colectiva o la restauración forestal a nivel del paisaje. Su objetivo general es promover una gobernanza responsable de la tenencia forestal que beneficie a mujeres y hombres de todo origen.

Este libro de consulta proporciona orientación de diverso tipo: ideas conceptuales, dirección operativa, buenas prácticas, información de estudios de caso, hallazgos de investigación y recursos para una exploración más profunda. Ha sido diseñado para apoyar a una amplia variedad de profesionales, tanto mujeres como hombres, de una gran diversidad de instituciones como oficinas de gobierno, organizaciones no gubernamentales, organizaciones de la sociedad civil, organizaciones donantes, organizaciones de mujeres, así como de redes y federaciones. Esto incluye a expertos en materia de género, quienes tienen la responsabilidad de integrar la igualdad de género y el empoderamiento de las mujeres en sus respectivas organizaciones, y también a aquellos que trabajan de manera más general en el ámbito de la tenencia de la tierra, la tenencia y la gobernanza forestal, la restauración de paisajes forestales, la agroforestería, el desarrollo de cadenas de valor y las empresas con impacto social.
Su objetivo es examinar las vías para promover una reforma de la tenencia forestal mediante un proceso de tres pasos: Analizar, Definir estrategias e Implementar estrategias. Un análisis de diagnóstico riguroso que permita crear una base empírica para el cambio puede contribuir al diseño de intervenciones secuenciales que promuevan la reforma de la tenencia forestal con perspectiva de género a diversas escalas. Por ello, esta guía es un recurso oportuno para respaldar intervenciones adecuadas de alto impacto y acelerar el cambio en regímenes de tenencia forestal colectiva en contextos tanto nacionales como locales.

El primer capítulo expone cómo pensar en la creación de aceleradores con perspectiva género para la reforma de la tenencia forestal. En el segundo capítulo, el enfoque se centra en cómo aumentar la igualdad de género y el empoderamiento de las mujeres mediante políticas, leyes y sistemas administrativos gubernamentales de tenencia forestal. El último capítulo aborda cómo lograr cambios con perspectiva género en los regímenes forestales bajo tenencia colectiva. No existe un conjunto único de métodos o enfoques que funcione para todos los contextos y, por ello, uno de los objetivos de esta guía es presentar una gran diversidad de conocimientos y herramientas. Estos pueden modificarse y ajustarse a lo largo del tiempo de una manera adaptativa y colaborativa para adecuarse a situaciones específicas. Esta guía para profesionales presenta numerosos estudios de caso, así como materiales de referencia de África, Asia y América Latina, de manera que cada tema pueda ser explorado a través de una experiencia práctica. Asimismo, la guía se ha basado en los más recientes manuales y documentos de orientación disponibles sobre la promoción de la reforma de la tenencia forestal con perspectiva de género. 



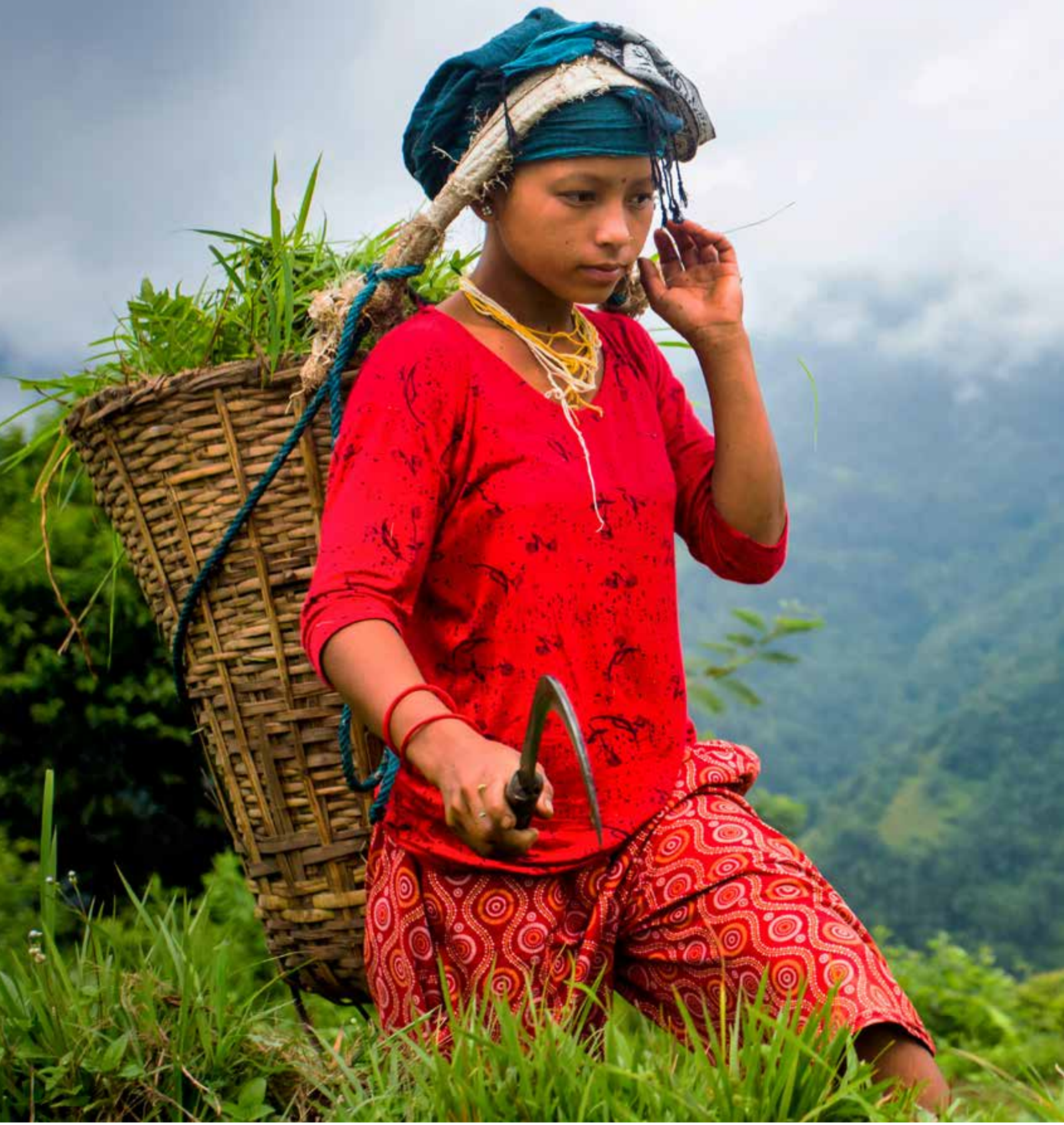




\section{ACELERADORES CON PERSPECTIVA DE GENERO PARA LA REFORMA DE LA TENENCIA FORESTAL}

No buscábamos la participación de las mujeres para incrementar las estadísticas, sino para que puedan ser parte activa de todos los procesos. Al mismo tiempo, nos dedicamos a crear conciencia acerca de que, además de convertirse en beneficiarias del manejo forestal, las mujeres eran igualmente responsables de cualquier pérdida que ocurriera. Alentamos a las mujeres a asumir el liderazgo en actividades de desarrollo de capacidades, como capacitación, talleres y oratoria. Identificar las necesidades de las mujeres y los menos favorecidos, darles prioridad política y apoyarlos ha dado frutos en términos de habilidades y capacidad de liderazgo.

En lo que respecta al desarrollo en materia de género, el papel de los hombres es igualmente crucial. En muchos grupos de usuarios forestales, son los hombres quienes insisten en una mayor participación de las mujeres y en el desarrollo de sus capacidades. Tenemos que brindar oportunidades en sus propios términos a quienes se encuentran en situación de desventaja. En nuestra comunidad hay personas con diferentes intereses y necesidades, y las oportunidades deben adaptarse a cada grupo de interés. Tenemos que incorporar esta práctica en todas las aldeas de las zonas rurales. En ello, FECOFUN ha desempeñado un papel importante en todo el país y a diferentes niveles.

\section{Apsara Chapagain}

Expresidenta de FECOFUN (2012) 


\section{1}

\section{EL GÉNERO Y EL ESCENARIO MUNDIAL DE LA TENENCIA FORESTAL}

La mayoría de las zonas forestales del mundo en los países en desarrollo son de propiedad pública. Sin embargo, hay una tendencia cada vez mayor a poner los derechos de tenencia y propiedad de los bosques en manos de comunidades, individuos y empresas privadas (Sunderlin et al. 2008; Larson et al. 2010; FAO 2011, 2015a; RRI 2015, 2018). En las últimas cuatro décadas, muchos gobiernos de Asia, África y América Latina han modificado sus leyes de tierras y leyes forestales para que brinden un mayor reconocimiento jurídico (de jure) a los derechos de tenencia forestal de los pueblos indígenas y comunidades locales (PICL). Aunque el área total de tierra fuera de la jurisdicción del Estado es aún pequeña, esta transición de la tenencia forestal es una tendencia de devolución influyente y con importantes ramificaciones positivas (Sunderlin et al. 2008; Larson et al. 2010; Dahal et al. 2012; Alden Wily 2014; Sunderlin 2014; RRI 2018).

Sin embargo, dentro de este proceso de devolución, solo unos pocos países han abordado de manera frontal la cuestión de la igualdad de género y el empoderamiento de las mujeres (véase el anexo 1: Términos comunes sobre género). Aunque la planificación en materia forestal y de género se inició en la década de 1980 (véanse Rojas 1993; FAO 1997; Hoskins 2016), sus avances han sido limitados. Es evidente que los derechos colectivos no son equivalentes a los derechos de la mujer en el sector forestal actual. Existe una discriminación de carácter estructural que margina la influencia de las mujeres en la forma en que se utilizan y gobiernan los recursos forestales en la forestería. Por ejemplo, las mujeres rara vez tienen el mismo nivel de representación que los hombres en los órganos locales de gobernanza forestal.
Ahora bien, las dimensiones de género de la tenencia forestal pueden presentar variaciones importantes de un lugar a otro debido a que son el resultado de procesos históricos complejos (como el colonialismo), movimientos de mujeres, transformaciones políticas y jurídicas, y dinámicas institucionales a nivel local (véase, por ejemplo, Elmhirst. 2017).

Alcanzar plenamente las mejoras sociales y ambientales de la actual transición de la tenencia forestal depende fundamentalmente de su capacidad para apoyar de manera inclusiva las diversas necesidades de mujeres y hombres (FAO 2018c). Si bien el mensaje acerca de la importancia de la igualdad de género comienza a ser escuchado, no siempre ha estado acompañado de una acción transformadora real sobre el terreno (Monterroso y Larson 2019a). Para acelerar el cambio en la práctica, debemos entender mejor las diversas vías que existen para lograr la igualdad de género en la tenencia forestal. Hay mucho que aprender y que puede dar inspiración. ¿Qué vías han ayudado a reducir la brecha de género? Echar un vistazo a países específicos que lideran el proceso puede guiar a otros a dar el salto hacia la igualdad de género. En particular, aprender de los fracasos y sobre la necesidad de identificar las formas en que las prácticas de las mujeres se integran y conectan en términos sociales, así como acerca del carácter multidimensional de su capacidad de acción, llevará a una transformación real y duradera (Rao 2017). Este es el objetivo del proceso Analizar, Definir estrategias e Implementar estrategias que se presenta en esta publicación (Figura 1). Se requiere de acciones sostenidas en varios frentes, debidamente organizadas de manera secuencial, para lograr un progreso sistemático. 

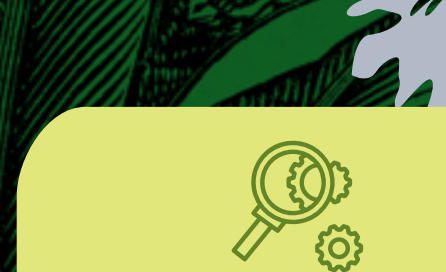

ANALIZAR

Comprender los logros, así como los desafíos y necesidades futuros

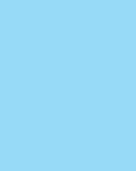
$x$
$\dot{0}^{\circ} x^{x}$

Figura 1. Acelerar la reforma de la tenencia forestal con perspectiva de género implica tres pasos clave

La tenencia forestal es un concepto amplio que se refiere a quién tiene derechos sobre las tierras forestales y, por lo tanto, quién usa, gestiona y toma decisiones sobre los recursos forestales (véase el anexo 2: Términos comunes sobre tenencia) (Larson 2012; Larson y Springer 2016; Banco Mundial 2019a; véase también Borelli et al. 2019 sobre la tenencia en la agroforestería). La tenencia forestal abarca diversos arreglos institucionales dentro de categorías generales, como control estatal, propiedad, tenencia, tenencia colectiva y tenencia consuetudinaria (o de facto) de los bosques. Incluso un término como "tenencia consuetudinaria" es simplemente una expresión general que abarca múltiples tipos de sistemas de tenencia (Chimhowu 2019). Cada uno tiene sus propios acuerdos de gobernanza de la tenencia, que implican diversos grados de participación y colaboración con el gobierno. A menudo, los bosques de propiedad colectiva forman parte de territorios consuetudinarios (Alden Wily 2014; Jhaveri et al. 2016). Cada tipo de tenencia afecta de maneras muy específicas a las mujeres y a los hombres que viven en los bosques y sus alrededores. Cuando se examina el conjunto de derechos de tenencia de mujeres y hombres (véase la Figura 2), el panorama de cualquier área boscosa es complicado. Las mujeres suelen tener derechos sobre los recursos forestales, como forraje, leña, plantas medicinales y algunos productos forestales no maderables (PFNM) con valor comercial. Los hombres suelen tener derechos sobre los recursos forestales que aportan más valor en efectivo, como la madera y los PFNM de alto valor. Además, son los hombres quienes suelen tener autoridad e influencia en la manera en que se establecen las normas sobre derechos como los de acceso, uso, gestión y alienación, mientras que las mujeres suelen operar de una manera más informal y concertada para hacer valer sus derechos de tenencia.

Si se examina el uso de los bosques desde la perspectiva de los hogares, en ellos las mujeres y los hombres negocian qué recursos forestales utilizará cada uno y cómo se distribuirán los beneficios. En la mayoría de los casos, esa distribución es determinada por las normas sociales imperantes. Todo hogar utiliza una gran variedad de recursos de su paisaje: áreas de cultivo agrícola (de regadío y de secano), bosques de uso común, huertos familiares y huertos ubicados cerca del hogar, parcelas agroforestales privadas e incluso áreas de concesión forestal de las que se extrae madera. Además de utilizar estos recursos, las mujeres y los hombres pueden trabajar en plantaciones forestales, como las de producción de palma aceitera, castañas del Brasil o cacao. Así pues, la forestería comunitaria se desarrolla en un contexto más amplio, en el que existen áreas para la producción agrícola, así como complejos continuos de "bosqueárboles-paisaje" (Parrotta et al. 2016).

La forma en que mujeres y hombres con diferentes niveles de activos sociales y financieros participan en la toma de decisiones y en la gestión de los bosques utilizados de manera conjunta por la comunidad tiene repercusiones importantes. Afecta el estado del bosque, 


\section{ACCESO}

El derecho a ingresar o atravesar un bosque puede otorgarse a una persona o un grupo. Dentro de este bosque puede haber derechos más específicos, como la capacidad de mujeres y hombres para acceder a ciertas zonas o árboles para extraer un producto forestal determinado.

\section{EXPLOTACION O USO}

Las mujeres y los hombres pueden tener diferentes derechos para extraer y beneficiarse de diversos productos forestales como madera,

combustible, alimentos, forraje, productos medicinales y otros PFNM.
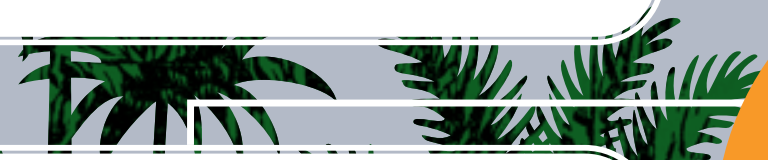

GESTIÓN

El derecho a tomar decisiones sobre el uso y manejo de un área forestal para satisfacer las necesidades de mujeres y hombres, incluso, por ejemplo, mediante zonificación y técnicas de forestería. La gestión es el más complejo de los derechos de tenencia porque implica establecer objetivos de manejo forestal, entender cómo evaluar el estado del bosque en todo el paisaje, determinar formas de regular los diversos tipos de usos a lo largo del ciclo anual y asegurar que estas reglas se cumplan en la práctica.
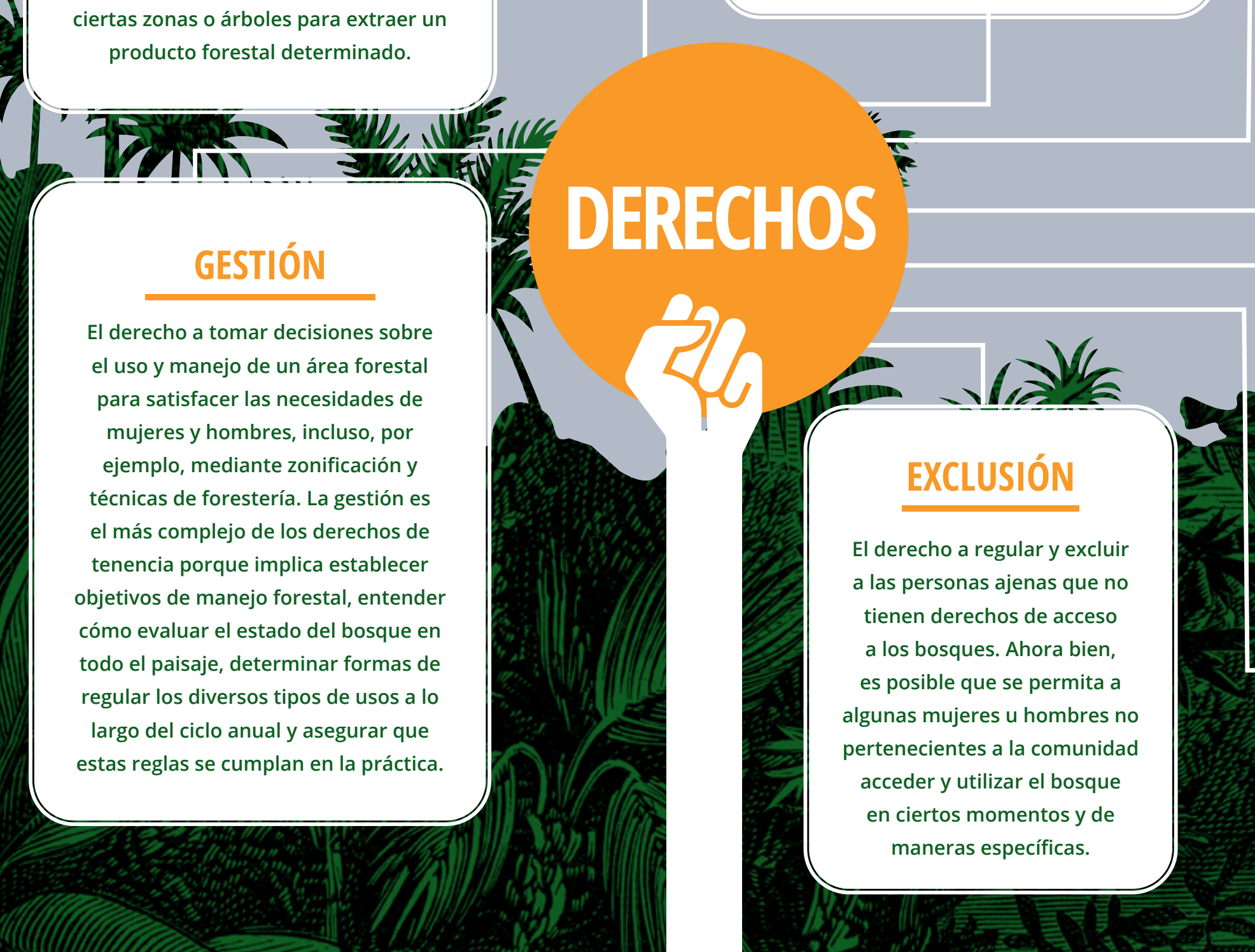

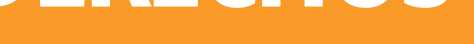

.

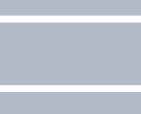




\section{ALIENACIÓN}

El derecho del propietario de transferir cualquier parte del bosque a otro por venta, arrendamiento u otros medios, así como la capacidad de utilizar el recurso como garantía.

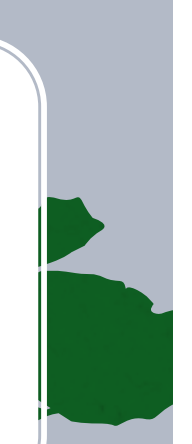

\section{DURACIÓN}

El tiempo que el titular de los derechos puede ejercer dichos derechos, ya sea por un periodo

limitado específico o a perpetuidad.

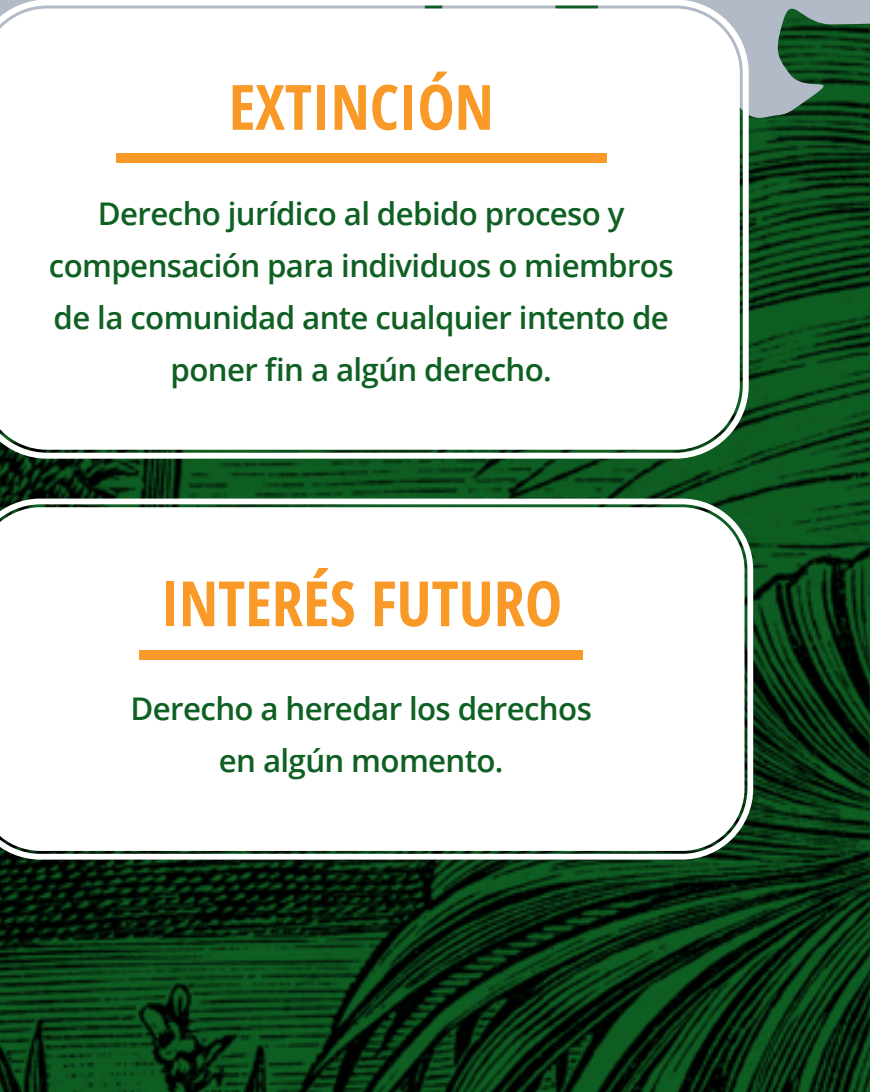

\section{RESPONSABILIDADES NORMATIVAS}

Pueden incluir: preparación del inventario forestal y el plan de manejo forestal sostenible, pago de impuestos, permisos para la extracción y transporte de recursos, y participación en las ganancias junto con el Estado.

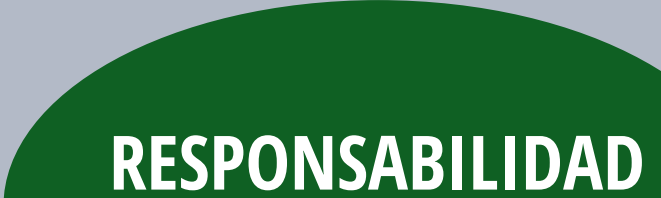 Y APOYO}

\section{SISTEMAS DE APOYO}

Apoyo gubernamental para la preparación de inventarios forestales y planes de manejo forestal, viveros forestales y subsidios; apoyo de organizaciones donantes y organizaciones no gubernamentales (ONG) para el desarrollo de capacidades en temas tales como enfoques forestales, igualdad de género, clasificación de la pobreza o el bienestar; apoyo financiero para equipo técnico; y desarrollo empresarial.

Nota: este marco de conjunto de derechos de tenencia o propiedad ha evolucionado a lo largo del tiempo (véase Banco Mundial 2019a). Recientemente, se han presentado argumentos en favor de su reformulación debido a que hay muchos otros actores, además de las comunidades locales, también involucrados en los regímenes de tenencia (Sikor et al. 2017).

Fuente: adaptado de Larson (2012); FAO y RECOFTC (2016); Larson y Springer (2016); Doss y Meinzen-Dick (2020); Banco Mundial (2019a); FAO (2019a). 


\section{La discriminación por motivos de género a menudo se entrecruza con otras formas de discriminación y genera diversos tipos de desventajas}

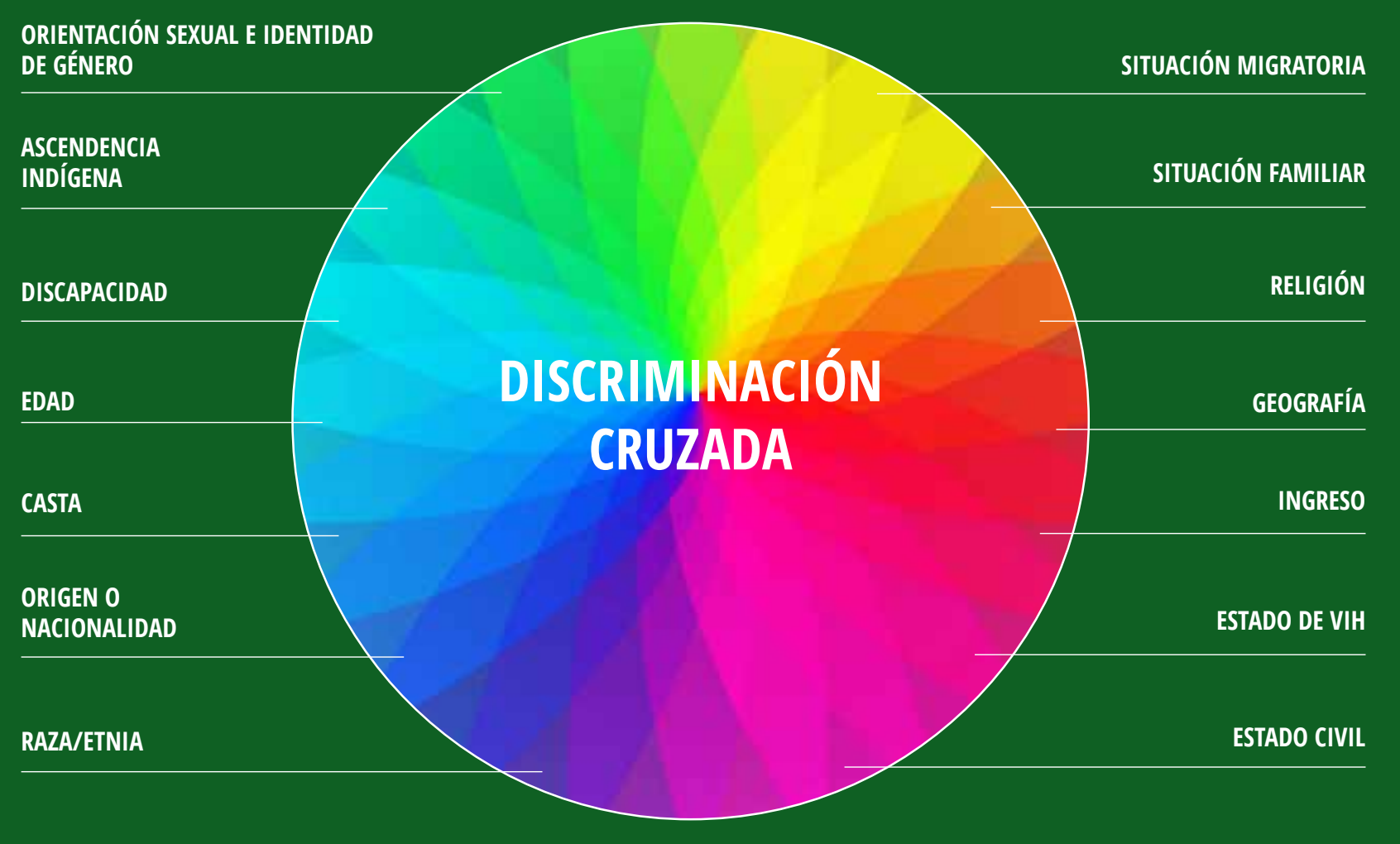

Figura 3. Carácter interseccional de los patrones de discriminación estructural por cuestiones de género.

así como la seguridad alimentaria de los hogares, la reducción de la pobreza, los medios de subsistencia y la generación de ingresos (véanse IFRI y RRI 2016; Larson et al. 2019c). No es útil pensar en las mujeres como una categoría monolítica. Más bien, para examinar la interseccionalidad de género se requiere identificar los diversos tipos de discriminación estructural que confluyen para crear obstáculos a grupos de mujeres o mujeres individuales (Figura 3). Las mujeres y los hombres aplican los beneficios que reciben de los recursos forestales de diferentes formas, ya sea para su uso personal o para satisfacer las necesidades de sus familias. Diferentes hogares de PICL cuentan con diversas redes sociales en comunidades locales que influyen en cómo se deciden y ejercen los derechos de tenencia, tanto dentro del órgano de gobernanza forestal como en las prácticas cotidianas. Los derechos de tenencia funcionan tanto de manera formal como informal. Además, cuando se encuentran nuevos recursos en los bosques, como el caso del carbono, las normas de tenencia necesariamente cambiarán para reflejar los nuevos objetivos. Los cambios en las normas de tenencia pueden provenir de diversos ámbitos, que incluyen no solo la lucha contra el cambio climático, sino también la construcción de nueva infraestructura vial, el desarrollo de mercados, la presión para convertir tierras forestales en agrícolas o crear concesiones forestales para la producción de madera, entre otros. La lista continúa.

En resumen, esta transición en marcha de la tenencia forestal tiene importantes efectos positivos porque proporciona incentivos para que los PICL participen activamente y se beneficien de la gestión forestal local. Promueve así la estabilidad y la seguridad social al reducir la pobreza y los conflictos. Se está formando un consenso respecto de que, con un conjunto adecuado de condiciones de gobernanza, la tenencia forestal colectiva tiene el potencial para reducir la deforestación, mejorar el secuestro de carbono y ampliar las opciones de subsistencia para las comunidades rurales en comparación con los bosques gestionados por el Estado (véanse, por ejemplo, Stevens et al. 2014; Ding et al. 2016; IFRI y 
RRI 2016; Stickler et al. 2017; Banco Mundial 2019a; Hajjar et al. 2020) ${ }^{1}$. Además, es un hecho reconocido que la igualdad de género ayuda a catalizar efectos multiplicadores positivos para una gran variedad de temas de desarrollo, como bosques, salud o educación (UN Women 2018a). Dada la evidencia de que el conocimiento de hombres y mujeres acerca de los bosques y sobre árboles específicos es bastante diferente y puede ser complementario, se requiere de su contribución conjunta para implementar formas colaborativas de gestión forestal sostenible (FAO y RECOFTC 2016; Colfer et al. 2017; Kristjanson et al. 2019). Al aunar sus recursos financieros provenientes de los bosques, las comunidades pueden construir clínicas locales, mejores caminos, infraestructura y usar tecnología que reduzca la carga de trabajo de las mujeres. De esta manera, mujeres y hombres pueden participar de manera eficaz en la toma de decisiones y abordar en conjunto las necesidades de bienestar social. En lo que respecta a beneficios para el hogar, las mujeres suelen utilizar los ingresos que obtienen de los recursos forestales para pagar por la salud, la educación y otras necesidades de sus hijos. En general, estas mejoras inclusivas pueden ayudar a reducir el número de conflictos y fortalecer los lazos comunitarios. Combinar los esfuerzos de mujeres y hombres aumenta las posibilidades de equidad, eficiencia y eficacia en los paisajes forestales. También puede reducir la pobreza y potenciar los beneficios del desarrollo.

Actualmente, una nueva ola de reformas de la tenencia forestal está ayudando a incrementar la visibilidad de la igualdad de género en regímenes de tenencia forestal colectiva. Su objetivo es lograr cambios en el sistema de discriminación arraigado. La enorme diversidad existente en los acuerdos de reforma de la tenencia forestal implica que, para crear una reforma con perspectiva de género, se debe prestar atención a los detalles. Utilizando un análisis situacional de género, se puede diseñar una estrategia para orientar el conjunto específico de intervenciones secuenciales y escalonadas que se necesitan para alcanzar dicho objetivo. Por supuesto, los cambios reales que se logren en las vías de la tenencia forestal por medio de estas intervenciones no necesariamente serán lineales o predecibles. Una reforma de la tenencia forestal se diferencia de una reforma agraria en que no implica la redistribución de tierras, sino que se centra en cómo estructurar de manera responsable la gobernanza local y el aseguramiento de derechos. Para satisfacer las expectativas de desarrollo y el bienestar ambiental de todos, se requiere de múltiples cambios en los regímenes de tenencia: permitir la participación igualitaria de mujeres y hombres, decidir de manera colectiva normas que sean socialmente inclusivas, desarrollar bosques sostenibles, distribuir equitativamente los beneficios y aprovechar los recursos forestales en pro del desarrollo empresarial. El trabajo hacia la igualdad de género y el empoderamiento de las mujeres implicará contar con vías hacia el cambio tanto inclusivas como centradas solo en mujeres y solo en hombres.

El impulso hacia la igualdad de género en los regímenes forestales bajo tenencia colectiva proviene de muchas direcciones: mujeres locales, hombres que asumen la función de defensores de la igualdad, federaciones de mujeres, federaciones forestales, grupos de la sociedad civil, ONG locales e internacionales, parlamentarios, organizaciones donantes y, principalmente, de la agenda de desarrollo y de políticas del gobierno. Una reforma de este tipo no se da de la noche a la mañana ni de manera lineal: el cambio puede provenir tanto desde arriba como desde abajo. Es necesario aprovechar todas las oportunidades importantes que se presenten. Las políticas y directrices globales pueden desempeñar un papel decisivo para impulsar el cambio a nivel nacional. A escala mundial, existen convenciones y declaraciones de carácter internacional relacionadas con los derechos humanos de las mujeres que inspiran el impulso hacia la igualdad de género. Entre ellas, la Convención sobre la Eliminación de Todas las Formas de Discriminación contra la Mujer (CEDAW, por sus siglas en inglés) ${ }^{2}$ de 1979 (y su Protocolo Opcional correspondiente) y la Declaración de las Naciones Unidas sobre los Derechos de los Pueblos

1 La investigación sobre este tema no es concluyente; véanse Runsheng et al. (2016) y Ojanen et al. (2017).

2 Esto incluye protocolos regionales relacionados, como el Protocolo a la Carta Africana de Derechos Humanos y de los Pueblos relativo a los derechos de la mujer (conocido como Protocolo de Maputo) aprobado en 2005. 
5.1 Poner fin a todas las formas de discriminación contra todas las mujeres y las niñas en todo el mundo
Eliminar todas las formas de violencia contra todas las mujeres y las niñas en los ámbitos público y privado
Eliminar todas las prácticas nocivas, como el matrimonio infantil, precoz y forzado y la mutilación genital femenina
5.4. Reconocer y valorar los cuidados y el trabajo doméstico no remunerados
5.5 Asegurar la participación plena y eficaz de las mujeres y la igualdad de oportunidades de liderazgo a todos los niveles decisorios en la vida política, económica y pública
5.6 Asegurar el acceso universal a la salud sexual y reproductiva y los derechos reproductivos

Figura 4. Metas del ODS 5 sobre igualdad de género. Fuente: UN (2017).

Indígenas (DNUDPI) de 2007, que establece de manera explícita la importancia de proteger a las mujeres y los niños indígenas de la violencia y la discriminación. Más específicamente en lo que respecta a cuestiones de tenencia, en los últimos años ha surgido una corriente de apoyo para fortalecer los derechos de tenencia. Las “Directrices voluntarias sobre la gobernanza responsable de la tenencia de la tierra, la pesca y los bosques en el contexto de la seguridad alimentaria nacional" (VGGT, por sus siglas en inglés) de la Organización de las Naciones Unidas para la Alimentación y la Agricultura (FAO) de 2012 han desempeñado un papel importante en el logro de una serie de objetivos de desarrollo fundamentales (FAO 2012). La igualdad de género es uno de los 10 principios rectores de implementación de las VGGT (véase FAO 2013).

Creada en 2015, la Agenda 2030 para el Desarrollo Sostenible, con sus 17 Objetivos de Desarrollo Sostenible (ODS), tiene mucho que decir en materia de género (UN Women 2018b). Aunque no se menciona de manera específica la importancia de la tenencia colectiva y la gobernanza comunitaria de los bosques (IFRI y RRI 2016; Katila et al. 2020), queda claro que una reforma de la tenencia forestal con perspectiva de género puede respaldar el logro de muchos ODS (FAO 2018; RRI 2018;
Arora-Jonsson et al. 2019; Winkel et al. 2019; Katila et al. 2020). Una meta sobre género de los ODS tiene que ver con la propiedad, la posesión y los recursos naturales: la meta 1.4.2 establece “De aquí a 2030, garantizar que todos los hombres y mujeres, en particular los pobres y los vulnerables, tengan los mismos derechos a los recursos económicos y acceso a los servicios básicos, la propiedad y el control de la tierra y otros bienes, la herencia, los recursos naturales, las nuevas tecnologías apropiadas y los servicios financieros, incluida la microfinanciación" (FAO 2018c). Además, el Objetivo 5 sobre Igualdad de Género incluye una meta sobre la igualdad de "acceso [de las mujeres] a la propiedad y al control de la tierra y otros tipos de bienes" (véase la Figura 4) (UNGA 2015), aunque el indicador relacionado 5.a.1 se centra solo en la propiedad o en asegurar los derechos a la tierra agrícola (no a los bosques) para cada sexo.

En particular, los informes recientes sobre el cambio climático global han destacado de manera específica la importancia de la tenencia colectiva de la tierra. Si bien el Acuerdo de París ${ }^{3}$ (RRI 2016) no ofrece apoyo para la tenencia colectiva y la gobernanza comunitaria, el informe especial de 2019 "El cambio climático y la tierra" del Grupo Intergubernamental de Expertos sobre el Cambio Climático (IPCC, por sus siglas en inglés) reconoce la

3 Una revisión de 161 Contribuciones Nacionalmente Previstas y Determinadas (INDC, por sus siglas en inglés) presentadas para la 21. ${ }^{a}$ sesión de la Conferencia de las Partes (COP-21) indica que solo 21 países, que representan el 13 \% de las áreas de bosques tropicales y subtropicales, se comprometieron explícitamente en sus presentaciones de INDC a implementar la seguridad de tenencia o la gestión colectiva de los recursos naturales de los PICL (RRI 2016). 
Emprender reformas que otorguen a las mujeres igualdad de derechos a los recursos económicos, así como acceso a la propiedad y al control de la tierra y otros tipos de bienes, los servicios financieros, la herencia y los recursos naturales, de conformidad con las leyes nacionales
5. B

Mejorar el uso de la tecnología instrumental, en particular la tecnología de la información y las comunicaciones, para promover el empoderamiento de las mujeres
5. C

Aprobar y fortalecer políticas acertadas y leyes aplicables para promover la igualdad de género y el empoderamiento de todas las mujeres y las niñas a todos los niveles importancia de la tenencia de la tierra, incluidas las formas de tenencia colectivas y consuetudinarias, así como la capacidad de acción en materia de género como factores esenciales para los resultados de sostenibilidad del clima y la tierra (IPCC 2020). En dicho informe, se afirma que:

La inseguridad en la tenencia de la tierra afecta la capacidad de las personas, las comunidades y las organizaciones para realizar cambios en la tierra que puedan promover la adaptación y la mitigación. El reconocimiento limitado del acceso consuetudinario a la tierra y la propiedad de la tierra puede conllevar a una mayor vulnerabilidad y una menor capacidad de adaptación. Las políticas relativas a la tierra (como el reconocimiento de la tenencia consuetudinaria, el mapeo comunitario, la redistribución, la descentralización, la gestión conjunta, la regulación de los mercados de alquiler) pueden proporcionar seguridad y respuestas flexibles al cambio climático

En paralelo, el informe hace un llamado a emplear un enfoque inclusivo de género, pues considera que el reconocimiento de los derechos de las mujeres a la tierra y la participación de mujeres con conocimientos de gestión de la tierra en la toma de decisiones relacionadas con esta pueden propiciar la adopción de medidas integradas de adaptación y mitigación. Es importante destacar que este documento reconoce que, dado que las mujeres no conforman un grupo homogéneo, se necesita un enfoque intersectorial (véase el anexo 1: Términos comunes sobre género). Esto requiere investigar el vínculo entre cambio climático y género antes de poder aprovechar los instrumentos basados en derechos adecuados para generar cambios, ya sea para la adaptación o la mitigación.

Los cambios en las políticas globales sobre igualdad de género y sobre bosques proporcionan una base sólida para la puesta en marcha de reformas de tenencia forestal para una transformación con perspectiva de género a nivel local y nacional. Para promover las vías hacia la igualdad de género en la tenencia forestal se requiere creatividad, determinación y aprovechar rápidamente las oportunidades que se presenten. A fin de cuentas, lograr un mundo con igualdad de género en los paisajes forestales de uso común depende de cada uno.

\section{SECCIÓN 1.1}

\section{LECTURAS COMPLEMENTARIAS}

[FAO]. Food and Agriculture Organization. 2012. Voluntary Guidelines on the Responsible Governance of Tenure of Land, Fisheries, and Forests in the Context of National Food Security. Roma: FAO.

Katila P, Colfer CJP, de Jong W, Galloway G, Pacheco P y Winkel G, eds. 2019. Sustainable Development Goals: Their Impacts on Forests and People. Londres: Cambridge University Press.

Katila P, McDermott C, Larson A, Agarwal B, y Giessen L. 2020. Forest tenure and the Sustainable Development Goals - A critical view. Forest Policy and Economics. https://doi.org/10.1016/j.forpol.2020.102294

World Bank. 2019. Securing Forest Tenure Rights for Rural Development. An Analytical Framework. Washington D. C.: Program on Forests (PROFOR), The World Bank. 
UN GRAN

POTENCIAL

\section{La justicia de género mediante la Ley de} Derechos sobre los Bosques de la India

\section{PREGUNTA DE REFLEXIÓN}

\section{¿Cómo pueden las mujeres y los hombres de las comunidades que dependen de los bosques reclamar legítimamente sus derechos sobre las tierras forestales en la India?}

En 2006 se promulgó la "Ley de Protección de los Derechos de las Comunidades que Habitan en los Bosques mediante [el reconocimiento de los derechos forestales de las] Tribus Registradas y Otros Habitantes Tradicionales de los Bosques" (o Ley de Derechos sobre los Bosques [FRA, por sus siglas en inglés]). Su objetivo era abordar las injusticias históricas y restablecer los derechos sobre la tierra y forestales de las comunidades dependientes de los bosques que tradicionalmente vivían en tierras designadas como bosques estatales. La FRA crea un nuevo paradigma de derechos para la gobernanza forestal con el reconocimiento de dos tipos de derechos forestales: los derechos forestales individuales y los derechos forestales colectivos, tanto para mujeres como para hombres. Tanto las Tribus Registradas que Habitan en los Bosques (FDST, por sus siglas en inglés) como Otros Habitantes Tradicionales de los Bosques (OTFD, por sus siglas en inglés) (unos 250 millones de personas que viven en los bosques y sus alrededores) son elegibles para presentar reclamos en virtud de la FRA. Aunque el organismo principal encargado de la implementación es el Ministerio de Asuntos Tribales, en la práctica esta se ve socavada por una serie de leyes, políticas y programas ejecutados por el Ministerio de Medio Ambiente, Bosques y
Cambio Climático, cuyo poder es mucho mayor.

La FRA ofrece a las mujeres igualdad de derechos sobre tierras y recursos forestales, tanto individuales como colectivos, y tiene como objetivo asegurar su representatividad. Sin embargo, en gran medida estas disposiciones de la ley han sido ignoradas (TISS 2018; véase también Tyagi y Das 2018). La FRA permite a las mujeres reclamar títulos junto con sus cónyuges como integrantes de un núcleo familiar, y también como titulares principales del hogar (por ejemplo, en el caso de mujeres solteras u hogares encabezados por mujeres). Además, un tercio de los miembros del Comité de Derechos Forestales (FRC, por sus siglas en inglés) a cargo del Gram Sabha ${ }^{4}$ (un organismo permanente de gobernanza de las aldeas que tiene la responsabilidad de procesar los reclamos de la FRA) deben ser mujeres. El Comité de Nivel Subdivisional y el Comité de Nivel Divisional, ambos involucrados en el procesamiento de los reclamos forestales, también deben contar con una mujer como miembro electo.

Sin embargo, se han identificado dificultades en varias dimensiones de la implementación con igualdad de género de la FRA (Bhalla 2016). El predominio de una mentalidad patriarcal en los organismos estatales lleva a que las mujeres sean percibidas como invasoras en lugar de titulares legítimas (Ramdas 2009; TISS 2018). Las mujeres de FDST a menudo desconocen el requisito de que un tercio de los asistentes a las reuniones del Gram Sabha sean mujeres. No saben cuál es su función en el Comité de Derechos Forestales ni reconocen la importancia de participar en la verificación de sitios (Working Group of Women and Land Ownership 2018). Más aún, debido a la ausencia de servicios públicos adecuados de agua, salud, etc., las mujeres han tenido dificultades para lograr una mejora significativa de su situación económica, a pesar de que cuentan con los derechos de la FRA (Zaidi 2019). En un giro inesperado, las mujeres bhil del sur de Rajastán, que ya se encargaban de la gestión de los recursos forestales de uso común en su sociedad, relativamente más igualitaria, vieron usurpada su autoridad cuando el FRC (con solo un

4 El quorum del Gram Sabha no será inferior a la mitad de sus miembros, y al menos un tercio de los miembros presentes en la reunión deben ser mujeres. 
$30 \%$ de mujeres miembros) tomó el control de los recursos forestales colectivos (Bose 2011). Esta reversión demuestra la importancia de examinar los patrones existentes de uso y acceso a los bosques antes de poner en marcha programas en favor de la igualdad de género.

Por último, aunque la FRA permite que los poseedores de títulos vendan sus PFNM como mejor prefieran, en la práctica esto no siempre funciona así. En estados como Madhya Pradesh, donde la FRA ha perjudicado el lucrativo monopolio del departamento forestal sobre las hojas de cursive o ébano coromandel (un PFNM que las mujeres recolectan y venden para la fabricación de cigarrillos bidi), el personal de dicho departamento confisca las hojas que no le son vendidas directamente (Kukreti 2017). A diferencia de Maharashtra, Madhya Pradesh no ha modificado sus leyes forestales para reconocer los derechos sobre PFNM otorgados por la FRA. A pesar de esos obstáculos, ha habido algunos cambios positivos en el empoderamiento de las mujeres gracias al trabajo de apoyo de organizaciones de la sociedad civil (OSC). En el sur de Rajastán, una vez que las mujeres obtuvieron los derechos de la FRA, pudieron acceder con mayor facilidad a las tierras forestales, sin tener que lidiar con el comportamiento arbitrario de los funcionarios ni efectuar pagos por la recolección de forraje (Zaidi 2019). Sus derechos seguros sobre la tierra también las habilitaron para vender sus productos agrícolas en el mercado local. Es importante destacar que contar con activos de tierras en el marco de la FRA ha aumentado el nivel de confianza de las mujeres, en especial de las viudas, y ha llevado a cuestionar prácticas retrógradas como la poligamia.

Entre las recomendaciones para fortalecer los derechos de género en el marco de la FRA en los estados de Odisha y Jharkhand están las siguientes (Bhalla 2016; Richardson 2016):

\section{A NIVEL NACIONAL}

- aumentar el número mínimo de mujeres miembros en el FRC (de un tercio a la mitad), en el Comité de Nivel Subdivisional y en el Comité de Nivel Divisional

- exigir que el jefe de cada FRC alterno sea una mujer

- asegurar que los miembros de las OSC en los Comités de Nivel Subdivisional y Divisional tengan un historial probado de trabajo con la FRA

- requerir periodos de servicio obligatorios para los miembros de los comités que no dependan de los ciclos de elecciones nacionales

- integrar un módulo sobre transversalización de la perspectiva de género en la capacitación de la FRA para los miembros de los comités

- desglosar los datos por género, casta, etnia y categorías relacionadas con OTFD.

\section{A NIVEL DISTRITAL Y ESTATAL}

- apoyar a los organismos gubernamentales mediante la capacitación y sensibilización de sus funcionarios

- compartir las mejores prácticas y lecciones aprendidas, incluidas las relacionadas con la verificación de las tierras forestales para los derechos individuales y colectivos, y con el registro de títulos otorgados en el marco de la FRA

- ayudar a los solicitantes a sopesar los beneficios de la titulación individual frente a la colectiva, o una combinación de ambas, cada una con sus propios flujos de beneficios relacionados

- promover una mayor participación en las comunidades objetivo con el fin de cambiar costumbres y prácticas de larga data que estén en contra de la igualdad de género

- celebrar reuniones frecuentes de grupos de mujeres para ayudar a empoderarlas

- iniciar diálogos sobre la transversalización de la perspectiva de género y la integración de grupos marginados (por ejemplo, mujeres, OTFD) en el proceso de implementación de la FRA

- distribuir las circulares progresistas del gobierno de Odisha sobre la FRA en otros estados

- realizar consultas a nivel distrital para explorar cómo se pueden implementar lecciones positivas en otras partes del estado.

Un apoyo firme de las ONG y las OSC para ayudar a las mujeres a reconocer y hacer valer sus derechos puede generar un cambio fundamental en las vidas de millones de mujeres marginadas y pobres en el importante cinturón tribal de la India.

\section{LECCIONES}

Tener una ley que apoye los principios de igualdad de género es un punto de partida importante que permite otras actividades de apoyo (por lo general, a través de ONG y OSC). Dichas actividades son fundamentales para lograr objetivos como enmendar normas, cambiar prácticas imperantes, realizar trabajo de sensibilización en materia de género, implementar programas de desarrollo de capacidades, revisar los flujos de beneficios, etc. 


\section{2 \\ CREACIÓN DE ACELERADORES CON PERSPECTIVA DE GÉNERO PARA UN CAMBIO EFICAZ EN LA TENENCIA}

La reforma de la tenencia forestal con perspectiva de género es posible: el trabajo conjunto de mujeres y hombres que ha llevado a generar cambios es un hecho ampliamente demostrado (Mayers et al. 2013). A nivel nacional, más de dos tercios de los directores de organismos forestales en la región Asia-Pacífico han observado que se está prestando mayor atención a las cuestiones de género (FAO 2019b). Esto presenta oportunidades cada vez mayores. Se puede crear una influencia positiva sobre ámbitos fundamentales de la formulación de políticas y la toma de decisiones para lograr cambios con perspectiva de género siempre y cuando haya un análisis cuidadoso, una planificación estratégica y una puesta en práctica de esas ideas. Y para ello es esencial aprovechar el impulso favorable a la reforma de la tenencia forestal, así como las lecciones que se han difundido ampliamente en los últimos años.

Se han producido cambios en la forma de concebir el papel de las mujeres en la forestería. La importancia de la mujer en la forestería se hizo patente por primera vez en la década de 1980 como resultado de la crisis de la leña, que puso en acción un enfoque de Mujeres en el Desarrollo (MED). Sin embargo, en la década de 1990, las deficiencias del enfoque MED se hicieron evidentes, pues este requería tomar en cuenta el papel tanto de las mujeres como de los hombres en el desarrollo. Las normas sociales relativas a los roles de las mujeres y los hombres en el hogar y en las actividades de subsistencia eran esenciales. Por ello, se introdujo un nuevo paradigma llamado Género en el Desarrollo (GED), el cual se centró en cómo transformar de manera positiva las relaciones estructurales y de poder entre mujeres $y$ niñas, por un lado, y hombres y niños, por otro.
Se ha debatido mucho acerca de cómo lograr la igualdad de género. Una estrategia importante presentada en 1985 para impulsar ese cambio fue la transversalización de la perspectiva de género. Luego de varias décadas de este enfoque, hay un creciente debate sobre cuáles son sus méritos. Si bien muchas instituciones han intentado transversalizar la perspectiva de género en sus programas de trabajo, la implementación ha sido deficiente o desigual y sus beneficios no están claros. Ha habido dudas sobre si se debe concentrar toda la energía en un solo enfoque. Se cree más bien que, para lograr que el desarrollo funcione para las mujeres y los hombres, se necesita un enfoque que tenga una visión más amplia que la transversalización de la perspectiva de género. Esto puede implicar, por ejemplo, centrarse en las organizaciones de mujeres y realizar trabajo independiente para el desarrollo de liderazgo y capacidades en mujeres y niñas (véase, por ejemplo, RECOFTC 2019). Otra opción es proporcionar apoyo a los hombres que asuman la función de defensores de la perspectiva de género en las instituciones locales y nacionales. Aprovechar las oportunidades a medida que surgen puede inspirar un método más ágil y fundamentado para movilizar los agentes de cambio en materia de género. En lugar de buscar desarrollar sensibilidad hacia las diferencias de género, existe un movimiento cada vez mayor hacia enfoques con perspectiva de género que apunten a generar cambios transformadores. En ocasiones, la impaciencia con la velocidad del cambio ha llevado a hacer llamados en favor de la justicia de género.

Es evidente que hay una amplia variedad de brechas de género que considerar en lo que respecta a la tenencia 


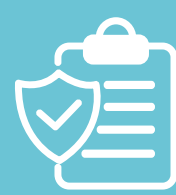

POLÍTICAS, LEYES Y

ADMINISTRACIÓN GUBERNAMENTAL

- Las políticas y leyes forestales del gobierno no abordan en absoluto las necesidades en materia de género 0 , si lo hacen, las abordan de manera periférica o carecen de disposiciones o directrices para implementarlas.

- Hombres que no tienen conciencia de las responsabilidades en materia de igualdad de género controlan instituciones importantes de toma de decisiones.

- Los organismos gubernamentales y otras instituciones forestales esenciales tienen escasez de conocimientos, capacidades y presupuesto para llevar a cabo una labor de tenencia forestal con perspectiva de género.

- Las divisiones sectoriales entre el organismo forestal y otros organismos, como el Ministerio de la Mujer, el Ministerio del Medio Ambiente o la Comisión Nacional de Planificación obstaculizan la integración y coordinación en materia de género en el sector forestal.

- Hay una falta de datos desglosados por género que permitan comprender cómo y por qué el género es esencial para apoyar la reducción de la pobreza, los medios de subsistencia y la equidad a nivel local, la reducción de conflictos y una gestión forestal eficaz, entre otros objetivos.

- No hay un registro de derechos de tenencia forestal desglosados por género.

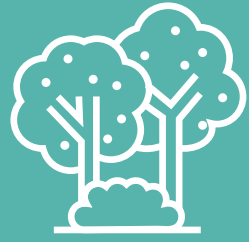

ధరం

\section{PROGRAMAS Y PROYECTOS FORESTALES}

- Los programas e intervenciones del gobierno, organizaciones donantes $u$ ONG son indiferentes a las cuestiones de género.

- No hay un reconocimiento de las necesidades de los diferentes tipos de mujeres y hombres, ni de las formas de discriminación interseccional.

- Quienes proponen proyectos tienen poca comprensión y reconocimiento del papel de la mujer en la implementación de políticas y leyes en las instituciones consuetudinarias de facto, legítimas y de derechos indígenas.

- El personal no está adecuadamente sensibilizado frente a las cuestiones de género.

- Los recursos presupuestarios o técnicos dedicados a las mejoras de la tenencia forestal con perspectiva de género son inadecuados.
ORGANIZACIONES FORESTALES Y DE APOYO A LA MUJER

- No existe comprensión suficiente de la importancia de la igualdad de género y el empoderamiento de las mujeres en general en el sector forestal, y en particular en cuestiones de tenencia.

- Hay una fuerte tendencia a priorizar la obtención y el fortalecimiento de los derechos de tenencia a nivel colectivo en lugar de centrarse en los derechos específicos de las mujeres y los hombres.

- No existe suficiente apoyo directo y continuo de ONG y federaciones de base para que las comunidades locales obtengan el reconocimiento de la tenencia y hagan valer los derechos forestales de las mujeres y los hombres mediante el desarrollo del liderazgo de las mujeres para una participación eficaz en los órganos de gobernanza forestal.

Figura 5. Brechas de género en las instituciones de tenencia forestal. 
- Existe un nivel inadecuado de investigación basada en evidencia sobre muchos temas clave en materia de género relacionados con la tenencia forestal, desde la escala local y regional hasta la nacional.

- Es necesario brindar apoyo educativo y capacitación a los nuevos investigadores (así como a otros, como funcionarios gubernamentales, académicos y ONG/OSC) sobre cómo integrar enfoques de género en sus investigaciones $y$ análisis orientados a la acción.

- Los resultados de las investigaciones sobre género y tenencia forestal no se comunican de manera accesible a los responsables de la formulación de políticas, parlamentarios, líderes locales y otros actores relevantes.
- Hay un predominio de normas patriarcales con discriminación de género y criterios morales acerca del papel de la mujer, que restringen su participación en la forestería más allá de la recolección de alimentos, combustible y forraje, $y$ al mismo tiempo otorgan a los hombres libertad de movimiento, derecho a hablar en público y autoridad, así como diversos tipos de usos forestales.

- Las limitaciones de las mujeres en términos de su pesada carga de responsabilidades en el hogar y en el cuidado de los niños generan restricciones de tiempo y movilidad para un compromiso de participación eficaz en la gobernanza de la tenencia.

- Los conflictos de larga data sobre los derechos de tenencia forestal tienen un impacto negativo en la capacidad de las mujeres para acceder a sus recursos forestales $y$ gestionarlos.

- Las políticas y leyes forestales no reconocen explícitamente la importancia de la igualdad de género, ni, por lo tanto, el apoyo que esta requiere, lo que conduce a restricciones relacionadas con el género y resultados excluyentes en las comunidades locales.

- Es posible que ni las mujeres ni los hombres estén al tanto de las disposiciones relativas a la igualdad de género de leyes, reglamentos o políticas, ni de cómo se deben implementar.
- Las mujeres y los marginados a menudo son excluidos de los órganos de gobernanza forestal y no tienen autoridad, legitimidad o habilidades de liderazgo para influir en la elaboración de normas.

- Los roles, derechos y responsabilidades, en especial en el caso de las mujeres, no están claros o son inseguros, lo que conduce a una gestión deficiente, conflictos y pobreza.

- Los derechos específicos de las mujeres sobre árboles y bosques no están reconocidos en el plan de manejo forestal bajo tenencia colectiva.

- El conocimiento diferenciado de mujeres y hombres sobre los bosques y su ciclo anual no está reconocido en los procesos de políticas, el diseño de proyectos y la gobernanza forestal.

- Las mujeres suelen recibir menores beneficios económicos que los hombres por la venta de productos forestales o el pago por servicios ambientales (PSA).

- Existen importantes brechas de género en una diversidad de ámbitos adicionales relacionados con la tenencia forestal, como alfabetización y educación; empleo justo; acceso a información y tecnologías móviles; disponibilidad de servicios de extensión, capacitación técnica y empresarial; crédito y mercados; transporte accesible; y participación en empresas forestales. 


\section{$\sqrt{30}$ ANALIZAR}

- Comprender los logros hasta la fecha, así como los desafíos y necesidades futuros.

- Llevar a cabo un análisis situacional de género a múltiples escalas, de la macro a la micro.

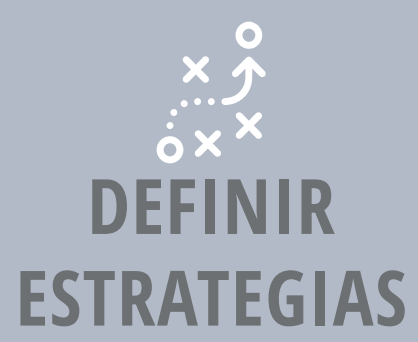

- Decidir una estrategia eficaz para lograr el cambio en un periodo de tiempo determinado.

IMPLEMENTAR ESTRATEGIAS

- Implementar la estrategia por medio de un conjunto de actividades secuenciadas y escalonadas en las que se integran la reflexión y el aprendizaje.

- Identificar a los socios adecuados para la acción colaborativa y las vías hacia el cambio.
- Desarrollar una visión de cómo sería la gobernanza responsable de la tenencia forestal con igualdad de género.

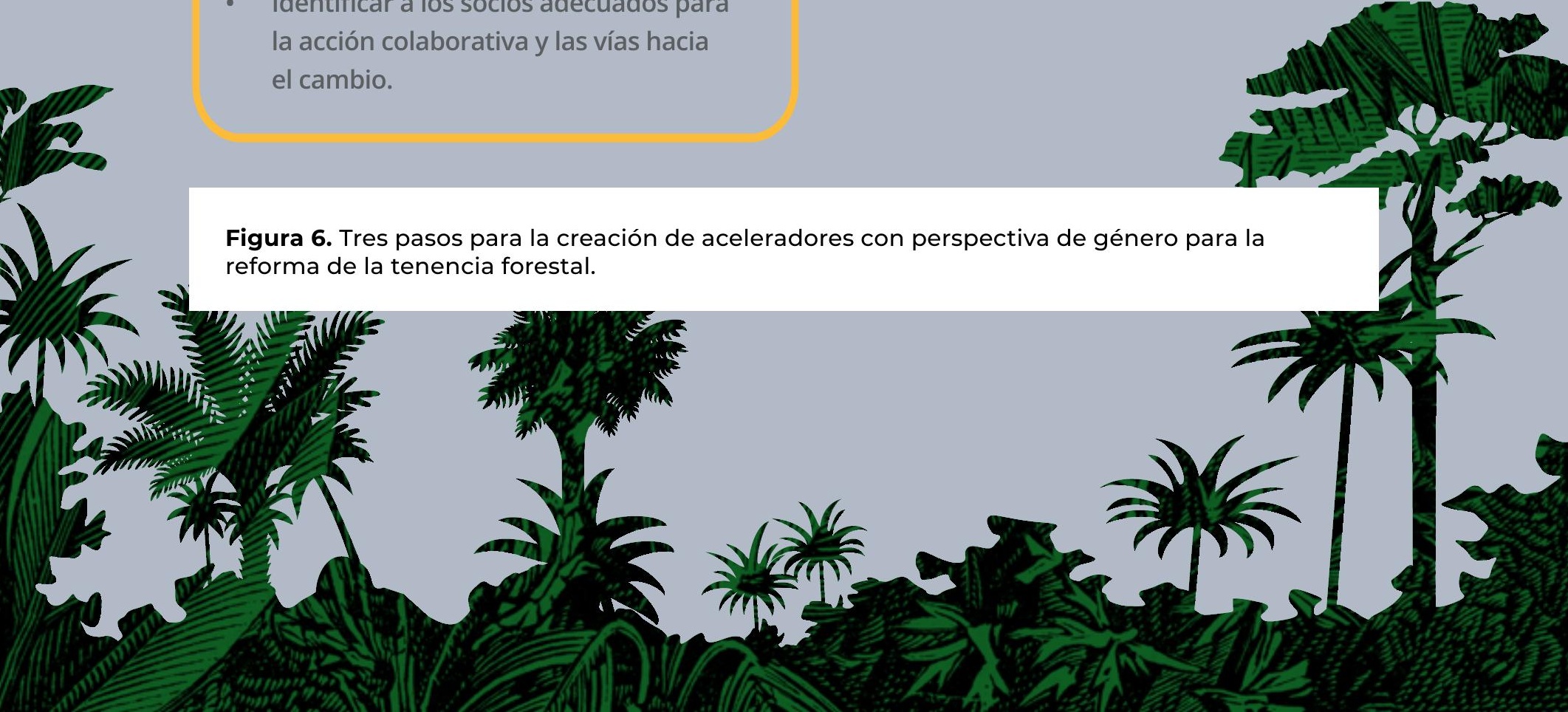


forestal colectiva (Figura 5). ¿Cómo priorizar en qué brechas centrarse primero para acelerar el cambio? ¿Qué tipo de análisis situacional de género se necesita para determinar las brechas de importancia prioritaria? Una vez que se ha realizado un análisis se puede implementar una buena estrategia por etapas y diseñar un conjunto secuencial de acciones o intervenciones.

Cualquiera que sea el contexto o los objetivos, acelerar la reforma de la tenencia forestal con perspectiva de género implica tres pasos para generar cambios en estas brechas de género: Analizar, Definir estrategias e Implementar estrategias (Figura 6). Esto cubre todo el ciclo iterativo de la reforma de la tenencia forestal desde una perspectiva de género, independientemente de si este es iniciado por una comunidad, una oficina de asuntos de género en el ministerio forestal, una ONG de mujeres, un proyecto de una organización donante o un grupo forestal de base a nivel local. Aunque se dispone de una serie de guías y herramientas sobre la reforma de la tenencia forestal, muchas de ellas tienen que ser reinterpretadas desde una perspectiva de género (véanse FAO 2011, 2014; Mayers et al. 2013; Coleman 2019; Banco Mundial 2019a). Repensar las cosas es vital porque se necesitan ideas nuevas para visualizar un futuro con igualdad de género. Como se establece en las VGGT, la reforma de la tenencia forestal es un proceso cíclico de mejora continua que genera seguridad en varias dimensiones de los regímenes de tenencia (FAO 2012). No es un esfuerzo que se haga una sola vez: es necesario generar un impulso coordinado para lograr una transformación eficaz.
SECCIÓN 1.2

\section{LECTURAS COMPLEMENTARIAS}

[FAO] Food and Agriculture Organization. 2016. How to Mainstream Gender in Forestry. Roma: FAO.

[FAO y RECOFTC] Food and Agriculture Organization y The Center for People and Forests. 2016. Mainstreaming Gender into Forestry Interventions in Asia and the Pacific. A Training Manual. Roma y Bangkok: FAO y RECOFTC.

Kristjanson P y Jensen A. 2018. In Brief: Gender in Forest Landscape Projects. Action and Indicators. Washington, DC: PROFOR. 
PERSPECT\|VAS SOBRE TENENC\|A FORESTAL

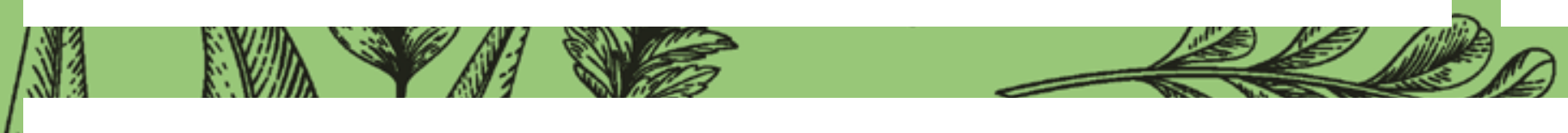

UN ACELERADOR

GLOBAL PARA

ASUNTOS DE

GENERO: Las

directrices de

política de la

Organización

Internacional

de las Maderas

Tropicales

sobre igualdad

de género y

empoderamiento

de la mujer

\section{PREGUNTA DE REFLEXIÓN}

\section{¿Qué está impulsando el desarrollo de nuevas políticas mundiales sobre igualdad de género para el sector de los bosques tropicales?}

En diciembre de 2017, el Consejo Internacional de las Maderas Tropicales (CIMT) dio un paso importante al adoptar sus nuevas "Directrices de política sobre igualdad de género y empoderamiento de la mujer", en apoyo de la integración y la transversalización de la perspectiva de género (Caswell 2018; Dieterle 2019). Su objetivo es cerrar la brecha de género y empoderar a las mujeres a todo nivel en el sector de comercio de maderas tropicales. El impulso detrás de esta medida innovadora de la Organización Internacional de las Maderas Tropicales (OIMT) ${ }^{5}$ fue la necesidad de vincularse directamente con varios mandatos de los ODS, los Objetivos Mundiales sobre los Bosques de las Naciones Unidas y el Plan Estratégico a 2030 del Foro de las Naciones Unidas sobre los Bosques.

Esta política de género se tomará en cuenta al desarrollar, implementar y evaluar los proyectos y actividades de la OIMT en sus países miembros. Los proyectos de la OIMT serán sensibles al género $y$, cuando sea posible, transformadores en materia de género. Se integrarán los asuntos de género en los criterios e indicadores que guían tanto a la OIMT como a sus socios implementadores. Esto facilitará la recopilación de datos desglosados por sexo (en particular sobre el papel de la mujer en la industria y el comercio forestales) y ayudará a entender mejor los problemas y los beneficios a lo largo del camino. Además, mediante este enfoque, se alentará a las políticas nacionales de los países miembros de la OIMT a crear marcos favorables que apoyen la igualdad de género.

En los países productores de maderas tropicales, las mujeres que trabajan y dirigen empresas forestales

5 La OIMT es una organización de productos básicos establecida en 1994, sus países miembros forman parte de los nodos de producción y consumo del comercio de maderas tropicales. Desarrolla políticas y tiene un foro para la discusión y el intercambio de información sobre la economía mundial de las maderas tropicales. Sus miembros representan el $80 \%$ de los bosques tropicales del mundo y son responsables del $90 \%$ del comercio mundial de maderas tropicales. 


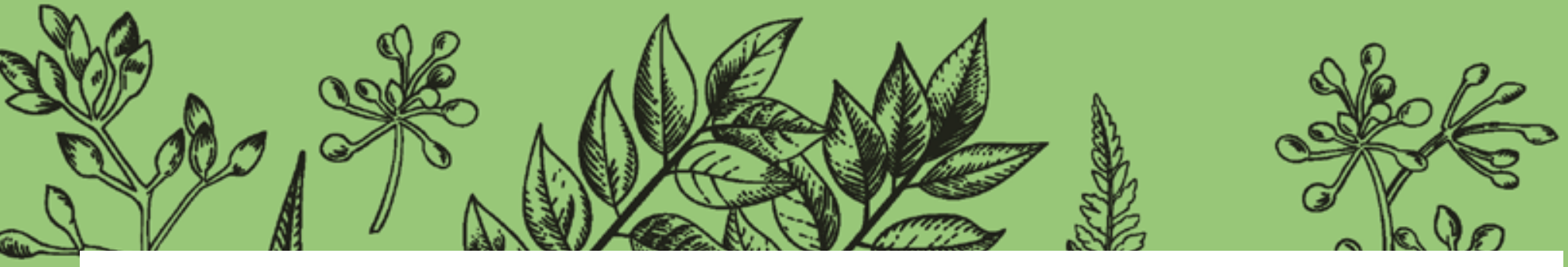

deben enfrentarse a una gran cantidad de desventajas. La naturaleza patriarcal de las instituciones de tenencia consuetudinaria, combinada con la indiferencia hacia las cuestiones de género de los marcos jurídicos de tenencia (como no exigir la titulación conjunta de la propiedad), significa que las normas imperantes tienen un impacto negativo en las mujeres (ITTO y RRI 2011). Las mujeres tampoco tienen un acceso igualitario a las oportunidades de empleo ni reciben la misma remuneración por realizar el mismo trabajo. Sin derechos formales de tenencia que les permitan obtener préstamos, no pueden iniciar proyectos empresariales (Caswell 2019). Por último, las mujeres tienen escasa representación en muchas empresas de comercio de madera, ya sea en la producción, el procesamiento o la fabricación (en especial en los niveles superiores); en las principales autoridades, instituciones y organizaciones forestales; y en los grupos de comercio internacional (Caswell 2019). La implementación de las directrices de política de la OIMT tendrá que lidiar con estos numerosos obstáculos.

Las directrices de la OIMT se componen de ocho elementos centrales (Caswell 2019):

a. Políticas, planes de acción y programas temáticos de la OIMT. Integración y transversalización de la perspectiva de género.

b. Ciclo de proyectos de la OIMT. La igualdad de género se abordará en todos los aspectos del ciclo del proyecto. El Manual de la OIMT para la formulación de proyectos contiene una guía actualizada sobre cómo realizar un análisis de género. c. Desarrollo de capacidades. Reforzar la capacidad para establecer, fortalecer e implementar leyes y políticas para lograr la igualdad de género y el empoderamiento de la mujer, en especial en el sector de bosques tropicales.

d. Estadísticas e información. Las cuestiones de género se integrarán en los procesos de recopilación de datos y en los procesos estadísticos.

e. Aprendizaje, gestión del conocimiento y comunicación. Intensificar el aprendizaje sobre la igualdad de género como parte de las prácticas de gestión del conocimiento, ampliando las buenas prácticas y mejorando la comprensión acerca de las cuestiones de género en la economía internacional de las maderas tropicales.

f. Redes y alianzas de cooperación. El CIMT y la secretaría de la OIMT trabajarán con el Grupo Asesor de Comercio y el Grupo Asesor de la Sociedad Civil para fortalecer la transversalización de la perspectiva de género. Se establecerán alianzas con organizaciones relevantes como ONU Mujeres.

g. Funcionamiento interno. La OIMT fortalecerá el equilibrio entre ambos géneros en las mesas del Consejo, los grupos de expertos y los grupos de trabajo. Se creará un clima de respeto de las mujeres que son parte del personal en todos los niveles.

h. Rendición de cuentas. Se establecerá un mecanismo para seguir y medir el progreso alcanzado.

\section{LECCIONES}

Los ODS, junto con otros objetivos forestales internacionales de las Naciones Unidas, cumplen un papel importante como catalizadores de la creación de políticas nacionales de igualdad de género para el sector forestal. 


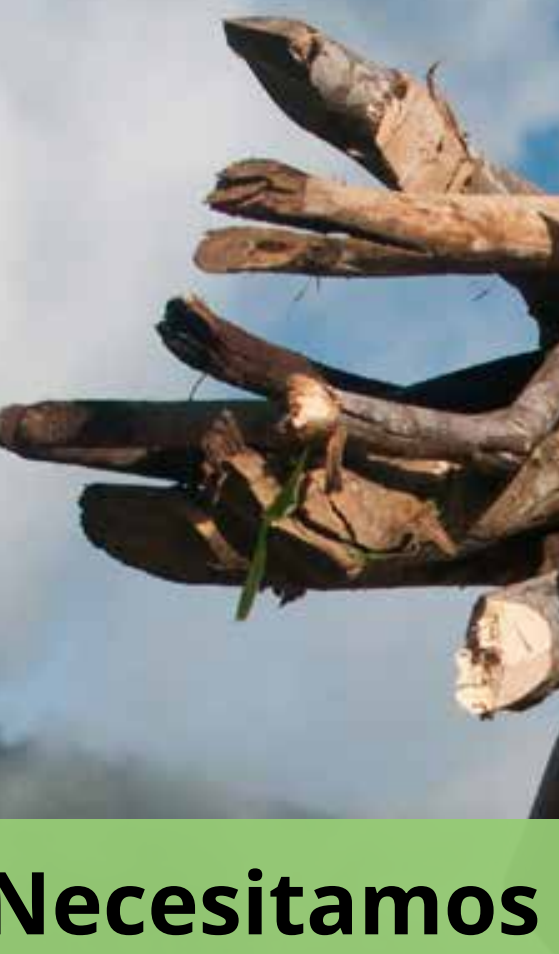

cuestionar nuestros puntos débiles y poner en práctica la investigación en materia de género. En el ámbito de las cuestiones de género, se han desarrollado muy buenas investigaciones y conocimientos relacionados con el enfoque de paisajes, pero desafortunadamente no han sido muy usados para progresar o crear acciones que promuevan la equidad de género - es una suerte de rompecabezas incompleto, y debemos pensar en diferentes acciones que puedan ayudarnos a avanzar en nuestros objetivos de igualdad de género.

\section{Dra. Esther Mwangi}

Científica principal de CIFOR (Mollins 2013) 


\section{3}

\section{CREAR CAMIBIO PASO 1: ANALIZAR}

Para empezar, debe haber una buena comprensión actualizada de la situación de las cuestiones de género en la tenencia forestal y su gobernanza responsable. Este es el primer paso: Analizar. Por lo general, la información disponible es bastante limitada, e incluso se relegan las discusiones sobre el tema a la periferia del debate. Por lo tanto, es esencial realizar un análisis del estado actual de las cuestiones de género en la tenencia forestal. Es una tarea que no tardará en rendir frutos. Lo que requerirá más esfuerzo es el arte de identificar las líneas de corte principales. Una evaluación detallada de lo que está sucediendo y de lo que requiere atención puede denominarse "análisis situacional de género". ¿Cuáles son las brechas de género particulares que operan en un contexto específico? ¿En qué medida influyen las leyes en la práctica real de los regímenes de tenencia forestal colectiva?

El análisis situacional de género de la tenencia forestal examina los factores que afectan la manera en que las mujeres y los hombres acceden a, utilizan y gestionan los recursos forestales, tanto para entender los factores de éxito como para identificar los desafíos clave que hay que abordar. Aunque hay muchos tipos de marcos disponibles para el análisis de género (para una evaluación comparativa en el sector forestal, véanse, por ejemplo, Manfre y Rubin
2012; FAO y RECOFTC 2016; y también IREX 2018; y Ochieng 2019), en la práctica, el enfoque y la orientación del análisis deben adaptarse a los objetivos y al paisaje correspondiente. Un conjunto de evidencias confiable sirve de base para establecer una estrategia con su respectiva hoja de ruta o plan de acción. Por supuesto, también ayudará a hacer un seguimiento a las tendencias para el cambio positivo y a actualizar la estrategia. Este análisis puede ayudar a definir objetivos de diverso tipo, desde el objetivo más general de enmendar las leyes forestales o las metas de políticas, hasta el objetivo del día a día de tratar de reducir todo tipo de daño a las mujeres y los hombres en las instituciones locales de tenencia forestal.

Sobre la base de este análisis, se puede dar amplia difusión a un informe de situación acerca del estado de las cuestiones de género y la tenencia forestal (sea de alcance nacional o local), para exponer lo que se ha logrado hasta la fecha y orientar la elaboración de una estrategia para el cambio. En la Figura 7 se presenta un conjunto de preguntas guía para ayudar a realizar el análisis situacional de género. Estas preguntas se basan en líneas generales en el marco forestal de la "caja de género", que examina cuestiones clave en materia de 


\section{PREGUNTAS DE ORIENTACIÓN}

\section{ESCALA}

\section{NACIONAL \\ Y ESCALA \\ SUBNACIONAL}

\section{FACTORES DE CONTEXTO}

- ¿Qué tipo de ecología y condiciones forestales predominan en diferentes partes del país? ¿Tiene la madera una gran demanda para fines comerciales? ¿Qué nivel de dependencia de los variados recursos forestales existe entre mujeres y hombres?

- ¿De qué manera los cambios en las condiciones socioeconómicas y de infraestructura locales han afectado las normas de tenencia forestal dentro de los órganos de gobernanza forestal local para mujeres y hombres en todo el país?

\section{ESTADO ACTUAL DE GÉNERO Y TENENCIA FORESTAL}

- ¿Quiénes se ven afectados por la situación actual de la tenencia forestal nacional (tome en cuenta mujeres y hombres de diferentes ingresos, condición social y étnica)? ¿Cuáles son los impactos diferenciados por género?

- ¿Existen condiciones de tenencia inseguras para mujeres y hombres? ¿Se deben a la ausencia de leyes y políticas que afirmen la importancia de la igualdad de género? ¿Existen conflictos de larga data o zonas de inestabilidad que estén afectando el reconocimiento y el aseguramiento de las condiciones de tenencia? ¿Existen presiones de inversión para convertir las tierras a usos agrícolas o en plantaciones forestales? ¿La prestación de servicios gubernamentales es deficiente?

Figura 7. Marco para el análisis situacional de género de la tenencia forestal colectiva Fuente: adaptado de Larson (2012), Colfer (2013), FAO (2019c), Kristjanson et al. (2019). 


\section{PROCESO DE REFORMA DE LA TENENCIA FORESTAL}

- ¿Se ha realizado alguna evaluación nacional de la tenencia forestal? ¿Adopta una perspectiva de género? ¿Se basa en buenas prácticas internacionales para su evaluación?

- ¿Existe un proceso de reforma de la tenencia forestal en curso? ¿Es un proceso con perspectiva de género? ¿Cómo participan mujeres y hombres en el diseño y la implementación del proceso? ¿Qué se ha logrado (en términos de políticas, leyes y su implementación) y qué requiere atención aún?

- ¿Quiénes son los parlamentarios, tomadores de decisiones clave, ONG/OSC o federaciones que apoyan la igualdad de género en la tenencia forestal? ¿Existe un fuerte liderazgo femenino entre estos influyentes agentes de cambio?

- ¿Ha habido devolución de derechos de tenencia forestal a los pueblos indígenas y las comunidades locales? ¿Sobre qué tipos de tierras o bosques? ¿Cuál fue la fuerza impulsora detrás del proceso? ¿Se llevó a cabo por medio de marcos políticos o jurídicos?

- ¿Qué tan bien se comparan la política y el marco jurídico de tenencia forestal con las VGGT, en especial con las referidas a cuestiones de género?

- ¿Ofrece la política o el marco jurídico protección frente a inversiones y comercialización a gran escala, así como frente a cambios en la tenencia debido a la adaptación y mitigación del cambio climático?

- ¿Se han logrado cambios positivos para la igualdad de género en las instituciones de tenencia forestal colectiva? ¿Quiénes han sido los actores clave detrás de estos cambios?

\section{ADMINISTRACIÓN GUBERNAMENTAL}

- ¿Qué tan bien se implementan en la práctica las leyes o políticas forestales?

- ¿Existen oficinas del gobierno local o proveedores de servicios locales que puedan responder de manera adecuada a las necesidades colectivas de mujeres y hombres?

- ¿Cómo se lleva a cabo la administración de los derechos de tenencia en relación con el registro de la tenencia, los impuestos, la valoración y el ordenamiento territorial? ¿Presta atención a cuestiones de género?

- ¿Existen datos desglosados por género sobre el sector forestal, incluida la tenencia? 


\section{ESCALA LOCAL}

\section{GOBERNANZA FORESTAL}

- ¿Es el actual acuerdo de tenencia forestal un sistema consuetudinario o uno desarrollado recientemente? ¿O se trata de un acuerdo híbrido que está haciendo reformas en un conjunto de prácticas de tenencia de larga data? ¿Es un sistema de facto o de jure?

- ¿Cómo se demarcaron y mapearon los actuales límites del régimen de tenencia forestal colectiva? ¿Se consultó e involucró a mujeres y hombres?

- ¿Cuál es el sistema de gobernanza forestal que gestiona los bosques locales? ¿Cuán equitativa es la composición del órgano de gobernanza en términos de género? ¿Cuáles son las fuentes de su legitimidad? ¿Hay mujeres líderes eficaces? ¿Hay algún grupo local de mujeres que respalde a las mujeres miembros del sistema de gobernanza forestal?

- ¿Qué tipo de participación tienen mujeres y hombres dentro del órgano de gobernanza? ¿En qué parte del espectro, que va desde una participación nominal hasta una de empoderamiento, se encuentran (véase Perspectivas sobre Tenencia Forestal n. ${ }^{\circ}$ 9)?

- ¿Qué tipo de marcos regulatorios gubernamentales (ya sea sobre bosques, extracción maderera o desarrollo empresarial) afectan la forma en que opera el órgano de gobernanza forestal? ¿Tiene que pagar impuestos? ¿Debe contar con un plan de gestión forestal aprobado por el gobierno para funcionar legítimamente como órgano de gobernanza? ¿Necesita obtener licencias para operar una empresa de base forestal? ¿Requiere permisos de transporte?
- ¿El gobierno brinda capacitación, desarrollo de capacidades o apoyo tecnológico de algún tipo al órgano de gobernanza forestal local?

- ¿Cuáles son los objetivos generales del órgano de gobernanza forestal con respecto al estado del bosque y los usos sociales del bosque? ¿Qué tipo de reglas ha establecido y sobre qué conjuntos de derechos? ¿Son adecuados los diversos incentivos para impulsar un compromiso a largo plazo con la gestión forestal sostenible por parte de las mujeres y los hombres miembros de la comunidad? ¿Abarca un "conjunto holístico de recursos", es decir, tanto de alto como de bajo valor?

- ¿Existen diferentes tipos de derechos de acceso, uso y manejo, para mujeres y hombres de diversos niveles socioeconómicos, a los diversos productos forestales? ¿Está esto determinado por normas sociales o por reglas establecidas de manera formal? ¿Existe un plan formal de manejo y operación forestal? ¿Este reconoce los derechos específicos de mujeres y hombres? ¿Influye el plan en cómo se gestionan realmente los bosques en la práctica?

- ¿Están las mujeres y los hombres involucrados en la vigilancia y el monitoreo, y en asegurar que se cumplan las normas?

- ¿Cómo se distribuyen los diferentes tipos de beneficios derivados de los bosques (tanto de subsistencia como comerciales) entre mujeres y hombres en la comunidad? ¿Son estos beneficios individuales o colectivos?

- Si aparecen disputas, ¿sobre qué temas suelen ser? ¿Cómo son abordadas? ¿Los sistemas de resolución de conflictos prestan atención a las diferencias de género? 


\section{DINÁMICA COMUNITARIA}

- ¿Cómo utilizan las mujeres y los hombres la tecnología (incluida la

\section{DINÁMICA DEL HOGAR}

- ¿Qué tipo de roles domésticos tienen las mujeres y los hombres en sus hogares? ¿Cuidado de los niños? ¿Cocina? ¿Recolección de alimentos? ¿Cuidado de la salud? ¿Cuidado de ancianos?

- ¿Qué tipo de activos y educación tienen las mujeres y los hombres en la comunidad local? ¿Cómo afecta esto la capacidad de mujeres y hombres para gestionar y beneficiarse de los bosques?

- ¿Cuáles son las dinámicas para la toma de decisiones entre mujeres (mayores y menores) y hombres (mayores y menores) dentro del hogar? ¿Cómo se desarrollan las negociaciones? ¿Quién controla los recursos financieros? ¿Qué tipos de derechos reproductivos existen?

- ¿Existen diferencias en el conocimiento que tienen las mujeres y los hombres sobre los bosques locales? ¿Qué factores afectan dicho conocimiento? ¿Hay conocimientos superpuestos?

- ¿Existen espacios geográficos específicos en los que se permite trabajar a mujeres y hombres? ¿Esto ocurre solo en el hogar? ¿O en áreas específicas de bosques cercanos a su hogar? ¿Qué tipos de bosque? ¿Y en bosques más lejanos?

- ¿Cómo afectan las prácticas y leyes sobre la herencia y el matrimonio la forma en que las mujeres y los hombres se benefician de las asignaciones de derechos de tenencia forestal existentes?

- ¿Tienen las mujeres y los hombres cuentas bancarias individuales? ¿Está disponible la banca móvil? 
género en tres escalas: macro, meso y micro (Colfer 2013). Para todo análisis situacional de género específico, se requerirá identificar un conjunto de preguntas a la medida, que dependerán del objetivo que se quiera lograr.

¿Cómo se puede realizar la investigación para este tipo de análisis situacional de género? Es muy probable que el análisis sea interdisciplinario, por lo que se requerirá contar con algunos conocimientos sobre temas ambientales y conocimientos amplios en ciencias sociales. Se necesitará una combinación de métodos de investigación (pluralismo metodológico), ya que el análisis tendrá que examinar numerosos temas, como el crecimiento económico, la dinámica comercial, las leyes, la administración gubernamental, la gobernanza, los sistemas de normas, el liderazgo y el uso de los bosques a nivel micro (Bose 2017; Bose et al. 2017).

No hay una fórmula sencilla para realizar esta investigación orientada a la acción, pero se puede hallar pautas en varias publicaciones sobre análisis de género (véase Manfre y Rubin 2012, por ejemplo). Existen numerosas metodologías posibles: revisión de la literatura, observación participante, cuestionarios, grupos focales o entrevistas individuales con funcionarios y expertos gubernamentales, entrevistas en grupos focales con ONG o comunidades locales, entrevistas de hogares, encuestas socioeconómicas de hogares, entrevistas con mujeres líderes, ejercicios de mapeo participativo, entre otras ${ }^{6}$. En lugares en donde los conflictos son un problema importante, vale la pena consultar el Manual de evaluación rápida de la tenencia de la tierra (Galudra et al. 2010). Si se necesita información detallada sobre medios de subsistencia y bienestar de los hogares, las Encuestas de caracterización saciaeconámica nacional en el sector farestal: arientaciones y mádulas de encuestas para medir las múltiples funcianes de las hasques en el lienestar y las medias de vida del hagar (FAO, CIFOR, IFRI y World Bank 2016) pueden ayudar a reflexionar sobre cómo satisfacer necesidades específicas. Independientemente de cuál sea el tipo de metodología empleado, al diseñar la

6 Es útil aprender sobre metodologías muy específicas que puedan inspirar un enfoque que se ajuste a sus necesidades. Este extenso menú incluye: mapeo de preferencias de género para el aprovechamiento de árboles y arbustos, comprensión de los roles de género en la producción y comercialización de productos arbóreos agroforestales mediante evaluación de tareas, evaluación de recursos naturales específicos por género utilizando el "juego de guijarros", mapeo participativo de recursos para análisis de género, captura de la apreciación de género de paisajes multifuncionales mediante interpretación de paisajes visuales, captura de la comprensión específica de género de las funciones del paisaje mediante SIG participativo, y análisis de redes sociales diferenciadas por género para determinar fuentes de información y plántulas, entre otras (véase Catacutan et al. 2014a).

\section{No existe un enfoque único}

Debido a que los roles y las relaciones de género se definen en el espacio y el tiempo, debe estar preparado para modificar y adaptar los métodos y herramientas que utiliza para diferentes contextos. Los roles y las relaciones de género varían de acuerdo con la geografía y a lo largo del tiempo. Por lo tanto, es esencial

estar preparado para aprender cómo son las dinámicas de género a nivel local.

\section{Conozca el contexto}

Precisamente debido a que las dinámicas de género se encuentran arraigadas en las dinámicas socioculturales locales, familiarizarse con el lugar lo ayudará a identificar los métodos y herramientas más adecuados para la investigación. Por ejemplo, el conocimiento sobre el lugar puede ayudarlo a determinar si las discusiones de los grupos focales deben ser de un solo sexo o mixtas,

o si es necesario desglosarlas por edad y/o sexo. Puede adquirir estos conocimientos mediante investigación primaria y

$$
\text { secundaria. }
$$

\section{Utilice métodos cuantitativos y cualitativos}

El uso de una combinación de métodos permite la triangulación de datos y tener más confianza en sus hallazgos. También le brinda la capacidad de adaptar argumentos a diversos públicos de acuerdo con sus preferencias por hallazgos cuantitativos o cualitativos. 


\section{Busque varias perspectivas}

Uno de los mayores errores que

puede cometer al integrar las cuestiones

de género en su investigación es entrevistar a muy pocas personas. Entrevistar solo a mujeres le proporcionará información desde la perspectiva de estas, pero no le permitirá entender en qué puntos y de qué manera las opiniones de hombres y mujeres difieren, entran en conflicto o se superponen. Del

mismo modo, entrevistar solo a las mujeres más elocuentes o expresivas del lugar probablemente lleve a una imagen sesgada de la situación.

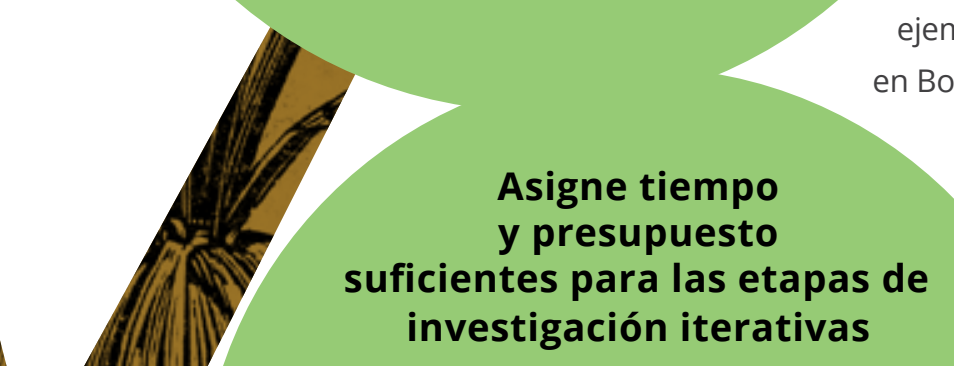

Comprender la dinámica de género es un proceso iterativo que puede requerir varias visitas de campo. Puede necesitar más de una entrevista

o conversación con sus informantes para apreciar plenamente la dinámica del hogar o la comunidad. Es su responsabilidad asegurarse de que el diseño de su propuesta de investigación considere suficientes recursos financieros y tiempo para ello.

Figura 8. Principios rectores para la investigación orientada a la acción sobre género y tenencia forestal.

Fuente: Manfre y Rubin (2012).
Antes de tomar una decisión sobre cómo llevar a cabo el estudio, se deben evaluar los beneficios de las diversas metodologías de recopilación de datos, en especial las de carácter participativo (para una discusión sobre este tema, véanse Nightingale 2003; Colfer y Minarchek 2012; Manfre y Rubin 2012; CGIAR Gender Platform s. f.). En términos de enfoques prospectivos, métodos como el análisis de prospectiva participativa (PPA, por sus siglas en inglés) pueden ayudar a determinar escenarios futuros. El PPA explora y anticipa cambios, e involucra conocimiento presciente y desarrollo de escenarios alternativos. También facilita la participación entre múltiples actores que pueden tener perspectivas diferentes y en ocasiones conflictivas. Al tratarse de un enfoque de tipo colaborativo, reúne a los actores involucrados en la implementación de la reforma de la tenencia forestal para crear una estrategia de consenso (véanse, por ejemplo, Liswanti et al. 2019 sobre Indonesia, y la orientación metodológica en Bourgeois et al. 2017).

Una vez recopilados los datos y la información, se puede preparar un informe preliminar y compartirlo en talleres con grupos específicos de actores para asegurar el equilibrio en la representación y su precisión. Una vez finalizado, el informe de situación puede utilizarse para preparar un resumen o síntesis (y traducirlo a los idiomas locales). Esto puede ayudar a dar difusión amplia a los hallazgos y recomendaciones principales para el desarrollo de una estrategia. Dicho estudio puede ser actualizado después de unos cinco años, por ejemplo, para obtener una idea de hacia dónde se dirige el cambio.

SECCIÓN 1.3

\section{LECTURAS COMPLEMENTARIAS}

Colfer CJP y Minarchek RD. 2012. Women, men and forest research: A review of approaches, resources and methods for addressing gender. Occasional Paper no. 80. Bogor, Indonesia: CIFOR.

Colfer CJP. 2013. The gender box: A framework for analysing gender roles in forest management. Occasional Paper 82. Bogor, Indonesia: CIFOR.

Manfre C y Rubin D. 2012. Integrating Gender into Forestry Research: A Guide for CIFOR Scientists and Programme Administrators. Bogor, Indonesia: CIFOR. 
ANÁLISIS DE

LA IGUALDAD

DE GENERO EN

UNA NUEVA

ESTRATEGIA

FORESTAL

COMUNITARTA:

Lecciones de

la República

Democrática del

Congo

\section{PREGUNTA DE REFLEXIÓN \\ ¿Cómo puede un análisis de los desafíos en materia de género ayudar a lograr la igualdad de género en un nuevo marco jurídico para la forestería comunitaria?}

En febrero de 2016, la República Democrática del Congo (RDC) completó un nuevo marco jurídico para la forestería comunitaria. En comparación con sus países vecinos, fue un avance extraordinario, ya que permitió ampliar el tamaño de las concesiones forestales de uso común a nivel local (hasta un máximo de 50000 hectáreas), que pudieran ser mantenidas en perpetuidad por las comunidades locales siguiendo el derecho consuetudinario y que pudieran utilizarse para propósitos diversos (Rainforest Foundation UK 2018). La RDC cuenta con el segundo bosque tropical continuo e intacto más grande del mundo. Esta era una gran oportunidad para lograr la igualdad de género: el impacto potencial en los 40 millones de personas que dependen de los bosques (la mitad de la población del país) podía ser considerable, con unos 75 millones de hectáreas (tres cuartas partes del área forestal nacional) disponibles para la forestería comunitaria.

Dado que se trataba de una nueva medida, su potencial para poner en marcha prácticas de equidad de género desde el principio era significativo. Debido a la magnitud de las tareas por delante, una ONG internacional que trabaja en temas de forestería comunitaria, Rainforest Foundation UK, consideró que era esencial aprender de proyectos piloto pequeños basados en un análisis detallado de las condiciones locales, y solo luego aumentar la escala7. Se temía que un fracaso temprano causara desilusión en las comunidades. Por ello, cuando en 2015 se creó una Mesa Redonda sobre Forestería Comunitaria con el fin de preparar una Estrategia Nacional Forestal Comunitaria (que fue concluida en 2018), esta se dedicó a elaborar principios clave acerca de género e igualdad ${ }^{8}$. A partir de esto, se estableció un conjunto de 10 concesiones piloto en la zona occidental de la RDC durante un periodo de 5 años (2018-2023). El diseño de estos pilotos implicó una revisión de la literatura y una evaluación sobre el terreno (en la provincia de Équateur) de los asuntos de género entre las comunidades bantús (Rainforest Foundation UK 2019b, véase también Moïse 2019) .

7 La investigación que analiza los beneficios financieros de los bosques de uso común en la zona oriental de la RDC indica que, debido a los altos costos de puesta en marcha y los requisitos regulatorios complejos, los bosques comunitarios estudiados tuvieron un desempeño financiero negativo (Lescuyer et al. 2019).

8 En esta estrategia, se considera el género como un "componente transversal" y "para ser inclusivos, sus ejes estratégicos también deben incorporar las perspectivas de género, jóvenes y grupos vulnerables". Además, establece que las mujeres "son usuarias importantes del ecosistema forestal y deben ser tomadas en cuenta al establecer estructuras de gobernanza, tomar decisiones y otorgar concesiones". En particular, protege contra una interpretación no inclusiva de las prácticas consuetudinarias: "el modelo de la RDC basado en entidades consuetudinarias y culturales (familias, clanes y linajes) no debe discriminar a las mujeres".

9 Dado que las mujeres indígenas enfrentan diferentes desafíos, la dinámica de género en sus comunidades deberá estudiarse por separado. 
Mediante este proceso, se hicieron patentes algunos elementos clave de los desafíos en materia de género: las mujeres, en comparación con los hombres, tenían un acceso limitado a la educación, la información, los servicios de salud reproductiva, las redes sociales y económicas y las oportunidades de toma de decisiones (véase también Samndong y Kjosavik 2017). Aunque las mujeres eran tan activas como los hombres en la gestión forestal, esto no se traducía en autoridad sobre las decisiones en el hogar o en la comunidad (Steim y Krause 2016). Debido a que los derechos sobre la tierra estaban basados en clanes y linajes, las mujeres dependían de los hombres para el acceso y la propiedad, y la legislación que garantizaba sus derechos y herencia era inadecuada (Moïse 2019). En vista de estas dinámicas restrictivas, las mujeres propusieron que un hombre y una mujer de cada clan formaran parte del comité de manejo forestal de la comunidad local, el cual debía incluir también a representantes de los grupos marginados. En esta región del país, debido a que los asuntos colectivos de las aldeas son manejados por diferentes conjuntos de clanes, la "comunidad" de la forestería comunitaria necesitaba contar con representatividad a nivel de clan. Y dado que las relaciones de género varían según el clan, abordar las cuestiones de género en la comunidad es una tarea delicada.

Más importante aún, la evaluación de género encontró que existía una gran necesidad de desarrollar capacidades entre el personal del gobierno local, así como de cambiar las actitudes entre los miembros de la comunidad mediante el apoyo de organizaciones de mujeres y otros grupos de la sociedad civil. Entre las muchas recomendaciones proactivas para la acción con perspectiva de género están las siguientes (ver Rainforest Foundation UK 2019b):

- Reconocer la importancia de la igualdad de género en la constitución de los órganos de gestión en el marco legislativo forestal comunitario actual
- Establecer un umbral o número mínimo para la participación de las mujeres

- Trabajar para lograr al menos un $30 \%$ de representación de mujeres en las estructuras de gestión locales, y aspirar a llegar al $50 \%$

- Fomentar el surgimiento de mujeres líderes

- Documentar el conocimiento y las prácticas forestales de las mujeres

- Elaborar un inventario de las prácticas colectivas existentes

- Desarrollar indicadores que midan la participación cuantitativa y cualitativa de las mujeres y los beneficios que obtienen

- Realizar ciertas actividades de manera separada con las mujeres, como grupos focales o mapeo

- Asegurar que la redistribución de los ingresos beneficie directamente a las mujeres

- Fomentar la creación de redes entre mujeres de diferentes comunidades

- Sensibilizar continuamente a diferentes grupos de hombres (ancianos, jefes de hogar, jóvenes)

- Identificar a hombres que asuman la función de defensores de la igualdad.

En última instancia, estos análisis de género condujeron a acciones positivas para cambiar las protecciones jurídicas a nivel provincial. En la provincia de Équateur, la Coalición de Mujeres Líderes por el Medio Ambiente y el Desarrollo Sostenible se movilizó con éxito para crear, por primera vez, un decreto a nivel provincial que protege los derechos de las mujeres a la tierra y los bosques, en mayo de 2018 (Losale y Cyr 2018). Actualmente, la Coalición está impulsando cambios similares en las provincias de Mai-Ndombe, Sud Kivu y Congo Central. Estas acciones podrían ser un punto de inflexión para el reconocimiento de los derechos forestales de las mujeres a nivel nacional.

\section{LECCIONES}

Es importante trabajar rápidamente en identificar los desafíos en materia de género para la creación de un nuevo marco jurídico para la forestería comunitaria realizando evaluaciones de género. Estas proporcionarán un conjunto de intervenciones con perspectiva de género adaptadas al contexto local junto con revisiones del marco jurídico. 


\section{$\mathrm{He}$}

defendido la necesidad de situar

geopolíticamente las luchas de las mujeres negras para comprender la naturaleza dinámica de la dominación y la resistencia, y las diversas $y$ desiguales relaciones de poder en las que actúan las mujeres. También he enfatizado la heterogeneidad de los movimientos de mujeres y he analizado cómo la raza y la etnia se entrecruzan con el género, la clase y otros factores para configurar las necesidades y el activismo de las mujeres afrocolombianas. Por último, he recurrido al feminismo poscolonial para sugerir a los estudiosos de temas forestales y expertos en cuestiones género que es imperativo hacer una reflexión crítica sobre los deseos y métodos para conservar los bosques y mejorar la vida de las mujeres del tercer mundo. Es decir, traigo a la discusión sobre bosques y género el recordatorio de que los proyectos de desarrollo y conservación son proyectos de cambio ambiental y social $y$, por lo tanto, proyectos políticos incrustados en redes complejas y desiguales de relaciones de poder. Comprender estas relaciones de poder y cómo se desarrollan en un lugary sector en particular es clave para la investigación y la acción de género y forestal.

\section{Dra. Kiran Asher}

Profesora de Estudios de Mujeres, Género y Sexualidad, Universidad de MassachusettsAmherst $(2016,217)$ 
El primer paso en el análisis situacional de género pone de relieve los desafíos para que el plan estratégico pueda definir la dirección general del cambio que se necesita para lograr una reforma con perspectiva de género de la tenencia forestal colectiva. El segundo paso para crear cambio es Definir estrategias. Este paso establece en qué situación quiere estar su comunidad, oficina o institución en un momento determinado en el futuro, y qué tipo de pasos deberá seguir para lograrlo. Puede incluir una declaración de visión acerca de qué tipo de mundo forestal con igualdad de género se está buscando, a fin de registrar los elementos inspiradores que impulsan el pensamiento y el trabajo estratégicos. Luego, la estrategia puede fijar objetivos específicos que deben cumplirse en un periodo determinado. Idealmente, incluirá también componentes sobre comunicación e influencia. Una vez completada la definición de estrategias, se puede proceder al tercer paso para el cambio, Implementar estrategias, con el fin de crear una hoja de ruta o un plan de acción que establezca el conjunto específico de pasos necesarios para asegurar que se pueda cumplir con las metas.

Al desarrollar un plan estratégico orientado a resultados, es útil considerar primero las lecciones surgidas del trabajo sobre la reforma de la tenencia forestal hasta la fecha (véase, por ejemplo, Coleman 2019) (Figura 9). Estas ayudan a explorar el panorama actual del pensamiento sobre el desarrollo, los objetivos del sector forestal y el contexto de la tenencia forestal, para así poder depurar y priorizar qué temas requieren más atención y cómo lograr la transformación.

Una vez que se tiene una idea de cuáles son las necesidades generales, es posible aproximarse al conjunto específico de objetivos. En la Figura 10, se presenta una lista de los elementos principales que requieren atención estratégica para garantizar una reforma de la tenencia forestal con perspectiva de género. Algunos de estos elementos necesitarán de una estrategia sostenida durante un largo periodo: por ejemplo, para lograr una reforma política o jurídica. Otros, como la creación de un sistema de registro de derechos de tenencia desglosados por género, podrían implementarse con mayor rapidez, sobre todo a nivel local. Al pensar de manera estratégica, es valioso secuenciar las intervenciones para que todo aquello que pueda generar éxito con rapidez y recibir un reconocimiento público amplio genere un impulso hacia la visión a largo plazo.

Para desarrollar un plan estratégico se requiere planificar con anticipación. ¿Quién debería liderar su desarrollo? Idealmente, la dirección de la oficina, la organización o la aldea debe ser el coordinador clave que, junto con personal de apoyo, diseñe el proceso de planificación estratégica. Esto implicará una reunión de uno o dos días, o incluso más. Un tema importante a considerar es quiénes participarán en dicha reunión: se debe involucrar no solo al personal representativo (en condiciones de igualdad de género), sino que puede ser útil invitar a otros miembros de organizaciones de colaboración con las que exista una relación ya establecida y productiva, así como a expertos en temas clave como género y gestión forestal. También se debe evaluar dónde realizarla. ¿En una oficina o en un lugar externo en el que los participantes puedan relacionarse socialmente mientras se enfocan en el plan estratégico? Además, será valioso contar con un facilitador que pueda ayudar a organizar el programa de la sesión de planificación estratégica y facilitar las sesiones principales (algunas se realizarán en plenaria y otras, en discusiones en grupos pequeños). Realizar una cuidadosa labor de planeamiento previo con el facilitador para organizar cada sección de la reunión de planificación estratégica allanará el terreno para un trabajo de colaboración exitoso. E inculcar una cultura de escucha, de reflexión conjunta y de lluvia de ideas sobre las posibilidades futuras permitirá garantizar que el plan respalde la visión general de los participantes.

SECCIÓN 1.4

\section{LECTURAS COMPLEMENTARIAS}

[FAO] Food and Agriculture Organization. 2011. Reforming Forest Tenure. Issues, Principles and Process. FAO Forestry Paper No. 165. Roma FAO.

Mayers J, Morrison E, Rolington L, Studd K y Turrall S. 2013. Improving governance of forest tenure: A practical guide. Governance of Tenure Technical Guide No.2. Londres y Roma: International Institute for Environment and Development (IIED) y FAO.

3I | UNA GUÍA PARA PROFESIONALES 


\section{(由)}

\section{AGENDAS DE DESARROLLO} GLOBAL Y NACIONAL

- Debe formar parte de una agenda de reforma holística e integrada para el sector forestal que se alinee con las políticas de igualdad de género e inclusión social, así como de alivio de la pobreza.

- Debe estar relacionada con los objetivos de la agenda general de desarrollo nacional, incluidos los referidos a la igualdad de género.

- Para ganar impulso, puede basarse en agendas globales como la Agenda 2030 sobre Desarrollo Sostenible, el Acuerdo de París, las VGGT, REDD+ y la Restauración del Paisaje Forestal.

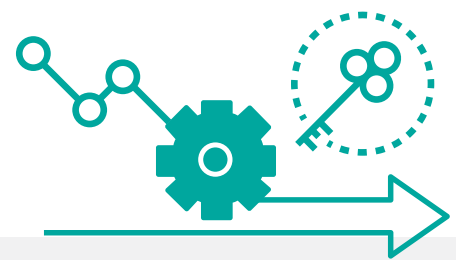

\section{ESTRATEGIA PARA EL CAMBIO}

- Aprovecha las ventanas de oportunidad para asegurar que sus acciones tengan una mayor probabilidad de lograr los objetivos deseados en la reforma de la tenencia forestal.

- Identifica a los agentes de cambio más poderosos: fortalece las organizaciones de mujeres, comunitarias e indígenas y a los defensores de la tenencia para que puedan promover la agenda de la tenencia forestal con perspectiva de género.

- Pone en práctica un proceso iterativo que implica colaboración, aprendizaje y reflexión en la transición hacia la igualdad de género.

- Recopila y comparte lecciones sobre los logros y desafíos de las instituciones y empresas de gestión forestal a nivel local mediante el seguimiento del proceso de cambio.

Figura 9. Lecciones para un enfoque estratégico eficaz para la reforma de la tenencia forestal con perspectiva de género

Fuente: adaptado de Hobley (2007), FAO (2011, 2014b); Agarwal y Freudenberger (2013);

Mayers et al. (2013); RRI (2017, 2018, 2019). 


\section{POLÍTICAS Y LEYES} NACIONALES

- Incorporan enfoques con perspectiva de género en los marcos jurídicos y de políticas existentes que promueven derechos justificables y duraderos, así como la equidad social, pero, al mismo tiempo, consideran proactivamente cómo llevar a cabo la implementación de una manera práctica y eficaz.

- Revisan los procedimientos y los marcos institucionales para garantizar que existan funciones, directrices y disposiciones claras para coordinar la implementación con perspectiva de género en todos los niveles de gobernanza.

- Tienen como objetivo armonizar los sistemas de tenencia forestal con los sistemas de tenencia de la tierra.

- Identifican si existen procesos constructivos de descentralización en los que se pueda trabajar en conjunto con el proceso de devolución para promover cambios con perspectiva de género.

- Desarrollan redes de apoyo para ayudar al punto focal de género del ministerio forestal a desempeñar su labor.

\section{GOBERNANZA RESPONSABLE DE LA TENENCIA FORESTAL COLECTIVA}

- Tiene como objetivo entender la integración cultural y social de prácticas de tenencia mediante la identificación de las diversas redes locales que influyen en el funcionamiento de los escenarios de toma de decisiones.

- Trabaja para lograr instituciones de gobernanza de la tenencia que sean transparentes, responsables y participativas, y tengan una orientación multiactor.

- Cuando los marcos jurídicos son nuevos para las formas colectivas de tenencia, trabaja para implementarlos, primero mediante proyectos piloto y luego a mayor escala, de manera que los derechos puedan traducirse en beneficios valorados en la práctica.

- Busca asegurar que no haya retrocesos o involución de los derechos de tenencia de los PICL.

- Asegura que las normas de tenencia forestal se adapten a las circunstancias, necesidades y objetivos locales; tener normas complejas significa menor posibilidad de implementación y mayores costos de transacción.

- Ayuda a centrarse en leyes y políticas, y también a desarrollar una tenencia forestal "suficientemente segura" mediante el trabajo en factores que afectan la percepción de la seguridad de la tenencia, como prácticas sociales, confianza en el gobierno y conocimientos en temas jurídicos.

- Promueve y fortalece la equidad social general en los regímenes de tenencia colectiva mediante procesos que benefician a todos, trabajando con líderes masculinos.

- Desarrolla sistemas de cumplimiento de las normas de tenencia forestal con perspectiva de género para asegurar que tengan costos mínimos de transacción y máxima capacidad de aplicación.

- Inicia proyectos piloto con el sector privado para fortalecer los derechos de tenencia forestal con igualdad de género de los PICL, a fin de promover empresas con impacto social y el crecimiento económico general. 

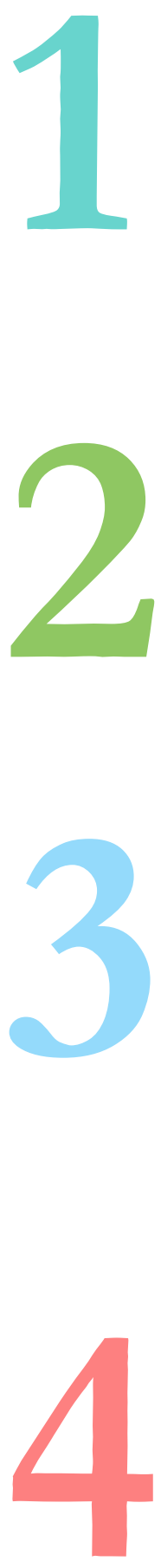

ÁMBITO DE ACCIÓN CLAVE

Marcos

jurídicos para

los derechos

de tenencia

ÁMBITO DE ACCIÓN CLAVE

Implementación

del reconocimiento

jurídico
DIMENSIONES

- Reconocimiento de todos los derechos y titulares de derechos, con inclusión de mujeres y hombres de diferente condición

- Reconocimiento de un conjunto sólido de derechos que se otorgan de manera inclusiva a todos, tanto mujeres como hombres

- Reconocimiento de un "conjunto holístico de recursos" que respalda el potencial de mujeres y hombres

DIMENSIONES

- Procedimientos accesibles y eficientes adaptados tanto a mujeres como a hombres

- Reconocimiento formal de tierras indígenas y de uso común
ÁMBITO DE ACCIÓN CLAVE

Regulaciones

adecuadas para la gestión de la tierra y

los recursos
DIMENSIONES

- Objetivos de gestión que tomen en cuenta las necesidades de mujeres y hombres

- Regulaciones sencillas, que minimicen los costos de transacción y sean adecuadas para los objetivos de gestión

- Implementación eficiente de los procesos de permisos

- Reconocimiento de la diversidad de los medios de subsistencia basados en recursos
ÁMBITO DE ACCIÓN CLAVE

Apoyo eficaz de

los organismos

gubernamentales

responsables
DIMENSIONES

- Procesos participativos y adaptativos para la toma de decisiones con participación igualitaria de mujeres y hombres

- Voluntad política y objetivos alineados, incluida la igualdad de género

- Mandatos claros y de refuerzo mutuo para los organismos responsables que incluyan la igualdad de género

- Capacidades y recursos financieros para la transformación hacia la igualdad de género mediante las funciones de implementación del gobierno

Figura 10. Ámbitos de acción clave para asegurar la reforma de la tenencia forestal con perspectiva de género

Fuente: adaptado de World Bank (2019a). 


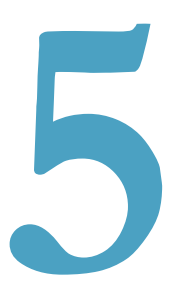

DIMENSIONES
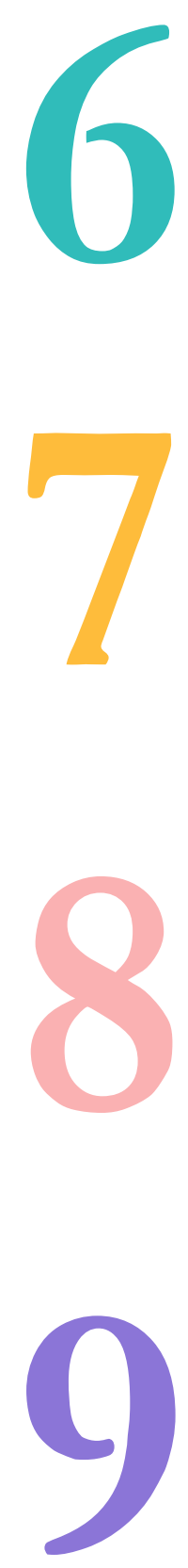

Gobernanza

de la tenencia

empoderada e inclusiva
ÁMBITO DE ACCIÓN CLAVE

Sistemas para el registro de derechos de tenencia
- Instituciones inclusivas y procesos de toma de decisiones que incluyan a mujeres y hombres de diferente condición

- Normas y/o planes definidos por la comunidad para la gobernanza de la tierra y los recursos

- Capacidades y recursos financieros para la seguridad de la tenencia y el rol de las instituciones de tenencia

- Vínculos a todo nivel con organizaciones de movilización social, promoción y apoyo, como organizaciones de mujeres $y$ federaciones forestales

- Marcos favorables para el desarrollo empresarial

DIMENSIONES

- Información exhaustiva, precisa y desglosada por género

- Accesibilidad y asequibilidad del sistema para registrar, mantener/actualizar y compartir información sobre derechos de tenencia

\section{DIMENSIONES}

- Capacidades sensibles al género y apoyo mutuo entre las instituciones responsables de su cumplimiento

- Implementación eficaz de sistemas de monitoreo y ejecución que involucren tanto a mujeres como a hombres

DIMENSIONES

- Claridad jurídica y mecanismos de resolución para la coherencia de las políticas rurales y ambientales

Protección de los derechos de tenencia en relación con otras formas de tenencia y uso de la tierra

- Salvaguardas sólidas para evitar infracciones de los derechos de tenencia, incluido el consentimiento libre, previo e informado (CLPI) y los estándares ambientales y sociales

ÁMBITO DE ACCIÓN CLAVE

Resolución de conflictos y disputas
- Mecanismos accesibles e idóneos para la resolución de conflictos sobre derechos de tenencia iniciados por mujeres y hombres

- Resolución de conflictos eficaz y sensible al género
DIMENSIONES 
PERSPECTIVAS SOBRE LA TENENCIA FORESTAL

ESTRATEGIAS

PARA AVANZAR EN MATERIA DE GÉNERO: AMAN moviliza el conocimiento de las mujeres para el reconocimiento de bosques consuetudinarios en Indonesia

\section{PREGUNTA DE REFLEXIÓN}

\section{¿Cómo puede el mapeo participativo y anticipativo ayudar a incorporar el conocimiento de las mujeres para un reconocimiento acelerado y a gran escala de las tierras forestales consuetudinarias?}

En un caso histórico, la Alianza de Pueblos Indígenas del Archipiélago (Aliansi Masyarakat Adat Nusantara, AMAN) en Indonesia presentó en 2012 una solicitud para una revisión jurídica oficial de la Ley Forestal n. ${ }^{\circ} 41$ de 1999. La AMAN afirmó que si bien la ley reconocía la existencia de bosques consuetudinarios (hutan adat), dichos bosques eran designados y gestionados como bosques estatales (hutan negara). La AMAN sostuvo que esta ley iba en contra de los principios consagrados en la Constitución indonesia. En respuesta a esta solicitud, la resolución del Tribunal Constitucional de Indonesia 35/PUU-X/2012 (conocida como MK 35) estableció un precedente importante al afirmar que los bosques consuetudinarios ya no serían parte de los bosques estatales. Este fallo ha legitimado una transferencia masiva de derechos de tenencia forestal del gobierno a las comunidades consuetudinarias, que afecta a entre 50 y 70 millones de habitantes de pueblos indígenas que viven en los bosques de Indonesia y sus alrededores. La pregunta es ¿qué tan rápido puede llevarse a cabo este proceso?

En 2010, antes de esta revisión jurídica, la AMAN había comenzado de manera anticipada a sentar las bases para el reconocimiento con perspectiva de género de los derechos consuetudinarios. Involucró activamente a las mujeres en su mapeo participativo de los bosques consuetudinarios (que ha cubierto más de siete millones de hectáreas hasta la fecha). Además, creó una Agencia de Registro de Dominios Ancestrales (Badan Registrasi Wilayah Adat, BRWA), junto con la Red Indonesia de Cartografía Comunitaria (Jaringan Kerja Pemetaan Partisipatif, JKPP) y Forest Watch Indonesia (Down to Earth Indonesia 2010). La BRWA establece estándares para el mapeo participativo comunitario y su documentación. Funciona como un centro de servicios que registra, verifica y certifica los reclamos antes de presentarlos al Ministerio de Medio Ambiente y Bosques. También integra estos mapas en otras iniciativas de mapeo unificado del gobierno. Por su parte, el enfoque de mapeo de la JKPP reconoció desde un inicio la importancia del conocimiento de las mujeres sobre los límites y los recursos en sus áreas (Down to Earth Indonesia 2014).

En lugar de utilizar un enfoque general en materia de género, la JKPP entendió la necesidad de tomar en cuenta las dinámicas de género locales reales, incluido 


\section{Hace 35 años, como mujer}

en una escuela de forestería, necesitaba capacitarme en algo que me permitiera conseguir un empleo, así que decidí trabajar en el mejoramiento de árboles. [...] Entrar a un sector dominado por hombres fue un desafío. [...] Me hizo más fuerte y creo que también aprendí sobre liderazgo. Una de las cosas que aprendí es que todos tus éxitos o fracasos dependen de cómo hagas las cosas. No tienen que ver con tu conocimiento, no tienen que ver con tu capacidad, sino con qué tan bien haces las cosas.

\section{Ivone Namikawa}

Copresidenta de EI Diálogo Forestal (Santiago 2020) 


\section{5}

\section{CREAR CAMBIO PASO 3: IMPLEMENTAR ESTRATEGIAS}

Este tercer paso, Implementar estrategias, se centra en cómo diseñar e implementar intervenciones que puedan generar los cambios previstos en el plan estratégico.

Esto conforma la hoja de ruta o el plan de acción. Una de las principales dificultades que enfrentan los impulsores de reformas de tenencia es que el plan estratégico nunca se implementa realmente. Esto implica tomar en consideración qué es factible en la práctica según el panorama político, quiénes pueden ser agentes colaborativos para el cambio, cuál es la situación presupuestaria y cuáles son los recursos humanos disponibles para llevarlo a cabo. La realidad es mucho más compleja, mucho más impredecible y demanda mucho más tiempo que un escenario ideal. Para obtener resultados positivos, se requerirá de acciones tanto a corto como a largo plazo que generen confianza y entusiasmo por el logro de los objetivos. Esto exige usar un enfoque persistente.

En toda hoja de ruta es esencial identificar el proceso de cambio necesario para el logro de cualquier objetivo secundario relacionado con un campo de acción específico. Es probable que este proceso sea escalonado e involucre cuatro ámbitos de acción diferentes (Figura 11).
Pensar detenidamente en posibles socios para el cambio ayudará a lograr el objetivo previsto. ¿Quiénes son los actores fundamentales y cuáles son los mecanismos o palancas para el cambio (Bhalla 2016)? ¿Qué organización tiene redes de contactos e influencia sobre ámbitos de acción específicos? ¿Qué líderes tienen la capacidad de afianzar el trabajo local de manera que se pueda implementar un enfoque productivo y bien focalizado? ¿Cuál es la manera correcta de cultivar gradualmente una relación con aquellos líderes que tienen influencia y conocimientos estratégicos?

¿Cómo se puede apoyar a las OSC influyentes con capacitación sobre temas de tenencia (véanse, por ejemplo, FAO 2014b; y FAO y FIAN International 2017)? Los siguientes son algunos consejos importantes al pensar en socios colaboradores:

- Diversifique su visión acerca de las vías hacia el cambio y los agentes de cambio: no elija a los candidatos de siempre; piénselo dos veces.

- Identifique a las mujeres agentes de cambio. Pueden ser de organizaciones de mujeres, así como lideresas influyentes, pero considere 


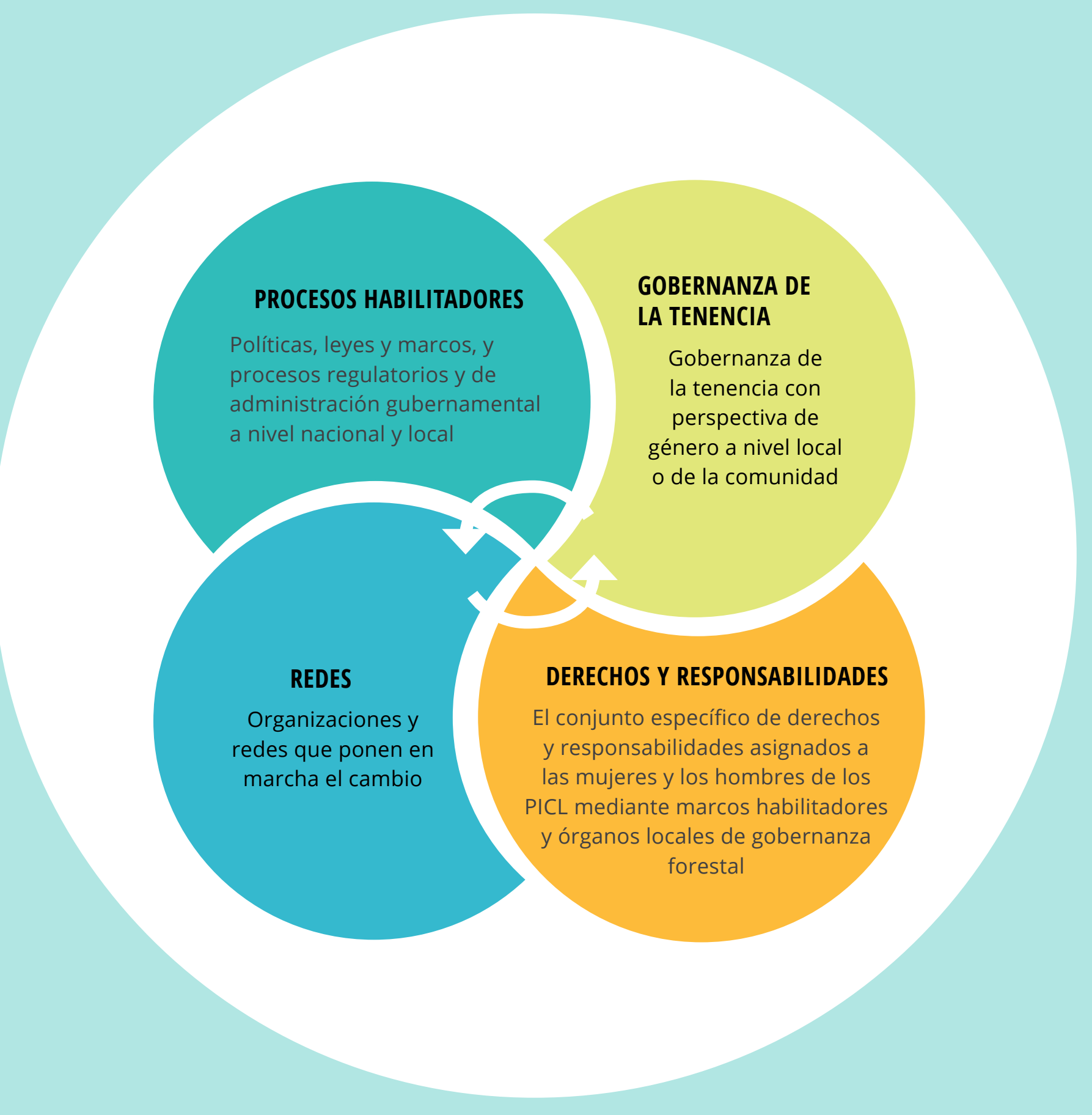

Figura 11. Cuatro ámbitos de acción para la reforma de la tenencia forestal con perspectiva de género 
también a aquellas que se han convertido en agentes de cambio gracias a su considerable experiencia, motivación y determinación.

- Trabaje con hombres como aliados e identifique hombres que asuman la función de defensores y líderes de organizaciones que promuevan activamente la igualdad de género en el sector forestal.

- Dedique tiempo a pensar en quiénes podrían oponerse a los cambios y cómo incorporarlos a los procesos y diálogos para el cambio.

- Desarrolle activamente las capacidades y la efectividad de miembros clave de las coaliciones y redes de apoyo de los objetivos del plan estratégico, para activar el cambio tanto a nivel nacional como local.

- Reflexione de manera conjunta sobre cómo establecer un compromiso sólido para inspirar a líderes con influencia, como parlamentarios y otros responsables de formulación de políticas o jefes de aldea, para que asuman el desafío de la reforma a largo plazo.

Reflexione sobre cuál es el tipo correcto de punto de entrada para cada componente de la hoja de ruta o plan de acción (véase Marin y Kuriakose 2017). Luego, piense en cuál puede ser una vía realista para el cambio (véase la Figura 12, que incluye una variedad de ejemplos). En lugar de pensar acerca de un objetivo en términos generales, como por ejemplo reformar la ley forestal para garantizar que se aborden las cuestiones de género en todas sus dimensiones, enfóquese y piense en cómo poner en práctica principios específicos dentro de la legislación forestal, por ejemplo, lograr mayor representación en la toma de decisiones, o cómo internalizar las cuestiones de género al desarrollar un plan de gestión forestal. Sin duda, una ley es importante, pues otorga facultades, pero también vale la pena examinar con detenimiento las regulaciones y directrices. Queda claro que la clave de todo está en los detalles.

\section{SECCIÓN I.5}

\section{LECTURAS COMPLEMENTARIAS}

[FAO] Food and Agriculture Organization. 2014. Strengthening Forest Tenure Systems and Governance. Training Module for Facilitators. Roma: FAO.

Kristjanson, P, Bah T, Kuriakose A, Shakirova M, Segura G, Siegmann K y Granat M. 2019. Taking Action on Gender Gaps in Forest Landscapes. Working Paper. Washington, D.C.: PROFOR. 
Figura 12. Ejemplos de intervenciones para abordar las brechas de género en ámbitos de acción específicos

Fuente: adaptado de Kristjanson y Jensen (2018); Kristjanson et al. (2019).
Falta de un punto

focal de género en el

ministerio forestal
Dirección del

ministerio forestal
El marco jurídico habilitador de la tenencia forestal no especifica ningún requisito con respecto al nivel de representación de las mujeres en los órganos de gobernanza local

Falta de datos desglosados por género y orientación metodológica para la recopilación de datos sobre tenencia forestal

Normas patriarcales de género y valores morales en comunidades rurales dependientes de los bosques con derechos de tenencia forestal existentes

La pesada carga de trabajo de las mujeres en el cuidado de los niños y las responsabilidades del hogar, que impide su participación activa en las instituciones de tenencia forestal
Unidad del ministerio forestal responsable de la redacción de instrumentos jurídicos

Ministerio forestal

Nivel local de gobernanza de la tenencia
Nivel local de gobernanza de la tenencia
Plan de manejo forestal local indiferente a las cuestiones de género
Nivel local de gobernanza de la tenencia 


\section{ACTORES/PARTES INTERESADAS RELEVANTES}

Miembros del ministerio forestal que apoyan al punto focal de género, autoridades del ministerio de la mujer y líderes de organizaciones de mujeres

\section{EJEMPLOS DE INTERVENCIONES}

Genere voluntad política en torno a la necesidad de un punto focal de género para cumplir con la nueva agenda de planificación del gobierno
Unidad de asuntos jurídicos del ministerio forestal, expertos jurídicos en tenencia forestal, dirigentes de organizaciones de mujeres y directores de organizaciones de investigación forestal
Ministerio forestal, institutos de investigación de mujeres; y federaciones y ONG/OSC forestales
Miembros de instituciones locales de gobernanza de la tenencia forestal; personal del gobierno local; y ONG/ OSC y federaciones forestales y de mujeres
Miembros de instituciones locales de gobernanza de la tenencia forestal; ONG/OSC y federaciones forestales y de mujeres; y organizaciones tecnológicas adecuadas
Desarrolle una investigación orientada a la acción sobre cómo la representación de las mujeres en diferentes instituciones de tenencia afecta el uso y la gestión forestales, así como los medios de subsistencia y la equidad, con el fin de dar a conocer por qué este requisito es esencial para la equidad, el desarrollo positivo y la gestión forestal sostenible

Proponga un sistema de base de datos desglosado por género y organice un taller multiactor para discutir su estructura y contenido
Desarrolle actividades de sensibilización con diferentes grupos de hombres y mujeres para evaluar alternativas de normas género y valores morales que puedan apoyar un enfoque socialmente inclusivo de la tenencia y el manejo forestal
Evalúe qué tipo de infraestructura (tecnológica o de otra clase, como un servicio colectivo para la molienda de granos), utilizada de manera conjunta a nivel de aldea, podría reducir la carga laboral de las mujeres de una manera económica y accesible para todos
Personal del departamento forestal local, miembros del comité ejecutivo de la institución de tenencia forestal local; ONG/OSC y federaciones forestales y de mujeres; $y$ expertos en mapeo participativo
Con el apoyo de enfoques de mapeo participativo transformador en materia de género, desarrolle un entendimiento de las diferentes zonas forestales y sus usos, sus niveles de sostenibilidad y sus técnicas forestales asociadas, para establecer una línea base en conjunto con los servicios de extensión forestal 
ARIMONIZAR EI CAMIBIO:

\section{La igualdad de} género y la Ley de Derechos Comunitarios de Lilberia

\section{PREGUNTA DE REFLEXIÓN}

\section{¿Por qué la Política Nacional Forestal de Liberia no coincide con los principios establecidos en su Política Nacional de Género en lo que respecta a la igualdad de género?}

En Liberia, país que ha salido de una guerra, se ha venido desarrollando un largo proceso de consolidación de la paz y de reforma, que ha incluido la reforma de la tenencia de la tierra y los bosques. Se han dado pasos eficaces para integrar la igualdad de género en la Constitución de 1986, crear un Ministerio de Género y Desarrollo en 2001 y promulgar una Política Nacional de Género en 2009 (posteriormente revisada y validada para el período 2018-2022). Sin embargo, las leyes que rigen la política forestal, como la Ley de Derechos Comunitarios (CRL, por sus siglas en inglés) de 2009, solo se refieren de pasada a las cuestiones de género (Weah 2012; BandiakyBadji et al. 2016; Zinnah et al. 2020). Esto es algo hasta cierto punto contradictorio, ya que Liberia tiene un claro compromiso con la igualdad de género: la Constitución consagra el principio de igualdad de derechos para hombres y mujeres y prohíbe la discriminación por razones de género; y además es signatario de la CEDAW. Por lo tanto, este desajuste probablemente se deba a un problema de sincronización, pues tanto la Política Nacional de Género como la CRL se publicaron el mismo año (2009). ¿Qué se puede hacer?

Es evidente que todos los objetivos de la Política Nacional de Género se relacionan directamente con el sector forestal. Esta política proporciona un conjunto integral de objetivos: promover el desarrollo socioeconómico con equidad de género; aumentar el empoderamiento de mujeres y niñas; incrementar la transversalización de la perspectiva de género en el desarrollo nacional; y crear y fortalecer estructuras, procesos y mecanismos en los que las mujeres participen en igualdad de condiciones y que garanticen que mujeres y hombres puedan acceder a controlar y beneficiarse por igual de los recursos del país. Estos objetivos ya se han aplicado al sector de la tenencia de la tierra. La expresidenta Ellen Johnson Sirleaf, la primera jefa de Estado elegida democráticamente en África, expresó de manera explícita su apoyo al reconocimiento jurídico de los derechos de las mujeres a la tierra. Como resultado, la Ley de Derechos a la Tierra de 2018 establece una titularidad sólida y derecho a reclamos de tierras consuetudinarias para las mujeres (y para jóvenes de grupos minoritarios), y dispone que cuenten con igualdad de derechos para el uso y gestión de las tierras comunitarias. También exige que el órgano de gobernanza de las tierras comunitarias esté compuesto a partes iguales por mujeres, hombres y jóvenes, y que sus decisiones se tomen por consenso. Además, establece que las concesiones deben alinearse con la Política Nacional de Género y otras políticas relacionadas (Dodd et al. 2018; Zinnah et al. 2020).

En lo que respecta a la forestería, el escenario es sorprendentemente diferente. La CRL se desarrolló de conformidad con la Ley Nacional de Reforma Forestal de 2006 con el fin de empoderar a las comunidades para su participación plena en la gestión forestal sostenible. Pero, aunque la CRL permite la creación de un Consejo Comunitario como su máximo órgano de 


\section{PENSAR DESDE}

UNA PERSP ECTIVA

DEGENERO:

POLIIICAS DE

TENENCIA FORESTA

REFORMA JURIDICA

Y ADMIINISTRACIÓ GUBERNAMIEN AL

A menos que las mujeres cuenten con igualdad de condiciones en todas las leyes que gobiernan las tierras indígenas, sus comunidades estarán en una situación precaria. En muchos pueblos indígenas, las mujeres son las productoras de alimentos $y$ las encargadas de gestionar sus tierras y bosques consuetudinarios. La salvaguarda de sus derechos cimentará los derechos de sus comunidades a la propiedad colectiva de las tierras y los bosques que han protegido y de los que dependen desde hace muchas generaciones.

\section{Victoria Tauli-Corpuz}

Ex relatora especial de las Naciones Unidas sobre derechos de los pueblos indígenas (Down to Earth India 2017) 
2.1

\section{GENERAR IMPULSO PARA EL CAMBIO: LEYES Y POLITICAS DE TENENCIA FORESTAL}

Ya sea que la motivación para una reforma con perspectiva de género de las políticas y leyes de tenencia forestal provenga de necesidades comunitarias a nivel local, de las agendas globales o los gobiernos nacionales, de donantes o de OSC, un elemento central de esta reforma es el desarrollo de políticas y leyes bien diseñadas que formen parte de un marco normativo general para la tenencia forestal. Si bien muchos países cuentan con políticas forestales, y un número cada vez mayor de ellas reconocen que la tenencia forestal es un requisito esencial para la mejora de los bosques, no se da importancia al tema de la igualdad de género. En muchos países, las leyes y políticas del sector forestal guardan silencio sobre el tema o incluyen una simple declaración en la que piden que se preste atención a las necesidades de las mujeres. Las leyes y regulaciones nacionales sobre los derechos de las mujeres de los PICL a la herencia, a pertenecer a la comunidad, a la gobernanza comunitaria y a la resolución de conflictos a nivel comunitario son por lo general injustas y están lejos de cumplir con los requisitos del derecho internacional y sus normas relacionadas (RRI 2017).

No se puede suponer que las cosas vayan a mejorar cuando se implementen las nuevas políticas forestales rediseñadas. La indiferencia hacia las cuestiones de género es un problema generalizado, tanto entre los responsables de la formulación de políticas del sector forestal como entre los funcionarios gubernamentales. No es un problema que se limite a un ámbito reducido del sistema administrativo o legislativo del gobierno; al contrario, está muy extendido, desde el nivel central hasta las oficinas del ámbito local. Asegurar la integración de las cuestiones de género en todas las leyes y políticas de tenencia forestal debe ser un componente central del marco regulatorio general de la tenencia forestal (véase Figura 13). Otros aspectos fundamentales de dicho marco regulatorio, como los 
1 El marco jurídico y de de tenencia reconoce la igualdad de género Implementación
del reconocimiento jurídico de la igualdad de género
Reforme los marcos jurídicos y de políticas que aborden los derechos de tenencia en el sector forestal (y/o de la tierra, etc.), junto con regulaciones de apoyo, para que sean reconocidos y protegidos los derechos de las mujeres y de los hombres a usar, gestionar y beneficiarse de los bosques, y participar en la demarcación de límites, la gobernanza y la toma de decisiones.

\section{Apoye la}

implementación de los marcos jurídicos de diversas maneras, como comunicación mediática, desarrollo de capacidades del personal del gobierno local y asignación de presupuestos adecuados.
Regulaciones con perspectiva de género adecuadas para la gestión de la tierra y los recursos

\section{Apoyo eficaz con perspectiva de género de los organismos gubernamentales relevantes}

Defina regulaciones detalladas que apoyen la implementación de los marcos jurídicos con especial atención en la capacidad de mujeres y hombres locales para cumplir a largo plazo.
Los organismos

gubernamentales apoyan los derechos de tenencia forestal de mujeres y hombres de diversas formas: registro de derechos de tenencia, gestión de la planificación forestal, sistemas de información de ordenamiento territorial y servicios de extensión forestal. Esto debe llevarse a cabo de una manera tal que permita reconocer y proteger estos derechos legítimos de mujeres y hombres.
Protección de los derechos de tenencia forestal en relación con otras formas de tenencia y uso de la tierra

\section{Sistemas con perspectiva de género para el registro de los derechos de tenencia forestal}

Desarrolle protocolos para la documentación formal de derechos de tenencia forestal para mujeres y hombres, a fin de asegurar que haya incentivos para la gestión forestal sostenible. Dichos registros pueden utilizarse como respaldo ante cualquier situación de resolución de conflictos que implique derechos superpuestos o ambiguos, y deben ser accesibles para mujeres y hombres en formatos de bajo costo y que ahorren tiempo.

Métodos con perspectiva de género para hacer cumplir los derechos de tenencia forestal

Asegúrese de que el cumplimiento de los derechos de tenencia forestal se lleve a cabo tomando en cuenta la igualdad de género. Los métodos para hacer cumplir los derechos deberán incluir formas de monitoreo, vigilancia, sanción y cumplimiento en general que sean sensibles al género. Además, eduque a las comunidades que dependen de los bosques sobre las leyes y regulaciones existentes, para que sus derechos de tenencia no puedan ser fácilmente ignorados, ya sea por personas ajenas a la comunidad o que buscan acceder ilegalmente a sus recursos.
Aborde las disputas y conflictos de una manera sensible al género. Estos mecanismos deberán prestar atención a las diferentes necesidades de mujeres y hombres en términos de su capacidad para defender sus derechos y comunicar sus preocupaciones.

Figura 13. Componentes clave del marco regulatorio de tenencia forestal con perspectiva de género. Fuente: adaptado de World Bank (2019a) 
servicios gubernamentales de apoyo para el registro de derechos de tenencia, permitirán la implementación de la base jurídica y de políticas.

Todo programa que aborde la igualdad de género deberá evaluar si las políticas y leyes forestales existentes son claras y coherentes en lo que respecta a la igualdad entre mujeres y hombres, y si la igualdad de género está integrada en todas las disposiciones. Las VGGT instan a los gobiernos a crear y mantener políticas y leyes que permitan una gobernanza responsable de la tenencia que incluya principios de género (FAO 2012). Además, toda política, ley o procedimiento adicional debe desarrollarse mediante un proceso participativo en el que la sociedad civil, el sector privado y la academia puedan contribuir al cumplimiento de los objetivos declarados por el gobierno.

Normalmente, cuando se actualizan las políticas forestales existentes, aparece una ventana de oportunidad importante para reconsiderar la manera en que se abordan las cuestiones de género. Esto luego formará la base para la reforma jurídica y regulatoria. A partir de la evaluación general de la tenencia realizada en el paso Analizar antes presentado, es posible identificar el nivel de reconocimiento de la igualdad de género en las políticas y leyes existentes, el cual puede ser mínimo, mejorado o bueno (Figura 14). Con base en ello, se puede llevar a cabo una revisión detallada del marco jurídico habilitador actual y sus normas relacionadas (incluidos los reglamentos) con una perspectiva de género. A partir de este punto, se puede llevar adelante un plan de acción secuencial que apunte a producir cambios fundamentales en los nodos clave del sistema regulatorio forestal, seguido por procesos graduales y sistemáticos para desarrollar capacidades, fortalecer los sistemas de conocimiento y asegurar su aplicación real donde más se necesita. Un aspecto importante será la toma de decisiones respecto a los puntos estratégicos de intervención y los socios colaboradores. Como es obvio, todo este proceso no es tarea fácil, pero produce cambios duraderos en materia de equidad social.
No existe una explicación sencilla de por qué diferentes países adoptan enfoques divergentes con relación a la igualdad de género. Por ejemplo, en una región como el sur de Asia, Nepal, un país pequeño con un elevado nivel de pobreza, tiene un conjunto bastante sólido de protecciones para mujeres y hombres en el sector forestal, en comparación con un país grande y más desarrollado como la India, cuyo más reciente Borrador de Política Forestal Nacional no menciona en lo absoluto ni el género ni a las mujeres (Bose 2018). En muchos países pueden haberse logrado cambios jurídicos positivos, pero la implementación sigue siendo débil por una serie de razones. Tal es el caso de Uganda, donde ya se han dado algunos pasos clave, puesto que tanto la Política Forestal como la Ley Forestal y el Plan Forestal abordan cuestiones de género y necesidades específicas de las mujeres (Mukasa et al. 2016). Sin embargo, sus resultados no son significativos debido a que la implementación es deficiente y las normas, creencias y prácticas culturales siguen siendo obstáculos para una participación y distribución de beneficios igualitaria (Banana et al. 2013; Mukasa et al. 2016; Monterroso et al. 2019).

Por lo general, han sido movilizaciones importantes en favor de la justicia social o los derechos de las mujeres organizadas por federaciones y redes forestales, o por parlamentarios, las que han conducido a cambios positivos en las políticas y la ley. Por ejemplo, en el caso de Indonesia, la transversalización de la perspectiva de género cobró impulso durante la introducción del Presupuesto con Perspectiva de Género por parte del ministro de Finanzas en 2009, así como por las movilizaciones de organizaciones locales en torno a las políticas y actividades de REDD+ (Arwida et al. 2017). El Ministerio de Medio Ambiente y Bosques reactivó el Grupo de Trabajo sobre Género en 2012, inició la elaboración de presupuestos con perspectiva de género, organizó capacitaciones de sensibilización sobre la igualdad de género y fortaleció las capacidades para realizar análisis de género. Esta movilización a menudo se da por medio de plataformas de consulta multiactor para el desarrollo de políticas, ya sea para una política 
del sector forestal o una estrategia de género para dicho sector. El nivel de aceptación de esta labor también dependerá de si el ministerio forestal es receptivo a estos llamados al cambio. Es necesario contar con agentes de cambio influyentes dentro del mismo ministerio, sean mujeres u hombres. Para generar un impulso eficaz, que permita lograr los cambios esperados en las políticas y el marco jurídico de la tenencia forestal, se requiere de un esfuerzo coordinado y continuo de parlamentarios, federaciones del sector forestal, ONG, OSC, organizaciones donantes y grupos del sector privado, a fin de crear alianzas y fortalecer la autoridad de mujeres y hombres clave defensores del cambio.

A menudo, el primer paso para lograr transformaciones con perspectiva de género en la tenencia forestal radica en la política forestal nacional (denominada a veces estrategia forestal). Esta presenta una visión de largo plazo para el sector forestal que no solo incluye sus aspiraciones y objetivos, sino además establece qué acciones son necesarias para alcanzar esa visión en un plazo determinado. Algo muy importante es que esta política forestal nacional debe ser puesta en acción por el nivel más alto del organismo forestal del gobierno y debe orientar su práctica cotidiana. La política forestal abarca principios fundamentales (como metas multidimensionales, igualdad de género, reducción de la pobreza, dirección para la devolución de derechos de tenencia, principios de buena gobernanza, etc.) que orientan los marcos generales jurídicos, políticos e institucionales. También abarca las diferentes categorías de uso forestal productivo y para la conservación; el estado de salud de los bosques en los paisajes; el sector forestal (incluidas las empresas forestales de propiedad local); las inquietudes acerca de la biodiversidad, la tenencia de la tierra y los bosques; la forestería comunitaria; el financiamiento y la inversión; y los PSA. En otras palabras, cubre la gama completa de preocupaciones del sector forestal, todas las cuales deben verse desde una perspectiva de género. Esto permitirá el desarrollo de un enfoque integral, multidimensional y con perspectiva de género para la política forestal.
Las políticas forestales solo pueden tener perspectiva de género si las condiciones para los diálogos multiactor prestan atención explícita a la inclusión con participación de mujeres, pueblos indígenas y comunidades marginadas (FAO 2010, 2020b; véase también Bandiaky-Badji 2011 sobre el caso de Senegal). De esta manera, los principios de la igualdad de género se integrarán en toda la variedad de temas presentes en cualquier política forestal bien diseñada. Es decir, se basarán en evidencia empírica, estarán vinculados a las agendas de desarrollo nacionales y globales (como los ODS), permitirán negociar acuerdos entre intereses de todo tipo, tendrán un enfoque intersectorial, tomarán en cuenta el abanico de regímenes de tenencia y gobernanza existente, serán socialmente inclusivos, se planificarán pensando en el largo plazo y se adaptarán a las necesidades que puedan surgir. Mediante un diálogo cuidadosamente estructurado es posible negociar y acordar una política con perspectiva de género que promueva la gestión forestal sostenible en todos los tipos de bosque del territorio nacional. Realizar consultas preliminares en diferentes regiones del país puede ayudar a definir el panorama desde la base. Este proceso puede incluir reuniones exclusivas para mujeres y otras formas de potenciar sus aportes al diálogo sobre políticas. En paralelo, es necesario preparar una base de evidencia empírica sobre la relación entre género y tenencia forestal que permita orientar la formulación de políticas. Hay varias guías disponibles acerca de cómo desarrollar compromiso y generar influencia en materia de políticas (véase ODI s. f.).

En lo que respecta a la tenencia forestal, dependiendo del compromiso nacional con los diferentes grados de devolución de derechos, los acuerdos de tenencia forestal con perspectiva de género se promulgarán únicamente a través de medidas de política, o por medio de marcos jurídicos habilitadores que ofrezcan un conjunto de protecciones más sólido. En el caso de la India, el antiguo manejo forestal conjunto (JFM, por sus siglas en inglés), una forma de gestión descentralizada, se puso en marcha a través de la Política Forestal Nacional de 1988, mientras que la Ley de Derechos 
Figura 14. Las tres etapas de las políticas, la legislación y la administración de la tenencia forestal con perspectiva de género

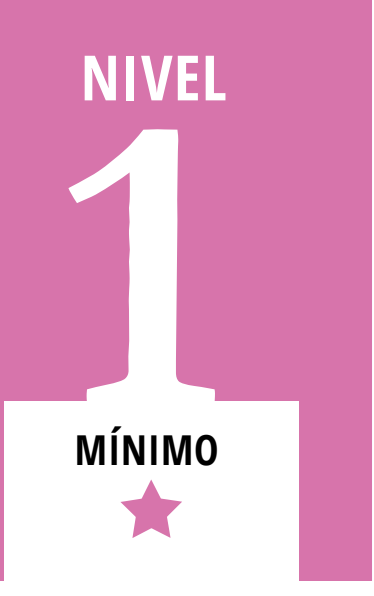

La Constitución

no hace

referencia al

tema de la no

discriminación

entre mujeres y

hombres.
Las leyes, políticas y planes estratégicos del sector forestal relacionados con la tenencia forestal no abordan cuestiones de género.
El gobierno no se refiere a la importancia de abordar las cuestiones de género en su sistema administrativo.
No hay una oficina en el ministerio forestal que brinde apoyo a la igualdad de género.
El gobierno subraya la importancia de la igualdad de género en su sistema administrativo, pero no especifica cómo ponerla en práctica.
Se ha designado un punto focal para cuestiones de género en el ministerio forestal, pero con poco apoyo de la dirección. $y$ beneficios. manera neutral en materia de género, pero no existen disposiciones específicas sobre cómo abordar el tema en términos de gobernanza, derechos de uso, gestión

Las leyes, políticas y

del sector forestal

la tenencia forestal establecen en términos generales la importancia de la equidad de una

\section{MEJORADO}

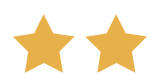

entre mujeres y hombres.

\section{La Constitución} establece el principio de igualdad de género y empoderamiento de la mujer.
Las leyes, políticas y planes del sector forestal relacionados con la tenencia (y otras leyes sectoriales pertinentes, como las relativas a la tierra y el financiamiento) expresan claramente cómo lograr la igualdad de género en la gobernanza, los derechos de uso, la gestión y los beneficios; se establecen directrices y disposiciones claras.
El gobierno no solo reconoce la importancia de la igualdad de género en su sistema administrativo, sino que además establece los protocolos que deben seguir el personal superior y subalterno, y asigna recursos humanos y financieros.
El punto focal para cuestiones de género del ministerio forestal cuenta con el respaldo activo de la dirección, y se le otorgan fondos para iniciar la transversalización de la perspectiva de género y actividades de proyecto. 
NIVEL DE RECONOCIMIENTO DE LA IGUALDAD DE GÉNERO

No hay un

reconocimiento

de la necesidad

de capacitar al

personal del sector

forestal acerca de

las dimensiones

de género de la

tenencia forestal

en las políticas y

leyes.
No se hace

referencia a

los conceptos

de igualdad de

género en el

sector forestal.
Hay poca

evidencia

de liderazgo

femenino en el

sector forestal.
Hay poca

evidencia de

participación

de las mujeres

en el proceso

de formulación

de políticas y

leyes de tenencia

forestal.
No existen disposiciones sobre el papel de las mujeres en las instituciones de toma de decisiones sobre tenencia forestal a nivel nacional o local.

\section{Capacitación}

preliminar del

personal del sector

forestal sobre

las dimensiones

de género de la

tenencia forestal

en políticas y leyes.
Difusión limitada de los conceptos de igualdad de género en todo el sector forestal.

\section{Algunas}

mujeres han sido designadas para puestos de liderazgo, pero no tienen influencia en el sector forestal.
Algunas

mujeres

desempeñan un

papel activo en

el proceso de

formulación de

leyes y políticas

de tenencia

forestal.
Las disposiciones

establecen la

necesidad de

contar con

un $30 \%$ de

representación

de mujeres en

las instituciones

de toma de

decisiones sobre

tenencia forestal

a nivel nacional o

local.

\section{Capacitación}

adecuada,

especializada y

continua del personal

del sector forestal

de nivel superior,

subalterno y local

(incluido el personal

encargado del

cumplimiento), en

diferentes niveles de

gobernanza, sobre

las dimensiones

de género de las

políticas y leyes

forestales, incluida la implementación.
Difusión adecuada

de los conceptos

de igualdad de

género en todos

los departamentos

del sector forestal,

lo que permite

la adopción e institucionalización

a largo plazo de

las prácticas de

transversalización

de la perspectiva

de género.
Varias mujeres

son nombradas

para puestos

de liderazgo

influyentes

en diferentes

niveles de

gobernanza del

sector forestal.
Varias mujeres

dinámicas tienen

un papel de

liderazgo en

el proceso de

formulación

de leyes y

políticas de

tenencia forestal

en diferentes

niveles de

gobernanza.
Las disposiciones

establecen la

necesidad de

contar con un $50 \%$

de representación

de mujeres en las

instituciones de toma de decisiones sobre tenencia forestal a nivel nacional o local. 
Forestales de 2006 impulsó un conjunto más fuerte de derechos de tenencia individuales y colectivos para comunidades "tribales" (adivasi) y otros habitantes tradicionales de los bosques. Aunque la FRA tiene un compromiso mucho más sensible al género que el JFM, son los detalles prácticos de cómo se interrelaciona el género con otros ejes sociales lo que requiere atención de las políticas (véase Elias et al. 2020). Sin embargo, las posibilidades de lograr ese tipo de reflexión parecen estar disminuyendo en la India, ya que el borrador más reciente de la nueva Política Forestal Nacional está más interesado en la forestería industrial y no menciona los derechos forestales de las mujeres o en materia de género ni la importancia de la equidad de género (Bose 2018; Warrier 2018). Cuando la política forestal nacional aborda temas de tenencia forestal en favor de los pobres, automáticamente entran en juego las preocupaciones de las mujeres, ya que estas suelen ser marginadas y reciben menos beneficios de alto valor de los sistemas de tenencia descentralizados (Hobley 2007; Miller et al. 2020). E incluso cuando se desarrollan políticas para propósitos específicos de los programas, como REDD+, la participación de mujeres que tomen decisiones requiere un trabajo de preparación muy cuidadoso. Dado el limitado número de mujeres en los niveles superiores de los organismos forestales, las posibilidades de que lleguen a ser miembros influyentes de los grupos de trabajo de REDD+ son escasas (Pham et al. 2016).

Una vez completada una política forestal nacional, se puede emprender la tarea de reformar los marcos jurídicos de la tenencia forestal. Aunque cada país tiene procesos muy específicos, promover una transformación con perspectiva género de la ley puede incluir una serie de actividades diversas a nivel nacional o subnacional (Figura 15).

Varias leyes (como las relacionadas con la forestería, la tierra y la herencia), incluida la Constitución, deberán ser sometidas a una revisión en materia de género y tenencia para darles una base más sólida (véase la lista de la Figura 16). Esta revisión debe evaluar si las leyes y sus reglamentos de operación correspondientes que rigen las tierras forestales de uso común cubren todos los elementos de tenencia necesarios para establecer un sistema de gestión forestal colectiva que sea eficaz y justo (ClientEarth 2019, 2020; véase también Larson y Pulhin 2012). Ya sea que se esté redactando una ley nueva o se esté revisando una ya existente, un proceso participativo puede favorecer el desarrollo de una ley que no solo sea integral, sino que abarque las perspectivas de todos los involucrados en la gobernanza de los acuerdos de tenencia forestal, cuya naturaleza es inevitablemente policéntrica (véanse Armitage 2008; Meinzen-Dick et al. 2020). En aquellos casos en los que la ley nacional no sea lo suficientemente sólida en cuestiones de género y tenencia forestal, por ejemplo, para la implementación de REDD+, se puede recurrir al derecho internacional para fortalecerlas (Silverman 2015). 


\section{EJEMPLOS DE INTERVENCIONES}

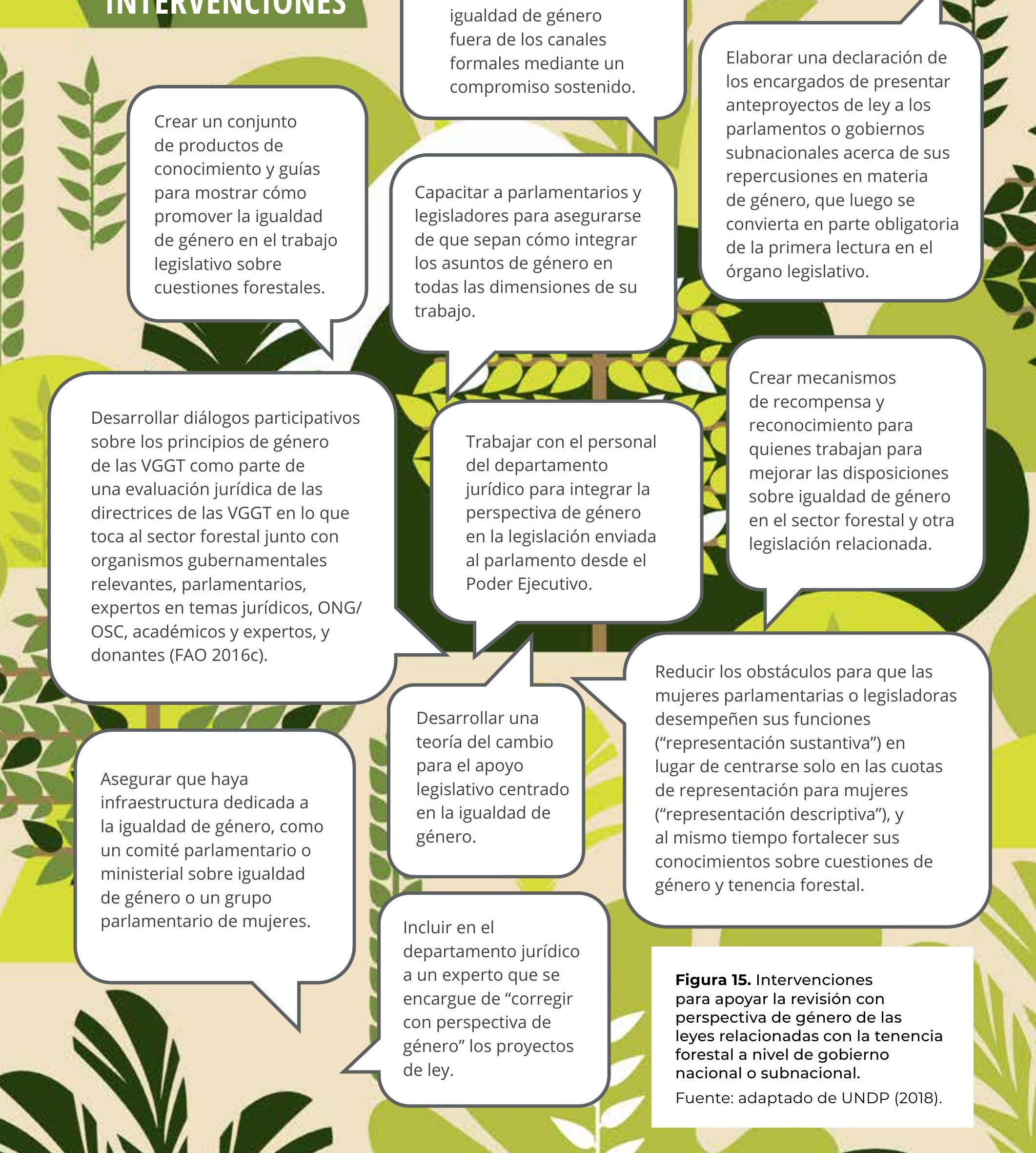


Figura 16. Buenas prácticas legislativas para garantizar los derechos de tenencia forestal de las mujeres indígenas y rurales.

Fuente: Keene y Ginsburg (2018).

\section{Leyes que regulan las tierras y los bosques de uso común}

- Prohíben la discriminación de género con respecto a la tierra y los bosques

- Dejan sin validez las prácticas consuetudinarias discriminatorias

- Ratificación general de los derechos de las mujeres a la tierra, los bosques y la propiedad

- Procesos de asignación, titulación y certificación de tierras con inclusión de género, incluidos los hogares encabezados por mujeres

- Reconocen el derecho de la mujer al empoderamiento económico

- Reconoce las leyes/prácticas consuetudinarias en la medida en que cumplan con la Constitución

- No otorga exenciones para el cumplimiento de la Constitución

- Tratados de derechos humanos de aplicación inmediata

- Igualdad en la familia y el matrimonio

- Garantiza los derechos de herencia

- Ratifica la capacidad jurídica igualitaria de la mujer

- Ratifica los derechos económicos relacionados con la propiedad, las tierras rurales y los recursos naturales

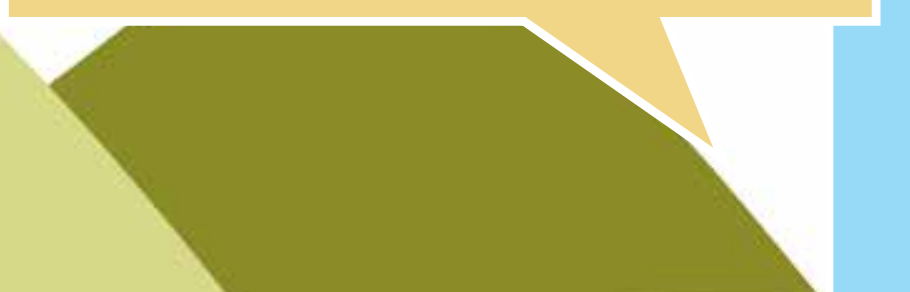
mujeres a llevar sus disputas sobre tierras y bosques ante foros comunitarios y de otros tipos 


\section{Códigos civiles, códigos familiares y leyes sobre sucesión, matrimonio y violencia doméstica}

- Reconocen la igualdad de derechos civiles, familiares y económicos de las mujeres

- Protección igualitaria para las niñas

- Prohíben la violencia doméstica, incluida

SECCIÓN 2.1

\section{LECTURAS COMPLEMENTARIAS} la violencia económica, contra todas las mujeres

- Reconocen la capacidad jurídica de la mujer

- Reconocen la igualdad de los derechos de propiedad de las mujeres

- Se requiere del consentimiento del cónyuge para disponer de la propiedad conyugal/conjunta, usada o poseída

\section{ClientEarth. 2020. Toolkit for Enabling Laws on Community Forestry. Londres: ClientEarth.}

Keene S y Ginsburg C. 2018. Legislative Best Practices for Securing Women's Rights to Community Lands. Washington D. C.: Rights and Resources Initiative (RRI). 
UN CAMBIO CON INSPIRACIÓN

DE BASE

COMUNITARIA

\section{Las directrices}

\section{forestales}

\section{comunitarias y de género en Nepal}

\section{PREGUNTA DE REFLEXIÓN}

¿De qué manera pueden influir en las regulaciones gubernamentales las políticas que promueven la igualdad de género desarrolladas por federaciones forestales o grupos de base?

En Nepal, las normas sobre igualdad de género establecidas inicialmente por la Federación de Grupos de Usuarios Forestales Comunitarios de Nepal (FECOFUN, por sus siglas en inglés) fueron luego adoptadas por las Directrices Forestales Comunitarias emitidas en el marco de la Ley Forestal de 1993. Durante la redacción de la Constitución de la FECOFUN en 1995, luego de una lucha prolongada y desafiante encabezada por un grupo de mujeres durante 33 días, la FECOFUN finalmente votó a favor de que el $50 \%$ de los miembros de su comité ejecutivo a nivel nacional, distrital y local fueran mujeres (Chapagain 2012). Además, una mujer debía ocupar uno de cada uno de los puestos titulares clave para presidente o vicepresidente, así como la secretaría o la tesorería. El objetivo era que esas formas de igualdad de género condujeran a la autonomía de las mujeres y que, fundamentalmente, cuestionaran los estereotipos sobre el liderazgo masculino.

Se trató de una decisión histórica y con un impacto significativo, ya que los cerca de 19300 grupos de usuarios forestales comunitarios (CFUG, por sus siglas en inglés) de la FECOFUN en todo el país abarcan aproximadamente al $40 \%$ de la población de Nepal. La FECOFUN se formó en julio de 1995 a partir de la visión de que los CFUG debían estar interconectados para aprender unos de otros y fortalecer su papel en el proceso de formulación de políticas forestales. Esta federación multinivel es una organización de movimientos sociales que fue impulsada por el activismo democrático de Nepal en la década de 1990 (Ojha et al. 2007) y constituye actualmente la OSC más grande del país (Paudel et al. 2010). Desde sus inicios en 1995, dos mujeres han sido elegidas presidentas de la federación nacional, una de las cuales fue miembro fundador (RECOFTC 2018 b, c). Con la igualdad de género como elemento central de su misión, la membresía de mujeres en los comités ejecutivos de los CFUG es ya del $35 \%$ y se va acercando a su meta del $50 \%$.

Poco después, a mediados de la década de 2000, el Gobierno de Nepal, con el apoyo de donantes, comenzó a crear una estrategia de "Igualdad de Género e Inclusión Social" (GESI, por sus siglas en inglés) para el sector forestal (Jhaveri 2013). Varios acontecimientos importantes condujeron a esta estrategia de género: en primer lugar, el Noveno Plan Quinquenal (1997-2002) supuso un cambio del enfoque anterior de MED a un marco de GED. En segundo lugar, el Banco Mundial, junto con el Departamento para el Desarrollo Internacional del Reino Unido, preparó una Evaluación de Género 


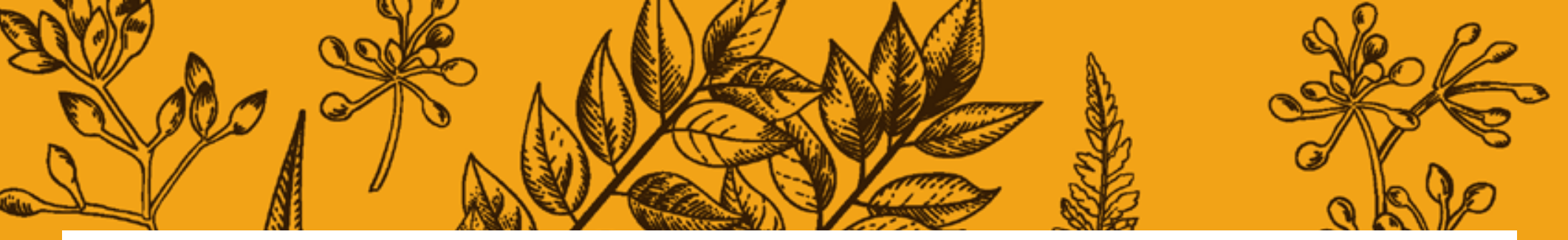

y Exclusión Social integral en todos los sectores gubernamentales en 2006. Por ello, en 2003 se inició el trabajo en materia de género en el sector forestal para elaborar una estrategia de GESI, así como un marco de seguimiento de género, pobreza y equidad social. Ambos fueron completados en 2007. Luego, en 2009, se realizaron enmiendas a las Directrices Forestales Comunitarias antiguas emitidas en el marco de la Ley Forestal de 1993: ahora, en lugar del requisito anterior de que el $30 \%$ de los miembros del comité ejecutivo de los CFUG sean mujeres, se requiere que el $50 \%$ lo sean (Paudel et al. 2010). Además, tanto las mujeres como los hombres de un mismo hogar pueden convertirse en miembros de los CFUG y, por lo tanto, participar en las reuniones de la asamblea general. El grupo de trabajo que preparó estas directrices incluyó a miembros de la FECOFUN y de HIMAWANTI (una ONG de recursos naturales dirigida por mujeres) e incorporó un proceso de consulta amplio de base comunitaria a través de los canales de la FECOFUN. Otra característica importante de los CFUG de Nepal es que hay más de 1000 CFUG exclusivos para mujeres.
Los efectos multiplicadores positivos de los principios de igualdad de género de las Directrices Forestales Comunitarias se hicieron evidentes en las primeras elecciones de gobiernos locales en 20 años, celebradas entre mayo y septiembre de 2017, luego de que el país pasara a un modelo de gobierno federativo. Numerosas mujeres comprometidas con la forestería comunitaria se postularon y obtuvieron escaños, lo que les ha permitido aumentar su autoconfianza y tener un sentido de visión (FECOFUN y RRI 2018). Por ejemplo, Manju Malashi, tesorera de la Secretaría Nacional de la FECOFUN, fue elegida alcaldesa del municipio de Silgudi en el distrito de Doti, y Kamala Basnet, miembro del comité central de la FECOFUN, fue elegida teniente alcaldesa del municipio de Bhimeshwor en el distrito de Dolakha. Alrededor del $41 \%$ de todos los cargos gubernamentales electos a nivel local están ocupados actualmente por mujeres. Así pues, desde su creación, la FECOFUN ha liderado el proceso de participación activa de las mujeres en la toma de decisiones, primero en los bosques de uso común y ahora en los gobiernos locales.

\section{LECCIONES}

Una organización o federación forestal nacional influyente y eficaz, con representación en todo el país y principios sólidos de igualdad de género incorporados en su Constitución puede crear las bases para que el gobierno adopte los mismos principios de género en la tenencia forestal.

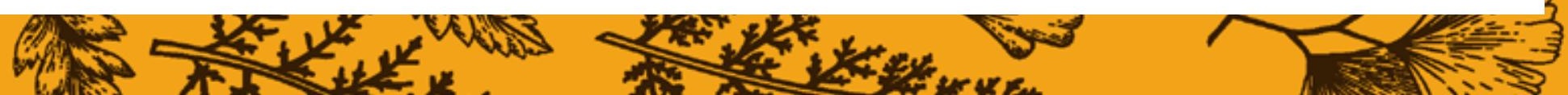




\section{Suelo usar la frase "No se puede}

llegar muy lejos con una sola pierna". Lo que quiero decir con esto es que nosotros, tanto mujeres como hombres, necesitamos saber, en igualdad de condiciones, de qué maneras y cómo proteger nuestros bosques. México es un ejemplo brillante del progreso que se está logrando en la transversalización de la perspectiva de género, y si bien hay otras naciones que también han logrado avances importantes, es esencial compartir la experiencia y las buenas prácticas de México con otros países para que puedan aprender de ellas e irradiarlas.

\section{Lorena Aguilar}

Asesora principal mundial en cuestiones de género de la UICN (2017)

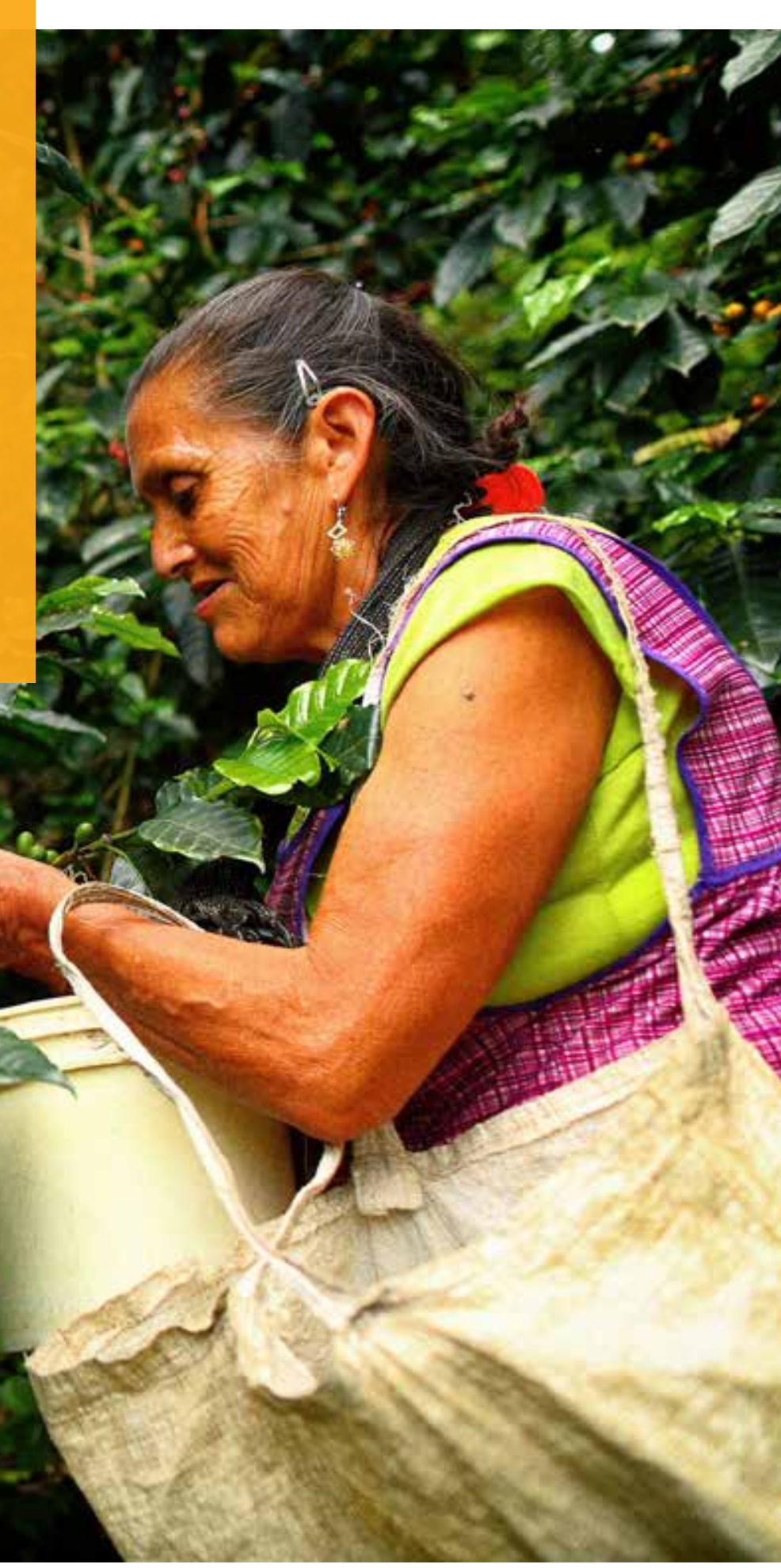




\section{2}

\section{CONSTRUIR HACIA ADELANTE: LA PERSPECTIVA DE GÉNERO EN LOS ORGANISMOS GUBERNAMENTALES}

Incorporar la perspectiva de género en la tenencia forestal dentro de los organismos gubernamentales es una tarea enorme y continua. Incluye varias dimensiones clave, como la creación de un mecanismo nacional para asuntos de la mujer; el apoyo a un punto focal para cuestiones de género en el ministerio forestal; contar con un número cada vez mayor de mujeres profesionales en forestería, que brinden orientación al personal sobre el proceso de trabajo y el desarrollo de capacidades; llevar registros de tenencia diferenciados por género; y la creación de una base de datos desglosada por género para el monitoreo de la tenencia forestal. A continuación, se brinda orientación sobre cada una de estas dimensiones. La puesta en marcha de iniciativas paralelas en estas dimensiones ayuda a cambiar la cultura general de la prestación de servicios gubernamentales y da luces sobre por qué y cómo la igualdad de género es importante para el ámbito forestal. Los obstáculos más frecuentes para mejorar la implementación gubernamental y la prestación de servicios para la reforma de la tenencia forestal son presupuestos inadecuados e insuficiente personal calificado (Arwida et al. 2017; Coleman 2019).

En el fondo, el problema generalizado de la falta de mujeres en puestos de liderazgo o de toma de decisiones dentro de los organismos forestales gubernamentales sigue siendo algo frecuente, aunque hay algunas señales de cambios positivos. Por ejemplo, en Nepal, Radha Wagle se convirtió en la primera mujer secretaria adjunta en el Ministerio de Bosques y Medio Ambiente, así como en jefa del Centro de Implementación de REDD+ en 2015 (World Bank 2019b). Wagle está trabajando en el fortalecimiento de la Estrategia de Igualdad de Género e Inclusión Social desarrollada en Nepal en la década de 1990, en particular en la creación de códigos de conducta para su implementación a nivel distrital y local. Hay varias acciones que se pueden poner en marcha para mejorar los enfoques transformadores de género en la tenencia forestal dentro de los organismos gubernamentales (Figura 17). 


\section{ACCIONES CON PERSPECTIVA DE GÉNERO}

Figura 17. Recomendaciones para cambiar la cultura administrativa del gobierno sobre tenencia forestal hacia una cultura con perspectiva de género

Garantizar la igualdad de salarios, beneficios y oportunidades para el personal femenino y masculino, a fin de incentivar el desempeño competente de sus responsabilidades.

Cultivar un liderazgo inspirador que apoye la igualdad de género en los niveles superiores de los departamentos y oficinas para orientar al personal sobre las prioridades en materia de género.

Dar prioridad al personal que trabaja a nivel local en temas de desarrollo institucional con perspectiva de género, planificación forestal, apoyo de extensión y cumplimiento.

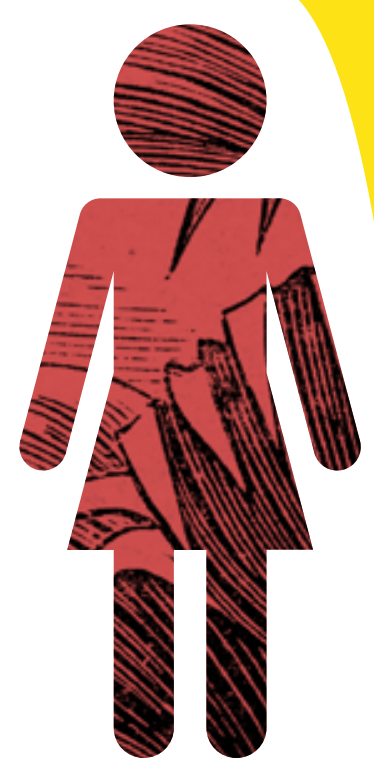

Desarrollar una estrategia o plan de acción en materia de género (e inclusión social) y un marco de monitoreo relacionado.

Desarrollar procesos de trabajo participativos sensibles al género que proporcionen orientación paso a paso que se adecúe a las necesidades específicas de la unidad u oficina.

Participar en actividades periódicas para el desarrollo de capacidades, de manera que estas interacciones sirvan para internalizar cómo lograr la igualdad de género y cómo compartir nuevas ideas.

Desarrollar mecanismos para consulta y validación periódicas de decisiones políticas con grupos de la sociedad civil, federaciones forestales y expertos en género que promuevan la igualdad de género.

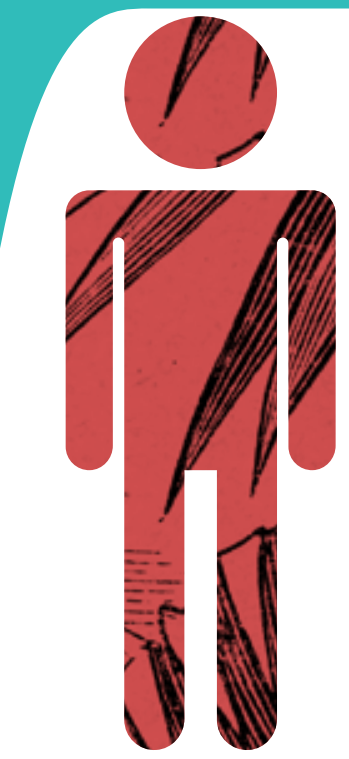




\section{MECANISMO NACIONAL PARA ASUNTOS DE LA MUJER}

Aunque es poco discutido en los estudios sobre el sector forestal, el mecanismo nacional para asuntos de la mujer (NMWA, por sus siglas en inglés) es un actor importante dentro de los gobiernos nacionales. Su objetivo es brindar apoyo a la promoción de políticas en todos los niveles de gobierno, con el fin de crear un enfoque coherente y justo para las necesidades de mujeres y hombres. Por lo general, el NMWA es una unidad central de coordinación dentro del gobierno. En la Cuarta Conferencia Internacional sobre la Mujer, celebrada en Pekín, se puso de relieve el papel de lo que en ese entonces se denominaba "maquinaria nacional de la mujer". Dado que los ministerios de la mujer no estaban en una posición adecuada para catalizar por sí solos la transversalización de la perspectiva de género en todos los niveles de gobierno (porque no disponían de recursos o no tenían la influencia suficiente), se requería de otro mecanismo institucional. Posteriormente, la maquinaria nacional de la mujer pasó a llamarse NMWA. Los NMWA suelen apoyar una serie de iniciativas: elaboración de presupuestos con perspectiva de género, reformas jurídicas basadas en mandatos globales, medidas específicas para poner fin a la discriminación por razones de género, promoción del uso de datos desglosados por género e investigación con perspectiva de género, apoyo al seguimiento y la evaluación de objetivos para la igualdad de género, e identificación de lecciones y buenas prácticas. Inicialmente centrados en las necesidades de las mujeres, ahora se han reorientado para transformar las relaciones de género en todos los enfoques programáticos y de políticas del gobierno. Junto con las organizaciones de mujeres y las federaciones forestales, pueden ejercer una presión considerable para lograr los cambios necesarios para apoyar las diferentes dimensiones de la igualdad de género en la tenencia forestal. Con el tiempo, los NMWA se han modificado para adaptarse a sus circunstancias $y$, por lo tanto, existe una enorme diversidad en su forma y ubicación a nivel institucional (Jahan 2010).

\section{PUNTO FOCAL PARA CUESTIONES DE GÉNERO}

La tarea principal de un punto focal (o unidad) para cuestiones de género es poner en marcha el proceso de transversalización de la perspectiva de género en toda oficina, departamento o ministerio forestal o sectorial. Junto con la dirección, se encargan de identificar áreas de trabajo específicas ene las cuales se puedan desarrollar actividades focalizadas para incorporar las cuestiones de género. Su trabajo es servir como catalizadores, más que ejecutar los proyectos por sí mismos. Como tales, su tarea principal es coordinar el desarrollo y la implementación de un Plan de Acción en Materia de Género que luego pueda allanar el camino a todas las unidades forestales del gobierno. Esto se puede complementar con un manual de operaciones que dé luces sobre cómo lograr la transversalización de la perspectiva de género. Suele ser útil echar un vistazo a la estructura organizativa del sector forestal, a los procedimientos de trabajo y a la cultura laboral en general, para determinar el tipo de enfoque más eficaz. En ocasiones, un enfoque centralizado puede funcionar mejor; en otros casos, un enfoque más descentralizado en muchas oficinas dispersas podría ser la combinación perfecta para el estilo organizacional. También puede incorporarse una estrategia comunicacional al Plan de Acción en Materia de Género.

La asignación especial de apoyo financiero, contar con un listado de consultores sobre cuestiones de género y la creación de redes con expertos de apoyo y OSC/ONG ayudarán a dinamizar el trabajo del punto focal para cuestiones de género.

Si el punto focal para cuestiones de género debe ser una mujer o no, es una cuestión que se debe considerar al crear el puesto. Si es una mujer, su adjunto puede ser un hombre para asegurar un equilibrio de género en las responsabilidades. Además, rotar los puestos cada dos o tres años ayuda a asegurar que el entusiasmo y las nuevas ideas sean una parte integral de esta responsabilidad. No se han realizado muchas investigaciones sobre los puntos focales para cuestiones género en el sector forestal. Algunos países han señalado su intención de contratar un punto focal para cuestiones de género, pero, más allá de eso, existe poco conocimiento sobre los desafíos reales de planificación que enfrenta este puesto (véase, por ejemplo, FAO y RECOFTC 2016). Muy a menudo, se nombra para estos puestos a personas con poca experiencia y recursos. Existe poca evidencia disponible acerca de lo que ha funcionado o cuáles son los desafíos.

\section{MUJERES PROFESIONALES EN LA FORESTERÍA}

La idea de que solo los hombres pueden incorporarse a 


\section{DOCTORADO}

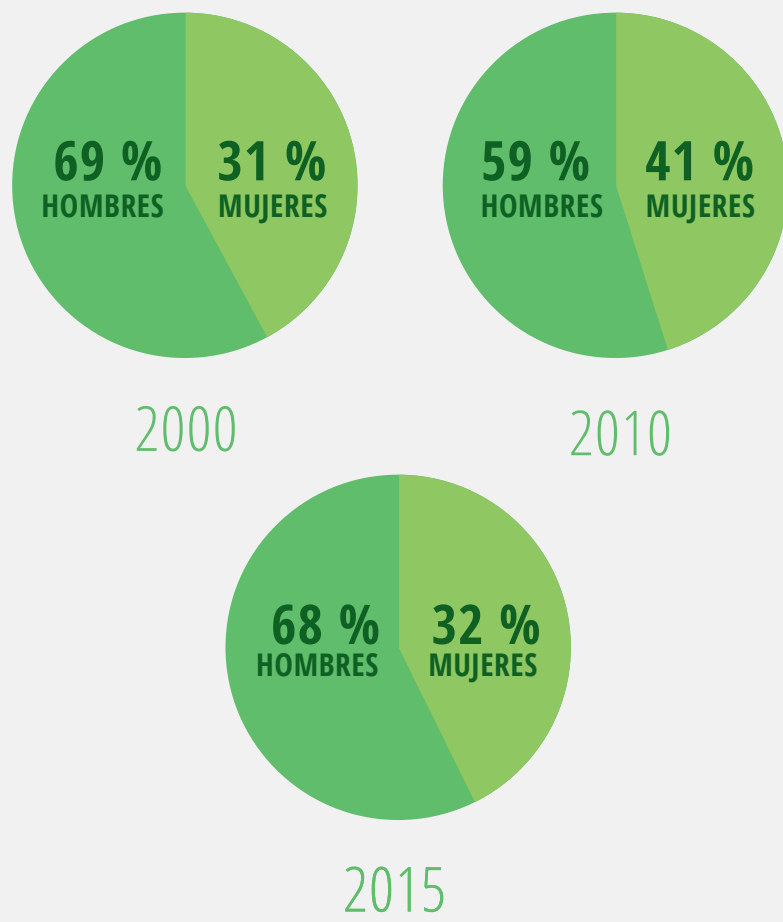

\section{MAESTRÍA}

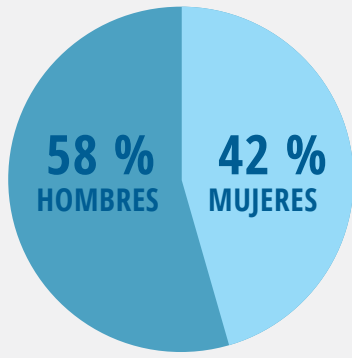

2000

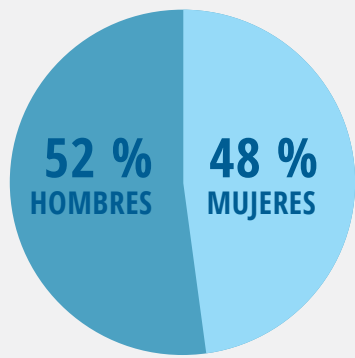

2010

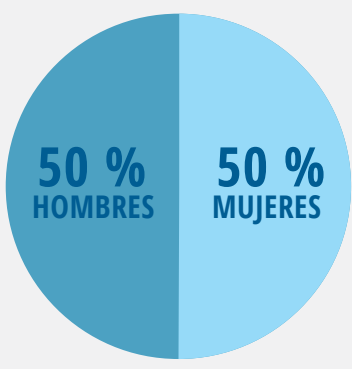

2015 la profesión forestal está sumamente extendida. Pero ese panorama está cambiando con rapidez y, gracias a ello, esta imagen estereotipada se está transformando. Una fuente importante de datos sobre este cambio es la Evaluación de los Recursos Forestales de la FAO, que recibe información sobre empleo en forestería y explotación forestal de 136 países que representan el $91 \%$ de los bosques del mundo. Los datos más recientes muestran que el $71 \%$ de los países (que representan el $38 \%$ de los bosques del mundo) proporcionan datos desglosados por género (FAO 2020a). Según las cifras, en 2015, de un total de 3,88 millones de empleados, alrededor del $58 \%$ eran hombres y $42 \%$ eran mujeres. Aunque no está claro qué porcentaje de estos empleados son de nivel superior o subalterno, el panorama a nivel agregado definitivamente luce más equilibrado de lo esperado. Al mismo tiempo, los datos sobre graduados en forestería indican una participación cada vez mayor de las mujeres y que la paridad de género es un objetivo alcanzable (FAO 2020a). De hecho, al desglosar los datos del periodo 2000-2015 por nivel de formación profesional, surge una imagen granular (véase la Figura 18) (FAO 2020a). Excepto a nivel de doctorado, la tendencia general parece ser un aumento del número de mujeres con formación a nivel de maestría, licenciatura y certificado/diploma técnico.

Más allá de estos datos, hay muchas historias inspiradoras de diferentes países sobre el papel dinámico que cumplen las mujeres en la profesión forestal. Existen numerosos ejes de cambio que evidencian un pensamiento y una acción innovadores. En la Comisión Forestal de Guyana, por ejemplo, todo el equipo del Sistema de Monitoreo, Reporte y Verificación (MRVS, por sus siglas en inglés) para REDD+ está dirigido y compuesto por mujeres con una fuerte motivación (Bholanath 2019)11. Actualmente,

11 Las razones de esto son importantes: debido a que el MRVS es un componente fundamental para la estrategia de desarrollo verde de Guyana, se requería asegurar que la retención del personal no constituyera un problema. Hombres calificados de la Comisión Forestal estaban migrando al extranjero y las mujeres ascendían rápidamente en la organización. Esta tendencia se vio respaldada además por un número cada vez mayor de alumnas que estudian en la Facultad de Agricultura y Silvicultura de la Universidad de Guyana. 


\section{LICENCIATURA}

\section{CERTIFICADO/DIPLOMA TÉCNICO}

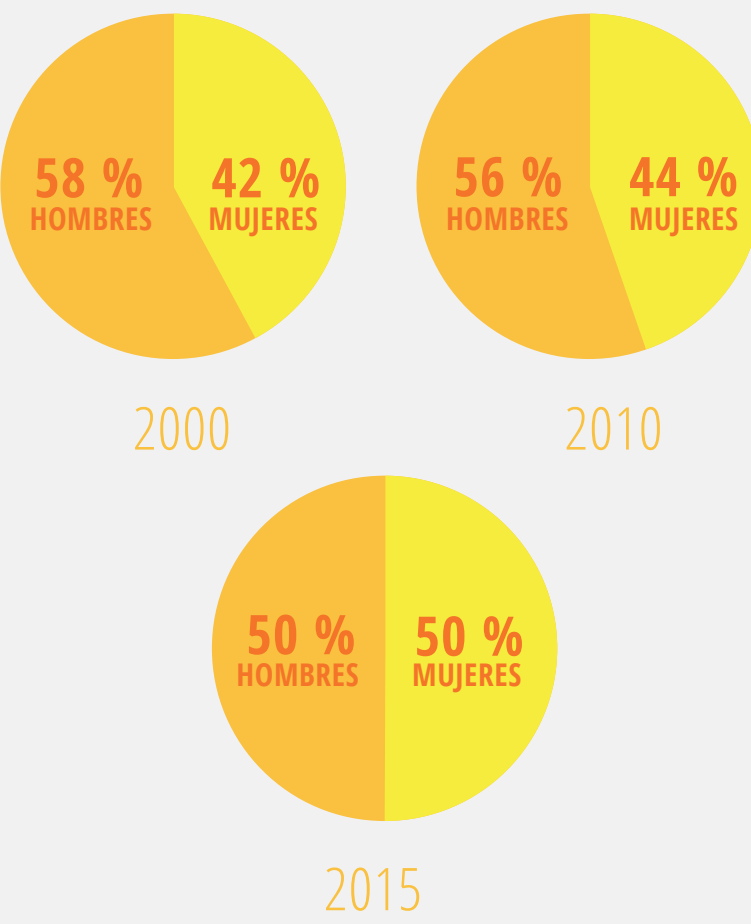

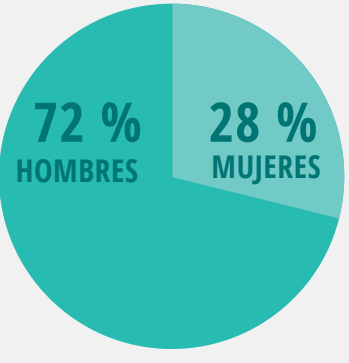

2000

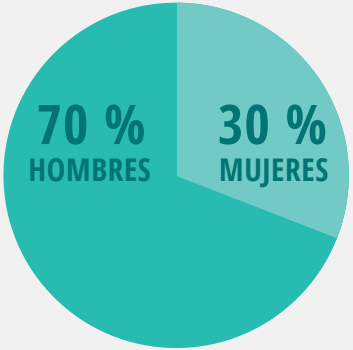

2010

\section{TOTAL}
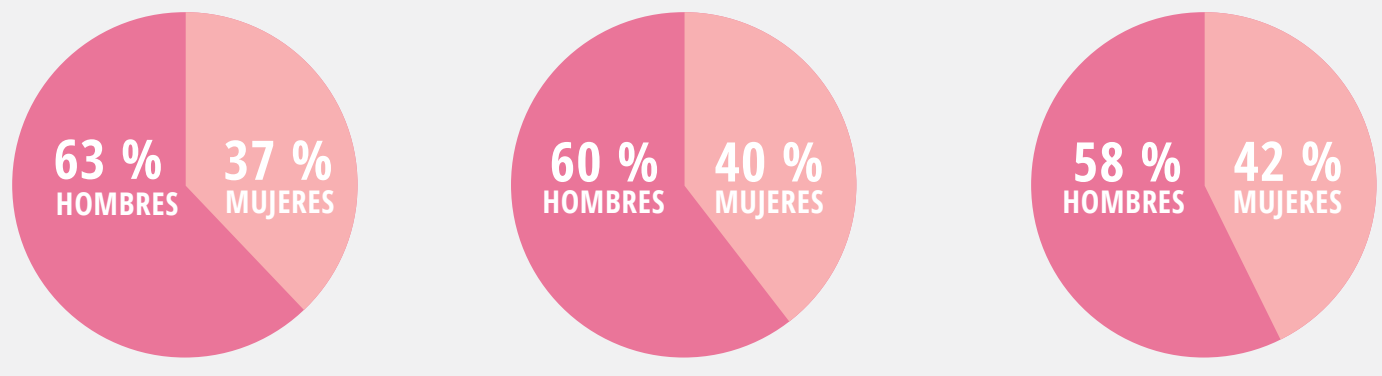

2000

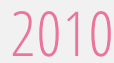

2015

Figura 18. Proporción de estudiantes de forestería graduados, mujeres y hombres, por nivel de educación, 2000-2015

Fuente: FAO (2020a). 


\section{TIPO DE INTERVENCIÓN}

Brindar apoyo personalizado a la alta dirección en términos de cómo integrar la igualdad de género en el desarrollo y la administración de políticas, incluido el suministro de informes

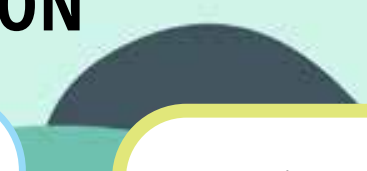

Crear incentivos para que el personal de nivel subalterno se inspire con la visión de una fuerza laboral con igualdad de género.
Figura 19. Intervenciones para orientar el proceso de trabajo y el desarrollo de capacidades del personal.

\section{sobre cuestiones de género, así como oportunidades comunicacionales y en medios. \\ 2000}
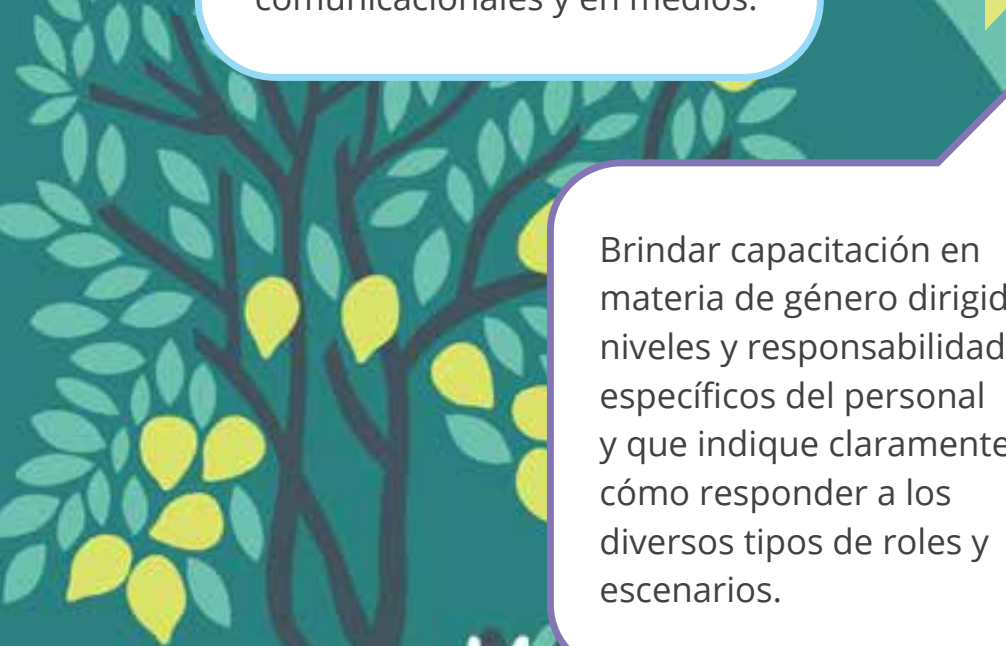

Brindar capacitación en materia de género dirigida a niveles y responsabilidades específicos del personal y que indique claramente cómo responder a los diversos tipos de roles y escenarios.

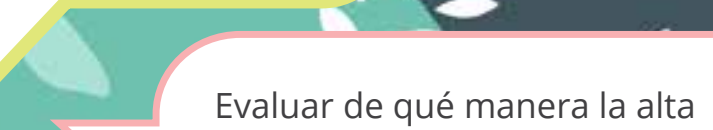
dirección puede crear alianzas estratégicas con federaciones forestales, grupos de mujeres, grupos de agricultores, grupos indígenas, grupos de pastores y expertos en temas jurídicos para fortalecer la igualdad de género dentro de las políticas y leyes de tenencia forestal pertinentes. alrededor del 45 \% de la fuerza laboral de la Comisión está compuesta por mujeres, muchas de ellas en cargos técnicos y de gestión. En el estado indio de Tamil Nadu, alrededor del 30 \% de las personas que reciben formación en forestería son mujeres; hay mucho interés en el personal femenino para puestos que requieren habilidades delicadas, por ejemplo, en las reservas de tigres (Bharadwaj 2017). En algunos estados de la India, como Haryana, se ha establecido una Célula para el Empoderamiento de la Mujer (Haryana Forest Department s. f.).

Un tema de especial interés es cómo las mujeres dedicadas a la forestería desarrollan su influencia colectiva. En Nepal, un grupo de estas mujeres formó la Red de Mujeres Silvicultoras, que busca promover la igualdad de género en las políticas y prácticas forestales ${ }^{12}$. Actualmente, sus 500 miembros, provenientes del ámbito gubernamental y del sector sin fines de lucro, están enfocadas en cambiar las formas predominantes de masculinidad hegemónica. Por medio de estas redes, las mujeres pueden desafiar los paradigmas imperantes para lograr un cambio más profundo y duradero. Por último, un hecho muy importante: aunque El Diálogo Forestal lleva 20 años dedicado a gestionar la participación global multiactor sobre diversos temas relacionados con los bosques, en 2020 dos mujeres líderes de la industria forestal fueron elegidas para codirigirlo por primera vez en su historia (Santiago 2020). Estos ejemplos son representativos de

12 Durante una teleconferencia global organizada por la red en mayo de 2020, varios hombres desconocidos que no estaban inscritos en el evento causaron disturbios al mostrar contenido sexual explícito y obsceno de manera abusiva (Giri y Dangal 2020). Este acoso fue denunciado ante las autoridades, y se puso en marcha una acción de protesta digital que generó la participación de 64000 personas en línea. 
los diversos tipos de cambio que están llevando a las mujeres a ingresar a la profesión forestal y asumir cada vez más puestos de liderazgo en el sector.

\section{ORIENTACIÓN DEL PROCESO DE TRABAJO Y DESARROLLO DE CAPACIDADES DEL PERSONAL}

Si un punto focal para cuestiones de género no fomenta la igualdad de género en todos los procesos de trabajo del personal de la administración forestal, no podrá lograr muchos cambios positivos por sí solo. En esencia, la dirección del organismo forestal debe establecer la visión y mostrar acciones claras en todos los niveles de la administración forestal. Crear un conjunto práctico de directrices sobre cómo el personal debe aplicar los requisitos de igualdad de género en su trabajo y desempeño conducirá a un cambio importante en la cultura laboral en un periodo razonable. No se trata de lanzar iniciativas completamente nuevas, sino de inculcar un pensamiento sensible al género en todos los procesos de trabajo y herramientas de gestión existentes (incluidas las evaluaciones de desempeño). Prestar especial atención a prever posibles obstáculos o dificultades ayudará a allanar el camino hacia la regularización de la igualdad de género en las operaciones administrativas. La dirección puede desarrollar una serie de intervenciones que ayuden a generar este cambio (véase Figura 19).

\section{REGISTROS DE TENENCIA DIFERENCIADOS POR GÉNERO}

Las VGGT hacen un Ilamado a los Estados para que identifiquen, registren, preserven y difundan los derechos de tenencia con el fin de reconocer y respetar todos los derechos legítimos de tenencia de una manera sensible al género. Los registros de tenencia no son necesarios en todas partes. Como bien se sabe, la formalización de un título puede ser un arma de doble filo tanto para mujeres como para hombres (Agarwal y Freudenberger 2013). Los sistemas informales tienden a adaptarse mejor a los cambios, mientras que la formalización tiende a fijar límites y a crear sistemas más estáticos. La formalización puede venir acompañada de mayor interferencia del Estado y control sobre sistemas de toma de decisiones que han sido utilizados durante largo tiempo en el ámbito local. Los nuevos requisitos y responsabilidades impuestos por el Estado suelen ser complicados y onerosos. Por lo tanto, toda comunidad debe hacer desde un principio una evaluación cuidadosa de las ventajas y desventajas de registrarse, antes de iniciar cualquier proceso de reconocimiento que fije límites de una manera detallada.

Así, en caso sea necesario, la siguiente pregunta es cómo crear un nuevo sistema para el registro de derechos y también para el registro de derechos por primera vez (para orientación al respecto, véase FAO 2017a). Una pregunta alternativa es cómo mejorar el sistema de registro de derechos de tenencia que ya existe (para poder documentar derechos superpuestos o en conflicto) (para orientación al respecto, véase FAO 2017b). Todo sistema de registro de derechos de tenencia es aplicable no solo a derechos privados sino también a derechos públicos, colectivos, comunales, consuetudinarios e informales. Y se pueden registrar derechos de tenencia sobre la tierra, pero también derechos sobre los bosques, derechos de pesca y derechos de aguas. Lo fundamental es que estos sistemas de datos independientes estén interconectados por medio de un sistema integrado que permita compartir la información (mediante sistemas geoespaciales) con el fin de reconocer los derechos y otros usos, como la planificación del uso de la tierra.

En primer lugar, el proceso de demarcación y armonización de límites para la titulación debe llevarse a cabo con perspectiva de género. Los procesos de consulta, por ejemplo, aquellos sobre derechos consuetudinarios, deben diseñarse de manera tal que los aportes y opiniones de mujeres y hombres de diferentes orígenes formen parte del proceso de identificación de límites para áreas de uso individual y colectivo. Se pueden preparar materiales comunicacionales diseñados de manera específica para mujeres, a fin de que comprendan el propósito del trabajo de mapeo participativo en el terreno. En lo que respecta al registro, el sistema de gestión de datos debe desglosarse por género. Se debe prestar atención al registro de hogares encabezados por mujeres o por hombres, e indicar si están divorciados de jure, si son viudos o si se trata de hogares monoparentales de facto. El lugar donde se 
INDICADOR

Porcentaje de mujeres y hombres de la comunidad/grupo de usuarios que participan en la demarcación de límites del área forestal para el reconocimiento de los derechos de tenencia

\section{FUENTES DE VERIFICACIÓN Y HERRAMIENTAS}

- Grupos focales

- Entrevistas con las partes interesadas

- Personal de implementación del proyecto

- Registros de la oficina forestal local

INDICADOR

Porcentaje de miembros del grupo de usuarios de bosques de uso común que son mujeres y hombres

\section{FUENTES DE VERIFICACIÓN Y HERRAMIENTAS}

- Actas de reuniones del comité

- Grupos focales

- Registros de la oficina forestal local

- Registros de programas y proyectos

\section{INDICADOR}

Porcentaje de mujeres y hombres que tienen una participación activa en los comités de gobernanza forestal que crean normas de tenencia (incluidas las funciones de signatarios de cuentas bancarias)

\section{FUENTES DE VERIFICACIÓN Y HERRAMIENTAS}

- Registros bancarios

- Actas de reuniones del comité

- Entrevistas con partes interesadas

- Autoridades tradicionales locales (como el líder de la aldea o el líder del consejo local)

- $\quad$ Registros de programas y proyectos
Figura 20. Ejemplos de indicadores de monitoreo y evaluación de género y tenencia forestal

Fuente: adaptado de World Bank, FAO e IFAD (2009).
INDICADOR

Cambios en las percepciones de mujeres y hombres con respecto a la importancia de las normas de tenencia con igualdad de género para lograr una buena gestión forestal y distribución de beneficios

FUENTES DE VERIFICACIÓN Y HERRAMIENTAS

- Grupos focales

- Entrevistas con las partes interesadas

INDICADOR

Apoyo al desarrollo de capacidades en métodos de gestión forestal (incluidas técnicas forestales) que reconocen las diferencias de género

FUENTES DE VERIFICACIÓN Y HERRAMIENTAS

- Registros de proyectos

- Registros de capacitaciones

\section{INDICADOR}

Porcentaje de mujeres y hombres involucrados en actividades de monitoreo y vigilancia forestal

FUENTES DE VERIFICACIÓN Y HERRAMIENTAS

- Monitoreo participativo

- Registros de proyectos 
INDICADOR

Cambio en el tiempo requerido para recolección de leña de los bosques por mujeres y hombres antes y después de una línea de base temporal

\section{FUENTES DE VERIFICACIÓN Y HERRAMIENTAS}

- Monitoreo participativo

- Registros de proyectos

\section{INDICADOR}

Número de mujeres y hombres con cuentas bancarias individuales en las que se pueden recibir beneficios en efectivo derivados de la venta de productos forestales o pagos por servicios ambientales

\section{FUENTES DE VERIFICACIÓN Y HERRAMIENTAS}

- Entrevistas con partes interesadas

- Entrevistas de grupos focales

INDICADOR

Aumento de los ingresos anuales provenientes del flujo de efectivo de los recursos forestales para mujeres $y$ hombres durante un periodo especificado

FUENTES DE VERIFICACIÓN Y HERRAMIENTAS

- Entrevistas de grupos focales

- Registros de programas y proyectos

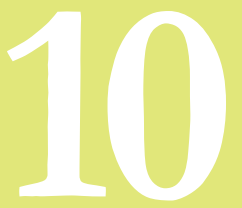

INDICADOR

Número de mujeres y hombres que recibieron capacitación empresarial para la creación de empresas forestales

FUENTES DE VERIFICACIÓN Y HERRAMIENTAS

- Registros de proyectos

- Registros de capacitaciones

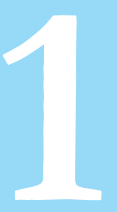

INDICADOR

Percepción del nivel de seguridad alimentaria debido a un acceso seguro a los bosques en un periodo especificado luego de la aclaración y el reconocimiento de los derechos de tenencia con igualdad de género

FUENTES DE VERIFICACIÓN Y HERRAMIENTAS

- Entrevistas de grupos focales

- Registros de programas y proyectos

\section{INDICADOR}

Percepción de sostenibilidad en la disponibilidad de recursos forestales para satisfacer diversas necesidades del hogar (combustible, forraje, alimentos, plantas medicinales)

FUENTES DE VERIFICACIÓN Y HERRAMIENTAS

- Entrevistas de grupos focales

- Registros de programas y proyectos

\section{INDICADOR}

Número de conflictos que involucran a mujeres y hombres por el acceso, uso y gestión de los bosques durante un periodo específico

\section{FUENTES DE VERIFICACIÓN Y HERRAMIENTAS}

- Entrevistas con partes interesadas (involucradas y no involucradas en el conflicto)

- Autoridades locales tradicionales (como el líder de la aldea o el líder del consejo local)

- Registros de programas y proyectos

\section{INDICADOR}

Percepción de una mejora del $\mathbf{5 0} \%$ en el nivel de seguridad de la tenencia forestal entre mujeres $y$ hombres

\section{FUENTES DE VERIFICACIÓN Y HERRAMIENTAS}

- Entrevistas con partes interesadas

- Entrevistas de grupos focales

- Registros de programas y proyectos 
conservan esos registros depende de muchos factores, entre ellos el nivel de descentralización del gobierno. Si se produce una devolución de derechos de tenencia, y esta se lleva a cabo junto con una descentralización del gobierno, entonces tiene sentido mantener los registros de tenencia descentralizados a nivel de distritos locales o de grupos de aldeas.

Los temas de accesibilidad y el costo de los registros tendrán repercusiones diferenciadas por género. Dada la enorme carga de trabajo y el limitado tiempo del que disponen las mujeres, todo sistema de registro de tenencia deberá ser práctico para poder ser utilizado. Además, todos los costos asociados del proceso de registro deberán contrastarse con los beneficios que traerá dicho registro; para muchos, los beneficios de la titulación y de estar registrado no siempre son evidentes de inmediato. A menudo, un servicio de oficina móvil al que todos puedan acceder con facilidad suele ser lo más adecuado en términos de efectividad de costos. Y contar con un enfoque simplificado hace que el sistema de registro de tenencia sea más inclusivo socialmente. Otro factor importante es elegir la tecnología adecuada al contexto local que permita una mayor reducción de tiempo y costos. Asimismo, el personal encargado del proceso de registro puede incluir tanto mujeres como hombres, para que todos se sientan cómodos de acercarse a la oficina para la prestación del servicio. Y puede ser muy valioso contar con publicaciones que ayuden a mejorar los conocimientos en temas jurídicos de mujeres y hombres. Un sistema sostenible es aquel en el que los beneficios superan a los costos en términos de tiempo, dinero y otros factores.

\section{DATOS DESGLOSADOS POR GÉNERO Y MONITOREO DE LA TENENCIA FORESTAL}

Para un monitoreo y una evaluación eficaces y con perspectiva de género, ya sea para la aplicación de políticas y leyes o para proyectos, se requiere de datos desglosados por género, tanto cualitativos como cuantitativos. Los datos proporcionan evidencia empírica acerca de cómo la tenencia forestal con perspectiva de género afecta las diversas vías hacia el cambio y sus resultados. Sin embargo, sigue habiendo una carencia grave de tales datos y, por lo tanto, se tiene un conocimiento fragmentado sobre cómo se producen realmente las transformaciones para la igualdad de género en lo que respecta a la tenencia forestal (FAO 2018c, 2019c).

Para medir y mejorar el desempeño de políticas, leyes o proyectos, es necesario elaborar indicadores claros para la medición de la igualdad de género y el empoderamiento de las mujeres, que reflejen tanto la amplitud como la profundidad de los diversos programas y proyectos del sector forestal. La identificación de las brechas de datos de género ayuda a determinar qué indicadores abordan mejor las necesidades, la cobertura de la población y la relevancia de las políticas. Estos indicadores serán utilizados de diferentes formas: por instituciones y oficinas que tengan el mandato de implementar y hacer seguimiento a instituciones forestales descentralizadas; por proyectos ejecutados por donantes u ONG/OSC; o por instituciones de gobernanza forestal a nivel local. En el caso de los pilotos, los datos e indicadores desglosados por género pueden ayudar en el diseño del proceso de ampliación de la escala. Al convertirse en la plataforma de datos mediante la cual se pueden realizar ajustes a las actividades del proyecto, los resultados e impactos previstos en grupos específicos de mujeres y hombres se vuelven más factibles.

Por supuesto, cada conjunto particular de indicadores tendrá que adaptarse a objetivos específicos, pero puede ser valioso contar con algunas pautas de orientación para su diseño (véase la Figura 20). Aunque muchos indicadores son cuantitativos y a menudo están estructurados para facilitar las comparaciones (a nivel nacional o mundial) o son compatibles con plantillas más grandes de recopilación de datos estadísticos, no necesariamente ayudan a los beneficiarios del proyecto a reflexionar sobre sus propias percepciones o sobre los cambios reales por los que han atravesado (Colfer et al. 2013). Por lo tanto, la metodología de recopilación de datos no solo debe elaborarse con una perspectiva de género 
(véanse Elias 2013; Doss y Kieran 2014), sino también tomando en cuenta de qué manera y quién utilizará el análisis.

Los resultados de este trabajo de evaluación pueden contribuir con numerosos tipos de actividades de monitoreo (véase World Vision 2020). Estas pueden ayudar a diseñar planes de acción en materia de género para el sector forestal. Si bien ya existen iniciativas para hacer seguimiento a la igualdad de género, como el grado en que los gobiernos cumplen con los ODS (UN Women 2018a), también hay un aumento en la cantidad de tipos más específicos de monitoreo de iniciativas globales centradas en cuestiones de tenencia. Estos datos también pueden formar parte del seguimiento de la implementación de las VGGT dentro del sector forestal. Hay disponibles guías y herramientas para apoyar el monitoreo de la implementación sensible al género de las VGGT (véanse Seufert y Suárez 2012; Action Aid 2017). También se han desarrollado otros tipos de herramientas de monitoreo para hacer seguimiento al nivel de integración de las cuestiones de género en la investigación forestal (CGIAR FTA 2019; Paez et al. 2019). Por ejemplo, para usar la Escala de Igualdad de Género en la Investigación, se requiere que los líderes de proyecto o los equipos completen anualmente un cuestionario de autoevaluación y reflexionen sobre cómo mejorar la integración de las cuestiones de género en su cartera de investigación (CGIAR FTA 2019).
SECCIÓN 2.2

\section{LECTURAS COMPLEMENTARIAS}

[FAO] Food and Agriculture Organization. 2017. Creating a system to record tenure rights and first registration. Governance of Tenure Guide n. ${ }^{\circ}$ 9. Roma: FAO.

[FAO] Food and Agriculture Organization. 2017. Improving ways to record tenure rights. Governance of Tenure Guide n. ${ }^{\circ}$ 10. Roma: FAO.

Seufert P y Suárez S. 2012. Monitoring the voluntary guidelines on the responsible governance of tenure of land fisheries and forests. A civil society perspective. FAO Land Tenure Working Paper n. ${ }^{\circ} 22$. Roma: FAO. 


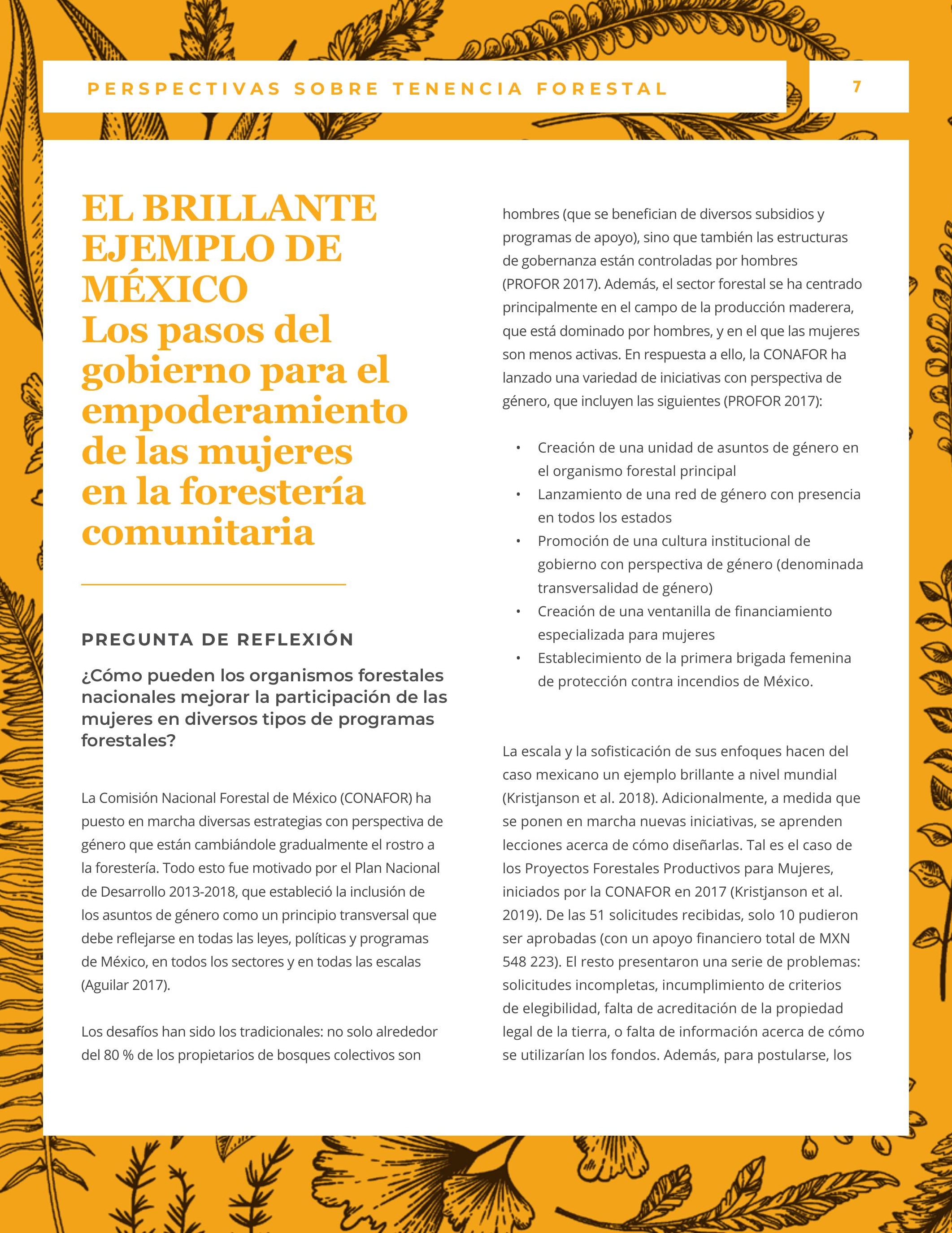


solicitantes debían aportar al proyecto entre un 10 y un $50 \%$, en efectivo o en especie. El bajo porcentaje de mujeres con cuentas bancarias y su escaso acceso a los servicios financieros también generó un problema. Este aprendizaje ha ayudado a refinar la siguiente ronda de iniciativas. Esto ejemplifica los problemas estructurales que obstaculizan la participación de la mujer en el sector forestal y que se encuentran arraigados en el acceso desigual a los activos, lo que en última instancia limita su capacidad para beneficiarse y empoderarse.

\section{LECCIONES}

Se requiere de una serie de iniciativas sensibles al género para cambiar la cultura y la forma de operación predominante del marco regulador de la tenencia forestal con el fin de lograr un cambio duradero. 


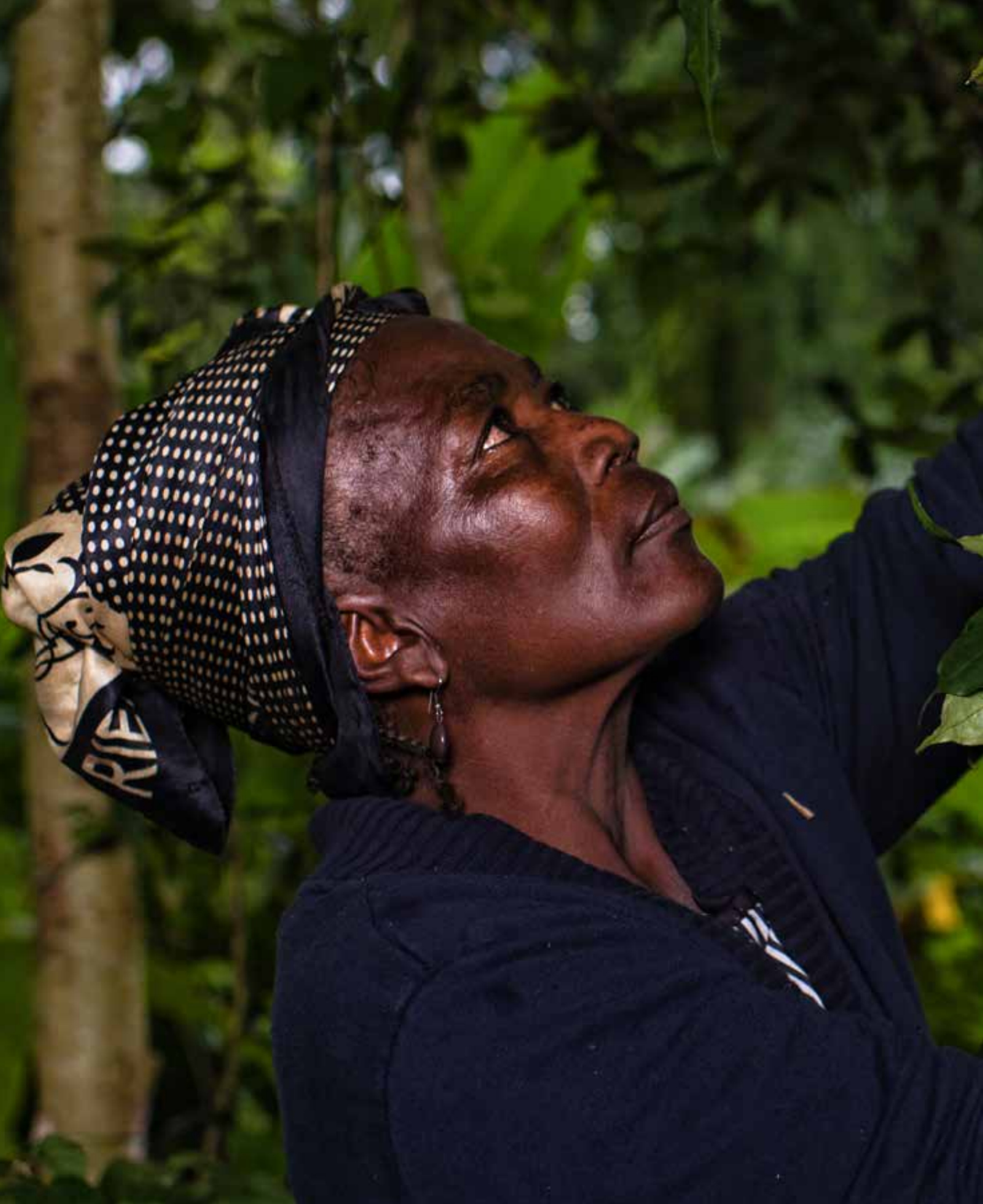





\section{1}

\section{EL ESTADO DE LA IGUALDAD DE GÉNERO EN LA TENENCIA FORESTAL COLECTIVA}

El proceso de devolución de la tenencia forestal ha llevado a que las tierras forestales queden bajo el control local de los PICL a través de derechos legítimos, políticas o medidas de carácter jurídico de facto. Se puede decir que esas tierras se encuentran en situación de tenencia colectiva o propiedad común. Ambos términos se utilizan indistintamente. Este tipo de tenencia supone un grupo de personas que utilizan en conjunto un área forestal según reglas acordadas (sean estas formales o informales) para su acceso, uso, manejo, etc. En aquellos lugares donde los bosques se gestionan de acuerdo con esta forma de tenencia, se utiliza normalmente el término "forestería comunitaria" en un sentido integral. En la práctica, sin embargo, las características de los derechos forestales colectivos en cuanto a escala, gestión, autonomía y duración pueden variar considerablemente de un país a otro, e incluso de una zona a otra. Pueden ir desde una situación de devolución débil en la que las comunidades participan, por ejemplo, en actividades de conservación de la naturaleza organizadas por el gobierno o una ONG durante algunos años; hasta derechos de propiedad sólidos en los que las comunidades tienen plena autoridad jurídica para gestionar, de manera autónoma y a perpetuidad, las tierras forestales para diversos propósitos basados en su propia estructura de gobernanza (véase la Figura 21) (véanse Ewers 2011; FAO 2019c; Larson et al. 2010).

Por lo tanto, es esencial centrarse en el modo de gobernanza específico y en los tipos de derechos y responsabilidades establecidos en el paquete de tenencia. Pueden ser derechos formales incluidos en los estatutos o prácticas tradicionales de uso general que predominan en el día a día. El término "forestería comunitaria" puede incluir tierras forestales que permanecen bajo el control jurisdiccional del gobierno o aquellas que son de propiedad plena de una comunidad, con derechos de venta, hipoteca y arrendamiento. También es necesario examinar con cuidado el término "comunidad": ¿cuáles son los supuestos acerca de lo que constituye una "comunidad" en un contexto específico? Puede ser una comunidad consuetudinaria en la que algunos nuevos inmigrantes 
$\hat{2}$

\section{DEVOLUCIÓN DÉBIL}

Derechos delegados

Involucramiento participativo en actividades dirigidas por programas

Poca autoridad para la toma de decisiones

Algunos derechos para extraer recursos forestales como leña, forraje u otros PFNM

\section{DEVOLUCIÓN MODERADA}

\section{Derechos compartidos y} parcialmente devueltos

Comparte los beneficios de los bosques de propiedad del gobierno

Establecida a través de un marco de políticas

Menor duración de la tenencia o inseguridad en la tenencia

Autoridad limitada de la comunidad

Algunas oportunidades de empleo en la labor de gestión forestal del gobierno

Derechos de uso de determinados productos forestales con controles sobre la extracción de madera

\section{DEVOLUCIÓN FUERTE}

\section{Derechos completamente devueltos}

Gestión colectiva de bosques que implica la devolución de los derechos de uso, gestión y regulación

Establecida a través de un marco jurídico

Derechos otorgados a perpetuidad

Autonomía

Devolución de derechos basada en la aprobación de un plan operativo o de gestión forestal

Derechos específicos para la venta comercial de madera
PROPIEDAD

\section{En propiedad}

Titularidad plena de las tierras consuetudinarias, incluidas las áreas forestales

\section{Toda la}

responsabilidad del uso y gestión recae en la comunidad
Proyectos de forestación a gran escala

Gestión colectiva de áreas protegidas

\section{Gestión forestal} conjunta

\section{Forestería comunitaria}

\section{Forestería comunitaria}

Concesiones forestales comunitarias locales
Comunidad nativa

o campesina

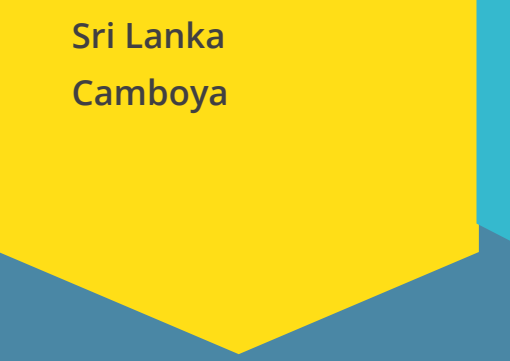

\section{India}

Tailandia

\section{Nepal}

República Democrática del Congo

Figura 21. Espectro del nivel de devolución en el régimen forestal bajo tenencia colectiva 
o colonos han establecido su hogar; un "grupo de usuarios" formado por miembros de diferentes aldeas contiguas que utilizan un área forestal específica; o una comunidad en la que varios clanes distintos que viven y se organizan en conglomerados de aldeas se unen en una sola "aldea" administrativa que es definida por el gobierno como una unidad. Todos estos detalles son fundamentales para entender cómo funciona la dinámica de género en diversos tipos de regímenes forestales bajo tenencia colectiva.

La dependencia que tienen las mujeres de una infinidad de recursos forestales ha sido invisible en gran medida para el ámbito formal de la gestión forestal. La preocupación por la participación de las mujeres en los bosques locales comenzó en la década de 1980 como resultado de la escasez de leña que llevó a un creciente interés en la utilización de los recursos forestales de manera diferenciada por parte de mujeres y hombres (Hoskins 2016). Actualmente, aunque existen algunas descripciones generales acerca de los intereses habituales de las mujeres y los hombres en los bosques (véase Sunderland et al. 2014), es imperativo conocer los tipos específicos de división por género o superposición de responsabilidades que están en juego (véase Larson et al. 2016b). Por ejemplo, la tenencia de árboles es muy importante para las mujeres porque estas buscan ejercer el control de aquellas especies que necesitan para alimentación, forraje, combustible para el hogar o para generar ingresos (Fortmann 1985; Bruce 1989; Rocheleau y Edmunds 1997). Una comprensión profunda sobre el tema permitirá dejar en claro el tipo de conocimientos y perspectivas que entran en discusión cuando grupos más numerosos de mujeres tienen una participación formal en las instituciones de gobernanza de la tenencia. De esta manera, su contribución esencial a la gestión forestal se vuelve parte de la toma autorizada de decisiones y de la distribución de beneficios (individuales o colectivos) para mujeres y hombres en la comunidad.

Queda claro que, en aquellos lugares donde se cuenta con una estructura de gobernanza funcional y regulaciones de gestión bien diseñadas, la devolución puede producir flujos de beneficios tanto para las mujeres como para los hombres de la comunidad, y además mejorar el estado del bosque. Ha habido logros considerables mediante la gestión directa de quienes tienen derechos sólidos sobre los bosques en su localidad (Gilmour 2016). Ahora bien, términos como "comunidad", "colectivo" o "comunal" son poco claros en lo que respecta a quiénes incluyen; para promover la equidad y la inclusión de género se necesita una comprensión adecuada de qué mujeres y qué hombres tienen la autoridad y el control de la toma de decisiones. Establecer una gobernanza forestal de base comunitaria no es suficiente; también son esenciales las innovaciones democráticas en los procesos de gobernanza y en los principios que guían el desarrollo y la implementación de las normas (Smith 2019). Esto requiere comprometerse con el proceso de diseño de regímenes de tenencia forestal, de manera que todos avancen juntos por la vía que conduce al desarrollo sostenible. Ahora bien, muchas comunidades pueden ver la introducción de nuevos principios, por ejemplo, la igualdad de género, como una imposición externa que atenta contra la soberanía local. Por lo tanto, vale la pena hacer pruebas de sensibilidad en cada comunidad: simplemente imitar lo que otra comunidad ha hecho dejará temas importantes sin atender. En resumen, hablar solo en términos de derechos "comunitarios" no resulta adecuado desde una perspectiva de género.

Otra dimensión importante de la forestería comunitaria que se debe tomar en cuenta es la escala en la que se desarrolla. No todo sucede a escala de la aldea. Términos como "forestería colaborativa" (que se utiliza en Nepal) se refieren a áreas boscosas más grandes que involucran varias unidades administrativas gubernamentales (que pueden incluir cientos de aldeas) en las que el gobierno y las comunidades locales trabajan juntos en la gestión de los bosques para la producción de madera de alto valor, así como para satisfacer necesidades de subsistencia, combustible y forraje. La capacidad de gestionar la gobernanza de la tenencia también se ve afectada cuando el tamaño geográfico es mayor $y$, por consiguiente, las comunidades numerosas y dispares no experimentan con regularidad interacciones personales que ayuden a generar confianza mutua. 
Todos los regímenes forestales bajo tenencia colectiva pasan por etapas de cambio en las que adaptan sus sistemas para responder a nuevos desafíos y lecciones, tanto internos como externos (véase Farjam et al. 2020). En algún punto de este proceso, se llega a un reconocimiento general de que la igualdad de género es fundamental para todos los involucrados. Cuando esto ocurre, resulta útil determinar cuál es la situación general de la gobernanza forestal en términos de equidad de género. La Figura 22 muestra las diferentes etapas del nivel de perspectiva de género de la gobernanza forestal comunitaria, desde un nivel “mínimo", pasando por uno "mejorado", hasta un nivel "bueno". Aunque esta es una descripción simplificada, es un primer paso para resumir el tipo de desafíos que se enfrentarán.

En la mayoría de los lugares, sin embargo, la puesta en marcha de enfoques participativos en los bosques bajo tenencia colectiva no ha llevado a una aceptación automática de la igualdad de género. Por lo general, las cuestiones de género, ya sea en términos de sensibilización o de objetivos más transformadores con perspectiva de género, no han recibido gran atención, más allá de expresiones meramente declarativas (Sun et al. 2012). Los derechos de las mujeres a acceder a los productos forestales no solo no son reconocidos formalmente de la misma manera que los derechos de los hombres, sino que las mujeres casi no tienen poder de decisión en temas de gobernanza forestal. Un mayor reconocimiento de las investigaciones que destacan la importancia de los derechos de tenencia seguros, la equidad y cohesión sociales, y la gobernanza democrática y equitativa para el éxito de la forestería comunitaria permitiría poner en marcha más acciones en favor de la equidad de género ${ }^{13}$ (véase Baynes et al. 2015; también Coleman y Mwangi 2013).
Incluso en países que han reconocido la importancia de las cuestiones de género en los bosques desde principios de la década de 1990, como Uganda, se ha mantenido a las mujeres fuera de los espacios de toma de decisiones en gran medida (Banana et al. 2013). Con todo, el panorama de Uganda no es del todo sombrío: por ejemplo, más del $50 \%$ de las mujeres participan activamente en la toma de decisiones forestales en Lamwo (con asociaciones de tierras colectivas registradas). Esto contrasta con el caso de Masindi (con tierras consuetudinarias superpuestas a bosques estatales de acceso restringido), donde la participación de las mujeres es muy baja (Monterroso y Larson 2019). En América Latina, se ha prestado muy poca atención a las cuestiones de género en la ahora considerable literatura sobre forestería comunitaria (Schmink y García 2015). Esto se debe en parte a que la necesidad de obtener el reconocimiento jurídico de los derechos de los pueblos indígenas o de las comunidades al territorio ha ocupado el primer lugar de la agenda política (el fenómeno de "la comunidad primero que el género") y, en parte, al enfoque de la forestería comunitaria en operaciones comerciales de gran escala.

En aquellos lugares donde ha habido logros relativamente importantes para avanzar hacia la igualdad de género en bosques de gestión local, estos han sido el resultado del apoyo de federaciones, ONG (de forestería comunitaria, de cuestiones de género o relacionadas con el desarrollo) o grupos de la sociedad civil. Por ejemplo, en Nepal, fue la FECOFUN, la federación nacional de forestería comunitaria, la que estableció la plataforma de políticas a mediados de la década de 1990, al declarar obligatorio que por lo menos el $50 \%$ de la membresía de los comités ejecutivos estuviera compuesta por mujeres, además de garantizar la rotación de los puestos titulares entre mujeres y hombres (véase Perspectivas sobre Tenencia Forestal n. ${ }^{\circ}$ 6) (Chapagain 2012; Giri 2012).

13 Un estudio identificó cinco factores de éxito interconectados para la forestería comunitaria (Baynes et al. 2015). Esto se basó principalmente en experiencias de México, Nepal y Filipinas, pero también tomó en cuenta experiencias de otros países de África, Asia y América Latina. Los cinco factores de éxito son: derechos seguros de propiedad (árboles y tierra); reducción de las diferencias socioeconómicas y la desigualdad de género para disminuir los conflictos y aumentar la cohesión; formas de gobernanza de grupos forestales comunitarios que sean democráticas y equitativas en términos de liderazgo, votaciones y distribución de beneficios; apoyo del gobierno a la forestería comunitaria (por ejemplo, mediante legislación habilitadora o incentivos); y beneficios materiales para los miembros de las comunidades (por ejemplo, ingresos por las ventas de PFNM, empleo o PSA). 


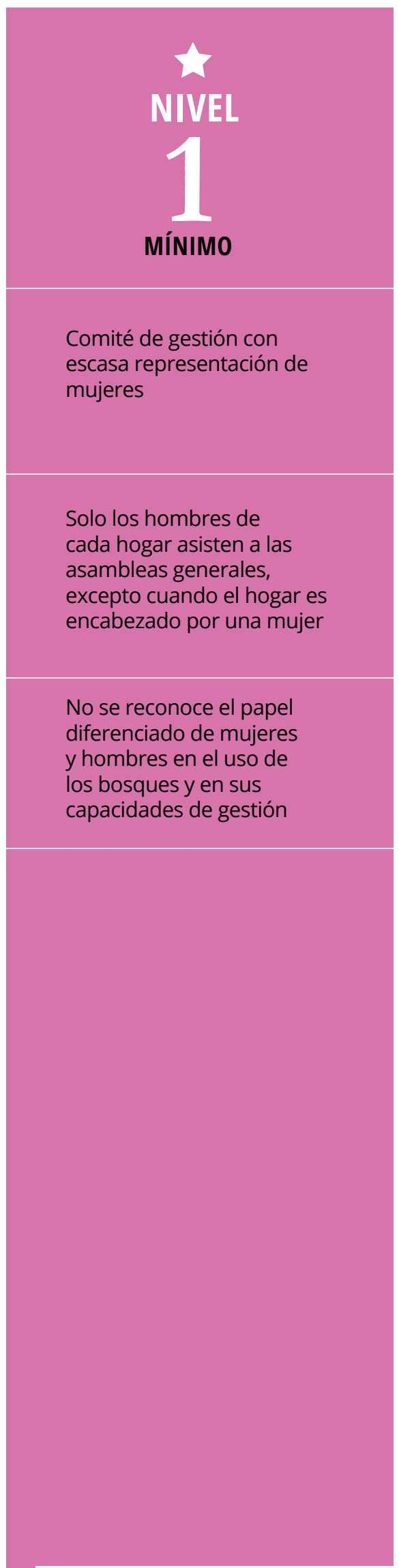

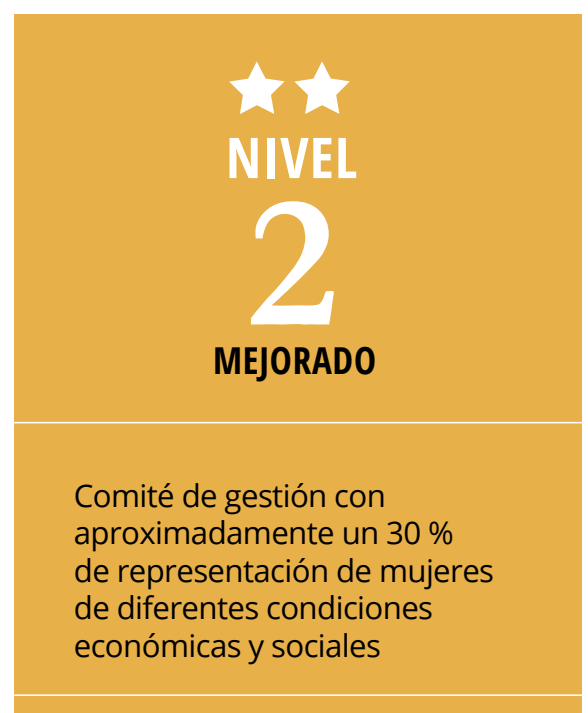

Tanto las mujeres como los hombres de cada hogar asisten a las asambleas generales

Reconocimiento formal parcial de las formas específicas en que mujeres y hombres usan y gestionan los bosques

Las mujeres y los hombres participan en la demarcación de límites y la zonificación de recursos

Las prácticas forestales reconocen las necesidades diferenciadas de productos forestales para mujeres y hombres de diversas condiciones económicas y sociales

El flujo de beneficios forestales considera de manera igualitaria las necesidades de mujeres y hombres

Las mujeres reciben capacitación en temas de liderazgo y desarrollo de capacidades para convertirse en participantes empoderadas

Figura 22. Etapas en el nivel de gobernanza con perspectiva de género de los bosques de uso común.

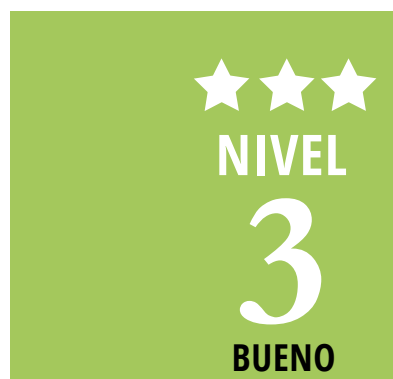

Comité de gestión con una representación cercana o mayor al $50 \%$ de mujeres de diferentes condiciones económicas y sociales

Las mujeres desarrollan relaciones horizontales con otros grupos de usuarios de los bosques y relaciones verticales con ONG, federaciones y grupos de la sociedad civil

Hay mujeres y hombres involucrados en el desarrollo del plan operativo forestal anual

Hay mujeres y hombres involucrados en el monitoreo y vigilancia de los bosques

Hay mujeres y hombres involucrados en la resolución de conflictos

Los fondos comunes están diseñados para satisfacer las necesidades colectivas de las mujeres

Hay mujeres que dirigen o están involucradas en empresas forestales (extracción, procesamiento, comercialización)

Las mujeres tienen un fuerte control sobre los ingresos que generan a partir de los productos forestales 
Cuando se promueve la igualdad de género en bosques de uso común, con demasiada frecuencia el enfoque se centra en cambiar las normas formales de los estatutos o las convenciones locales. Claramente, cambiar las normas formales mediante la institución de la gobernanza forestal es de vital importancia. Sin embargo, en la práctica, debido a que los derechos de las mujeres al acceso, uso y gestión a menudo se basan en normas socialmente aceptadas o se negocian de manera informal (mediante una combinación de compromisos a nivel comunitario, entre las propias mujeres y a nivel del núcleo familiar), puede ser que la realidad en el terreno no coincida con las normas formales o los planes de gestión. Por lo tanto, al analizar la realidad del género y la tenencia forestal en la forestería comunitaria, se debe prestar mucha atención a estas prácticas informales que conforman el "bricolaje institucional" (véase Friman 2020) y a cómo orientarlas hacia la equidad de género. Por ejemplo, las mujeres a menudo tienen que hacer pagos a los guardabosques para que les permitan ingresar a los bosques a recolectar leña y forraje, o tienen que negociar con los hombres su derecho a recolectar hojas de sal (Shorea robusta) (para la fabricación de un PFNM), mientras que estos conservan los derechos sobre la madera. Además, puede ser que, en lo que respecta a las decisiones sobre el uso de los bosques y la tierra, las mujeres cumplan un rol más importante en el hogar que en los órganos de gobernanza forestal (véase, por ejemplo, Larson et al. 2016b) ${ }^{14}$. Más allá del ámbito formal del órgano de gobernanza forestal, es esencial identificar otros espacios de toma de decisiones que influyan en los patrones de uso y gestión de los bosques. Específicamente cuando se trata de zonas de conflicto o guerra, las mujeres y los hombres están a merced del líder del territorio o área, y las organizaciones donantes o de ayuda rara vez pueden brindarles apoyo para proteger los derechos de tenencia necesarios para su subsistencia básica. En dichas zonas, es fundamental comprender lo que sucede con los derechos de tenencia para brindar ayuda humanitaria y servicios de apoyo.
En la práctica, muchas mujeres de PICL perciben que sus derechos forestales son inseguros por una serie de razones. Donde existen inseguridades de tenencia forestal de diversos tipos, hay una alta probabilidad de que se produzcan disputas (véase Oyerinde 2019 para una discusión sobre la violencia colectiva y las tierras de uso común en África). La inseguridad de la tenencia no tiene que ver solo con la ausencia de políticas o marcos jurídicos claros que apoyen los acuerdos de tenencia forestal (Doss y Meinzen-Dick 2020). Más bien, un sentimiento de tenencia "suficientemente segura" es una percepción conjunta de mujeres y hombres que se basa en una combinación de factores como la aceptación de las normas en materia de género por parte de la comunidad, el reconocimiento generalizado de los derechos de tenencia con igualdad de género o qué tan confiable es el gobierno en la implementación de leyes y políticas (Figura 23). En ocasiones, algún acontecimiento puede crear un "efecto cascada" de inseguridad, por ejemplo, cuando la tenencia forestal colectiva se ve socavada debido a una individualización y venta de tierras autorizada por el órgano de gobernanza forestal que conduce a la marginación de algunos miembros de la comunidad.

Los sistemas de tenencia forestal no son estáticos y, cuando cambian, también cambia la forma de participación en ellos y cómo se distribuyen los beneficios. Por ejemplo, cuando se inicia un proyecto de REDD+, normalmente hay diferencias importantes en cómo entienden el proyecto las mujeres y los hombres afectados (Larson et al. 2016a), y la participación de las mujeres suele ser más superficial que la de los hombres (Larson et al. 2014). Un análisis cuidadoso de la tenencia y la dinámica de género en el marco de REDD+ puede ser decisivo para aumentar el éxito de las iniciativas de REDD+ (para sistemas de tenencia consuetudinaria, véase Tebtebba 2018, por ejemplo). Hay una gran variedad de factores que pueden producir cambios en la orientación de las políticas y en las normas específicas que rigen los bosques de uso

14 Parte de la investigación inicial y más reciente sobre cuestiones de género y negociación a nivel de hogares rurales puede ser útil para entender la toma de decisiones y el empoderamiento en la forestería comunitaria. Véanse, por ejemplo, Agarwal (1997), Locke y Okali (2010) y Seebens (2011). 


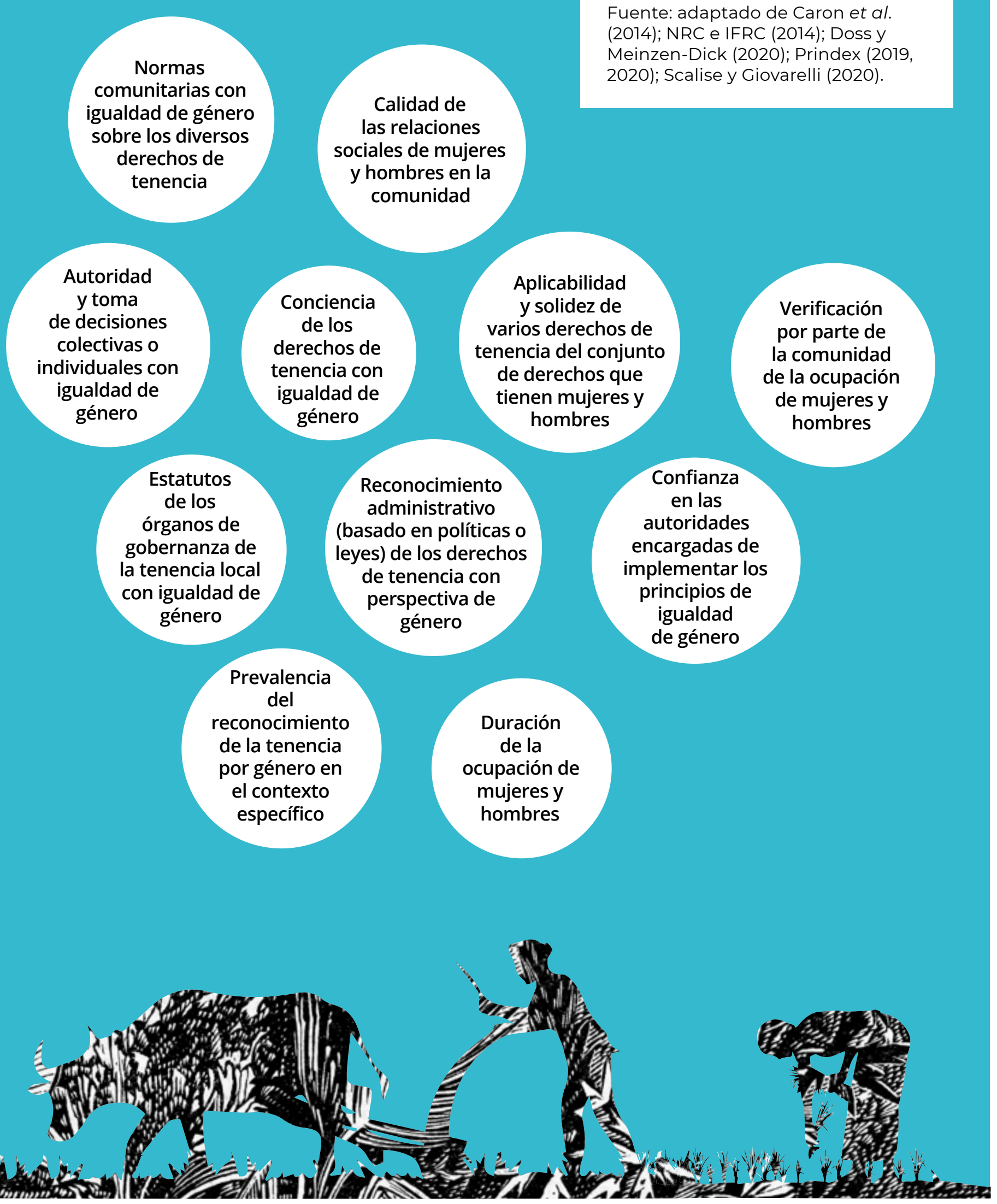

Figura 23. Factores que afectan la percepción de una tenencia forestal "suficientemente segura" para la igualdad de género

Fuente: adaptado de Caron et al. (2014); NRC e IFRC (2014); Doss y Meinzen-Dick (2020); Prindex (2019, 2020); Scalise y Giovarelli (2020).

munitarias con ce genero ciales de mujeres hombres en la 
común, entre ellos: expansión agrícola, individualización de tierras forestales, comercialización e inversión de fuentes externas, infraestructura de transporte, presiones demográficas, captura de la élite, nuevos marcos jurídicos y de gobernanza, y conflictos por recursos (Fuys et al. 2008). Por ejemplo, la emigración masculina (véase Perspectivas sobre Tenencia Forestal n. ${ }^{\circ} 8$, a continuación) de las zonas rurales puede alterar, para bien o para mal, la capacidad de las mujeres para participar en las instituciones de tenencia forestal. De manera similar, a medida que más mujeres ocupan puestos influyentes en el gobierno local o nacional, existe un interés creciente en cómo esto creará un efecto dominó positivo que ayudará a fortalecer aún más la agenda de igualdad de género en la tenencia forestal.

De cara al futuro, es necesario ir más allá de los análisis de género simplistas, de manera que una mejor comprensión de las causas y efectos de las normas y prácticas sociales diferenciadas por género pueda orientar el pensamiento estratégico (Asher y Varley 2018). En la igualdad de género, las mejoras generales no existen; por ello, hay que prestar especial atención a cómo algunas mujeres se beneficiarán y otras quedarán aún más excluidas. Aunque es obvio que se necesita tener datos desglosados por género, su función no es simplemente la de informar sobre los desequilibrios relativos, sino más bien impulsar una mayor aceleración de los avances en materia de género gracias a que se cuenta con una imagen más rica de la dinámica social y las relaciones de poder (Asher y Varley 2018).

\section{SECCIÓN 3.1}

\section{LECTURAS COMPLEMENTARIAS}

[FAO y RECOFTC] Food and Agriculture Organization y The Center for People and Forests. 2016. Mainstreaming Gender into Forestry Interventions in Asia and the Pacific. A Training Manual. Roma y Bangkok: FAO y RECOFTC.

Hecht SB, Yang AL, Sijapati Basnett B, Padoch C y Peluso NL. 2015. People in motion, forests in transition: Trends in migration, urbanization and remittances and their effects on tropical forests. Occasional Paper n. ${ }^{\circ} 42$. Bogor, Indonesia: CIFOR.

[RECOFTC] The Center for People and Forests. 2016. Ensuring Women's Participation in Forest Decision-Making. Advancing Sustainable Development Goal 5 on Gender Equality through Community Forestry in the Asia-Pacific. Annual Report 2015-2016. Bangkok: RECOFTC. 


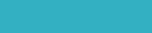

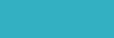

\section{1}

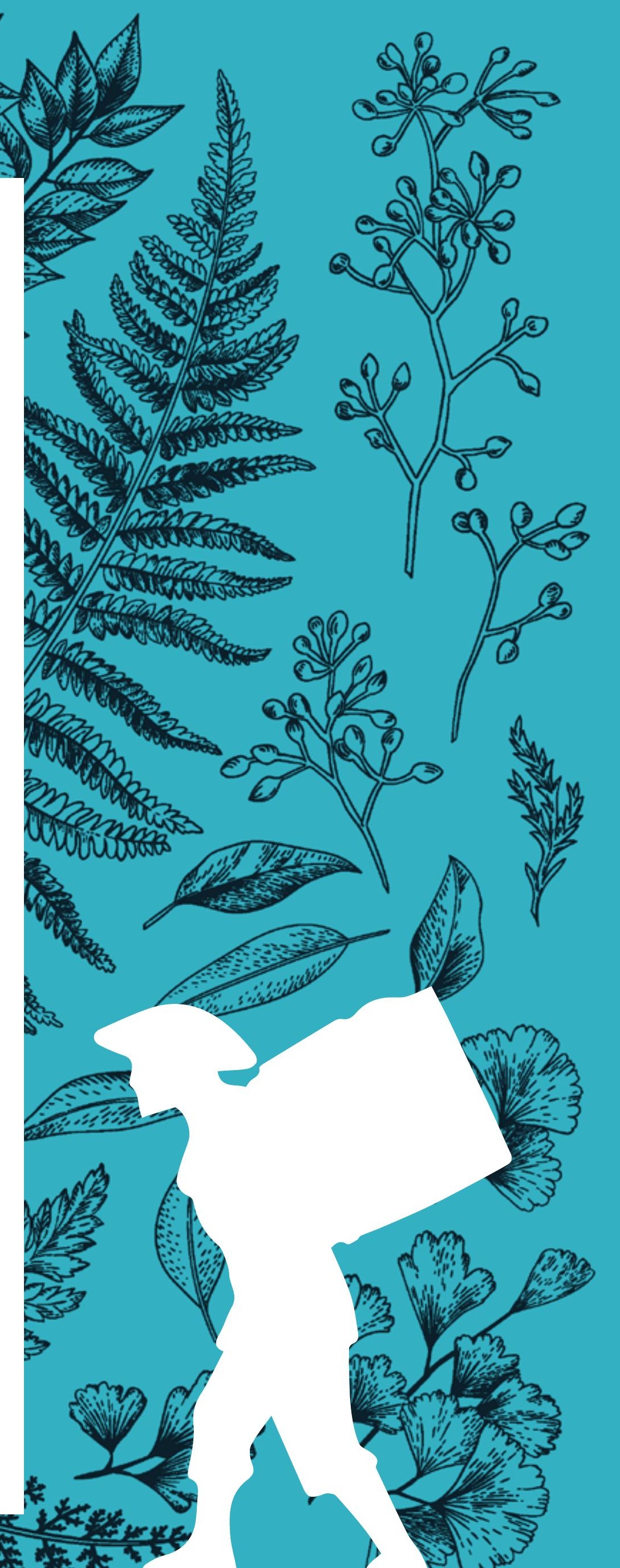

interseccionalidad de género, surge una imagen aún más compleja basada en etnias y castas (Sijapati Basnett 2016). En la aldea Bhatpole del distrito de Kavrepalanchowk, un área mayoritariamente tamang (con prácticas culturales bastante igualitarias en materia de género), la forestería comunitaria ha sido una iniciativa liderada por las mujeres desde el principio. Nueve de los 11 miembros del comité ejecutivo del CFUG eran mujeres, y la lista de usuarios del plan operativo del CFUG incluía principalmente a mujeres. En contraste, en la aldea Gharmi del distrito de Kaski, con altas tasas de emigración masculina entre los bishwakarmas (dalits) de casta baja, su impulso para crear un bosque comunitario como parte de una lucha entre castas, en un área que también incluía a los poudyals y a los khatri-chhetris, ambos de casta alta, terminó excluyendo a las mujeres de la toma de decisiones sobre temas forestales. Las comunidades de castas bajas, imitando las normas de género de las castas altas relativas al honor de la mujer y la división del trabajo, optaron por no extender las ideas de "igualdad", "derechos" o "ciudadanía" para abarcar también a las mujeres.

\section{LECCIONES}

La emigración masculina no abre de manera automática oportunidades para un mayor liderazgo y participación de las mujeres: la investigación apunta a la importancia de entender los diversos ejes de la dinámica social existente. 


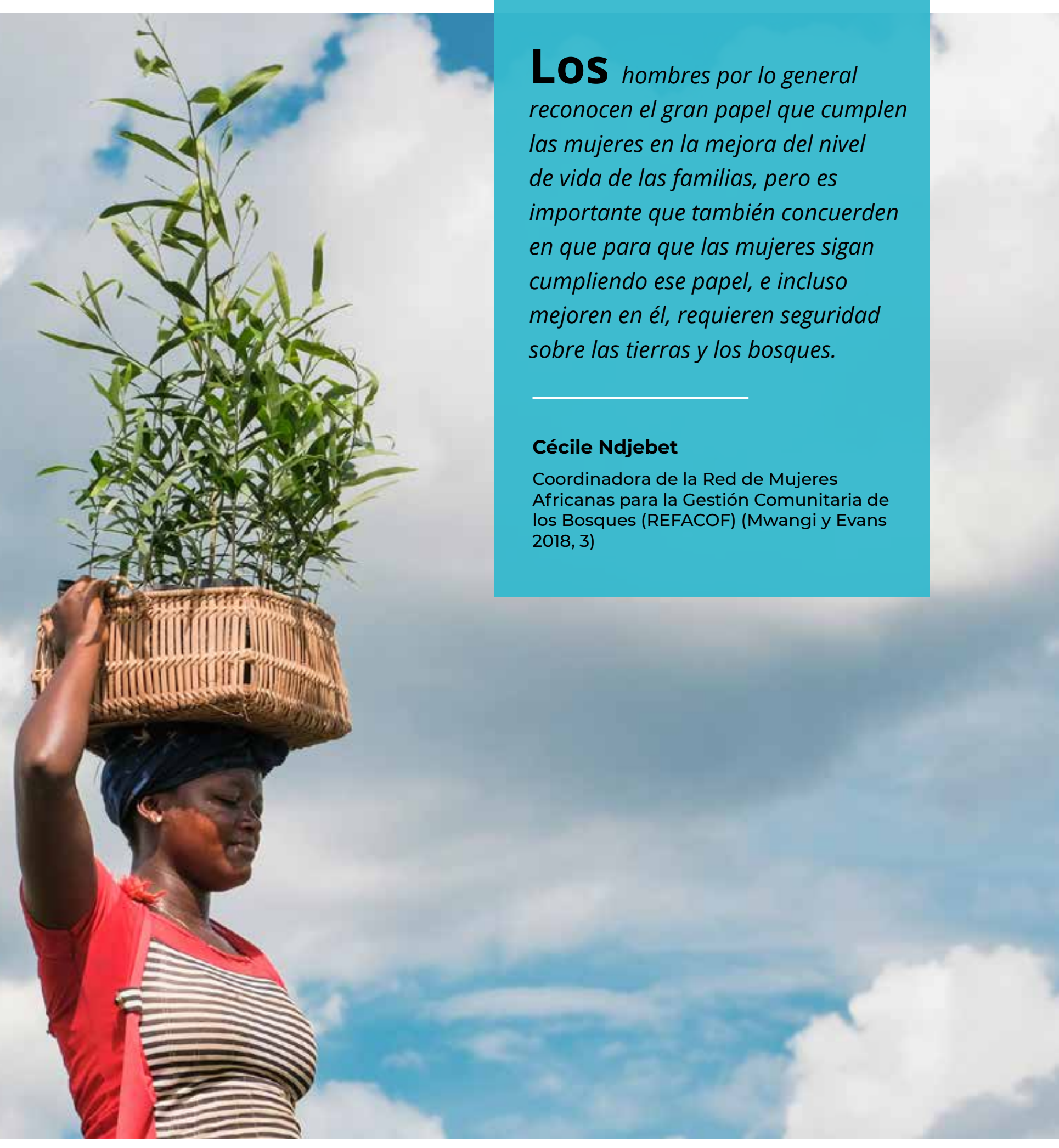




\section{2 CREACIÓN DE UNA GOBERNANZA DE LA TENENCIA CON PERSPECTIVA DE GÉNERO PARA LA FORESTERÍA COMUNITARIA}

Para lograr una gobernanza responsable de la tenencia forestal en los bosques de uso común se requieren intervenciones en varios ámbitos de acción. Estos incluyen cómo se implementan las leyes y políticas nacionales, cómo se selecciona a los miembros de las instituciones de gobernanza, cómo se identifican los objetivos de las políticas forestales locales y cómo las normas específicas sobre acceso, uso, gestión, monitoreo y sanción, y los métodos de resolución de conflictos abordan las necesidades específicas de cada género. Antes de entrar en detalles se revisarán algunos principios generales sobre cómo lograr una participación estratégica en la mejora de la tenencia forestal colectiva para la igualdad de género (Figura 24, véase también Giovarelli et al. 2016). 


\section{MANTENER EL ENFOQUE EN TODA LA COMUNIDAD}

La participación de toda la comunidad es esencial para un progreso sostenible $y$ generalizado. Los procesos e intervenciones exitosos dirigidos a un cambio sostenible y generalizado empoderan a las mujeres y fortalecen sus derechos de gobernanza como parte de un proceso continuo y colaborativo que involucra a toda la comunidad.

Involucre a los líderes comunitarios: los proyectos exitosos a menudo reciben el apoyo de líderes comunitarios, tanto hombres como mujeres.

Brinde apoyo culturalmente adecuado: las actividades exitosas implementadas por organizaciones externas a las comunidades se diseñan junto con los miembros de las comunidades, reflejan sus normas culturales y dan prioridad a su capacidad de acción.

Reconozca que el cambio social toma tiempo: las actividades exitosas dedican el tiempo suficiente a transformar las actitudes patriarcales hacia los roles de género y para que los cambios en las normas se manifiesten a favor de los derechos de las mujeres a la gobernanza de la tierra.

Figura 24. Cómo apoyar los derechos de las mujeres indígenas y rurales a la gobernanza de la tenencia de tierras forestales.

Fuente: RRI (2019). 
Resalte las valiosas contribuciones que las mujeres ya hacen a sus comunidades: visibilice el impacto positivo del trabajo de las mujeres en la gestión y conservación de las tierras de la comunidad.
Demuestre las ventajas para toda la comunidad de asegurar los derechos de gobernanza de las mujeres: las iniciativas exitosas que empoderan a las mujeres son beneficiosas también para toda la comunidad, y son presentadas como tales.
Utilice información para empoderar a las mujeres como líderes comunitarias y responsables de la toma de decisiones: las actividades exitosas usan el intercambio de información con las mujeres como base para el desarrollo de su capacidad de liderazgo y de toma de decisiones.
Cree espacios de encuentro, actividades, redes o instituciones solo para mujeres: las iniciativas exitosas a menudo facilitan redes, instituciones, actividades, espacios de encuentro o acuerdos exclusivos para mujeres.

\section{Cree redes} autosostenibles y multinivel de mujeres líderes: las actividades exitosas crean redes de mujeres líderes que participan en actividades de tutoría e intercambio de información para maximizar resultados.
Desarrolle e impulse relaciones estratégicas con diversos actores externos a las comunidades: las iniciativas exitosas se comunican y relacionan eficazmente con una gran variedad de actores externos a fin de obtener su apoyo. 
Las mujeres y los hombres de las comunidades y los gobiernos participan activamente en el diseño de planes, proyectos y políticas de gestión forestal.
Las mujeres y

los hombres, individualmente y como grupos, acceden, utilizan y se benefician por igual de los paisajes forestales.
Las mujeres y los hombres, individualmente y como grupos, obtienen ingresos por plantar árboles, cosechar de manera sostenible y proteger los paisajes forestales mediante iniciativas con equidad (PSA, certificaciones, etc.).

ALCANCE

Las mujeres y los

hombres están involucrados en actividades de gestión tales como trabajo en forestería, control de incendios, desarrollo de viveros, vigilancia y monitoreo, y resolución de conflictos.

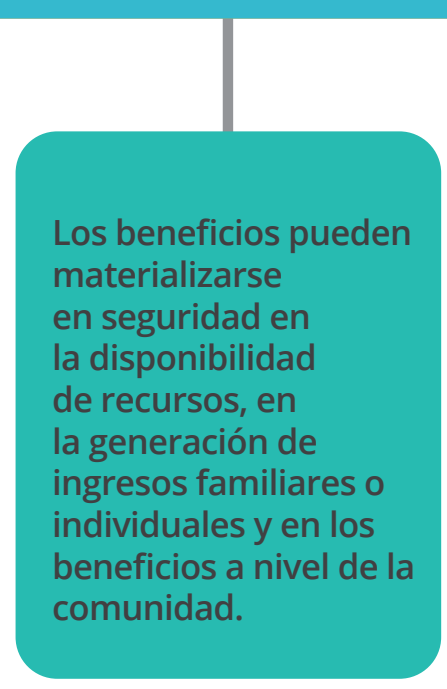

Se empodera a las mujeres en los hogares con un mayor control sobre las finanzas, la seguridad alimentaria, la educación y los derechos a los recursos.

Las mujeres tienen mayor autoridad efectiva sobre la toma de decisiones dentro de los órganos de gobernanza forestal.

Figura 25. Vías con perspectiva de género para obtener resultados

Fuente: adaptado de Johnson et al. (2018). 


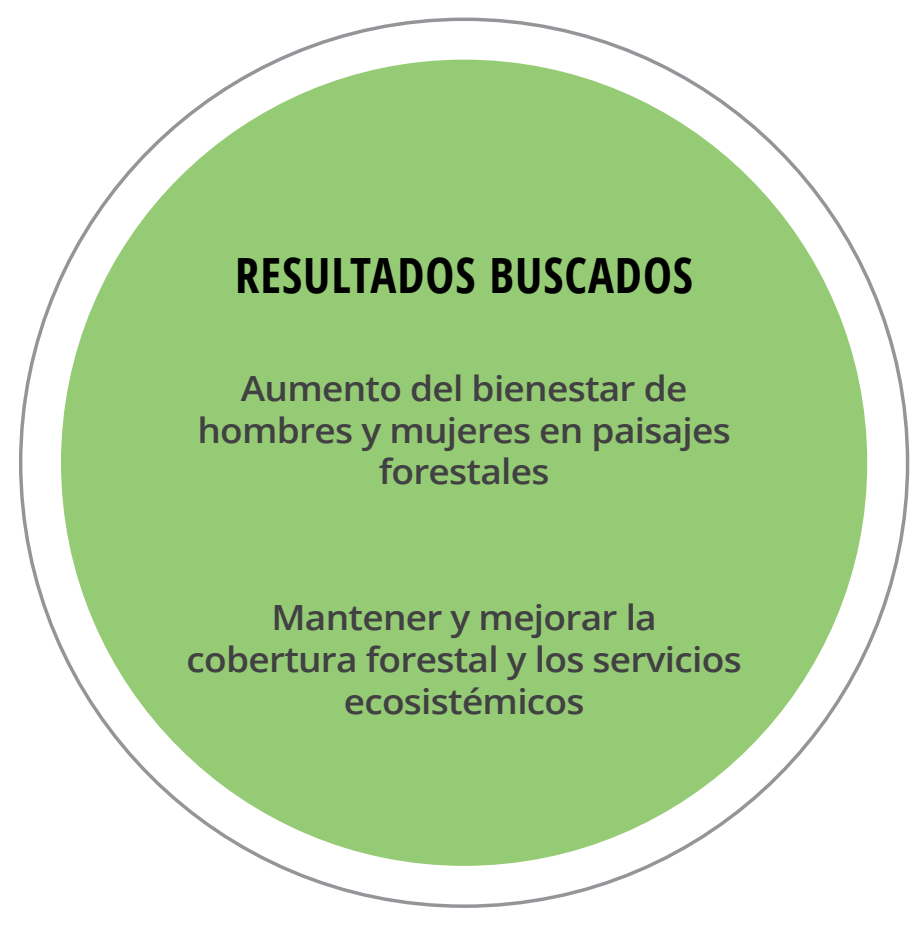

Es fundamental pensar en vías hacia el cambio para mujeres y hombres. Aunque se ha trabajado mucho para llevar a más mujeres a la mesa de toma de decisiones para que puedan impulsar cambios, es imperativo evaluar los tipos de cambios que se buscan. La Figura 25 plantea vías hacia el cambio por medio de las cuales las mujeres y los hombres que participan activamente en las actividades de gestión forestal recibirán beneficios y, por lo tanto, se empoderarán a nivel del hogar o de la comunidad. Estas tres etapas se denominan Alcance, Beneficio y Empoderamiento. La investigación indica que no existen diferencias claras en resultados basados únicamente en si los regímenes de tenencia forestal designaron tierras forestales para uso de la comunidad o si otorgaron titularidad plena a las comunidades (Larson et al. 2019a). Más bien, para lograr objetivos como la seguridad alimentaria o mejoras en los medios de subsistencia, se requiere analizar cómo funcionan determinadas intervenciones en tipos específicos de vías hacia el cambio para generar transformaciones.

Para identificar las vías hacia el cambio se requiere examinar con detenimiento el tipo de empoderamiento de las mujeres que se busca. El empoderamiento de las mujeres tiene muchas dimensiones, como la producción, la toma de decisiones a nivel de la comunidad, la autoridad sobre las decisiones del hogar, los ingresos individuales y familiares, el liderazgo en la comunidad y la reducción de las sobrecargas de tiempo y trabajo (Figura 26). 


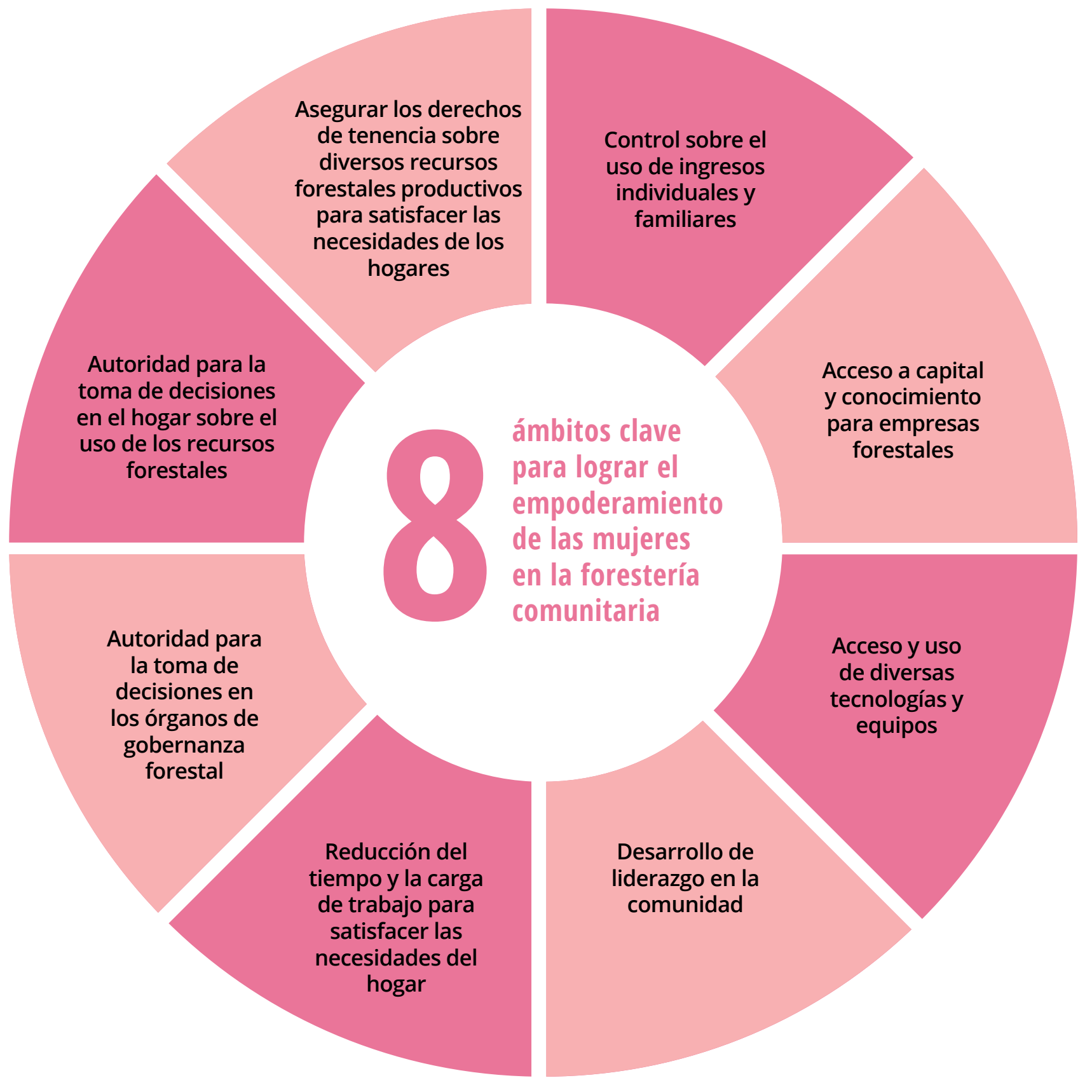

Figura 26. Ocho ámbitos clave para el empoderamiento de las mujeres en la forestería comunitaria 
Antes de entrar en detalles sobre vías hacia el cambio e intervenciones específicas, es necesario abordar el tema central de la dinámica de poder en la creación de un cambio transformador en materia de género. La dinámica de poder a nivel del hogar, la comunidad y la aldea desempeña un papel central en determinar cómo se llevan a cabo las prácticas cotidianas en los bosques, cómo se utilizan los recursos forestales, cómo se toman las decisiones sobre los productos forestales en los hogares y cómo se implementa la gobernanza. Cualquier intento de crear transformaciones positivas que conduzcan a la igualdad de género probablemente encuentre resistencia entre quienes están interesados en mantener la situación actual. Para entender lo que está en juego se requiere hacer un análisis objetivo de la interseccionalidad de género: es decir, los diversos ejes de discriminación estructural presentes en las prácticas de todo hogar o comunidad. Esto implica examinar las normas sociales predominantes, las relaciones jerárquicas, cómo se lleva a cabo normalmente la toma de decisiones y qué tipos de conflicto son los más comunes. Además, ¿cuáles son las relaciones y redes en las que los más poderosos y los menos poderosos ejercen su influencia y cultivan beneficios para ellos o sus familias? Por medio de este proceso, los enfoques creativos e inspiradores que crean alianzas entre mujeres, y entre hombres y mujeres, y estimulan el surgimiento de personas de ambos géneros que asumen el papel de líderes, pueden generar fuerzas positivas que permitan la participación gradual de todos. Es esencial contar con una comunicación sensible y cuidadosamente diseñada que permita llevar a todos los actores a la mesa de discusión para identificar metas y enfoques realistas. Es ideal aprovechar lo ya existente, antes que crear nuevas iniciativas que requieran grandes inversiones de tiempo y dinero para la preparación del trabajo de campo. Independientemente de cómo se lleve a cabo esta labor, es primordial contar con un enfoque optimista que esté alineado con la reflexión estratégica sobre cómo generar cambios equiparando los activos y la autoridad para la toma de decisiones entre mujeres y hombres.

Un enfoque de manejo adaptativo y colaborativo (ACM, por sus siglas en inglés) puede ayudar a abordar los diversos desafíos a los que se enfrenta el proceso de cambio. El ACM tiene un estilo iterativo que básicamente sigue el conjunto de pasos Analizar, Definir estrategias e Implementar estrategias, centrados en la reflexión y el aprendizaje (Mukasa et al. 2016; Evans et al. 2014, 2017). El ACM es un viaje de aprendizaje en el que los facilitadores trabajan con las comunidades siguiendo estos pasos.

Una reflexión detenida sobre el diseño de la intervención puede producir múltiples beneficios (Figura 27). Esta tabla se divide en dos secciones principales: una está relacionada con las intervenciones centradas en la institución u órgano de gobernanza forestal, y la segunda está relacionada con intervenciones más generales para toda la comunidad. Dada la diversidad de los ámbitos de acción involucrados, se requiere una preparación estratégica para determinar qué necesita atención prioritaria y cómo implementar la secuencia de intervenciones. Se sabe que un compromiso firme a nivel de la comunidad, con un espacio adecuado para discusiones secuenciadas y trabajo iterativo, produce resultados considerablemente mejores que los de un enfoque exhaustivo de una sola aplicación. 


\section{GOBERNANZA RESPONSABLE \\ DE LA TENENCIA FORESTAL}

\section{CREAR UNA GOBERNANZA LOCAL RESPONSABLE DE LA TENENCIA FORESTAL}

\section{C \\ POLIITICAS Y LEYES HABILITADORAS
; La Constitución, las políticas y leyes
nacionales o subnacionales prohíben la discriminación basada en el sexo? ¿Establecen la igualdad de derechos entre mujeres y hombres? ¿Existe alguna disposición en la ley mujeres que deben tener los comités ejecutivos locales de gobernanza forestal? ¿Hay algo estipulado sobre distribución de beneficios con igualdad de género? forestal que indique la proporción de miembros}

Los órganos locales de gobernanza forestal pueden proporcionar evidencia empírica y apoyar investigación orientada a la acción acerca de cómo la igualdad de género en la tenencia forestal crea un efecto acelerador para varios objetivos de desarrollo. Esto puede respaldar la formulación de políticas y la reforma jurídica.

Los órganos locales de gobernanza forestal pueden crear y unirse a alianzas ya existentes para la reforma de las políticas y leyes de tenencia forestal en temas como la representación proporcional en los órganos de gobernanza forestal, la distribución de beneficios entre mujeres y hombres, y la igualdad de género en CLPI.
REPRESENTACIÓN DE GÉNERO IGUALITARIA EN EL ÓRGANO DE GOBIERNO FORESTAL

; Todos los hombres y mujeres de la comunidad pueden convertirse en miembros del órgano de gobernanza forestal comunitaria? ¿Existe el requisito de que entre el 30 y el $50 \%$ de los miembros del comité ejecutivo sean mujeres? ¿Se estipula que los puestos titulares deben rotar entre mujeres y hombres? ¿Las mujeres también tienen autoridad para administrar los fondos forestales de uso común?

\section{Realice actividades de sensibilización y
enmienda de estatutos para que el órgano
de gobernanza forestal local pueda emitir
un mandato acerca de cómo lograr la
representación con igualdad de género
(en sus múltiples formas). \\ Realice actividades de sensibilización y
enmienda de estatutos para que el órgano
de gobernanza forestal local pueda emitir
un mandato acerca de cómo lograr la
representación con igualdad de género
(en sus múltiples formas). \\ Realice actividades de sensibilización y
enmienda de estatutos para que el órgano
de gobernanza forestal local pueda emitir
un mandato acerca de cómo lograr la
representación con igualdad de género
(en sus múltiples formas). \\ Realice actividades de sensibilización y
enmienda de estatutos para que el órgano
de gobernanza forestal local pueda emitir
un mandato acerca de cómo lograr la
representación con igualdad de género
(en sus múltiples formas). \\ Realice actividades de sensibilización y
enmienda de estatutos para que el órgano
de gobernanza forestal local pueda emitir
un mandato acerca de cómo lograr la
representación con igualdad de género
(en sus múltiples formas). \\ Realice actividades de sensibilización y
enmienda de estatutos para que el órgano
de gobernanza forestal local pueda emitir
un mandato acerca de cómo lograr la
representación con igualdad de género
(en sus múltiples formas).}

\section{MEMBRESIÍA GENERAL EN EL RÉGIMEN FORESTAL BAJO TENENCIA COLECTIVA}

- Existe una asamblea general en la que - participen todos los miembros del régimen de tenencia forestal colectiva? Si es así, ¿pueden participar en ella todos los miembros adultos de los hogares, tanto hombres como mujeres? ¿La hora y el lugar de las reuniones son adecuados para mujeres y hombres, tanto para los que viven cerca como para los que viven lejos? 


\section{TOMA DE DECISIONES DE GOBERNANZA FORESTAL}

- Cuál es el proceso de toma de decisiones?

¿Existe un conjunto de normas o estatutos que incluya el paquete completo de derechos de tenencia sobre recursos forestales de alto y bajo valor? ¿Son sólidos y duraderos? ¿Reconocen los diferentes tipos de derechos que las mujeres y los hombres necesitan para gestionar de manera sostenible los recursos forestales, crear medios de subsistencia y dirigir empresas? ¿Cómo se actualizan los estatutos? ¿La mayoría de las personas de la comunidad participan en la toma de decisiones sobre cambios en los estatutos?

\section{OBJETIVOS DE POLÍTICAS DE LA GOBERNANZA FORESTAL}

- Cuáles son los objetivos de políticas del órgano de gobernanza forestal? ¿Reconocen estos objetivos los usos multifuncionales del área forestal? ¿Cómo utilizan mujeres y hombres los diferentes recursos y zonas del bosque? ¿Cómo se relacionan los objetivos de la gestión forestal con el cambio climático, el crecimiento de los mercados y los cambios en los objetivos nacionales de desarrollo?
Capacite a las mujeres sobre políticas y leyes relevantes para que puedan participar con conocimiento de causa en las reuniones del comité ejecutivo.

Capacite a las mujeres en cómo gestionar comités ejecutivos y asambleas generales con un enfoque que permita introducir y lograr cambios en favor de la igualdad de género.

Brinde a las mujeres habilidades para participar de manera eficaz en la toma de decisiones, capacitándolas para hablar y debatir en público, de manera que puedan lograr los objetivos que buscan y aumentar su autoconfianza.

Asegúrese de que todas las mujeres y hombres entiendan la importancia de organizar reuniones que tomen en cuenta los compromisos de tiempo, los requisitos de movilidad y las normas culturales para que las mujeres puedan participar con comodidad.

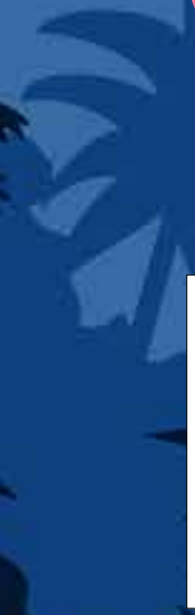

\section{ron comodidad.}

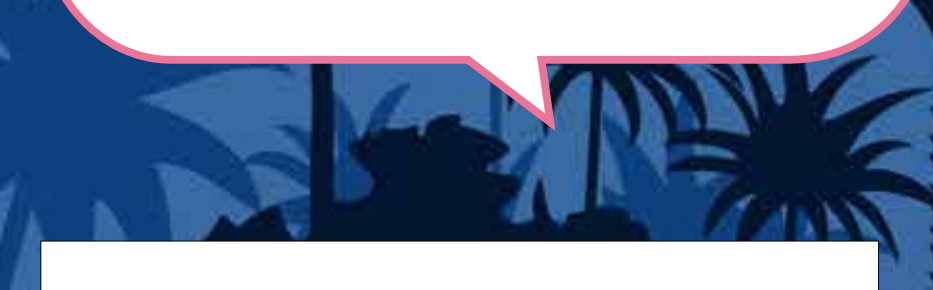

Figura 27. Diseño de intervenciones para un cambio sensible al género en la gobernanza local responsable de la tenencia forestal

Fuente: Adaptado de Ostrom (1990); Fuys et al. (2008); Caron et al. (2014); FAO (2016a); Gilmour (2016); Mayers et al. (2016).

\section{DISCRIMINACIÓN, POBREZA Y BIENESTAR}

Córgano de gobernanza forestal para entender los patrones de discriminación, pobreza y bienestar en la comunidad?

Organice una serie escalonada de talleres para la identificación de objetivos de políticas mediante el aporte de todos los actores clave de un régimen forestal bajo tenencia colectiva; recurra a un facilitador que sea sensible a cuestiones de género. 


\section{LÍMITES DE LOS BOSQUES DE USO COMÚN}

- Están claramente definidos los límites geográficos del régimen forestal bajo tenencia colectiva? ¿Fueron trazados estos límites con la participación de mujeres y hombres de la comunidad? ¿Involucran a una aldea o a un conglomerado de aldeas, o a un grupo de hogares que dependen de un área forestal en particular? ¿Está disponible este mapa (en papel o en formato digital) en la oficina del régimen forestal colectivo o en el gobierno local? ¿Existen recursos audiovisuales asociados con el mapa que reflejen áreas (o zonas) forestales que las mujeres y los hombres suelen utilizar de diferentes formas?
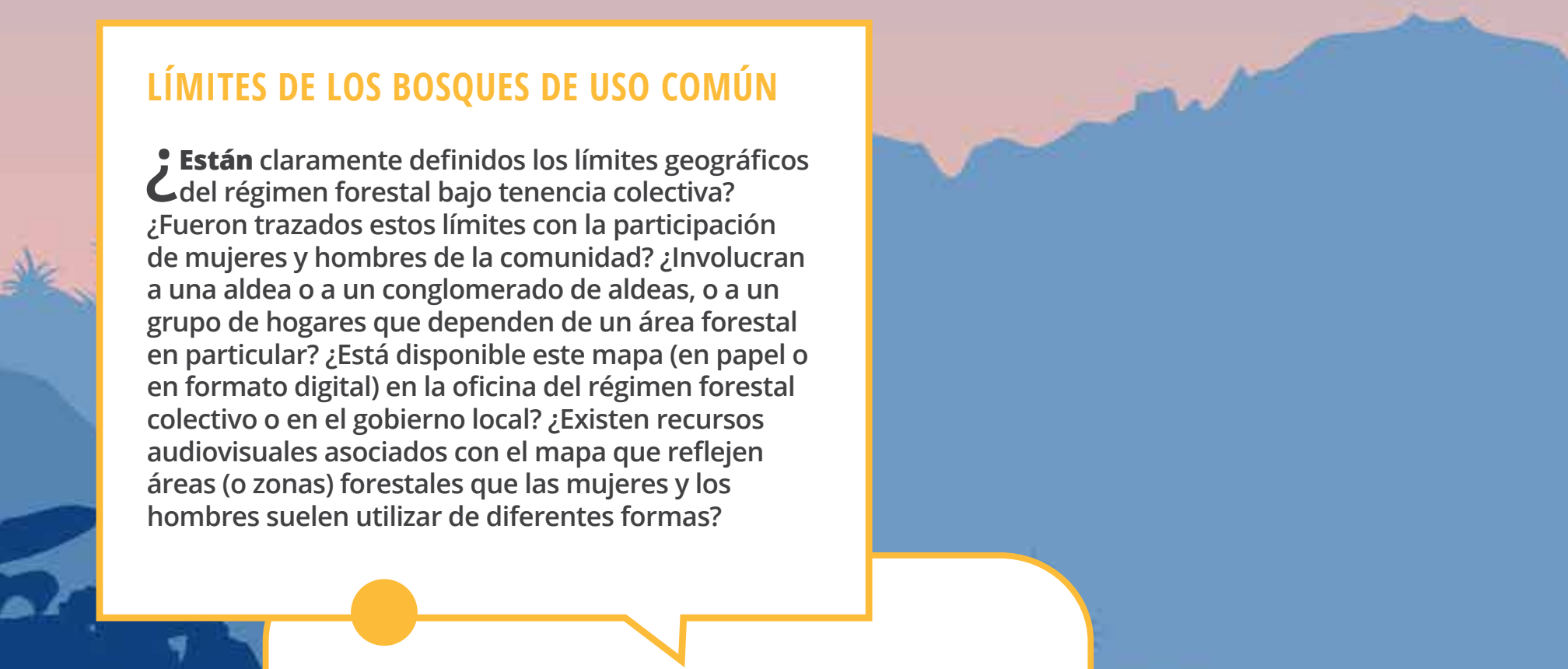

Realice un mapeo participativo (junto con una ONG) que involucre por igual a mujeres y hombres que aporten conocimiento para la consulta inicial, contribuyan con la preparación de mapas, y participen como cartógrafos y como analistas de datos.

Asegúrese de conservar el mapa y los datos audiovisuales en un lugar al que todos puedan acceder a un bajo costo.

\section{DERECHOS DE REGISTRO}

- Los estatutos (con mapas asociados y planes Cde manejo forestal) y la lista de miembros del régimen forestal bajo tenencia colectiva se encuentran incluidos en el registro de tenencia local o digital? ¿Es accesible para todos a un bajo costo? 


\section{NORMAS OPERATIVAS PARA EL DÍA A DÍA}

\section{PLAN DE GESTIÓN FORESTAL}

- Están tanto las mujeres como

Clos hombres involucrados en la preparación de un plan de gestión forestal? ¿Existe un entendimiento claro y consensuado sobre cómo se ponen en práctica los usos y métodos de gestión de los bosques por parte de hombres y mujeres (véase Ombogoh y Mwangi 2019)? ¿Se requieren encuestas socioeconómicas a nivel de hogares para obtener una imagen más precisa de la situación?
Documente el conocimiento de mujeres y hombres sobre diferentes áreas y árboles del bosque y sus recursos, así como sobre adaptación y mitigación del cambio climático.

Determine si existe correspondencia entre las condiciones ecológicas locales y las diversas normas sobre uso y gestión de mujeres y hombres.

Involucre a las mujeres en el manejo forestal y en el desarrollo de planes operativos forestales.

Fomente activamente desde un comienzo la participación de las mujeres en la planificación de proyectos específicos, como REDD+, PSA o de adaptación (véase FAO 2018b).

\section{NORMAS DE TENENCIA DE LOS BOSQUES}

Cobre la base del plan de gestión forestal, será necesario establecer en el conjunto de derechos de tenencia una serie del normas estatutarias acerca de acceso, uso, gestión, monitoreo, resolución de conflictos, alienación, etc. ¿Las diversas normas de tenencia se ajustan a las condiciones ecológicas y socioeconómicas? ¿Son claras las normas respecto a los momentos y lugares, el nivel de explotación y la tecnología que se pueden utilizar para un uso y un manejo sostenibles?

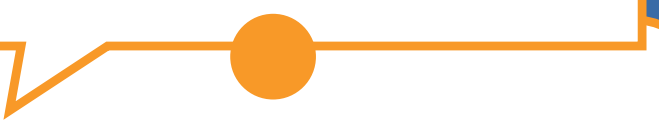

Desarrolle un proceso de varias etapas en el que primero se enumeren en voz alta las normas existentes que afectan a mujeres $y$ hombres, luego revise cada una dos o tres veces, y finalmente incluya un nuevo conjunto de normas en los estatutos; es importante crear conciencia acerca de los principios de las VGGT durante este proceso.

VGGT durante este proceso.

\section{DISTRIBUCIÓN DE BENEFICIOS}

- Cómo se distribuyen los múltiples beneficios que brindan los diferentes recursos de los bosques, incluida la conservación del agua a cargo de mujeres y hombres de la comunidad pertenecientes a diferentes condiciones sociales y en diferentes espacios geográficos? ¿Se acumulan estos beneficios para los individuos, los hogares o la comunidad en su conjunto? 


\section{MONITOREO}

Quién se encarga de monitorear el

estado del bosque y el cumplimiento de los estatutos en diferentes áreas?

¿Cómo se identificará a quienes incumplan los estatutos? ¿Qué acciones se tomarán a continuación? ¿Tienen las mujeres mayor capacidad para identificar a otras mujeres que incumplen las normas?

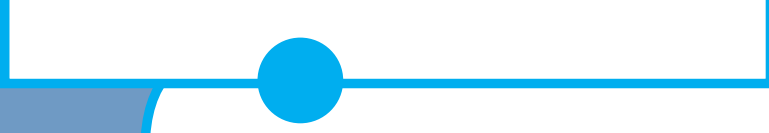

Asegúrese de que en la vigilancia y el monitoreo participen tanto mujeres como hombres mediante la creación de equipos separados por género con responsabilidades específicas.

\section{MECANISMOS DE RESOLUCIÓN DE CONFLICTOS}
- Existen tipos comunes de disputas que ocurren con frecuencia? ¿Cómo se abordan las disputas pequeñas y los conflictos más grandes? ¿Tiene el comité ejecutivo la capacidad de abordar estos problemas de una manera económica? ¿Son estos mecanismos sensibles a las necesidades de género, de manera que las mujeres puedan hablar y expresar sus preocupaciones?

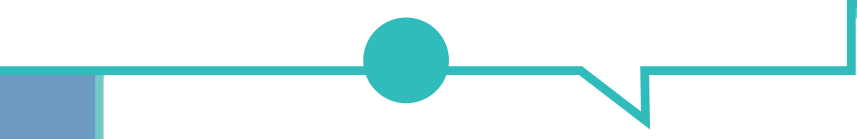

Incluya a mujeres en todo órgano de resolución de conflictos (idealmente a las que participan en labores de monitoreo), o asegúrese de contar con órganos de resolución de conflictos integrados solo por mujeres para abordar los casos de mujeres que incumplen las normas; bríndeles capacitación para que puedan mejorar sus competencias técnicas y cumplir eficazmente con sus responsabilidades.

\section{SANCIONES GRADUALES}

Q Qué tipo de sanciones se

Cimpondrán a quienes violen los estatutos? ¿Existe un conjunto de sanciones graduales relacionadas con el nivel de gravedad y el contexto de la infracción?

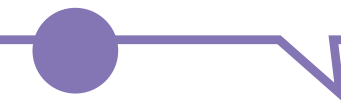

Anualmente, destine un momento a reflexionar acerca de las sanciones graduales establecidas para evaluar si satisfacen las necesidades de mujeres y hombres con diferentes tipos de dependencia del bosque.

\section{REDES Y CONEXIONES A NIVEL NACIONAL O DEL PAISAJE}
- El órgano de gobernanza forestal
local tiene vínculos formales o informales con otros órganos de gobernanza a nivel del paisaje, o con federaciones a nivel nacional? ¿Reciben las mujeres la misma cantidad de información relacionada con el paisaje forestal que los hombres?

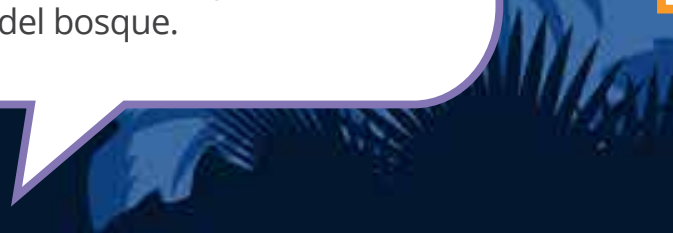

Explore oportunidades para mujeres y hombres integrantes del órgano de gobernanza forestal local para desarrollar conexiones de trabajo en red con otros organismos de gobernanza forestal a nivel del paisaje o a nivel nacional. 
¿ En qué medida el órgano de gobernanza

de la tenencia tiene autonomía para diseñar, implementar y abordar las nuevas necesidades en materia de género a medida que surgen? ¿Existe un alto o bajo nivel de participación del gobierno en el régimen forestal de tenencia colectiva? ¿Los funcionarios del gobierno son sensibles a los asuntos de género?

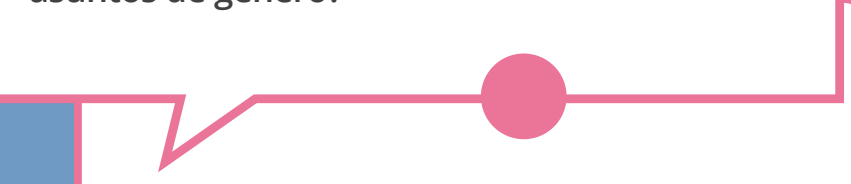

Organice reuniones con el personal del gobierno local (que tenga autoridad y poder de toma de decisiones) acerca de una serie de necesidades emergentes de mujeres y hombres, para que comprenda la importancia de la autonomía para una gestión forestal exitosa.

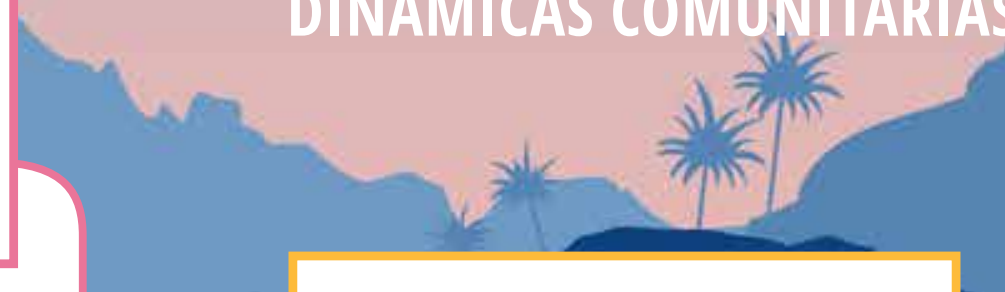

\section{TRABAJO CON EL GOBIERNO LOCAL}

\section{- Los miembros de la} comunidad tienen confianza en que el gobierno implementará de manera eficaz las leyes $y$ políticas, en especial las que promueven la igualdad de género? ¿Existe una buena prestación de servicios en términos de apoyo técnico para la gestión forestal, aplicación

\section{INTERACCIÓN CON PROMOTORES E} INVERSIONISTAS EXTERNOS DE PROYECTOS

En aquellos lugares con presencia de Epromotores e inversionistas externos de proyectos a nivel local, ¿existe una comprensión cabal de cómo implementar el principio de CLPI con igualdad de género (FAO 2014a; Coleman 2019)? ¿Existen principios establecidos en los estatutos para la gestión colaborativa de proyectos, así como modelos de contratos para acuerdos con inversionistas (véase FAO 2015b, 2016d)?

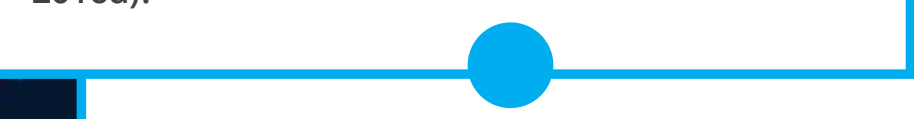

Brinde capacitación sobre la importancia del CLPI con igualdad de género en el contexto de proyectos de donantes que cubran temas como forestería comunitaria, REDD+ e iniciativas de PSA. de la legislación forestal o incubación de empresas para el desarrollo empresarial?

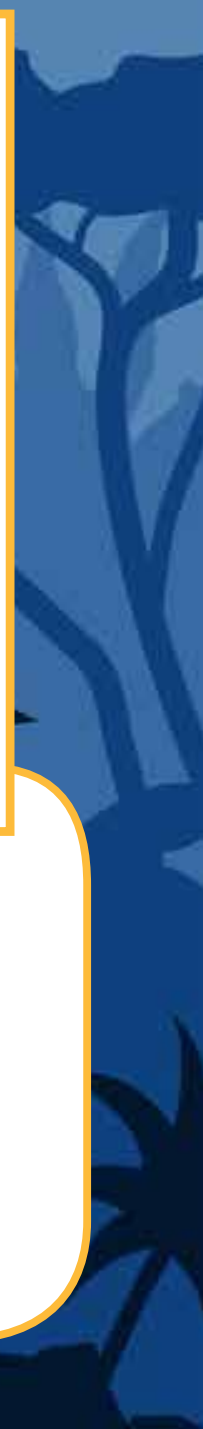

Cuando haya inversionistas en busca de oportunidades, trabaje con una ONG para identificar la mejor forma de lograr el compromiso preliminar y las negociaciones posteriores, así como para preparar acuerdos de inversión que aborden la equidad de género. 


\section{EDUCACIÓN, SENSIBILIZACIÓN Y CAPACITACIÓN}

\section{CAMBIO DE LAS NORMAS DE GÉNERO}

- Cuáles son las normas de género

$C$ predominantes entre los diferentes grupos de la comunidad, clasificados por estatus? ¿Cómo afectan la manera en que mujeres y hombres pueden acceder a y utilizar los bosques? ¿Cómo afecta esto la participación de las mujeres en las reuniones de gobernanza? ¿Quiénes son los nuevos referentes para las niñas y las mujeres jóvenes, y para los niños y los hombres jóvenes?

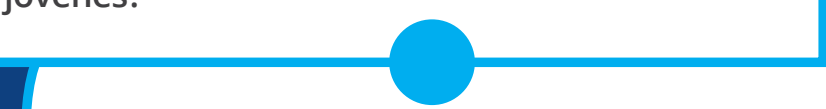

Cambie las normas de género mediante un esfuerzo gradual y sostenido a lo largo de numerosas intervenciones, como diálogos inclusivos con líderes comunitarios y religiosos influyentes; difusión de mensajes específicos por medio de la radio y el teatro; recompensas a los logros públicos, etc. Esto requiere un enfoque que transmita la importancia de la inclusión y la igualdad de género entre mujeres y hombres de diferentes orígenes.

Se pueden establecer programas de tutoría para apoyar a hombres y mujeres jóvenes que estén asumiendo un papel activo en la gobernanza y la gestión forestal.

\section{CAPACITACIÓN E INCUBACIÓN DE EMPRESAS}

; Apoya el marco regulatorio Cla entrada de las mujeres a la creación de empresas forestales? ¿Existe algún incentivo que apoye a las mujeres en el proceso de registro o mediante exoneraciones tributarias? ¿Tienen las mujeres de la comunidad la oportunidad de unirse a capacitaciones sobre cómo iniciar una empresa forestal? ¿Pueden participar en visitas de estudio a otras comunidades con empresas forestales rentables? ¿Se brinda capacitación sobre cómo administrar una empresa? ¿O sobre tecnologías para el procesamiento de productos forestales? ¿Existe algún centro de incubación de empresas que preste atención a las necesidades diferenciadas por género?

de




\section{REDUCCIÓN DE OBSTÁCULOS PARA UNA PARTICIPACIÓN EFICAZ}

\section{REDUCIR LA CARGA}

\section{LABORAL Y DE TIEMPO}

¿ Qué áreas específicas de intervención pueden ayudar a reducir las enormes responsabilidades que las mujeres tienen en el hogar, como cocinar, recolectar combustible, cuidar a los niños, cuidar a los ancianos, cuidar el ganado, etc.?
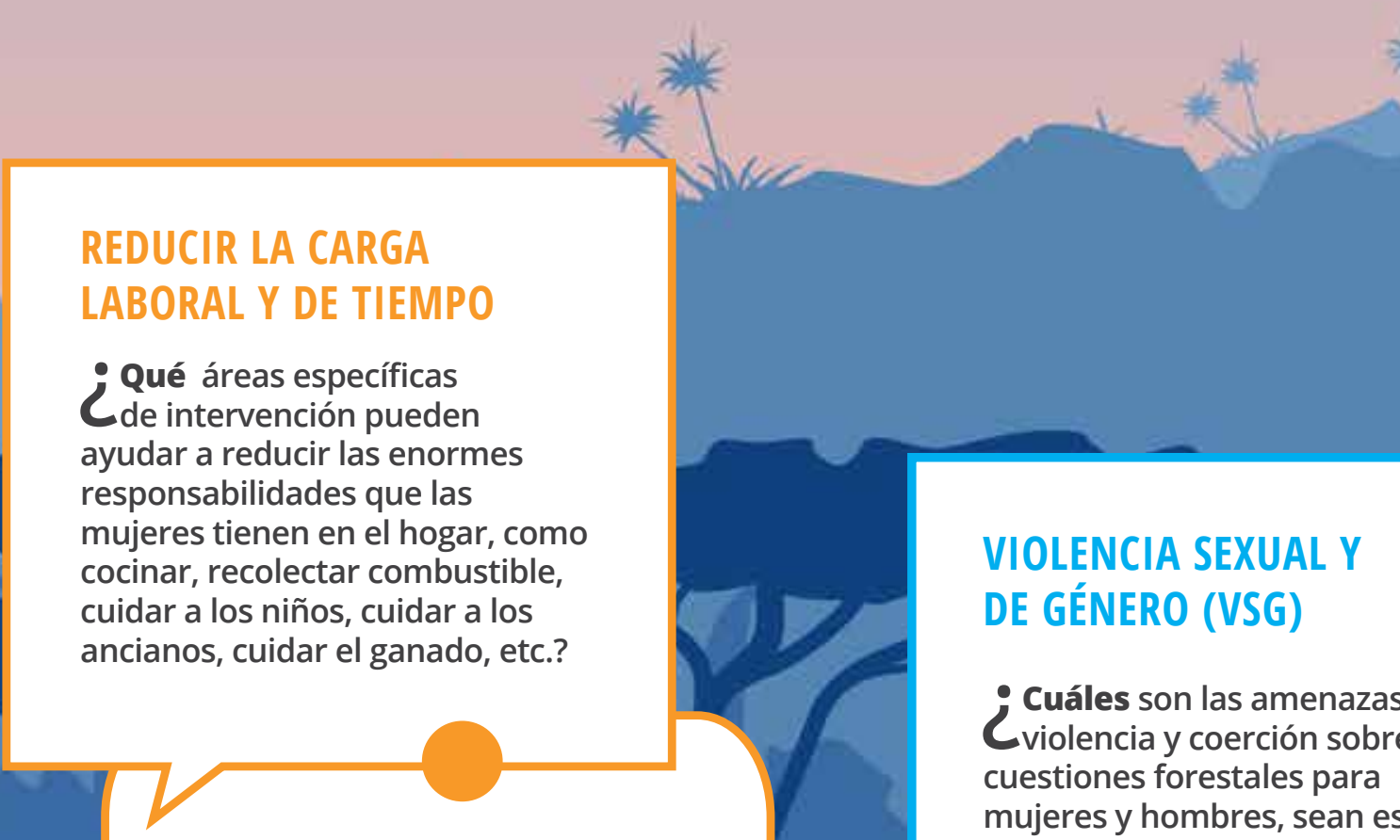

Desarrolle una investigación orientada a la acción sobre las intervenciones que mujeres y hombres consideran prioritarias para reducir la carga de trabajo del hogar y el tiempo dedicado a la recolección de recursos forestales. Esto sentará las bases para elegir las mejores acciones de apoyo. 
LO QUE DICE LA INVESTIGACIÓN: ¿Por qué es importante la participación de las mujeres en los bosques de uso común?

\section{PREGUNTA DE REFLEXIÓN}

\section{¿Qué tan importante es la participación de las mujeres como miembros de los comités de gobernanza forestal para el logro de la igualdad de género?}

Desde principios de la década de 2000, el tema predominante de la investigación sobre género y gobernanza forestal bajo tenencia colectiva ha sido la participación de la mujer (Mai et al. 2011; véase también Asher y Varley 2018 para una actualización). Desde hace mucho se considera que el aumento de la participación de las mujeres en la gobernanza forestal local es la piedra angular del cambio transformador en materia de género. La idea central es que si un número suficiente de mujeres tienen una participación activa y eficaz, inevitablemente se producirán mejoras en la igualdad de género. La representación con igualdad de género no solo conduciría a beneficios para mujeres de diferentes condiciones sociales, también generaría normas que beneficiarían a todos los miembros de la comunidad.

El trabajo de la economista india Bina Agarwal sobre cuestiones de género y forestería comunitaria en el sur de Asia ha tenido gran influencia en abrir la puerta a esta discusión. Frente a exageraciones optimistas sobre la mejora de la participación de la mujer en la gobernanza forestal, su interpretación crítica de lo que denominó "exclusiones participativas" (es decir, exclusiones dentro de instituciones en apariencia participativas) (Agarwal 2001, 1623) llevó a un examen profundo del nivel de participación real de la mujer en los bosques de uso común. Para ayudar a esclarecer las cosas, Agarwal desarrolló una tipología que diferencia los niveles de participación de la mujer en la forestería comunitaria, que aún se utiliza con frecuencia hoy en día (Figura 28). Esta tipología apunta a la importancia de comprender cuán resueltas e influyentes pueden ser las mujeres al participar en los órganos de gobernanza. No es raro que las mujeres tengan una participación mayoritaria y expresen sus opiniones con firmeza y aun así sean ignoradas, como en el caso del proyecto Lam Dong de REDD+ en Vietnam (Gurung y Setyowati 2012). Al mismo tiempo, la participación implica más que simplemente la manera en que expresan sus opiniones en los foros de toma de decisiones: las enormes responsabilidades domésticas que enfrentan significan que, con frecuencia, solo las mujeres de la élite tengan tiempo para participar en esas reuniones.

Un tema complementario tiene que ver con la "masa crítica": ¿qué proporción de mujeres se necesita en un órgano colectivo de toma de decisiones forestales para apoyar la representación con igualdad de género y, por lo tanto, para mejorar los bosques, los medios de subsistencia y la generación de ingresos? Aunque se han realizado investigaciones sobre este tema desde hace unos 20 años, todavía no hay consenso. Algunos estudios han demostrado que un aumento de la participación de las mujeres hasta aproximadamente el $30 \%$ de los miembros de los órganos de gobernanza de los grupos de usuarios forestales en el sur de Asia ha producido mejoras en la gestión de los recursos forestales y en la equidad distributiva, a menudo asegurando un mayor cumplimiento de las normas (Agarwal 2010, 2017). Además, la presencia de mujeres de mayor edad en los comités ha tenido un efecto positivo. Esta investigación 


\section{GÉNERO, MAPEO PARTICIPATIVO Y TENENCIA FORESTAL COMUNITARIA}

Con un enfoque tan centrado en mejorar la participación de las mujeres en la gobernanza de la tenencia forestal, es fácil olvidar otras intervenciones esenciales que también son necesarias para mejorar la igualdad de género.

El establecimiento de los límites de los bosques de la comunidad, así como el mapeo de sus recursos, es un paso fundamental para aclarar y hacer valer los derechos de tenencia forestal. Si bien el mapeo participativo ha crecido a pasos agigantados en los últimos 30 años, las diversas formas en que las mujeres pueden participar en la creación y análisis de mapas están ganando cada vez más importancia (IFAD 2009; Tebtebba 2013). Estos mapas pueden utilizarse para documentar en términos geoespaciales las relaciones de tenencia; por ejemplo, para crear un catastro ciudadano, demarcar tierras consuetudinarias o ancestrales, determinar los límites de los bosques de la comunidad, identificar áreas de uso de recursos y resolver conflictos. También pueden utilizarse para otras necesidades relacionadas, como estrategias para medios de subsistencia, planificación participativa del uso de la tierra o documentación y registro de historias y mitos orales propios del lugar (véase, por ejemplo, Etongo y Glover 2012). El mapeo puede ser requerido para procesos de reclamos, o puede ser iniciado por la comunidad para legitimar sus derechos de tenencia de facto. Las mujeres pueden contribuir en la etapa de consultas previa al inicio del mapeo, e identificar y validar límites y zonas de recursos, pero también pueden trabajar como mapeadoras, supervisoras comunitarias y analistas. Este proceso de visibilización crea una nueva comprensión y representación del conocimiento en materia de género. De esta manera, el mapeo participativo con perspectiva de género se convierte en parte fundamental de los procesos de aclaración, afirmación, registro y análisis de los derechos de tenencia forestal.

En los últimos años, el uso de tecnologías móviles no solo ha ayudado a reducir costos, también ha facilitado una participación más inclusiva de varios miembros de la comunidad con conocimientos especializados (véase, por ejemplo, USAID s. f.) en el proceso de captura de datos audiovisuales diferenciados por género. Una reflexión detenida sobre cómo incluir las diversas perspectivas de mujeres y hombres en el uso de tecnologías móviles permitirá producir un mapa con el que todos puedan estar de acuerdo. Es posible que las guías de mapeo participativo sugieran realizar el trabajo con hombres y mujeres por separado, para permitir que estas últimas puedan expresarse con libertad y encuentren un momento y lugar para hacerlo que no afecte sus otras obligaciones laborales. Sin embargo, existen pocos informes acerca de cómo se ha llevado a cabo el mapeo en la práctica y qué efectos en materia de género ha tenido sobre el liderazgo local, la gestión y gobernanza forestal o la puesta en marcha de empresas forestales. Existen algunos avances positivos en curso, como la creación de guías de mapeo participativo sensibles al género (véanse, por ejemplo, Vasundhara 2016; Rainbow Environment Consult 2018; Rainforest Foundation UK 2019a; USAID LTS Team 2019). De cara al futuro, se trata de un área importante para el desarrollo de herramientas y protocolos con perspectiva de género y relevantes a nivel local, ya sea en formato escrito o audiovisual. El mapeo no es una herramienta de un solo uso: puede ser muy valioso para hacer seguimiento a los cambios, evaluar los impactos de proyectos de desarrollo o crear sistemas de planificación del uso de la tierra de manera adaptativa. Tomará un tiempo llegar a comprender el efecto dominó del mapeo en la consolidación de la reivindicación de derechos.

SECCIÓN 3.3

\section{LECTURAS COMPLEMENTARIAS}

Boissière M, Duchelle AE, Atmadja S y Simonet G. 2018. Technical Guidelines for Participatory Village Mapping Exercise. Bogor, Indonesia: CIFOR.

Rainbow Environment Consult. 2018. Synthetic and Practical Guide of the Unified Methodology of Participatory Mapping in Cameroon. Yaundé, Camerún: Rainbow Environment Consult. 
El papel de la mujer en el mapeo participativo en países de América Latina

\section{PREGUNTA DE REFLEXIÓN}

\section{¿Por qué se ha excluido a las mujeres del mapeo participativo para la demarcación de límites de tierras consuetudinarias en muchos países de América Latina?}

En América Latina, el $33 \%$ de los bosques se gestionan de acuerdo con algún tipo de régimen de tenencia colectiva otorgado a comunidades, la mayoría de los cuales están a cargo de pueblos indígenas (como los resguardos o reservas indígenas) (RRI 2018). Sin embargo, a pesar de este importante avance, la formalización de los reclamos sobre tierras sigue siendo lenta en muchos países y es poco lo que se sabe acerca de cómo estos procesos de reforma involucran y benefician a las mujeres. Aunque los procedimientos existentes para la formalización de derechos son largos, complejos y costosos, tanto para la demarcación de límites como para el mapeo de recursos naturales clave (Monterroso et al. 2017), es cada vez más evidente que incorporar a las mujeres en los procedimientos de demarcación es fundamental para evitar el riesgo de perpetuar la diferenciación social de los grupos vulnerables. Además, es importante porque las mujeres y los hombres rurales e indígenas tienen diferentes tipos de conocimiento sobre la tierra y los recursos naturales (Cruz-Burga et al. 2019; Duran et al. 2018). Debido a que rara vez existen disposiciones jurídicas referidas al procedimiento de demarcación, la mayoría de las comunidades dependen de sus propias capacidades de autoorganización (Notess et al. 2018). En este punto, las mujeres suelen ser excluidas (Monterroso et al. 2019b).

En consecuencia, las organizaciones de mujeres se han movilizado en países como Perú y Colombia con el fin de tener una participación más activa no solo en los procesos de formalización sino también en las discusiones de políticas relevantes para sus territorios (Bolaños 2017). Por ejemplo, la Organización Nacional de Mujeres Indígenas Andinas y Amazónicas del Perú (ONAMIAP) ha destacado la necesidad de revisar procedimientos de formalización que actualmente solo requieren la participación del jefe de hogar, y sostiene que tanto mujeres como hombres deben ser incluidos. (ONAMIAP y RRI 2017).

Es necesario establecer mecanismos claros para involucrar a las mujeres en el mapeo y otros pasos de la titulación (Larson et al. 2019b; Monterroso et al. 2019b). Hay otras iniciativas en marcha que brindan apoyo técnico para el trabajo de mapeo participativo con perspectiva de género. Por ejemplo, Cadasta (una organización que proporciona herramientas técnicas y servicios para la documentación de derechos sobre la tierra y los recursos) ha trabajado junto con Aso Manos Negra, la Asociación para la Defensa del Medio Ambiente y Nuestra Cultura Negra (una organización dirigida por mujeres en Colombia, creada en 1996) para mapear y documentar las tierras comunitarias 


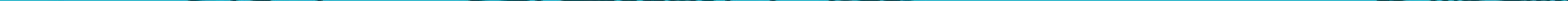




\section{Gracias al desarrollo de}

mecanismos de financiamiento, las

empresas forestales comunitarias

han podido modernizar sus procesos

[de producción]. Al modernizar los

aserraderos y brindar asistencia

técnica para la capacitación de

mujeres, estas ahora pueden

participar en el proceso trabajando

en los aserraderos. Esto ha sido

muy positivo. La mecanización del

proceso y los beneficios económicos

[derivados] han llevado a las mujeres

a participar en... trabajos que antes

eran exclusivos para hombres.

\section{Berenice Hernández Toro}

Directora de Financiamiento en

CONAFOR y punto focal del Programa de Inversión Forestal para México

(Kuriakose 2018)

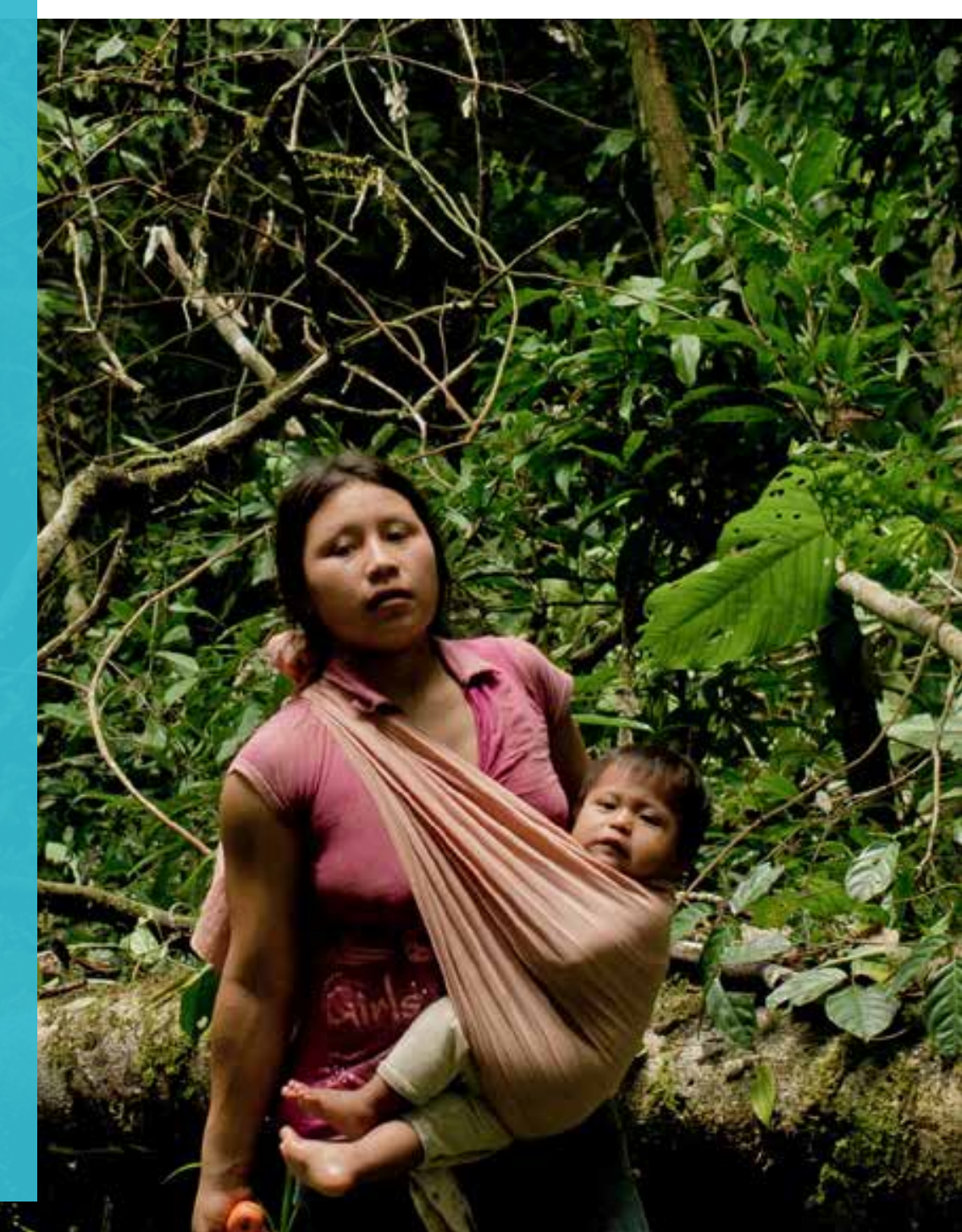

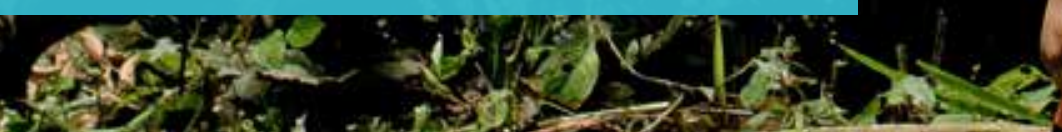

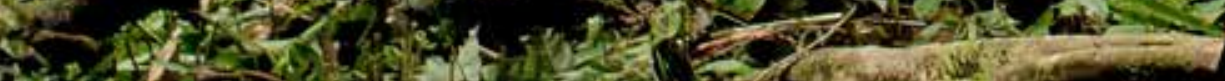

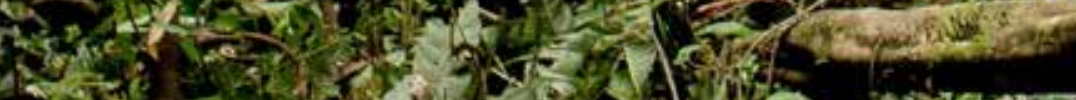
$\frac{7}{14}$ $\frac{11}{11}$ tive 
3.4

\section{LAS MUJERES EMPRENDEDORAS APROVECHAN LOS DERECHOS DE TENENCIA FORESTAL COLECTIVA}

Asegurar el reconocimiento igualitario de los derechos de las mujeres y los hombres sobre los bosques no tiene que ver solo con garantizar que cuenten con medios de subsistencia y satisfagan sus necesidades de seguridad alimentaria. Estos derechos son también una poderosa herramienta para impulsar las aspiraciones empresariales y establecer empresas con impacto social. Es una dimensión importante de la factibilidad de los derechos de tenencia. Sin embargo, estos derechos de tenencia de gran importancia comercial rara vez forman parte del conjunto de derechos de tenencia reconocidos que el gobierno transfiere a los PICL. Por lo tanto, los detalles del paquete de derechos (así como sus marcos regulatorios correspondientes) deben diseñarse de tal manera que tanto las mujeres como los hombres cuenten con un conjunto de derechos adecuado que les permitan iniciar emprendimientos empresariales. En aquellos lugares donde la transición a la tenencia forestal se ha afianzado y donde los derechos de tenencia de bosques bajo control jurisdiccional del gobierno son transferidos a comunidades, empresas o individuos, el crecimiento sustancial de las empresas forestales comunitarias ha sido la norma (Molnar et al. 2007; véase también Greijmans et al. 2014). La forestería a pequeña escala o a nivel local es un sector enorme que puede convertirse en una fuerza para cambiar la cara del desarrollo rural si cuenta con un conjunto 
adecuado de intervenciones catalizadoras para mujeres y hombres (Mayers et al. 2016). Sin embargo, es poco lo que se sabe acerca de la igualdad de oportunidades de género, debido a limitaciones en los estudios y en los datos desglosados por género sobre empresas de tipo forestal (Ingram et al. 2016; FAO 2018a).

Varios estudios demuestran que existen grandes obstáculos para que las mujeres puedan beneficiarse en los nodos más altos de las cadenas de valor de productos forestales (véase Ingram et al. 2014). Las mujeres más pobres cosechan plantas medicinales u otros PFNM, se convierten en empleadas en la cría de plántulas medicinales o aromáticas, o se encargan de su procesamiento con tecnologías muy básicas que requieren abundante uso de mano de obra. Es bastante menos común encontrar a mujeres trabajando como empleadas en una empresa forestal; en labores de procesamiento, comercialización y mercadeo; o dedicadas a la prestación de servicios.

En la India, por ejemplo, el sector de la pequeña empresa forestal (SSFE, por sus siglas en inglés) proporciona empleo a millones de personas pobres que recolectan, procesan y venden productos forestales (Saigal y Bose 2003). Alrededor del $50 \%$ de los empleados de pequeñas empresas forestales son personas sin tierras, o mujeres. Aunque el dinero en efectivo adicional aumenta la seguridad de sus ingresos, existen importantes obstáculos políticos para que puedan obtener una mayor rentabilidad. Tal es el caso, por ejemplo, de la hoja de ébano coromandel (conocido también como tendu o kendu), que se usa para enrollar bidis (un tipo de cigarrillo), actividad en la que muchos de los recolectores y enrolladores son mujeres y niños. Existen alrededor de 750000 recolectores de hojas de tendu, la mayoría en el centro de la India. Luego de la aprobación de la Ley de Panchayats (Ley de Extensión a Áreas Registradas) de 1996 y la Ley sobre Derechos de los Bosques (FRA) de 2006, los estados de la India están obligados a ceder los derechos de tenencia de la hoja de tendu y otros PFNM a los habitantes de los bosques (Lele et al. 2015). En Madhya Pradesh (el mayor productor de hojas de tendu), la transferencia ha comenzado a beneficiar a los recolectores de hojas de manera limitada. En cambio, en el estado de Odisha, donde en 2005 las mujeres de varios comités de protección de los bosques salieron a protestar a las calles de la capital para pedir al gobierno que instalara centros de recolección de hojas en lugares más cercanos a donde vivían (medida que tuvo un éxito limitado) (Singh 2007), el gobierno estatal ha conservado su monopolio sobre las hojas de tendu y otros PFNM, lo que contraviene las disposiciones de la FRA (Pani 2018). A consecuencia de ello, las mujeres, el principal grupo de recolectores de hojas, no podrán recibir los beneficios que les corresponden según la ley federal.

En los niveles más altos de la cadena de valor, los obstáculos son aún mayores. Uno de los problemas puede ser que hay estereotipos de género asociados a determinados tipos de empresas forestales. Tal es el caso de las numerosas empresas forestales comunitarias de explotación maderera que son operadas y administradas predominantemente por hombres, como ocurre en México (Antinori y Bray 2005). Aunque el sector del carbón, que genera ingresos a millones de personas, también es presentado como un sector dominado por hombres, de hecho, cada vez más mujeres están ingresando en la cadena de valor. Nuevos estudios revelan que, aunque las mujeres participan a lo largo de toda la cadena de valor, tienen mayor presencia en los nodos de comercio minorista, mientras que los hombres se encargan por lo general de la producción y el transporte (Ihalainen et al. 2020; véanse también Delagneau y Ahoussi 2019; González 2020). El grado en que las mujeres asumen responsabilidades en los nodos más altos de una cadena de valor como comerciantes o mayoristas (en lugar de recolectoras o procesadoras) varía entre regiones (Ingram et al. 2016; Gumicio et al. 2018). Cada vez hay más guías disponibles sobre cómo comprender las características diferenciadas por género de las cadenas de valor forestales (véanse Stein y Barron 2017; FAO 2018a), y en especial para brindar apoyo a las mujeres como comerciantes (Awono et al. 2010; Rousseau et al. 2015). 
Los derechos de tenencia cumplen un papel importante en la dinámica de la cadena de valor con igualdad de género. Uno de los principales obstáculos para las mujeres que participan en actividades de mayor valor es la falta de derechos reconocidos de tenencia sobre árboles y bosques. Cuando las mujeres participan en actividades comerciales de menor escala para los mercados locales, como la tala de madera y la comercialización, la tenencia de árboles es uno de los factores que afectan su capacidad para beneficiarse de la extracción, sobre todo en el caso de mujeres pobres (Friman 2020). Las mujeres no pueden utilizar sus derechos informales de tenencia como garantía para obtener un préstamo para el desarrollo empresarial, ya sea para producción, procesamiento, comercialización o venta al por menor. En este contexto, es necesario comprender de qué manera las mujeres de los bosques de uso común aprovechan su fuerza conjunta para mejorar su participación en las empresas forestales (véase Bolin 2018). En la mayoría de los casos, las mujeres de familias con más recursos económicos recurren a sus tierras agrícolas privadas para impulsar iniciativas comerciales. Ello hace que muchas mujeres queden excluidas de oportunidades empresariales rentables.

\section{SECCIÓN 3.4}

\section{LECTURAS COMPLEMENTARIAS}

[FAO] Food and Agriculture Organization. 2018. Developing Gender-Sensitive Value Chains. Guidelines for Practitioners. Roma: FAO.

Haverhals M, Ingram V, Elias M, Sijapati Basnett B, y Petersen S. 2016. Exploring gender and forest, tree and agroforestry value chains. Evidence and lessons from a systematic review. InfoBrief n. ${ }^{\circ} 161$. Bogor, Indonesia: CIFOR. 


\section{La tenencia de árboles y las cadenas de valor de la manteca de karité en Burrkina Faso}

\section{PREGUNTA DE REFLEXIÓN \\ ¿De qué manera la tenencia informal de los lucrativos árboles de karité plantea obstáculos para que las mujeres puedan beneficiarse de oportunidades de procesamiento de mayor valor?}

La tenencia de árboles por parte de mujeres es fundamental para asegurar los flujos financieros de la cadena productiva de la manteca de karité. En los parques agroforestales de las regiones central y centrooccidental de Burkina Faso, el árbol de karité es de importancia crucial porque la manteca que se produce con sus nueces tiene un alto valor en las cadenas mundiales de productos básicos para la industria cosmética y de confitería (Elias 2016). El karité, un árbol de crecimiento lento que produce frutos después de 15 a 20 años, es valorado a nivel local no solo por su manteca de nueces, sino también por sus frutos nutritivos, sus propiedades medicinales y su madera dura. Es llamado el árbol de la manteca o "el oro verde de las mujeres", porque les proporciona un importante ingreso agregado (como recolectoras y como procesadoras de manteca).
Sin embargo, los hombres siguen ocupando los roles más rentables del sector y ganan entre tres y cuatro veces más. Las mujeres utilizan el dinero que reciben principalmente para dedicarlo a la educación de sus hijos. Algo interesante es que, aunque el conocimiento y las prácticas culturales relacionados con su uso y gestión están claramente en manos de mujeres, los hombres también saben mucho acerca de este árbol debido a su importancia económica (Elias 2016).

Como recolectoras principales de las nueces, las mujeres tienen que operar en el marco del sistema consuetudinario de propiedad de la tierra, que se basa en linajes y es de carácter patrilineal. En este contexto, la dinámica de la tenencia de árboles es de suma importancia para las mujeres. Esta dinámica ha cambiado a lo largo del tiempo debido a la afluencia en los últimos 20 años de nuevos colonos, que actualmente superan en número a los residentes tradicionales. Aun así, las normas vigentes que rigen el acceso a los árboles de karité en tierras cultivadas y en barbecho otorgan mayores derechos a las familias indígenas que a las familias de colonos (Poudyal 2009; Rousseau et al. 2016).

Como resultado de ello, el acceso a los árboles de karité se ha vuelto cada vez más competitivo. En respuesta, las mujeres pertenecientes a familias indígenas han tratado de fortalecer las relaciones de cooperación informal entre sí (en especial, para restringir el acceso a las colonas), mientras que las colonas (que se encuentran en una clara situación de desventaja) han optado por dedicarse a la elaboración de productos de karité de mayor valor, así como crear cooperativas formales (Poudyal 2009).

Un problema mayor que enfrentan todas las recolectoras tiene que ver con la liberalización de la industria del karité en la década de 1990. Esta creó una 
estructura oligárquica de mayoristas dominada por hombres (Rousseau et al. 2015; Chen 2017). Los intentos de evitar el trato con estos comerciantes mediante proyectos de comercio justo que podrían beneficiar a las recolectoras han tenido poco efecto en la dinámica predominante de la cadena de valor.

Las mujeres siguen teniendo dificultades para participar en actividades de procesamiento de mayor valor porque no pueden aprovechar formalmente sus derechos de tenencia forestal para acceder a capital. Si hubiera menos barreras a la propiedad de la tierra y los activos, las mujeres tendrían el capital necesario para participar en los mercados e influir en la toma de decisiones. Dado que se trata del tercer producto más exportado del país, la política de tenencia forestal debe evaluar cómo promover la igualdad de género a lo largo de la cadena de valor y aclarar de qué manera los derechos de tenencia de las mujeres sobre los árboles pueden traducirse en capital de inversión.

\section{LECCIONES}

Las mujeres que cosechan karité enfrentan una doble carga: no solo hay una mayor competencia entre las mujeres por los frutos debido a la llegada de colonas, sino que su carencia de derechos formales de tenencia sobre los árboles les impide acceder al capital necesario para ingresar a los nodos de procesamiento de mayor valor de la cadena.

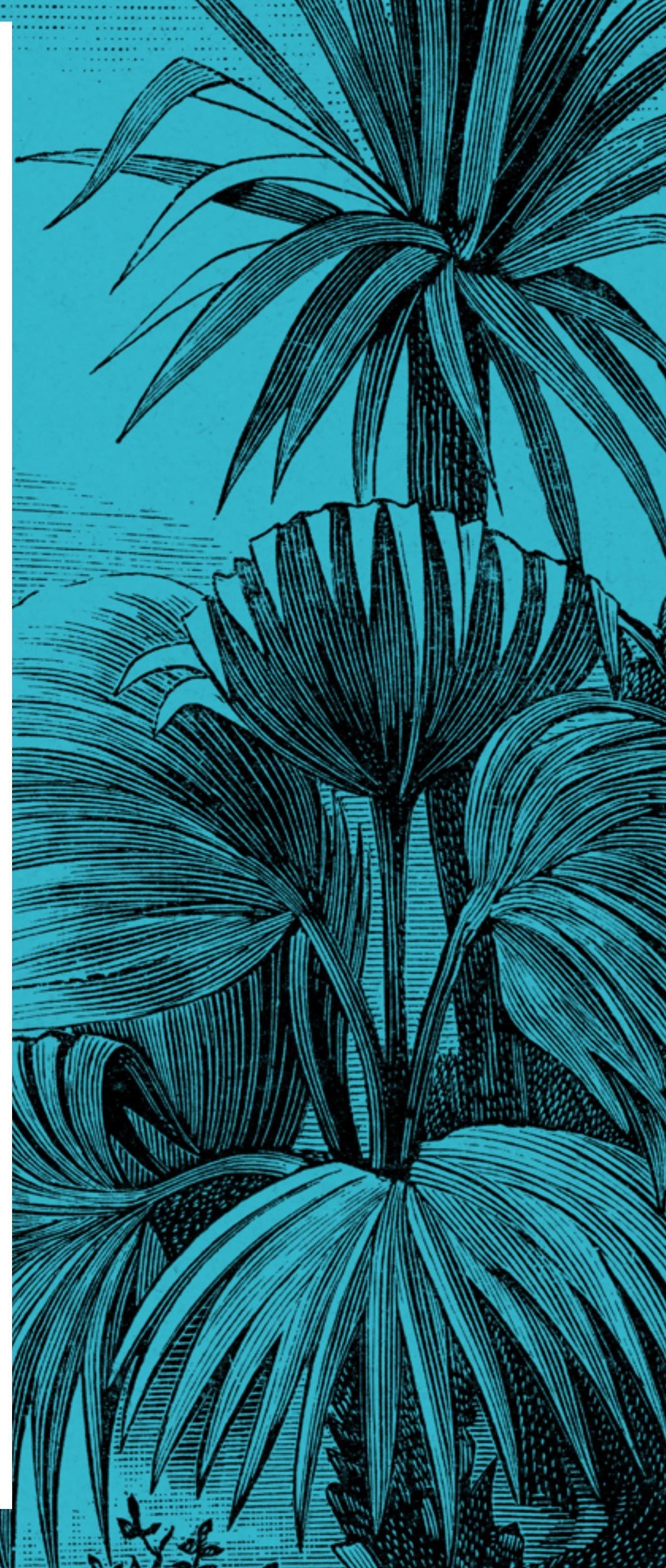




\section{Orientar las}

políticas de desarrollo

sostenible hacia un marco

de "enfoque de paisajes"

que aplique un enfoque

integrado a la gestión de la

tierra, hará aún más evidente

la importancia del género

para los debates sobre el

medioambiente.

\section{Dra. Seema Arora-Jonsson}

Profesora asociada de Desarrollo Rural en la Universidad de Ciencias Agrícolas de Uppsala, Suecia (Mollins 2013) 
3.5

GÉNERO, TENENCIA

FORESTAL Y RESTAURACIÓN

DE PAISAJES FORESTALES

MULTIFUNCIONALES

La creación de efectos positivos a gran escala también es parte de la línea de pensamiento de la reforma de la tenencia forestal. En lugar de considerar los derechos de tenencia forestal a nivel de un solo bosque, la mejora de los bosques y la equidad social puede implicar pensar en términos de todo un paisaje, con sus múltiples nichos de tenencia. Las mujeres y los hombres de los hogares aprovecharán diversos tipos de recursos en "continuos bosque-árbol-paisaje" con diferentes nichos de tenencia, lo que creará un mosaico de bosques protegidos, bosques gestionados, huertos, áreas agroforestales de varios niveles, producción de monocultivos y otros usos de la tierra (Bruce 1989; Parrotta et al. 2016). Para el gobierno y mejora de esos paisajes forestales se requerirá un pensamiento con perspectiva de género que tome en cuenta los múltiples y complejos factores, de manera tal que las iniciativas de colaboración puedan fomentar una mayor ecologización que respalde la multifuncionalidad.
El trabajo a nivel de paisaje está comenzando a manifestarse en una serie de iniciativas como REDD+ jurisdiccional o la restauración del paisaje forestal (RPF) Uhaveri y Adhikari 2016; Irawan et al. 2019). De hecho, dado que la RPF recibe cada vez más atención pública, ha habido una tendencia a aprovechar de nuevas formas programas ya existentes como REDD+ (Sijapati Basnett et al. 2017). En este contexto, queda claro que implementar algún tipo de reforma de la tenencia es una manera de fomentar los resultados, incluida la igualdad de género (Sunderlin et al. 2018; McLain et al. 2019). Si bien las metodologías para la RPF, como la Metodología de Evaluación de Oportunidades de Restauración (ROAM, por sus siglas en inglés), incluyen ahora dimensiones con perspectiva de género (IUCN 2017; Siles y Prebble 2018; FAO y WRI 2019; Seymour 2020), lograr una comprensión detallada de las vinculaciones entre género y tenencia es un objetivo aún no concretado. 
Una revisión de ocho informes de ROAM reveló que, aunque estos señalaron que la falta de derechos o los derechos débiles eran obstáculos para aumentar la escala de la RPF, ninguno realizó una evaluación en profundidad de la tenencia y la gobernanza (McLain et al. 2019).

Uno de los obstáculos principales para ello es la falta de orientación sobre el análisis de los derechos de propiedad en el marco de la gobernanza de paisajes policéntricos o multinivel (Buck et al. 2019). Debido a que trabajar a escala del paisaje es complicado, los conceptos aún están en evolución. Rara vez los regímenes de tenencia, y mucho menos sus dimensiones relacionadas con el género, son fáciles de clasificar a esta escala. Por lo tanto, se vuelve aún más importante que quienes participan en la gobernanza del paisaje estén capacitados en herramientas de diagnóstico de la tenencia, para que los diferentes tipos de sistemas de tenencia híbridos puedan ser analizados con precisión (Ranjatson et al. 2019). Esto requiere una exploración del conocimiento indígena y local de mujeres y hombres sobre árboles y múltiples usos del paisaje (Elias 2018).

La tenencia con perspectiva de género cumple un papel fundamental en una serie de factores que conducen a una restauración exitosa porque permite que los actores perciban que las recompensas por sus esfuerzos fluirán de vuelta hacia ellos en el largo plazo. La tenencia afecta factores como el nivel de compromiso de la variedad de actores involucrados, la participación de los implementadores (intermediarios de nivel medio y funcionarios gubernamentales) y la voluntad de escuchar a quienes tienen un interés claro en sus paisajes, en particular a las mujeres y los marginados (Sarmiento Barletti et al. 2020). Estudios longitudinales sobre género y REDD+ realizados en diversos lugares muestran que la percepción de bienestar entre las mujeres tuvo una mayor disminución que entre los hombres y, por lo tanto, apuntan a la necesidad de prestar más atención a la igualdad de género y a proteger los derechos de las mujeres en la regeneración de bosques (Larson et al. 2018).
SECCIÓN 3.5

\section{LECTURAS COMPLEMENTARIAS}

Buck LE, Scherr SJ, Chami B, Goldman M, Lawrence T, Mecham J, Nevers E y Thomas R. 2019. Exploring Property Rights and Tenure in Integrated Landscape Management. Washington D. C.: EcoAgriculture Partners on behalf of the Landscapes for People, Food and Nature Initiative.

[IUCN] International Union for Conservation of Nature. 2017. Gender-Responsive Restoration Guidelines: A Closer Look at Gender in the Restoration Opportunities Assessment Methodology. Gland, Suiza: IUCN.

McLain R, Lawry S, Guariguata MR y Reed J. 2019. Integrating tenure and governance into assessments of forest landscape restoration opportunities. Infobrief $n .^{\circ}$ 241. Bogor, Indonesia: CIFOR. 


\section{Restauración del paisaje forestal con perspectiva de género en Malawi}

\section{PREGUNTA DE REFLEXIÓN \\ ¿Cuáles son los componentes fundamentales de un enfoque con perspectiva de género para llevar a cabo una evaluación nacional de restauración del paisaje forestal?}

En 2016, Malawi se comprometió con la Iniciativa para la Restauración del Paisaje Forestal Africano y el Desafío de Bonn a restaurar 4,5 millones de hectáreas de tierras forestales. Poco después, puso en marcha la Evaluación Nacional para la Restauración de Paisajes Forestales (NFLRA, por sus siglas en inglés) mediante un grupo de trabajo nacional multisectorial. Utilizando la metodología ROAM buscó identificar áreas prioritarias e intervenciones que se adaptaran al contexto socioeconómico y ecológico local. Desde un comienzo, en colaboración con la Unión Internacional para la Conservación de la Naturaleza (IUCN), aplicó un enfoque con perspectiva de género (UICN 2017).
El objetivo era asegurar que un Plan de Acción sobre Género (GPA, por sus siglas en inglés) orientara la NFLRA. Para ello, se tomaron una serie de medidas: primero, se creó un grupo de especialistas mediante el desarrollo de capacidades de expertos en temas de género de varios ministerios relevantes para la restauración forestal. Antes de aplicar la metodología ROAM, se realizó un taller inicial con este grupo para familiarizar a los expertos con la RPF y sus vínculos con los asuntos de género. Luego, se agregaron dos miembros de este grupo de expertos a cada uno de los tres grupos de trabajo técnicos encargados de desarrollar la NFLRA, con el fin de asegurar la integración de las cuestiones de género. Un grupo de trabajo en particular, dedicado a temas de inventario y mapeo, realizó un análisis de género basado en el Marco de Análisis de Restauración del Paisaje Forestal con Perspectiva de Género de la UICN (IUCN 2017). Con el objetivo de orientar a los grupos de trabajo técnicos, el GPA trabajó con una gran variedad de datos recolectados, como las políticas relevantes, las dimensiones de género de las iniciativas de RPF ya existentes, los datos socioeconómicos desglosados por sexo (y sus dimensiones geoespaciales) y las perspectivas a nivel de distrito sobre la RPF con perspectiva de género. Luego, los hallazgos del GPA se integraron en el informe de la NFLRA y en la Estrategia Nacional y el Plan de Acción. También se incluyó en la NFLRA un capítulo adicional y detallado que presenta los hallazgos del análisis de género. Pensar de manera proactiva en la etapa de planificación sobre enfoques con perspectiva de género facilita la integración en todos los ámbitos.

\section{LECCIONES}

La experiencia de Malawi indica que un proceso de NFLRA con perspectiva de género puede beneficiarse de lo siguiente: capacitar a expertos en temas de género de diferentes sectores para que se unan al grupo de especialistas en cuestiones de género; incluir a miembros del grupo de especialistas en varios grupos de trabajo técnicos para asegurar la integración de los asuntos de género; recopilar datos relevantes para preparar un GPA; y llevar a cabo un análisis de género empleando un marco de análisis de restauración del paisaje forestal con perspectiva de género. 
Action Aid. 2017. Assessing Gender-Sensitive Implementation and Country-Level Monitoring of the Tenure Governance and Africa Land Policy Guidelines. Johannesburgo: Action Aid International.

Agarwal B. 1997. "Bargaining" and gender relations: Within and beyond the household. Feminist Economics $3(1): 1-51$.

Agarwal B. 2001. Participatory exclusions, community forestry and gender: An analysis for South Asia and a conceptual framework. World Development 29(10):162348. https://doi.org/10.1016/S0305-750X(01)00066-3

Agarwal B. 2010. Does women's proportional strength affect their participation? Governing local forests in South Asia. World Development 38(1):98-112. https://doi. org/10.1016/j.worlddev.2009.04.001

Agarwal B. 2015. The power of numbers in gender dynamics: Illustrations from community forestry user groups. Journal of Peasant Studies 42(1). https://doi.org/1 $\underline{0.1080 / 03066150.2014 .936007}$

Agarwal B. 2017. The hidden side of group behavior: A gender analysis of community forestry in South Asia. En Colfer CJP, Elias M, Sijapati Basnett B y Hummel SS, eds. The Earthscan Reader on Gender and Forests. Nueva York: Routledge. 123-52.

Agarwal B y Freudenberger M. 2013. Tenure, governance and natural resource management. Contributions to USAID development objectives. USAID Issue Brief. Washington D. C.: USAID.

Agkara M. 2020. Forest communities in Thailand use mapping technology to secure and manage their land. Bangkok, Tailandia: Center for People and Forests, RECOFTC.

https://www.recoftc.org/stories/forest-communitiesthailand-use-mapping-technology-secure-and-managetheir-land

Aguilar L. 2017. Mexico as a shining example of gender and forest policy. Huffington Post. https://www.huffpost.com/entry/mexico-as-a-shiningexamp b 6211614
[AIPP] Asia Indigenous People's Pact. 2013. Research on the roles and contributions of Indigenous women in sustainable forest management in Mekong Countries/Asia. Chiang Mai, Tailandia: AIPP.

Alden-Wily L. 2014. Rights to resources in crisis: Reviewing the state of customary land tenure in Africa. Washington D. C.: Rights and Resources Initiative (RRI).

Antinori C y Bray D. 2005. Community forest enterprises as entrepreneurial firms: Economic and institutional perspectives from Mexico. World Development 33(9).

Armitage D. 2008. Governance and the commons in a multi-level world. International Journal of the Commons 2(1):7-32.

http://doi.org/10.18352/ijc.28

Arora-Jonsson S. 2014. Forty years of gender research and environmental policy: Where do we stand? Women's Studies International Forum 47:295-308.

https://doi.org/10.1016/j.wsif.2014.02.009

Arora-Jonsson S, Agarwal B, Colfer CJP, Keene S, Kurian P y Larson AM. 2019. SDG 5: Gender equality: A precondition for sustainable forestry. En Katila P, Colfer CJP, de Jong W, Galloway G, Pacheco P y Winkel G, eds. Sustainable Development Goals: Their Impacts on Forests and People. Cambridge: Cambridge University Press. 146-77.

Arwida SD, Maharani C, Sijapati Basnett B y Yang AL. 2017. Gender relevant considerations for developing REDD+ indicators: Lessons learned for Indonesia. InfoBrief n. 168. Bogor, Indonesia: CIFOR.

Asher K. 2016. Tenure vs territory in the Pacific lowlands of Colombia. En Colfer CJP, Sijapati Basnett B y Elias M, eds. Gender and Forests. Climate Change, Tenure, Value Chains and Emerging Issues. Londres: Earthscan. 206-18.

Asher K y Varley G. 2018. Gender in the jungle: A critical assessment of women and gender in current (20142016) forestry research. International Forestry Review 20(2):149-59.

https://doi.org/10.1505/146554818823767537 
Awono A, Ndoye O y Preece L. 2010. Empowering women's capacity for improved livelihoods in non-timber forest product trade in Cameroon. International Journal of Social Forestry 3(2):151-63.

Banana AY, Bukenya M, Arinaitwe E, Birabwa B y Ssekindi S. 2013. Gender, tenure and community forests in Uganda. Working Paper n. ${ }^{\circ}$ 87. Bogor, Indonesia: CIFOR.

Bandiaky-Badji S. 2011. Gender equity in Senegal's forest governance history: Why policy and representation matter. International Forestry Review 13(2):177-94. https://doi. org/10.1505/146554811797406624

Bandiaky-Badji S, Ntamag-Ndjebet CN, Weah JTB y Meyers J. 2016. Women and tenure in Liberia and Cameroon. En Colfer CJP, Sijapati Basnett B y Elias M, eds. Gender and Forests. Climate Change, Tenure, Value Chains and Emerging Issues. 171-85.

Baynes J, Herbohn J, Smith C, Fisher R y Bray D. 2015. Key factors which influence the success of community forestry in developing countries. Global Environmental Change 35:226-38.

https://doi.org/10.1016/j.gloenvcha.2015.09.011

Bhalla P. 2016. Gender dynamics in Odisha's Forest Rights Act. En Colfer CJP, Sijapati Basnett B y Elias M, eds. Gender and Forests. Climate Change, Tenure, Value Chains and Emerging Issues. Londres: Earthscan. 186-205.

Bhardwaj R. 2017. Protecting forests a man's job? These 38 women foresters take up the challenge. The Better India. https://www.thebetterindia.com/124969/tamil-naduforest-to-be-saved-by-women-foresters/

Bholanath P. 2019. The increasing role of women in Guyana's forest sector. ITTO Tropical Forest Update 28(1):13-18.

Boissière M, Duchelle AE, Atmadja S y Simonet G. 2018. Technical Guidelines for Participatory Village Mapping Exercise. Bogor, Indonesia: CIFOR.

Bolaños O. 2017. Resumen político: Los derechos de las mujeres indígenas y los desafíos para los proyectos de titulación de la propiedad comunal en el Perú. Lima: RRI, ONAMIAP, CIFOR.

Bolin A. 2018. Transforming gender relations: Upscaling collective action in women's entrepreneurship. Briefing. Londres: International Institute for Environment and Development (IIED).

Borelli S, Simelton E, Agarwal B, Olivier A, Conigliaro M, Hillbrand A, Garant D y Desmyterre H. 2019. Agroforestry and tenure. Forestry Working Paper $n .{ }^{\circ}$ 8. Roma y Nairobi: FAO e ICRAF.
Bose P. 2011. Forest tenure reform: Exclusion of tribal women's rights in semi-arid Rajasthan, India. The International Forestry Review 13(2):220-32. https://www.jstor.org/stable/24310670

Bose P. 2017. Land tenure and forest rights of rural and indigenous women in Latin America: empirical evidence. Women's Studies International Forum 65:53-9. https://doi.org/10.1016/j.wsif.2017.10.006

Bose P, Larson AM, Lastarria-Cornhiel S, Radel C, Schmink M, Schmook B y Vásquez-García V. 2017. Women's right to land and communal forest tenure: A way forward for research and policy agenda in Latin America. Women's Studies International Forum 65:53-9. https://doi.org/10.1016/j.wsif.2017.10.005

Bose P. 2018. Women are the guardians of the forest. So why does India ignore them in its policies? Scroll India. https://scroll.in/magazine/875823/women-are-theguardians-of-the-forest-so-why-does-india-ignore-themin-its-policies

Bourgeois R, Liswanti N, Mukasa C, Zamora A, Herawati T, Monterroso I, Banjade MR, Mwangi E, Larson AM y Mshale B. 2017. Building Shared Understanding and Joint Action for Reform and Security of Forest Tenure. Bogor, Indonesia: CIFOR.

Bromley DW. 1990. The Commons, Property, and Common Property Regimes. Bloomington, IN: Workshop in Political Theory and Policy Analysis.

Bruce J. 1989. Community forestry rapid appraisal of tree and land tenure. Community Forestry Note 5. Roma: FAO. http://www.fao.org/3/t7540e/T7540E00.HTM

Bruce J. 1998. Review of Tenure Terminology. Tenure Brief n. ${ }^{\circ}$ 1. Madison, WI: University of Wisconsin - Madison Land Tenure Center.

Buck LE, Scherr SJ, Chami B, Goldman M, Lawrence T, Mecham J, Nevers E y Thomas R. 2019. Exploring Property Rights and Tenure in Integrated Landscape Management. Washington D. C.: EcoAgriculture Partners on behalf of the Landscapes for People, Food and Nature Initiative.

Cadasta. s. f. Aso Manos Negra. Washington D. C.: Cadasta.

https://cadasta.org/partners-list/aso-manos-negra/

Camey IC, Sabater L, Owren C, Boyer AE y Wen J. 2020. Gender-based Violence and Environment Linkages. The Violence of Inequality. Gland, Suiza: IUCN.

Caron C, Menon G y Kuritz L. 2014. Land Tenure and Disasters. Strengthening and Clarifying Land Rights in Disaster Risk Reduction and Post-Disaster Programming. USAID Issues Brief. Washington D. C.: USAID. 
Caswell S. 2018. ITTO policy guidelines on gender equality and the empowerment of women. Yokohama: International Tropical Timber Organization.

https://www.itto.int/guidelines/

Caswell S. 2019. The gender defender. Tropical Forest Update 28(1):5-8.

Catacutan D, McGaw E y Llanza MA, eds. 2014a. In Equal Measure: A User Guide to Gender Analysis in Agroforestry. Nairobi: World Agroforestry.

Catacutan D, Mwangi E, Sijapati Basnett B y Pradhan U. 2014b. Introduction. En Catacutan D, McGaw E y Llanza MA, eds. 2014. In Equal Measure: A User Guide to Gender Analysis in Agroforestry. Nairobi: World Agroforestry. vii-xii.

Chapagain A. 2012. Interview with Apsara Chapagain Chairperson, FECOFUN. En Buchy M, ed. The Challenges of Securing Women's Tenure and Leadership for Forest Management: The Asian Experience. Washington D. C.: Rights and Resources Initiative (RRI).

Chen T. 2017. The Impact of the Shea Nut Butter Industry on Women's Empowerment in Burkina Faso. A MultiDimensional Study focusing on the Central, Central-West and Hauts-Bassins Region. Roma: FAO.

Chimhowu A. 2019. The 'new' African customary land tenure. Characteristics, features and policy implications of a new paradigm. Land Use Policy 81:897-903. https://doi.org/10.1016/j.landusepol.2018.04.014

CGIAR Gender Platform. s. f. Gender Training Resources. Nairobi: CGIAR.

https://gender.cgiar.org/cgiar-training-materials/

[CGIAR FTA] CGIAR Research Program on Forests, Trees and Agroforestry. 2019. The Gender Equality in Research Scale (GEIRS). Bogor: CGIAR Research Program on Forests, Trees and Agroforestry (FTA).

ClientEarth. 2019. Communities at the Heart of Forest Management: How Can the Law make a Difference? Sharing Lessons from Nepal, the Philippines, and Tanzania. Londres: ClientEarth.

ClientEarth. 2020. Toolkit for Enabling Laws on Community Forestry. Londres: ClientEarth.

Coleman EA. 2019. Practitioner's Handbook on Good Practice in Implementing Forest Tenure Reform. Bogor, Indonesia: CIFOR.

Coleman EA y Mwangi E. 2013. Women's participation in forest management: a cross-country analysis. Global Environmental Change 23(1). https://doi.org/10.1016/j.gloenvcha.2012.10.005
Colfer CJP y Minarchek RD. 2012. Women, men and forest research: A review of approaches, resources and methods for addressing gender. Occasional Paper n. ${ }^{\circ} 80$. Bogor, Indonesia: CIFOR.

Colfer CJP. 2013. The gender box: A framework for analysing gender roles in forest management. Occasional Paper 82. Bogor, Indonesia: CIFOR.

Colfer CJP, Achdiawan R, Adnan H, Erni E, Yuliani L, Balang y Lepmil. 2013. Gender and natural resource governance indicators: A need to assess and address 'sensitive and taboo' topics. Forests, Trees and Livelihoods 22(3):143-55. https://doi.org/10.1080/14728028.2013.807143

Colfer CJP, Elias M, Sijapati Basnett B y Hummel SS, eds. 2017. The Earthscan Reader on Gender and Forests. Nueva York: Routledge.

Colfer CJP, Sijapati Basnett B e Ihalainen M. 2018. Making sense of 'intersectionality': A Manual for lovers of people and forests. Occasional Paper 184. Bogor, Indonesia: CIFOR.

Colfer CJP. 2020. Masculinities in Forests: Representations of Diversity. Nueva York: Routledge.

Cruz-Burga Z, Monterroso I, Larson AM, Valencia Fy Saldaña JS. 2019. The impact of formalizing rights to land and forest: Indigenous community perspectives in Madre de Dios and Loreto. InfoBrief n. ${ }^{\circ} 242$. Bogor, Indonesia: CIFOR.

Dahal GR, Atkinson J y Bampton J. 2012. Forest Tenure in Asia: Status and Trends. Joensuu, Finlandia: EFl; y Bangkok: RECOFTC, The Center for People and Forests.

Delagneau B y Ahoussi D. 2019. Malebi: Changing minds in Cote d'Ivoire. Tropical Forest Update 28(1):9-12.

Dieterle G. 2019. Introducing ITTO's gender policy guidelines. Tropical Forest Update 28(1):3-4.

Ding H, Veit P, Gray E, Reytar K, Altamirano J-C, Blackman A y Hodgdon B. 2016. Climate Benefits, Tenure Costs: The Economic Case for Securing Indigenous Land Rights in the Amazon. Washington D. C.: World Resources Institute (WRI).

Djoudi H, Locatelli B, Vaast C, Asher K, Brockhaus M y Sijapati Basnett B. 2016. Beyond dichotomies: Gender and intersecting inequalities in climate change studies. Ambio 45 (Suppl 3):S248-S262.

Dodd M-L, Duncan J, Uvuza J, Nagbe I, Neal VD y Cummings L. 2018. Women's Land Rights in Liberia in Law, Practice and Future Reforms. Washington D. C.: USAID Liberia Land Governance Support Activity.

Doss C y Kieran C. 2014. Standards for Collecting SexDisaggregated Data for Gender Analysis: A Guide for CGIAR 
Researchers. Washington D. C.: CGIAR Research Program on Policies, Institutions and Markets.

Doss C y Meinzen-Dick R. 2020. Land tenure security for women: A conceptual framework. Land Use Policy 99.

https://doi.org/10.1016/j.landusepol.2020.105080

Dowd M-L, Duncan J, Uvuza J, Nagbe I, Neal VD y Cummings L. Women's Land Rights in Liberia in Law, Practice, and Future Reforms. LGSA Women's Land Rights Study. Washington D. C.: Land Governance Support Activity (LGSA) Project.

Down to Earth Indonesia. 2010. Securing recognition for indigenous land. Yakarta: Down to Earth Indonesia. http://www.downtoearth-indonesia.org/node/160

Down to Earth Indonesia. 2014. Participatory mapping: presenting in full information on the management of indigenous territories. Yakarta: Down to Earth Indonesia.

http://www.downtoearth-indonesia.org/story/ participatory-mapping-presenting-full-informationmanagement-indigenous-territories

Down to Earth India. 2017. India fails to protect property rights of indigenous and rural women, says report. Nueva Delhi: Down to Earth India, Centre for Science and Environment.

https://www.downtoearth.org.in/news/forests/indiafails-to-protect-property-rights-of-indigenous-and-ruralwomen-says-report-57937

Durán-Fernández RL, Monterroso I y Larson AM. 2018. Género e interculturalidad en la formalización de las comunidades nativas en Perú: Desafíos y recomendaciones. Bogor, Indonesia: CIFOR.

Elias M. 2013. Practical Tips for Conducting GenderResponsive Data Collection. Roma: Bioversity International.

Elias M. 2016. Gendered knowledge sharing and management of shea (Vitellaria paradoxa) in central-west Burkina Faso. En Colfer CJP, Sijapati Basnett B y Elias M, eds. Gender and Forests. Climate Change, Tenure, Value Chains and Emerging Issues. Londres: Earthscan. 263-282.

Elias M. 2018. Mobilizing Indigenous and local knowledge for successful forest restoration. Lessons for GenderResponsive Landscape Restoration. Global Landscapes Forum Brief n. ${ }^{\circ}$ 4. Bogor: CIFOR.

Elias M, Grosse M y Campbell N. 2020. Unpacking "gender" in joint forest management: Lessons from two Indian states. Geoforum 111: 218-28.

https://doi.org/10.1016/j.geoforum.2020.02.020
Elias M, Jalonen R, Fernandez M y Grosse A. 2016. Genderresponsive participatory research for social learning and sustainable forest management. Forests, Trees and Livelihoods 26(1):1-12.

https://doi.org/10.1080/14728028.2016.1247753

Elmhirst E, Siscawati M, Sijapati Basnett B y Ekowati D. 2017. Gender and generations in engagements with palm oil in East Kalimantan, Indonesia: Insights from feminist political ecology. The Journal of Peasant Studies 44(6):11351157.

https://doi.org/10.1080/03066150.2017.1337002

Etongo DB y Glover EK. 2012. Participatory resource mapping for livelihood values derived from the forest in Ekondo-Titi Subregion, Cameroon: A gender analysis. International Journal of Forestry Research. https://doi.org/10.1155/2012/871068

Evans K, Flores S, Larson AM, Marchena R, Müller P y Pikitle, A. 2017. Challenges for women's participation in communal forests: Experience from Nicaragua's indigenous territories. Women's Studies International Forum 65:37-46.

https://doi.org/10.1016/j.wsif.2016.08.004

Evans K, Larson AM., Mwangi E, Cronkleton P, Maravanyika T, Hernandez X, Müller P, Pikitle A, Marchena R, Mukasa C, et al. 2014. Field Guide to Adaptive Collaborative Management and Improving Women's Participation. Bogor, Indonesia: CIFOR.

Ewers KE. 2011. Communal tenure and the governance of common property resources in Asia. Lessons from experiences in selected countries. Land Tenure Working Paper n. ${ }^{\circ}$ 20. Roma: FAO.

[FAO] Food and Agriculture Organization. 1997. Women's participation in national forest programmes. Formulation, execution and revision of national forest programmes. Roma: FAO.

[FAO] Food and Agriculture Organization. 2010. Developing effective forest policy. A guide. FAO Forestry Paper n. ${ }^{\circ} 161$. Roma: FAO. [FAO] Food and Agriculture Organization. 2013. Governing land for women and men. A technical guide to support the achievement of responsible gender-equitable governance of land tenure. Governance of Tenure Technical Guide n. ${ }^{\circ}$ 1. Roma: FAO.

[FAO] Food and Agriculture Organization. 2011. Reforming forest tenure. Issues, principles and process. FAO Forestry Paper n. ${ }^{\circ}$ 165. Roma: FAO.

[FAO] Food and Agriculture Organization. 2012. Voluntary Guidelines on the Responsible Governance of Tenure of Land, Fisheries, and Forests in the Context of National Food Security. Roma: FAO. 
[FAO] Food and Agriculture Organization. 2014a. Respecting free, prior, and informed consent. Practical guidance for governments, companies, NGOs, indigenous peoples and local communities in relation to land acquisition. Governance of Tenure Technical Guide n. ${ }^{\circ} 3$. Roma: FAO.

[FAO] Food and Agriculture Organization. 2014b. Strengthening Forest Tenure Systems and Governance. Training Module for Facilitators. Roma: FAO.

[FAO] Food and Agriculture Organization. 2015a. Global Forest Resources Assessment 2015. How are the World's Forests Changing? Roma: FAO.

[FAO] Food and Agriculture Organization. 2015b. Safeguarding Land Tenure Rights in the Context of Agricultural Investments. A technical guide on safeguarding land tenure rights in line with the Voluntary Guidelines for the Responsible Governance of Tenure of Land, Fisheries and Forests in the Context of National Food Security, for government authorities involved in the promotion, approval and monitoring of agricultural investments. Governance of Tenure Technical Guide n. ${ }^{\circ}$ 4. Roma: FAO.

[[FAO]. Food and Agriculture Organization. 2016a. Governing tenure rights to commons. A guide to support the implementation of the Voluntary Guidelines on the Responsible Governance of Tenure of Land, Fisheries, and Forests in the Context of National Food Security. Governance of Tenure Technical Guide n. ${ }^{\circ}$ 8. Roma: FAO.

[FAO] Food and Agriculture Organization. 2016b. How to Mainstream Gender in Forestry. Roma: FAO.

[FAO] Food and Agriculture Organization. 2016c. Responsible governance of tenure and the law: A technical guide for lawyers and other legal service providers. Governance of Tenure Technical Guide n. ${ }^{\circ}$ 6. Roma: FAO.

[FAO] Food and Agriculture Organization. 2016d. Responsible governance of tenure: A technical guide for investors. Governance of Tenure Technical Guide n. ${ }^{\circ} 7$. Roma: FAO.

[FAO, CIFOR, IFRI y World Bank] Food and Agriculture Organization, Center for International Forestry Research, International Forestry Resources and Institutions y World Bank. 2016. National Socioeconomic Surveys in Forestry: Guidance and Survey Modules for Measuring the Multiple Roles of Forests in Household Welfare and Livelihoods. En RK Bakkegaard, A Agrawal, I Animon, N Hogarth, D Miller, L Persha, E Rametsteiner, S Wunder y A Zezza. FAO Forestry Paper n. ${ }^{0}$ 179. Roma; Bogor, Indonesia; y Hyderabad: FAO, CIFOR, IFRI Research Network y World Bank.
[FAO y RECOFTC] Food and Agriculture Organization y The Center for People and Forests. 2016. Mainstreaming Gender into Forestry Interventions in Asia and the Pacific. A Training Manual. Roma y Bangkok: FAO y RECOFTC.

[FAO] Food and Agriculture Organization. 2017a. Creating a system to record tenure rights and first registration. Governance of Tenure Guide n. ${ }^{\circ}$ 9. Roma: FAO.

[FAO] Food and Agriculture Organization. 2017b. Improving ways to record tenure rights. Governance of Tenure Guide n. ${ }^{\circ}$ 10. Roma: FAO.

[FAO y FIAN International]. Food and Agriculture Organization and Food First Information and Action Network International. 2017. Putting the Voluntary Guidelines on Tenure into Practice - A Learning Guide for Civil Society Organizations. Roma y Heidelberg: FAO y FIAN International.

[FAO] Food and Agriculture Organization. 2018a. Developing Gender-Sensitive Value Chains. Guidelines for Practitioners. Roma: FAO.

[FAO] Food and Agriculture Organization. 2018b. Land and Forest Tenure Reform to Support REDD+ Implementation. Roma: FAO.

[FAO] Food and Agriculture Organization. 2018c. The State of the World's Forests. Forest Pathways to Sustainable Development. Roma: FAO.

[FAO] Food and Agriculture Organization. 2019a. Assessing the governance of tenure for improving forests and livelihoods. A tool to support the implementation of the voluntary guidelines on the responsible governance of tenure. Forestry Working Paper n. ${ }^{\circ} 13$. Roma: FAO.

[FAO] Food and Agriculture Organization. 2019b. Forest futures. Sustainable pathways for forests, landscapes and people in the Asia-Pacific Region. Asia-Pacific Forest Sector Outlook Study III. Bangkok: FAO.

[FAO] Food and Agriculture Organization. 2019c. A framework to assess the extent and effectiveness of community forestry. Working Paper n. ${ }^{\circ}$ 12. Roma: FAO.

[FAO y WRI] Food and Agriculture Organization y World Resources Institute. 2019. The Road to Restoration. A Guide to Identifying Priorities and Indicators for Monitoring Forest and Landscape Restoration. Roma y Washington D. C.: FAO y WRI

[FAO] Food and Agriculture Organization. 2020a. Global forest resources assessment 2020. Main Report. Roma: FAO. 
[FAO] Food and Agriculture Organization. 2020b. Multistakeholder Platforms. Building on FAO's Experience for Improved Governance of Tenure. Roma: FAO.

Farjam M, De Moor T, van Weeren R, Forsman A, Dehkordi MAE, Ghorbani A y Bravo G. 2020. Shared patterns in long-term dynamics of commons as institutions for collective action. International Journal of the Commons 14(1):78-90.

https://doi.org/10.5334/ijc.959

[FECOFUN y RRI] Federation of Community Forestry Users, Nepal y Rights and Resources Initiative. 2018. These women ran for office to protect Nepal's forests. They won. Katmandú y Washington D. C.: FECOFUN y RRI. https://rightsandresources.org/en/women-fecofun/\#. XYQILTXhXIU

Fortmann L. 1985. The tree tenure factor in agroforestry with particular reference to Africa. Agroforestry Systems 2:229-51.

Friman J. 2020. Gendered woodcutting practices and institutional bricolage processes. The case of woodcutting permits in Burkina Faso. Forest Policy and Economics 111.

https://doi.org/10.1016/j.forpol.2019.102045

Fuys A, Mwangi E y Dohrn S. 2008. Securing Common Property Regimes in a Globalizing World. Synthesis of 41 Case Studies on Common Property Regimes from Asia, Africa, Europe and Latin America. Roma: International Land Coalition (ILC).

Galudra G, Sirait M, Pasya G, Fay C, Suyanto, van Noordwijk M y Pradhan U. 2010. RaTA: A Rapid Land Tenure Assessment Manual for Identifying the Nature of Land Tenure Conflicts. Bogor, Indonesia: World Agroforestry.

Gilmour DA. 2016. Forty years of community-based forestry: A review of its extent and effectiveness. FAO Forestry Paper n. ${ }^{\circ}$ 176. Roma: FAO.

Giovarelli R, Richardson A y Scalise E. 2016. Gender and Collectively Held Land. Good Practices and Lessons Learned from Six Global Case Studies. Friday Harbor, WA, y Seattle, WA: Resource Equity y Landesa.

Giri K. 2012. Gender in forest tenure: Pre-requisite for sustainable forest management in Nepal. En Buchy M, ed. The Challenges of Securing Women's Tenure and Leadership for Forest Management: The Asian Experience. Brief n. ${ }^{\circ} 1$. Washington D. C.: Rights and Resources Initiative (RRI).

Giri K y Dangal S. 2020. Woes of women foresters. Katmandú: Rising Nepal Daily. https://risingnepaldaily.com/detour/woes-of-womenforesters
Giri K y Darnhofer I. 2010a. Nepali women using community forestry as a platform for social change. Society and Natural Resources 23(12):1261-329. https://doi.org/10.1080/08941921003620533

Giri K y Darnhofer I. 2010b. Outmigrating men: A window of opportunity for women's participation in community forestry? Scandinavian Journal of Forest Research 25 Issue Sup 9:55-61. https://doi.org/10.1080/02827581.2010.506769

Gonzalez A. 2020. Unlocking the power of entrepreneurship to promote local development in forest communities. Bogor, Indonesia: CIFOR News. https://forestsnews.cifor.org/66247/unlockingthe-power-of-entrepreneurship-to-promote-localdevelopment-in-forest-communities?fnl=en

Greijmans M, Triraganon R y Gritten D. 2014. Fundamentals of viable community forestry business models. Preliminary research findings. Working Paper. Bangkok: RECOFTC, The Center for People and Forests.

Guerrero C, Herrera J, Helo E, Beltrán A, Aramburo A, Zapata S y Arrieta MJ. 2017. Derechos territoriales de las comunidades negras. Conceptualización y sistema de información sobre la vulnerabilidad de los territorios sin titulación colectiva. Bogotá: Observatorio de Territorios Étnicos y Campesinos, Facultad de Estudios Ambientales y Rurales - Departamento de Desarrollo Rural y Regional de la Universidad Javeriana.

Gumicio T, Alves M de A, Orientlicher N y Ceballos MCH. 2018. Analysis of gender research on forest, tree and agroforestry value chains in Latin America. Journal of Forest, Trees and Livelihoods 27(2):69-85. https://doi.org/10.1080/14728028.2017.1417921

Gurung J y Setyowati A. 2012. Re-envisioning REDD+: Gender, forest governance and REDD+ in Asia. En Buchy $\mathrm{M}$, ed. The challenges of securing women's tenure and leadership for forest management: The Asian experience. Brief n. ${ }^{\circ}$ 4. Washington D. C.: Rights and Resources Initiative (RRI).

Hajjar R, Oldekop JA, Cronkleton P, Newton P, Russell AJM y Zhou W. 2020. A global analysis of the social and environmental outcomes of community forests. Nature Sustainability. https://doi.org/10.1038/s41893-02000633-y

Haryana Forest Department. s. f. Women empowerment. India: Haryana Forest Department. http://haryanaforest.gov.in/en-us/Overview/WomenEmpowerment 
Haverhals M, Ingram V, Elias M, Sijapati Basnett B y Petersen S. 2016. Exploring gender and forest, tree and agroforestry value chains. Evidence and lessons from a systematic review. InfoBrief n. ${ }^{\circ} 161$. Bogor: CIFOR.

Haywood C. 2019. How Liberian community forestry laws are empowering women. Londres: ClientEarth.

https://www.clientearth.org/latest/latest-updates/ stories/how-liberian-community-forestry-laws-areempowering-women/

Hecht SB, Yang AL, Sijapati Basnett B, Padoch C y Peluso NL. 2015. People in motion, forests in transition: trends in migration, urbanization and remittances and their effects on tropical forests. Occasional Paper n. ${ }^{\circ} 42$. Bogor, Indonesia: CIFOR.

Herrera Arango J y Helo Molina E. 2018. El derecho a la tenencia y a la propiedad colectiva en Colombia: Cifras y debates. CIFOR Working Paper n. ${ }^{\circ} 239$. Bogor, Indonesia: CIFOR.

Hobley M. 2007. Where in the World is there Pro-Poor Forest Policy and Tenure Reform? Washington D. C.: Rights and Resources Initiative (RRI).

Hoskins M. 2016. Gender and the roots of community forestry. En Colfer CJP, Sijapati Basnett B y Elias M, eds. Gender and Forests. Climate Change, Tenure, Value Chains and Emerging Issues. Londres: Earthscan. 17-32.

[IFAD] International Fund for Agricultural Development. 2009. Good Practices in Participatory Mapping. Roma: International Fund for Agricultural Development (IFAD).

[IFRI y RRI] International Forestry Resources and Institutions and Rights and Resources Initiative. 2016. The Science is In: Community Governance Supports Forest Livelihoods and Sustainability. Gachibowli, Hyderabad: IFRI y RRI.

Ihalainen M, Schure J y Sola P. 2020. Where are the women? A review and conceptual framework for addressing gender equity in charcoal value chains in Sub-Saharan Africa. Energy for Sustainable Development 55:1-12.

https://doi.org/10.1016/j.esd.2019.11.003

Ingram V, Haverhals M, Petersen S, Elias M, Sijapati Basnett B y Phosiso M. 2016. Gender and forest, tree, and agroforestry value chains. Evidence from literature. En Colfer CJP, Sijapati Basnett B y Elias M, eds. Gender and Forests. Climate Change, Tenure, Value Chains and Emerging Issues. Londres: Earthscan. 221-42.

Ingram V, Schure J, Tieguhong JC, Ndoye O, Awono A e Iponga DM. 2014. Gender implications of forest product value chains in the Congo basin. Forests, Trees and Livelihoods 23(1-2):67-86.

https://doi.org/10.1080/14728028.2014.887610

[IPCC] Intergovernmental Panel on Climate Change. 2020. Climate Change and Land. Ginebra: Intergovernmental Panel on Climate Change (IPCC). https://www.ipcc.ch/srccl/

Irawan S, Widiastomo T, Tacconi L, Watts JD y Steni D. 2019. Exploring the design of jurisdictional REDD+: The case of central Kalimantan. Forest Policy and Economics 108.

https://doi.org/10.1016/j.forpol.2018.12.009

[IREX] International Research \& Exchanges Board. 2018. Gender and Social Inclusion Resource Guide. Washington D. C.: IREX.

https://www.irex.org/sites/default/files/IREX\%20

Guide\%20to\%20GESI\%20Resources\%20(1).pdf

[ITTO y RRI] International Tropical Timber Organization and Rights and Resources Initiative. 2011. Tropical forest tenure assessment. Trends, Challenges and Opportunities. Technical Series n. ${ }^{\circ}$ 37. Yokohama y Washington D. C.: ITTO y RRI.

[IUCN] International Union for Conservation of Nature. 2017. Gender-Responsive Restoration Guidelines: A Closer Look at Gender in the Restoration Opportunities Assessment Methodology. Gland, Suiza: IUCN.

[IUCN y WRI] International Union for Conservation of Nature y World Resources Institute. 2014. A Guide to the Restoration Opportunities Assessment Methodology (ROAM): Assessing Forest Landscape Opportunities at the National or Subnational Level. Gland, Suiza, y Washington D. C.: IUCN y WRI.

Jahan R. 2010. Strengthening National Mechanisms for Gender Equality and the Empowerment of Women. A Global Synthesis Study. Nueva York: UN Division for the Advancement of Women (ahora parte de UN Women).

Jhaveri N. 2013. Nepal: Gender mainstreaming in the forest sector. Report for RECOFTC. Bangkok: RECOFTC, The Center for People and Forests.

Jhaveri NJ y Adhikari J. 2016. Nepal Land and Natural Resource Tenure Assessment for Proposed Emission Reductions Program in the Terai Arc Landscape. Washington D. C.: USAID Tenure and Global Climate Change (TGCC) Program.

Jhaveri N, Litz V, Girard J, Oberndorf R y Stickler MM. 2016. Community Land and Resource Tenure Recognition: Review of Country Experiences. Washington D. C.: USAID Tenure and Global Climate Change (TGCC) Program. 
Johnson N, Balagamwala M, Pinkstaff C, Theis S, Meinzen-Dick R y Quisumbing A. 2018. How do agricultural development projects empower women? What hasn't worked and what might. Journal of Agriculture, Gender, and Food Security 3(2):1-19. http://agrigender.net/views/agricultural-developmentprojects-empowering-women-JGAFS-322018-1.php

Juniwaty KS, Moeliono M y Maharani C. 2019. Migration. The potential for inclusive forest management. CIFOR InfoBrief n. ${ }^{\circ}$ 260. Bogor: CIFOR.

Katila P, Colfer CJP, de Jong W, Galloway G, Pacheco P y Winkel G, eds. 2019. Sustainable Development Goals: Their Impacts on Forests and People. Londres: Cambridge University Press.

Katila P, McDermott C, Larson A, Agarwal B y Giessen L. 2020. Forest tenure and the Sustainable Development Goals: A critical view. Forest Policy and Economics 120. https://doi.org/10.1016/j.forpol.2020.102294

Keene S y Ginsburg C. 2018. Legislative Best Practices for Securing Women's Rights to Community Lands. Washington D. C.: Rights and Resources Initiative (RRI).

Kristjanson P. 2017. Being inspired by gender actions in forest landscapes around the world. Washington D. C.: PROFOR. [Consultado el 30 de octubre de 2020] https:// www.profor.info/content/being-inspired-gender-actionsforest-landscapes-around-world

Kristjanson P, Bah T, Kuriakose A, Shakirova M, Segura G, Siegmann K y Granat M. 2019. Taking action on gender gaps in forest landscapes. Working Paper. Washington D. C.: PROFOR.

Kristjanson P y Jensen A. 2018. In Brief: Gender in Forest Landscape Projects. Action and Indicators. Washington D. C.: PROFOR.

Kukreti I. 2017. Madhya Pradesh forest department violates FRA, seizes tendu leaves from tribals.

Nueva Delhi: Down to Earth, Centre for Science and Environment. [Consultado el 30 de octubre de 2020] https://www.downtoearth.org.in/news/forests/madhyapradesh-forest-department-violates-fra-seizes-tenduleaves-from-tribals-58017

Kuriakose A. 2018. From policy to practice: translating gender goals into forest action in Mexico. Climate Investment Funds. [Consultado el 30 de octubre de 2020]

https://www.climateinvestmentfunds.org/news/policypractice-translating-gender-goals-forest-action-mexico-0
Lama AS, Kharel S y Ghale T. 2017. When the men are away: Migration and women's participation in Nepal's community forestry. Mountain Research and Development 37(3):263-70.

https://doi.org/10.1659/MRD-JOURNAL-D-16-00092.1

Larson AM. 2012. Tenure Rights and Access to Forests. A Training Manual for Research. Part I. A Guide to Key Issues. Bogor, Indonesia: CIFOR.

Larson AM. 2014. The need for a gendered approach to REDD+. Global Landscapes Forum. [Consultado el 30 de octubre de 2020]

https://news.globallandscapesforum.org/12901/anne-

larson-need-gendered-approach-redd/

Larson AM, Barry D y Dahal GR. 2010. New rights for forest-based communities? Understanding processes of forest tenure reform. International Forestry Review, 12(1):78-96.

https://doi.org/10.1505/ifor.12.1.78

Larson AM, Dokken T, Duchelle AE, Atmadja S, Resudarmo IAP, Cronkleton P, Cromberg M, Sunderlin W, Awono A y Selaya G. 2016a. Gender gaps in REDD+: Women's participation is not enough. En Colfer CJP, Sijapati Basnett B y Elias M, eds. Gender and Forests. Climate Change, Tenure, Value Chains and Emerging Issues. Londres: Earthscan. 68-88.

Larson AM, Dokken T y Duchelle AE. 2014. Can safeguards guarantee gender equity? Lessons from research on women in early REDD+ implementation. REDD+ Safeguards Brief n. ${ }^{\circ}$ 4. Bogor, Indonesia, y Montpellier, Francia: CIFOR y CGIAR.

Larson AM, Flores S y Evans K. 2016b. Forest use in Nicaragua. Results of a survey on gendered forest use, benefits and participation. InfoBrief n. ${ }^{\circ} 162$. Bogor, Indonesia: CIFOR.

Larson AM, Monterroso I y Cantuarias P. 2019b. Gender and the formalization of native communities in the Peruvian Amazon. InfoBrief n. ${ }^{\circ}$ 238. Bogor, Indonesia: CIFOR.

Larson AM, Monterroso I y Vigil NH. 2019a. Conflict in collective forest tenure: Lessons for Peru from a comparative study. InfoBrief n. ${ }^{\circ}$ 243. Bogor, Indonesia: CIFOR.

Larson AM, Monterroso I, Liswanti N, Herawati T, Banana A, Cantuarias P, Rivera K y Mwangi E. 2019c. Models for formalizing customary and community forest lands. The need to integrate livelihoods into rights and forest conservation goals. InfoBrief n. ${ }^{\circ} 253$. Bogor, Indonesia: CIFOR. 
Larson A, Solis D, Duchelle AE, Atmadja S, Resusudarmo IAP, Dokken Ty Komalasari M. 2018. Gender lessons for climate initiatives: A comparative study of REDD+ impacts on subjective wellbeing. World Development 108:86-102.

https://doi.org/10.1016/j.worlddev.2018.02.027

Larson A y Pulhin J. 2012. Enhancing forest tenure reforms through more responsive regulations.

Conservation and Society 10(2):103-13.

https://doi.org/10.4103/0972-4923.97482

Larson AM y Springer J. 2016. Recognition and respect for tenure rights. NRGF Conceptual Paper. Gland, Suiza: IUCN, CEESP y CIFOR.

Leisher C, Temsah G, Booker F, Day M, Samberg L, Prosnitz D, Agarwal B, Matthews B, Roe D, Russell D, Sunderland T y Wilkie D. 2016. Does the gender composition of forest and fishery management groups affect resource governance and conservation outcomes? A systematic map. Environmental Evidence 5:6. https://doi.org/10.1186/s13750-016-0057-8

Lele S, Ramanujam RV y Rai J. 2015. Cooperative procurement and marketing of tendu leaves in Madhya Pradesh. Image and reality. Environment and Development Discussion Paper n. ${ }^{\circ}$ 3. Bangalore: Ashoka Trust for Research in Ecology and Environment (ATREE).

Lescuyer G, Kakundika TM, Lubala IM, Ekyambu IS, Tsanga R y Cerutti PO. 2019. Are community forests a viable model for the Democratic Republic of Congo? Ecology and Society 24(1):6. https://doi.org/10.5751/ES-10672-240106

Liswanti N, Mwangi E, Banjade MR y Herawati T. 2019. What future direction for forest tenure reform implementation in Indonesia. Infobrief n. ${ }^{\circ} 256$. Bogor: CIFOR.

Locke C y Okali C. 2010. Analysing changing gender relations: Methodological challenges for gender planning. Development in Practice 9(3):274-286. https://doi.org/10.1080/09614529953016

Losale C y Cyr MRF. 2018. In DRC, a network of women leaders successfully advocated for an unprecedented legal framework to secure women's land and forest rights. Washington D. C.: Rights and Resources Initiative (RRI). https://rightsandresources.org/blog/in-drc-a-networkof-women-leaders-successfully-advocated-for-anunprecedented-legal-framework-to-secure-womensland-and-forest-rights/

Mai YH, Mwangi E y Wan M. 2011. Gender analysis in forestry research. Looking back and thinking ahead. International Forestry Review 13(2):245-58.
Manfre C y Rubin D. 2012. Integrating Gender into Forestry Research: A Guide for CIFOR Scientists and Programme Administrators. Bogor, Indonesia: CIFOR.

Marin AB y Kuriakose AT. 2017. Gender and Sustainable Forest Management: Entry Points for Design and Implementation. Washington D. C.: Climate Investment Funds.

Mayers J, Buckley J y Macqueen D. 2016. Small, but many, is big: Challenges in assessing the collective scale of locally controlled forest-linked production and investment. Issue Paper. Londres: International Institute for Environment and Development (IIED).

Mayers J, Morrison E, Rolington L, Studd K y Turrall S. 2013. Improving governance of forest tenure: $A$ practical guide. Governance of Tenure Technical Guide n. ${ }^{\circ}$ 2. Londres y Roma: International Institute for Environment and Development (IIED) y FAO.

McLain R, Lawry S, Guariguata MR y Reed S. 2019. Integrating tenure and governance into assessments of forest landscape restoration opportunities. InfoBrief n. ${ }^{\circ} 241$. Bogor, Indonesia: CIFOR.

Meinzen-Dick RS, Rao JP, Chaturvedi R, Rao K, Bruns B, Kandikuppa S y EIDidi H. 2020. Securing the commons in India. Mapping polycentric governance. IFPRI Discussion Paper n. ${ }^{\circ} 1944$. Washington D. C.: IFPRI. https://www.ifpri.org/publication/securing-commonsindia-mapping-polycentric-governance

Miller D, Mansourian S y Wildburger C, eds. 2020. Forests, trees, and the eradication of poverty: potential and limitations. A global assessment report. IUFRO World Series Volume 39. Viena: IUFRO.

Moïse RE. 2019. Making Community Forestry Successful in DRC: Anthropological Perspectives on CommunityBased Forest Management. Under the Canopy Series. Londres: Rainforest Foundation UK.

Mollins J. 2013. Toss clichés aside and consider gender in 'landscape' context - expert. Bogor, Indonesia: CIFOR. https://forestsnews.cifor.org/20697/toss-clichesaside-and-consider-gender-in-landscape-contextexpert\#.Us022ifzzT

Molnar A, Liddle M, Bracer C, Kharu A, White A y Bull J. 2007. Community-based Forest Enterprises in Tropical Forest Countries: Status and Potential. Yokohama: International Tropical Timber Organization, y Washington D. C.: Rights and Resources Initiative (RRI). https://rightsandresources.org/wp-content/ exported-pdf/cfescopingitto62207final.pdf 
Monterroso I, Cronkleton P, Pinedo D y Larson AM. 2017. Reclaiming collective rights: Land and forest tenure reforms in Peru (1960-2016). InfoBrief n. ${ }^{\circ} 224$. Bogor, Indonesia: CIFOR.

Monterroso I, Larson A, Mwangi E, Liswanti N y CruzBurga Z. 2019a. Mobilizing Change for Women within Collective Tenure Regimes. Friday Harbor, WA: Resource Equity.

Monterroso I, Larson AM, Gutiérrez Y, Quaedvlieg J y Jarama L. 2019b. Guía práctica para el proceso de titulación de comunidades nativas. Lima, Perú: CIFOR.

Mukasa C, Tibazalika A, Mwangi E, Banana AY, Bomuhangi A y Bushoborozi J. 2016. Strengthening women's tenure rights and participation in community forestry. Infobrief n. ${ }^{\circ} 155$. Bogor: CIFOR.

Mwangi E y Evans M. 2018. Women gaining ground through reforestation on the Cameroonian coast. Bogor, Indonesia: CIFOR y Global Landscapes Forum. https://www.cifor.org/publications/pdf files/brief/ GLFNairobi-Story2.pdf

Mwangi E, Meinzen-Dick E y Sun Y. 2011. Gender and sustainable forest management in East Africa and Latin America. Ecology and Society 16(1):17.

http://www.ecologyandsociety.org/vol16/iss1/art17/

Nightingale A. 2003. A feminist in the forest: Situated knowledge and mixing methods in natural resource management. ACME 2:77-90.

https://www.acme-journal.org/index.php/acme/article/ view/709

Nightingale AJ. 2011. Bounding difference:

Intersectionality and the material production of gender, caste, class and environment in Nepal. Geoforum 42:153-62.

https://doi.org/10.1016/j.geoforum.2010.03.004

Notess L, Veit PG, Monterroso I, Andiko, Sulle E, Larson AM, Gindroz AS, Quaedvlieg J y Williams A. 2018. The Scramble for Land Rights. Reducing Inequity between Communities and Companies. Washington D. C.: World Resources Institute (WRI).

[NRC e IFRC] Norwegian Refugee Council e International Federation of Red Cross and Red Crescent Societies. 2014. Security of Tenure in Humanitarian Shelter Operations. Oslo: NRC e IFRC.

Ochieng RO. 2019. Adapting the Gender Action and Learning System (GALS) framework for qualitative gender action research. Nairobi: CGIAR. [Consultado el 30 de octubre de 2020] https://gender.cgiar.org/gals-for-qualitative-research/

[ODI] Overseas Development Institute. s. f. ROMA: a guide to policy engagement and policy influence. Londres:

Overseas Development Institute (ODI).

https://www.odi.org/features/roma/home

Ojanen M, Zhou W, Miller DC, Nieto SH, Mshale B y Petrokofsky G. 2017. What are the environmental impacts of property rights regimes in forests, fisheries, and rangelands? Environmental Evidence 6:12.

https://doi.org/10.1186/s13750-017-0090-2

Ojha H, Khanal DR, Sharma N, Sharma H y Pathak B. 2007. Federation of community forest user groups in Nepal: an innovation in democratic forest governance. En Proceedings of International Conference on Poverty Reduction and Forests. Bangkok: The Center for People and Forests.

Oldekop JA, Sims KRE, Whittingham MJ y Agrawal A. 2018. An upside to globalization: International outmigration drives reforestation in Nepal. Global Environmental Change 52:66-74.

https://doi.org/10.1016/j.gloenvcha.2018.06.004

Ombogoh D y Mwangi E. 2019. Integrating gender in development of participatory forest management plans in Kenya. A "How To" Note. Bogor, Indonesia: CIFOR.

[ONAMIAP y RRI] Organización Nacional de Mujeres Indígenas Andinas y Amazónicas del Perú y Rights and Resources Initiative. 2017. Guía para la inclusion de las mujeres indígenas en la titulación comunal de comunidades campesinas. Lima, Perú, y Washington D. C.: ONAMIAP y RRI.

Onzere S, Elwell N, Carr E, Caron C y Bebbington D. 2020. Who's governing community forests? Gendered participation in Liberian forest management. Working Paper. Washington D. C.: World Resources Institute. www.wri.org/publication/genderedparticipation-liberiaforest

Ostrom E. 1990. Governing the Commons. Nueva York: Oxford University Press.

Oyerinde OK. 2019. Design principles, common land, and collective violence in Africa. International Journal of the Commons 13(2):993-1002.

https://doi.org/10.5334/ijc.930

Paez AM, Ihalainen M, Elias M y Sijapati Basnett B. 2019. The gender equality in research scale. A tool for monitoring and encouraging progress on gender integration in research for and in development. Brief n. ${ }^{\circ}$ 1. Bogor, Indonesia: CIFOR. 
Pani CR. 2018. In Odisha, state's monopoly on minor forest produce needs to end. Nueva Delhi: Down to Earth India.

https://www.downtoearth.org.in/blog/in-odisha-state-smonopoly-on-minor-forest-produce-needs-to-end-61463

Parrotta J, de Pryck JD, Obiri BD, Padoch C, Powell B, Sandbrook C, Agarwal B, Ickowitz A, Jeary K, Serban A, et al. 2016. The historical, environmental and socioeconomic context of forests and tree-based systems for food security and nutrition. En Vira B, Wildburger C y Mansourian S, eds. Forests and Food. Addressing Hunger and Nutrition across Sustainable Landscapes. Cambridge: Openbook Publishers. 73-136.

Paudel NS, Monterroso I y Cronkleton P. 2010. Community networks, collective action and forest management benefits. En Larson AM, Barry D, Dahal GR and Colfer CJP, eds. Forests for People: Community Rights and Forest Tenure Reform. Londres, Earthscan. 116-36. www.cifor.org/publications/pdf files/Books/ BLarson100106.pdf.

Perempuan Aman. s. f. About Us. Yakarta: Perempuan Aman.

https://perempuan.aman.or.id/en/about-us/

Pham TT, Mai YH, Moeliono M y Brockhaus M. 2016. Women's participation in REDD national decision-making in Vietnam. International Forestry Review 18(3):334-44. https://doi.org/10.1505/146554816819501691

Poudyal M. 2009. Tree tenure in agroforestry parklands: Implications for the management, utilisation, and ecology of the shea and locust bean trees in northern Ghana. Ph.D. dissertation. York, Reino Unido: University of York.

Prindex. 2019. Women's Perception of Tenure Security. Evidence from 33 Countries. Londres: Prindex, Overseas Development Institute (ODI).

Prindex. 2020. Global Perceptions of Tenure Security: Looking Beyond the Formalisation of Property Rights. Londres: Prindex, Overseas Development Institute (ODI).

[PROFOR] Program on Forests. 2017. Gender and Forest Landscapes: Enhancing Development Impacts of Projects and Programs. In Brief. Washington D. C.: PROFOR.

Rainbow Environment Consult. 2018. Synthetic and Practical Guide of the Unified Methodology of Participatory Mapping in Cameroon. Yaundé, Camerún: Rainbow Environment Consult.

Rainforest Foundation UK. 2018. A national strategy for community forestry in Democratic Republic of Congo. Briefing. Londres: Rainforest Foundation UK.
Rainforest Foundation UK. 2019a. Securing Forests. Participatory Mapping and Community Forests in the Democratic Republic of Congo. Londres: Rainforest Foundation UK.

Rainforest Foundation UK. 2019b. Women's Participation in Community Forestry in the DRC. Londres: Rainforest Foundation UK.

Ramdas S. 2009. Women, forest spaces and the law: Transgressing the boundaries. Economic and Political Weekly 44(44):65-73.

Ranjatson P, McLain R, Mananga J, Radrianasolo R, Razafimbelo NYT y Lawry S. 2019. Tenure security and forest landscape restoration. Results from exploratory research in Boeny, Madagascar. Presented at the 2019 World Bank Conference on Land and Poverty, March 2529, 2019. Washington, D. C.

Rao N. 2017. Assets, agency and legitimacy: Toward a relational understanding of gender equality policy and practice. World Development 95:43-54.

https://doi.org/10.1016/j.worlddev.2017.02.018

[RECOFTC] The Center for People and Forests. 2016. Ensuring Women's Participation in Forest Decision-Making. Advancing Sustainable Development Goal 5 on Gender Equality through Community Forestry in Asia and the Pacific. Annual Report 2015-2016. Bangkok: RECOFTC.

[RECOFTC] The Center for People and Forests. 2018a. Applying a Rights-Based Approach (RBA) in Forest Governance. A Training Manual. Bangkok: RECOFTC.

[RECOFTC] The Center for People and Forests. 2018b. Women's leadership circle for inclusive forest governance in Nepal. Bangkok: RECOFTC.

https://www.recoftc.org/en/nepal/stories/womensleadership-circle-inclusive-forest-governance-nepal

[RECOFTC] The Center for People and Forests. 2018c. Women leadership in enhancing forest quality in Nepal. Bangkok: RECOFTC.

https://www.recoftc.org/en/nepal/stories/womenleadership-enhancing-forest-quality-nepal

[RECOFTC] The Center for People and Forests. 2019. WAVES leaders pursue gender equality in Asia's forest landscapes. Bangkok: RECOFTC.

https://www.recoftc.org/stories/waves-leaders-pursuegender-equality-asias-forest-landscapes

[RECOFTC] The Center for People and Forests. 2020. Forest communities in Thailand use mapping technology to secure and manage their land. Bangkok: RECOFTC. https://www.recoftc.org/stories/forest-communities- 
thailand-use-mapping-technology-secure-and-managetheir-land

Richardson A. 2016. India: Gender in a Forest Rights Project in Jharkhand. Seattle: Landesa; y Friday Harbor, WA: Resource Equity.

Rocheleau D y Edmunds D. 1997. Women, men and trees: Gender, power and property in forest and agrarian landscapes. World Development 25(8):1351-1371. https:// doi.org/10.1016/S0305-750X(97)00036-3

Rojas M. 1993. Integrating Gender Considerations into Forestry Projects. Roma: FAO.

Rousseau K, Gautier D y Wardell DA. 2015. Coping with the upheavals of globalization in the shea value chain: The maintenance and relevance of upstream shea nut supply chain organization in Western Burkina Faso. World Development 66:413-27.

Rousseau K, Gautier D y Wardell DA. 2016. Renegotiating access to shea trees in Burkina Faso. Challenging power relationships associated with demographic shifts and globalized trade. Journal of Agrarian Change 17(3):495-517. https://doi.org/10.1111/joac.12198

[RRI] Rights and Resources Initiative. 2015. Who Owns the World's Lands? A Global Baseline of Formally Recognized Indigenous and Community Land Rights. Washington D. C.: Rights and Resources Initiative (RRI).

[RRI] Rights and Resources Initiative. 2016. Indigenous People and Local Community Tenure in the INDCSs. Washington D. C.: Rights and Resources Initiative (RRI).

[RRI] Rights and Resources Initiative. 2017. Power and Potential: A Comparative Analysis of National Laws and Regulations Concerning Women's Rights to Community Forests. Washington D. C.: Rights and Resources Initiative (RRI).

[RRI] Rights and Resources Initiative. 2018. At a Crossroads. Consequential Trends in Recognition of Community-based Forest Trends from 2002-2017. Washington D. C.: Rights and Resources Initiative (RRI).

[RRI] Rights and Resources Initiative. 2019. Strengthening Indigenous and Rural Women's Rights to Govern Community Lands. Ten Factors Contributing to Successful Initiatives. Washington D. C.: RRI.

Runsheng Y, Zulu L, Qi J, Freudenberger M y Sommerville M. 2016. Empirical linkages between devolved tenure systems and forest conditions: Challenges, findings, and recommendations. Forest Policy and Economics 73:294-9. https://doi.org/10.1016/j.forpol.2016.05.008
Saigal S y Bose S. 2003. Small-scale Forestry Enterprises in India: Overview and Key Issues. Nueva Delhi: Winrock International India.

Samndong RA y Kjosavik DJ. 2017. Gendered forests: exploring gender dimensions in forest governance and REDD+ in Équateur Province, Democratic Republic of Congo (DRC). Ecology and Society 22(4):34. https://doi.org/10.5751/ES-09753-220434

Santiago S. 2020. TFG welcomes women leadership on its 20th anniversary. New Haven, CT: The Forests Dialogue. https://theforestsdialogue.org/news/tfd-welcomeswomen-leadership-its-20th-anniversary

Sarmiento Barletti JP, Larson AM, Hewlett C y Delgado D. 2020. Designing for engagement: A Realist Synthesis Review of how context affects the outcomes of multistakeholder forums on land use and/or land-use change. World Development 127.

https://doi.org/10.1016/j.worlddev.2019.104753

Scalise E y Giovarelli R. 2020. What Works for Women's Land and Property Rights? Friday Harbor, WA: Resource Equity.

Schmink M y García MAG. 2015. Under the canopy: Gender and forests in Amazonia. Occasional Paper 121. Bogor, Indonesia: CIFOR.

Seebens H. 2011. Intra-household bargaining, gender roles in agriculture, and how to promote welfare enhancing changes? ESA Working Paper n. ${ }^{\circ} 11-10$. Roma: FAO.

Seufert P y Suárez S. 2012. Monitoring the voluntary guidelines on the responsible governance of tenure of land fisheries and forests. A civil society perspective. FAO Land Tenure Working Paper n. ${ }^{\circ} 22$. Roma: FAO.

Seymour F. 2020. Insider; 4 reasons why a jurisdictional approach for REDD+ crediting is superior to a projectbased approach. Washington D. C.: World Resources Institute.

https://www.wri.org/blog/2020/05/insider-4-reasonswhy-jurisdictional-approach-redd-crediting-superiorproject-based

Shanley P, Da Silva FC y MacDonald T. 2011. Brazil's social movement, women and forests: a case study from the National Council of Rubber Tappers. International Forestry Review 13(2):233-44. https://doi.org/10.1505/146554811797406570

[SIDA] Swedish International Development Agency. 2016. Hot issue: Gender Equality or Gender Equity. Estocolmo: Swedish International Development Agency (SIDA). 
https://publikationer.sida.se/

contentassets/43b0eb228c464d2499c5eb00a68a0346/

brief-hot-issue-equity-equality.pdf

Sijapati Basnett B. 2016. Gender, migration and forest governance: rethinking community forestry policies in Nepal. En Colfer CJP, Sijapati Basnett B y Elias M, eds. Gender and Forests. Climate Change, Tenure, Value Chains and Emerging Issues. 283-99.

Sijapati Basnett B, Elias M, Ilhalainen M y Valencia AMP. 2017. Gender Matters in Forest Landscape Restoration. A Framework for Design and Evaluation. Bogor, Indonesia: CIFOR.

Sikor T, Jun H y Lestrelin G. 2017. Property rights regimes and natural resources: A conceptual analysis revisited. World Development 93:337-49.

https://doi.org/10.1016/j.worlddev.2016.12.032

Siles J y Prebble M. 2018. Gender-responsive restoration opportunities assessment methodology (ROAM). Engendering national forest landscape restoration assessments. Lessons for Gender-Responsive Landscape Restoration. Global Landscapes Forum Brief n. ${ }^{\circ} 5$. Bogor, Indonesia: CIFOR.

Silverman A. 2015. Using International Law to Advance Women's Tenure Rights in REDD+. Washington D. C.: RRI y Center for International Environmental Law.

Singh NM. 2007. Transgressing Political Spaces and Claiming Citizenship: The Case of Women Kendu LeafPluckers and the Community Forestry Federation, Ranpur, Orissa. En Krishna S, ed. Women's Livelihood Rights: Recasting Citizenship for Development. Nueva Delhi: Sage Publications. 62-81.

Siscawati M. 2020. Gender and forest tenure reform in Indonesia. Working Paper n. ${ }^{\circ}$ 258. Bogor, Indonesia: CIFOR.

Siscawati M y Mahaningtyas A. 2012. Gender justice: Forest tenure and forest governance in Indonesia. En Buchy M, ed. The challenges of securing women's tenure and leadership for forest management: The Asian experience. Brief n. ${ }^{\circ}$ 3. Washington D. C.: RRI.

Smith G. 2019. CBNRM and Democratic Innovation. Washington D. C.: PROFOR y the World Bank.

Stiem L y Krause T. 2016. Exploring the impact of social norms and perceptions on women's participation in customary forest and land governance in the Democratic Republic of Congo- Implications for REDD+. International Forestry Review 18(1)110-22. https://doi.org/10.1505/146554816818206113
Stein C y Barron J. 2017. Mapping Actors along Value Chains: Integrating Visual Network Research and Participatory Statistics into Value Chain Analysis. Research for Development (R4D) Learning Series 5. Colombo, Sri Lanka: International Water Management Institute. CGIAR Research Program on Water, Land and Ecosystems. https://doi.org/10.5337/2017.216

Stevens C, Winterbottom R, Springer J y Raytar K. 2014. Securing Rights, Combating Climate Change. Washington D. C.: WRI.

Stickler M, Huntington $\mathrm{H}$, Hafflet A, Petrova S y Bouvier I. 2017. Does de facto forest tenure affect forest condition? Community perceptions from Zambia. Forest Policy and Economics 85(1):32-45. https://doi.org/10.1016/j.forpol.2017.08.014

Sun Y, Meinzen-Dick E y Mwangi E. 2011. Is gender an important factor influencing user groups' property rights and forestry governance? Empirical analysis from East Africa and Latin America. International Forestry Review 13(2):205-19.

https://www.jstor.org/stable/24310669

Sun Y, Mwangi E, Meinzen-Dick R, Bose P, Shanley P, da Silva FC y MacDonald T. 2012. Forests: Gender, property rights, and access. InfoBrief n. ${ }^{\circ}$ 47. Bogor, Indonesia: CIFOR.

Sunderland T, Achdiawan R, Angelsen A, Babigumira R, Ickowitz A, Paumgarten A, Reyes-García V y Shively G. 2014. Challenging perceptions of men, women and forest product use: A global comparative study. World Development 64 (Supplement 1):S56-S66.

https://doi.org/10.1016/j.worlddev.2014.03.003

Sunderlin W. 2014. The global forest tenure transition: Background, substances, and prospects. En Sikor Ty Stahl J, eds. Forests and People. Property, Governance and Human Rights. Londres: Earthscan. 19-32.

Sunderlin W, de Sassi C, Sills EO, Duchelle AE, Larson AM, Resosudarmo IAP, Awono A, Kweka DL y Huynh TB. 2018. Creating an appropriate tenure foundation for REDD+: The record to date and prospects for the future. World Development 106:376-92. https://doi.org/10.1016/j.worlddev.2018.01.010

Sunderlin W, Hatcher J y Liddle M. 2008. From Exclusion to Ownership? Challenges and Opportunities in Advancing Forest Tenure Reform. Washington D. C.: RRI.

Tebtebba. 2013. Mapping Our Lands and Water. Protecting Our Future. Report of the Global Conference on Community Participatory Mapping in Indigenous People's Territories. August 25-31, 2013, North Sumatra, Indonesia. Baguio City, Filipinas: Tebtebba Foundation. 
Tebtebba. 2018. Customary Tenure Systems and REDD+. Ensuring Benefits for Indigenous Peoples. Baguio City, Filipinas: Tebtebba Foundation.

The Tenure Facility. s. f. A visual history of Indigenous People's land rights in Indonesia. Estocolmo: The Tenure Facility.

https://thetenurefacility.org/timeline/indonesia/

[TISS] Tata Institute for Social Studies. 2018. Forest Rights and Governance in India. A Webinar Report. Bombay: Tata Institute for Social Studies.

Tyagi N y Das S. 2018. Assessing gender responsiveness of forest policies in India. Forest Policy and Economics 92:160-8.

https://doi.org/10.1016/j.forpol.2018.05.004

UN. 2017. Global Indicator Framework for the Sustainable Development Goals and Targets of the 2030 Agenda for Sustainable Development. A/RES/71/313. Nueva York: UN.

[UNDP] UN Development Programme. 2016. Strategies and good practices in promoting gender equality outcomes in parliaments. Guidance note. Nueva York: UN Development Programme (UNDP).

[UNGA] UN General Assembly. 2015. Transforming Our World: The 2030 Agenda for Sustainable Development. A/ RES/70/1. Nueva York: United Nations.

[UNICEF] United Nations Children's Fund. 2017. Gender Equality. Glossary of Terms and Concepts. Katmandú: UNICEF Regional Office for South Asia.

[UN-REDD] United Nations Programme on Reducing Emissions from Deforestation and Forest Degradation. 2013. Guidance Note on Gender Sensitive REDD+. Nueva York: UN-REDD.

UN Women. 2018a. Gender Equality as an Accelerator for Achieving the Sustainable Development Goals. Nueva York: UN Women.

UN Women. 2018b. Turning Promises into Action: Gender Equality in the 2030 Agenda for Sustainable Development. Nueva York: UN Women.

UN Women Training Centre. s. f. Gender Equality Glossary. Nueva York: UN Women Training Centre. https:// trainingcentre.unwomen.org/mod/glossary/view. php?id=36

Upadhyay B, Arpornsilp R y Soontornwong S. 2013. Gender and Community Forests in a Changing Landscape. Lessons from Ban Thung Yao, Thailand. Bangkok: RECOFTC, The Center for People and Forests.
[USAID] United States Agency for International Development. s. f. What is MAST? Washington D. C.: USAID.

https://www.land-links.org/tool-resource/mobileapplications-to-secure-tenure-mast/

[USAID] United States Agency for International Development. 2013. Land Tenure and Property Rights Framework. Washington D. C.: USAID.

USAID LTS Team. 2019. MAST: Supporting community forest management in Liberia. Washington D. C.: USAID. https://www.land-links.org/2019/05/mast-supportingcommunity-forest-management-in-liberia/

Vasundhara. 2016. Recognition and Mapping of Community Forest Resource Rights. Bhubaneshwar, Odisha: Vasundhara.

Warrier SG. 2018. India's new forest policy draft draws criticism for emphasis on industrial timber. Nueva Delhi: Scroll India.

https://news.mongabay.com/2018/04/indias-newforest-policy-draft-draws-criticism-for-emphasis-onindustrial-timber/

Weah JTB. 2012. Women and forests in Liberia: gender policy and women's participation in the forest sector of Liberia. Brief n. 1 in series on African Women's Rights to Forests: Gender in Forest Management and Policy in Central and West Africa. Washington D. C.: RRI.

Winkel G, Galloway G, Colfer CJP, de Jong W, Katila P y Pacheco P. 2019. The impacts of the Sustainable Development Goals on forests and people: Conclusions and the way forward. En Katila P, Colfer CJP, de Jong W, Galloway G, Pacheco P y Winkel G, eds. Sustainable Development Goals: Their Impacts on Forests and People. Cambridge: Cambridge University Press. 601-17.

Working Group of Women and Land Ownership. 2018. FRA: There is little awareness in tribal women about their one-third presence for gram sabha quorum. Nueva Delhi: Counterview.

https://counterview.org/2018/10/23/fra-there-is-littleawareness-in-tribal-women-about-their-one-thirdpresence-for-gram-sabha-quorum/

[World Bank, FAO e IFAD] World Bank, Food and Agriculture Organization e International Fund for Agricultural Development. 2009. The Gender in Agriculture Sourcebook. Washington D. C. y Roma: World Bank, FAO e IFAD.

World Bank. 2018. Closing the Gender Gap in Natural Resource Management Programs in Mexico. Washington D. C.: The World Bank. 
World Bank. 2019a. Securing Forest Tenure Rights for Rural Development. An Analytical Framework. Washington D. C.: PROFOR, World Bank.

World Bank. 2019b. Want to protect forests? Engage more women, says Nepal's Joint-Secretary for Forests. Washington D. C.: World Bank.

https://www.worldbank.org/en/news/

feature/2019/03/07/want-to-protect-forests-engage-

more-women-says-nepals-joint-secretary-for-forests

World Economic Forum. 2018. The Global Gender Gap Report 2018. Ginebra: World Economic Forum. https://www.weforum.org/reports/the-global-gendergap-report-2018
World Vision. 2020. A Toolkit for Integrating Gender Equality and Social Inclusion in Design, Monitoring and Evaluation. Uxbridge, Reino Unido: World Vision.

Zaidi M. 2019. Tribal women's empowerment through the Forest Rights Act, 2006 in southern Rajasthan. Asian Journal of Women's Studies 25(1):47-75.

https://doi.org/10.1080/12259276.2019.1565637

Zinnah MM, Jackollie MS, Crayton E y Cisco OB. 2020. Gender assessment of the policy environment in relation to the cocoa, oil palm, rubber and timber value chains in Liberia. Londres: PROFOREST. 


\section{ANEXO 1}

\section{Términos comunes sobre género ${ }^{17}$}

Género: "género" no significa "sexo" o "mujeres". Se refiere a ideas aceptadas en términos sociales y culturales (roles, comportamientos e identidades) que la sociedad enseña sobre lo que significa ser mujer u hombre. En vez de una noción con un marco biológico, requiere comprender las prácticas de socialización. Estas diferencias de género afectan las relaciones de poder entre mujeres y hombres ( $y$ entre ellos mismos) y pueden conducir a desigualdades en los procesos de toma de decisiones, distribución de beneficios, empoderamiento y resultados. En forestería, puede referirse a cómo mujeres y hombres ocupan determinados espacios en el hogar, la finca y el bosque; qué tipos de actividades de recolección de recursos forestales se consideran socialmente aceptables; y cómo se demuestra respeto a la autoridad masculina. Por ejemplo, en Burkina Faso, las mujeres son consideradas recolectoras de nueces de karité, aun cuando tanto mujeres como hombres saben cómo crece un árbol de karité, qué tipos de nueces de karité son las mejores y cómo deben ser cosechadas, dada la importancia económica de este producto forestal. Por lo tanto, los hombres se apoyan en el conocimiento de las mujeres, ya que estos tienen los derechos principales sobre los frutos y nueces de karité.

Análisis de género: implica un análisis de las cuestiones de género que se interponen en el camino hacia la igualdad de género, ya sea para cabildear en favor de cambios políticos y jurídicos, para diseñar un proyecto de desarrollo o para mejorar las instituciones comunitarias locales de toma de decisiones. Por lo tanto, puede formar parte de una evaluación de necesidades, un análisis situacional o una revisión de políticas. No existe un tipo estándar de análisis de género: debe adaptarse a las necesidades. Esto por lo general incluye dimensiones como la identificación de los diferentes roles de mujeres y hombres en un contexto dado, su acceso y control diverso de los recursos y beneficios, así como los efectos concomitantes en el desarrollo. Puede incluir información tanto cualitativa como cuantitativa. Es un componente clave de las actividades de transversalización de la perspectiva de género. En el sector forestal, por ejemplo, se puede utilizar para comprender los desafíos y las brechas que enfrenta la igualdad de género en la administración gubernamental, o para identificar cómo mejorar las instituciones de toma de decisiones en materia de género y los beneficios de las iniciativas de REDD+.

Empoderamiento de la mujer: el empoderamiento de la mujer es un proceso mediante el cual las mujeres adquieren mayor poder y control sobre sus vidas $y$, por lo tanto, tienen una mayor capacidad para tomar decisiones estratégicas en los hogares y la comunidad. Tener la capacidad de influir en la dirección del cambio social para promover el desarrollo sostenible y la justicia social es, en última instancia, lo que conduce a la igualdad de género. Por medio de una mayor participación y de su acceso a los beneficios de la gobernanza y las normas de tenencia forestal, las mujeres estarán empoderadas para tomar decisiones en una gran variedad de ámbitos, como las prácticas forestales cotidianas, la gestión financiera, la tecnología, la generación de ingresos y el desarrollo empresarial, la educación, la salud, entre otros.

Igualdad o equidad de género: se refiere a que mujeres y hombres tienen la oportunidad de disfrutar por igual

17 Hay varias fuentes disponibles para entender mejor los términos relacionados con el género (véase, por ejemplo, UN Women Training Centre s. f.) 
de los bienes, oportunidades, recursos y beneficios de la sociedad. Es el término utilizado en muchos acuerdos internacionales como la CEDAW (véase SIDA 2016). No se trata de que mujeres y hombres se conviertan en lo mismo, sino que tengan la misma dignidad, oportunidades y apoyo para alcanzar resultados deseables. Según la ley, tanto mujeres como hombres son iguales. En un mundo con paridad de género, la discriminación, los prejuicios y los roles de género rígidos no serían imperantes. La igualdad de género no es solo una cuestión de mujeres: implica la participación tanto de mujeres como de hombres en el proceso de transición hacia un mundo más justo. La equidad de género se centra más en la equidad y la justicia en términos de beneficios y necesidades.

La igualdad de género se encuentra, por ejemplo, en el papel igualitario de mujeres y hombres (representantes de todo el espectro de condiciones sociales y económicas) en los órganos de gobernanza forestal, donde los miembros pueden aprovechar sus conocimientos, hacer valer su autoridad eficazmente $y$, por lo tanto, influir en los resultados de la toma de decisiones mediante normas que reconocen los derechos de las mujeres y los hombres en condiciones de igualdad. La representación de la mujer no significa proteger únicamente los derechos de las mujeres: lo que se busca es el bienestar general de la comunidad. Para la creación de gobernanza y de normas de tenencia se requiere de un enfoque hábil e ingenioso que permita equilibrar los intereses diversos.

Brecha de género: originalmente, este término se refería a la diferencia sistemática entre la participación de mujeres y hombres en la fuerza laboral. El Informe global de brecha de género que publica anualmente el World Economic Forum tiene un índice que monitorea un conjunto más amplio de brechas: las diferencias de género en la participación y oportunidad económicas, en logros educativos, en salud y supervivencia, y en empoderamiento político (véase World Economic Forum 2018). La brecha de género en forestería se refiere a una variedad de factores que se interponen en el camino hacia la paridad de género, y ha sido analizada en algunos países como México (World Bank 2018).

Interseccionalidad de género: centrarse simplemente en las mujeres, como una categoría amplia, no es suficiente. Analizar la interseccionalidad de género implica ir más allá de descripciones simplistas sobre las polaridades de género para discernir cómo mujeres y hombres individuales se enfrentan a una variedad de formas interrelacionadas de discriminación estructural, así como de empoderamiento (Colfer et al. 2018). El término "interseccionalidad" puede sonar vago, pero las desigualdades rara vez son causadas por un solo factor. Por lo general, las privaciones se encuentran agrupadas, lo que significa que diferentes tipos de discriminación aparecen juntos en un patrón correlacionado. Sin embargo, los estudios muestran que casi toda la investigación forestal diferenciada por género existente no toma en cuenta la interseccionalidad (Djoudi et al. 2016; como una excepción, véase Nightingale 2011). Esto puede deberse a que existe poca orientación acerca de cómo utilizar el concepto para comprender situaciones específicas y cómo aprovechar los conocimientos desarrollados (Colfer et al. 2018). Si bien al mundo de las políticas no le gustan estas complejidades (Arora-Jonsson 2014), la interseccionalidad es un enfoque necesario para el análisis forestal basado en el género.

\section{Transversalización de la perspectiva de género:}

hoy un término casi omnipresente, el enfoque de transversalización de la perspectiva de género se acordó en la Cuarta Conferencia Mundial sobre la Mujer de 1995, celebrada en Pekín, para promover la igualdad de género. La transversalización de la perspectiva de género significa que cualquier acción planificada, ya sea de legislación, políticas, programas o desarrollo institucional, debe evaluar expresamente sus repercusiones para la igualdad de género, de manera que se pueda abordar proactivamente cualquier obstáculo o limitación. De esta manera, se convierte en parte integral del diseño, la implementación, el monitoreo y la evaluación de 
cualquier iniciativa, para asegurar que los asuntos de género no sean simplemente una actividad complementaria, sino que estén integrados en todos los pasos. También facilita el aprendizaje en cualquier organización. Este es a menudo un proceso de doble vía, que involucra programas dirigidos específicamente a mejorar la equidad de género y a integrar las cuestiones de género en otros procesos de planificación. En los organismos forestales gubernamentales, el punto focal para cuestiones de género es la persona central encargada de apoyar la transversalización de la perspectiva de género tanto en términos de procesos administrativos como de desarrollo de políticas y leyes, y su implementación.

\section{Verificación de la integración de asuntos de género:} implica analizar cualquier propuesta de política o plan estratégico en busca de tipos específicos de posibles impactos discriminatorios de género. Es un enfoque preventivo que tiene como objetivo reconocer y prevenir consecuencias negativas. En el caso del desarrollo de una estrategia nacional de REDD+, por ejemplo, la verificación de la integración de asuntos de género implica examinar cómo dicha estrategia puede afectar el acceso de las mujeres a leña, forraje y productos medicinales, así como sus derechos a los beneficios de REDD+, tanto financieros como de bienestar social.

Perspectiva de género: este término surgió porque se consideró que la sensibilidad de género era insuficiente para crear las transformaciones necesarias. En lugar de solo promover un principio de "no hacer daño", la perspectiva de género es un enfoque más activo que toma medidas específicas para mejorar la participación de mujeres y hombres, sus habilidades de liderazgo, su autoridad y compromiso efectivo, sus beneficios y su empoderamiento. Esto implica tomar medidas para reducir las barreras y obstáculos existentes, como las normas que diferencian por género, las normas y regulaciones discriminatorias y los desincentivos para participar y negociar de manera productiva. Para entender si una intervención está logrando sus metas transformadoras se requiere de algún tipo de monitoreo y evaluación. En el campo de la forestería, por ejemplo, las acciones con perspectiva de género buscarán garantizar que las normas establecidas en las leyes o políticas que exigen una participación del 50 \% de mujeres y hombres en los órganos de toma de decisiones se implementen de manera eficaz para la mayoría de los miembros de los PICL.

Sensibilidad de género: se trata de políticas y programas que toman en cuenta los factores culturales y sociales que conducen a la exclusión y discriminación de género en los hogares, el ámbito público y los órganos de toma de decisiones. Su objetivo es desarrollar respeto por la persona independientemente de su género.

\section{Mecanismos nacionales para asuntos de la mujer:} consisten en oficinas, departamentos, comisiones o ministerios gubernamentales que lideran y brindan apoyo a las acciones gubernamentales para el logro de una mayor igualdad de género. 


\section{ANEXO 2}

\section{Términos comunes sobre tenencia ${ }^{18}$}

El siguiente es un glosario condensado con los términos más utilizados en esta publicación.

Derechos de acceso: la capacidad de acceder o atravesar un área boscosa o acceder a árboles específicos para poder extraer determinados recursos. Las mujeres y los hombres pueden tener acceso (ya sea de manera informal o formal) solo a ciertas áreas de un bosque. A menudo, los derechos de acceso están relacionados con la pertenencia a un grupo o un hogar en la comunidad.

Alienación: el derecho del propietario a transferir el bosque a otra persona natural o jurídica por venta, arrendamiento u otros medios, así como la capacidad de utilizar el recurso como garantía para obtener financiamiento. Muchos regímenes de tenencia forestal consuetudinarios o colectivos están siendo afectados por la venta de parcelas de tierra de propiedad individual.

Conjunto de derechos forestales: los diversos derechos que en suma constituyen la tenencia forestal, como el acceso, el uso, la gestión, la exclusión y la alienación. La tenencia forestal sobre un área forestal específica puede ser otorgada a un individuo, empresa, comunidad o al Estado.

\section{Tenencia forestal colectiva o de propiedad de}

uso común: estos son términos que se refieren a un régimen de tenencia forestal en el que un área forestal de uso común se rige a través de una institución de gobernanza de la comunidad o colectiva.

\begin{abstract}
Derecho de tenencia forestal consuetudinario o de
facto: se refiere a un tipo de tenencia informal basado en derechos reconocidos a nivel local, sin reconocimiento jurídico formal del Estado. Puede ser un conjunto de normas y regulaciones legítimas que se han heredado de generaciones anteriores.
\end{abstract}

\section{Derecho de tenencia forestal jurídico o de jure: se trata de un conjunto de derechos de tenencia forestal establecidos y protegidos por el Estado. Esto implica, entre otras cosas, la definición de la distribución de derechos y responsabilidades entre el Estado y otros actores.}

Derechos de exclusión: el derecho a regular y excluir a las personas ajenas que no tienen derechos de acceso a los bosques. Ahora bien, es posible que se permita a algunas mujeres $u$ hombres no pertenecientes a la comunidad acceder y utilizar el bosque en ciertos momentos y de maneras específicas.

Propiedad forestal: el derecho a usar, controlar, transferir o disfrutar de una parcela de tierra con actividades permitidas por la ley. En términos de derecho estatutario, a menudo se asocia este término con el de tierras de dominio pleno o absoluto.

Posesión forestal: la posesión forestal consiste en un flujo de beneficios (o ingresos) para mujeres y hombres, y un derecho de posesión forestal es un reclamo de beneficios provenientes de recursos forestales que están protegidos por el Estado u otro órgano superior (Bromley 1990).

\footnotetext{
18 Hay una serie de publicaciones que cuentan con un glosario completo de términos sobre tenencia (Bruce 1998, FAO 2012, Larson 2012, USAID 2013, RRI 2018 y Banco Mundial 2019a).
} 
Tenencia forestal: define quién es el propietario de los bosques y quién usa, gestiona y toma decisiones sobre los recursos forestales. El término "tenencia forestal" otorga importancia a las relaciones e instituciones sociales que determinan los patrones de uso de los bosques. El término "posesión" a veces se usa de manera intercambiable con tenencia, aunque la posesión se refiere al derecho a un flujo de beneficios. La tenencia, sin embargo, no equivale a propiedad. Más bien, dirige la atención hacia un conjunto de derechos (como acceso, uso, gestión o alienación) que constituyen una institución de tenencia forestal.

Reforma de la tenencia forestal: es un término general que se refiere a un cambio en el conjunto de derechos y responsabilidades para el uso, gestión o control de los bosques o las tierras forestales. Puede implicar cambios en políticas, leyes, regulaciones, gobernanza forestal y normas de tenencia para diferentes titulares de derechos (Larson et al. 2010). Estos cambios pueden dar lugar a nuevos tipos de acuerdos de tenencia que se adapten al contexto ecológico, socioeconómico y político local para una gestión forestal sostenible (FAO 2011).

Transición de la tenencia forestal: es el proceso de devolución en curso por medio del cual las tierras forestales bajo la jurisdicción del Estado cambian gradualmente al transferirse los derechos de tenencia forestal a autoridades de pueblos indígenas y comunidades locales, a empresas y a individuos. Esta tendencia de devolución tiene diversos patrones y ritmos en diferentes continentes, pero en términos generales continúa avanzando.

Derechos de manejo o gestión: este es un derecho complicado debido a que abarca muchas dimensiones, entre ellas establecer objetivos de manejo forestal, entender cómo evaluar el estado del bosque en todo el paisaje, saber cómo regular los diversos tipos de uso a lo largo del ciclo anual, administrar viveros forestales y desarrollar diferentes tipos de gestión forestal para parcelas específicas. También puede incluir el derecho a convertir el bosque en tierras agrícolas o a permitir que una empresa del sector privado utilice y gestione parte de las tierras forestales de la comunidad.
Gobernanza responsable de la tenencia: se centra en cómo se diseñan e implementan de manera responsable los derechos de tenencia de los recursos forestales para permitir tanto el ejercicio de los derechos humanos como el desarrollo social y económico sostenible. Las VGGT han establecido tanto sus principios generales como los principios para su implementación, incluida la igualdad de género.

Tenencia de árboles: derechos específicos de tenencia de un individuo o grupo de individuos sobre determinadas especies de árboles en un área forestal. Puede incluir el derecho a plantar árboles, cosechar frutos y otros productos de ellos, aprovechar los propios árboles y ser propietario de árboles o heredarlos. Puede ocurrir que los derechos de los árboles no necesariamente prevalezcan sobre los derechos a la tierra donde se encuentran.

Registro de tenencia: un registro público que se utiliza para conservar información (incluidos mapas) sobre escrituras, títulos o regímenes de tenencia forestal colectiva.

Seguridad de la tenencia: se refiere al nivel de confianza que tienen las personas en que no se verán privadas arbitrariamente de sus derechos de tenencia forestal (incluidos los beneficios derivados de ellos), y que estos no serán cuestionados injustificadamente cuando deban enfrentar alguna dificultad. Aunque la protección jurídica aporta formalidad a la seguridad de la tenencia, en la práctica se trata de una percepción conformada por una serie de factores, como la confianza en la implementación gubernamental de las normas de tenencia, las normas sociales imperantes sobre tenencia forestal, el conocimiento acerca de los derechos jurídicos para obtener compensaciones ante posibles dificultades, entre otros.

Derechos de uso: consisten en el derecho a apropiarse de recursos forestales específicos, a menudo designados en términos de nivel de uso y tiempo de cosecha. Las mujeres y los hombres pueden tener diferentes tipos de derechos de uso sobre diversos productos de un área forestal, o tener el derecho de uso de una tierra forestal (por ejemplo, para el pastoreo). A veces, también se denominan derechos de usufructo. 


\section{CRÉDITOS FOTOGRÁFICOS}

Página 1

Mujer joven cuyo esposo trabaja en el extranjero recolecta forraje de los bosques en Nepal

Mokhamad Edliadi/CIFOR

Página 12

Responsables del grupo de usuarios de forestería comunitaria de Jhalari, exclusivo para mujeres, en Terai, Nepal

Nayna J Jhaveri

Página 20

En Nusa Tenggara Oriental, Indonesia, las mujeres dependen de la leña como su única fuente de energía Aulia Erlangga/CIFOR

Página 30

Plántulas de acacia plantadas en Yangambi, República Democrática del Congo

Axel Fassio/CIFOR

Página 38

Mujer lijando productos artesanales de madera en

Jepara, Indonesia

Melati Kaye/CIFOR

Página 46

Cosecha de leperonia, utilizada para la fabricación de tejidos y artesanías en el sur de Sumatra, Indonesia Rifky/CIFOR
Página 60

Cosecha de café en la Sierra Otomí Tepehua, en el estado de Hidalgo, México

Manuel A Espinosa S/ITESO

Página 74

Mujer recogiendo hojas comestibles de okok (especie del género Gnetum) en la Región Central, Camerún

Olivier Girard/CIFOR

Página 86

Plantones de acacia jóvenes plantados en Yangambi, República Democrática del Congo

Axel Fassio/CIFOR

Página 106

Mujeres en un taller de mapeo en el distrito de Kassena Nankana, Ghana

Axel Fassio/CIFOR

Página 110

Mujer dedicada a la extracción maderera a pequeña escala en Ecuador

Tomas Munita/CIFOR

Página 116

Una mujer muestra alimentos y frutas del bosque que se recolectan y cultivan en Zambia

Joe Nkaadani/CIFOR 
Esta guía para profesionales explica cómo promover una reforma de la tenencia forestal con perspectiva de género en regímenes forestales colectivos; y está dirigida a quienes han asumido este reto en países en desarrollo. No existe un enfoque único para reformar las prácticas de tenencia forestal con el fin de que aborden la igualdad de género y el empoderamiento de las mujeres. Se trata más bien de aprovechar las oportunidades que surgen en diversos ámbitos institucionales, como el de la formulación e implementación de políticas y leyes, la administración gubernamental, la gobernanza de la tenencia consuetudinaria o colectiva o la restauración forestal a nivel del paisaje.

Este libro de consulta proporciona orientación de diversa índole: ideas conceptuales, dirección operativa, buenas prácticas, información de estudios de caso, hallazgos de investigación y recursos para una exploración más profunda, provenientes de experiencias en África, Asia y América Latina. Ha sido diseñado para apoyar a una amplia variedad de profesionales, tanto mujeres como hombres, de una gran diversidad de instituciones, como oficinas de gobierno, organizaciones no gubernamentales, organizaciones de la sociedad civil, organizaciones donantes, organizaciones de mujeres, así como de redes y federaciones. Esto incluye a expertos en materia de género, quienes tienen la responsabilidad de integrar la igualdad de género y el empoderamiento de las mujeres en sus respectivas organizaciones, y también a aquellos que trabajan de manera más general en el ámbito de la tenencia de la tierra, la tenencia y la gobernanza forestal, la restauración de paisajes forestales, la agroforestería, el desarrollo de cadenas de valor y las empresas con impacto social.

Su objetivo es examinar las vías o rutas para promover una reforma de la tenencia forestal mediante un proceso de tres pasos: Analizar, Definir estrategias e Implementar estrategias. Un análisis de diagnóstico riguroso que permita crear una base empírica para el cambio puede contribuir al diseño de intervenciones secuenciales que impulsen la reforma de la tenencia forestal con perspectiva de género a diversas escalas. Por ello, esta guía es un recurso oportuno para respaldar intervenciones adecuadas de alto impacto y acelerar el cambio en regímenes de tenencia forestal colectivos en contextos tanto nacionales como locales.

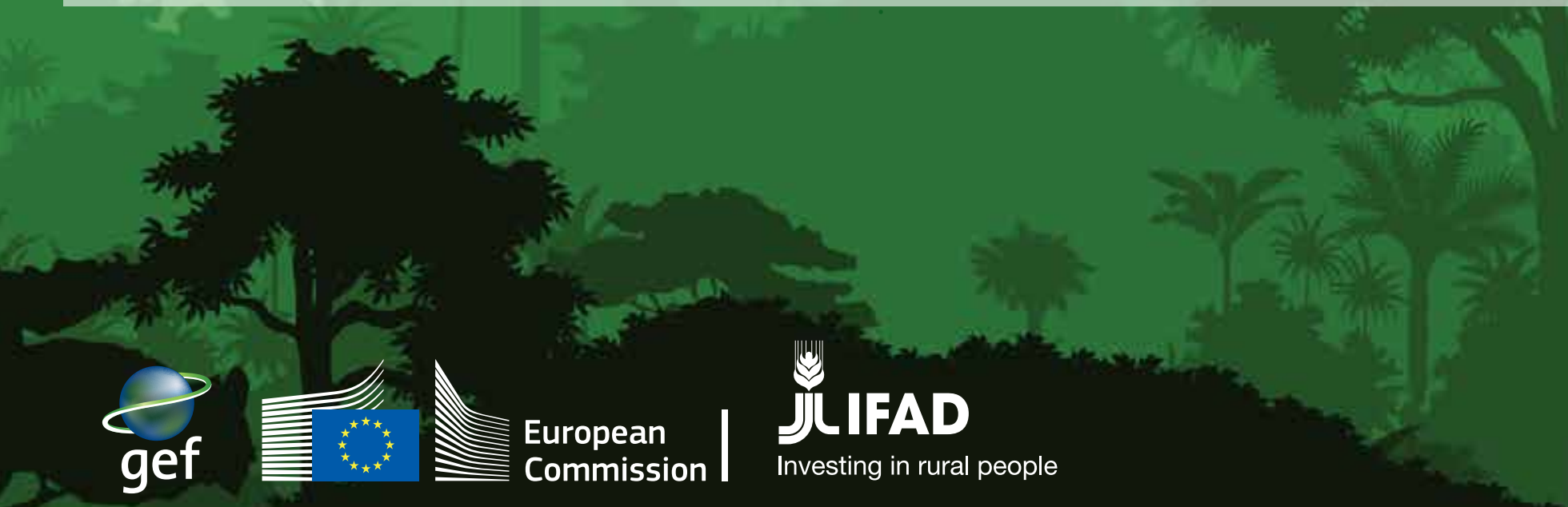

Centro para la Investigación Forestal Internacional (CIFOR)

CIFOR promueve el bienestar humano, la integridad del medioambiente y la equidad mediante investigación de avanzada, desarrollando las capacidades de sus socios y dialogando activamente con todos los actores involucrados, para informar sobre las políticas y las prácticas que afectan a los bosques y a las personas. CIFOR es un centro de investigación CGIAR y lidera su Programa de Investigación sobre Bosques, Árboles y Agroforestería (FTA, por sus siglas en inglés). Nuestra sede central se encuentra en Bogor, Indonesia, y contamos con oficinas en Nairobi, Kenia; Yaundé, Camerún; Lima, Perú, y Bonn, Alemania. 